Supporting Information

\title{
Engineered Substrate for Cyclooxygenase-2: A Pentapeptide iso- Conformational to Arachidonic Acid for Managing Inflammation
}

Baljit Kaur, ${ }^{\psi}$ Manpreet Kaur, ${ }^{\psi}$ Navjot Kaur, ${ }^{\psi}$ Saweta Garg, ${ }^{\Phi}$ Rajbir Bhatti, ${ }^{\Phi}$ Palwinder Singh ${ }^{* \psi}$

${ }^{\psi}$ Department of Chemistry and Centre for Advanced Studies, University with Potential for Excellence, Guru Nanak Dev University, Amritsar-143005. India

${ }^{\Phi}$ Department of Pharmaceutical Sciences, Guru Nanak Dev University, Amritsar-143005. India

Table of contents

\begin{tabular}{|c|l|c|}
\hline S. No. & \multicolumn{1}{|c|}{ Content } & Page no. \\
\hline 1 & Molecular docking (Figure S1-S3) & S2-S3 \\
\hline 2 & Radical mechanism of AA metabolism (Scheme S1) & S4 \\
\hline 3 & NMR, mass, IR spectra (Figure S4-S149) & S5-S68 \\
\hline 4 & Percentage purity (Figure S93) & S41-42 \\
\hline 5 & LC-MS (Figure S150-S158) & S69-74 \\
\hline 6 & Scheme S2 & S75 \\
\hline 7 & Kinetic constants (Figure S159) & S76 \\
\hline 8 & Molecular dynamics (Figure S160-S161) & S76-77 \\
\hline 9 & $\begin{array}{l}\text { Metabolism of Peptide 2 with Y385F COX-2 with LC-MS } \\
\text { (S162) }\end{array}$ \\
\hline 10 & Molecular dynamics (Figure S163) & S79 \\
\hline 11 & Figure S164 & \\
\hline
\end{tabular}




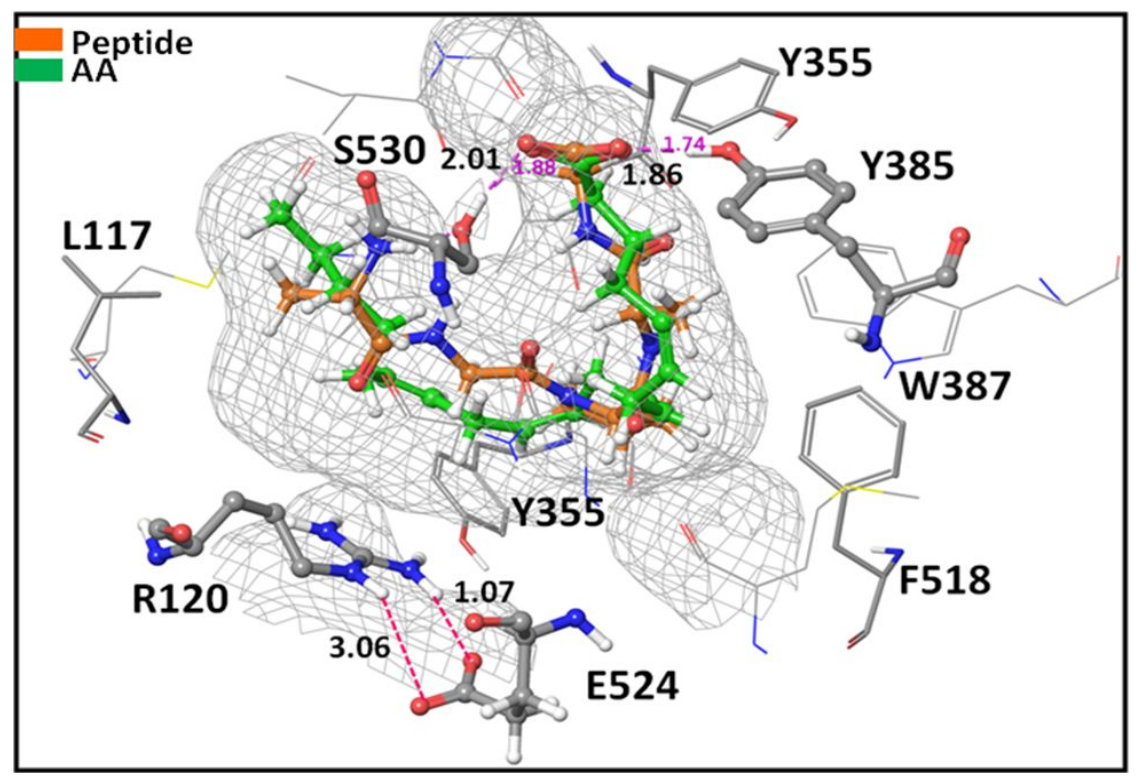

Figure S1. Crystal coordinates of COX-2 in association with AA (pdb ID 1CVU). ${ }^{1}$ Molecular docking of peptide 2 (Chart 1) in the active site pocket of the enzyme was performed. The peptide has occupied same space where AA binds.

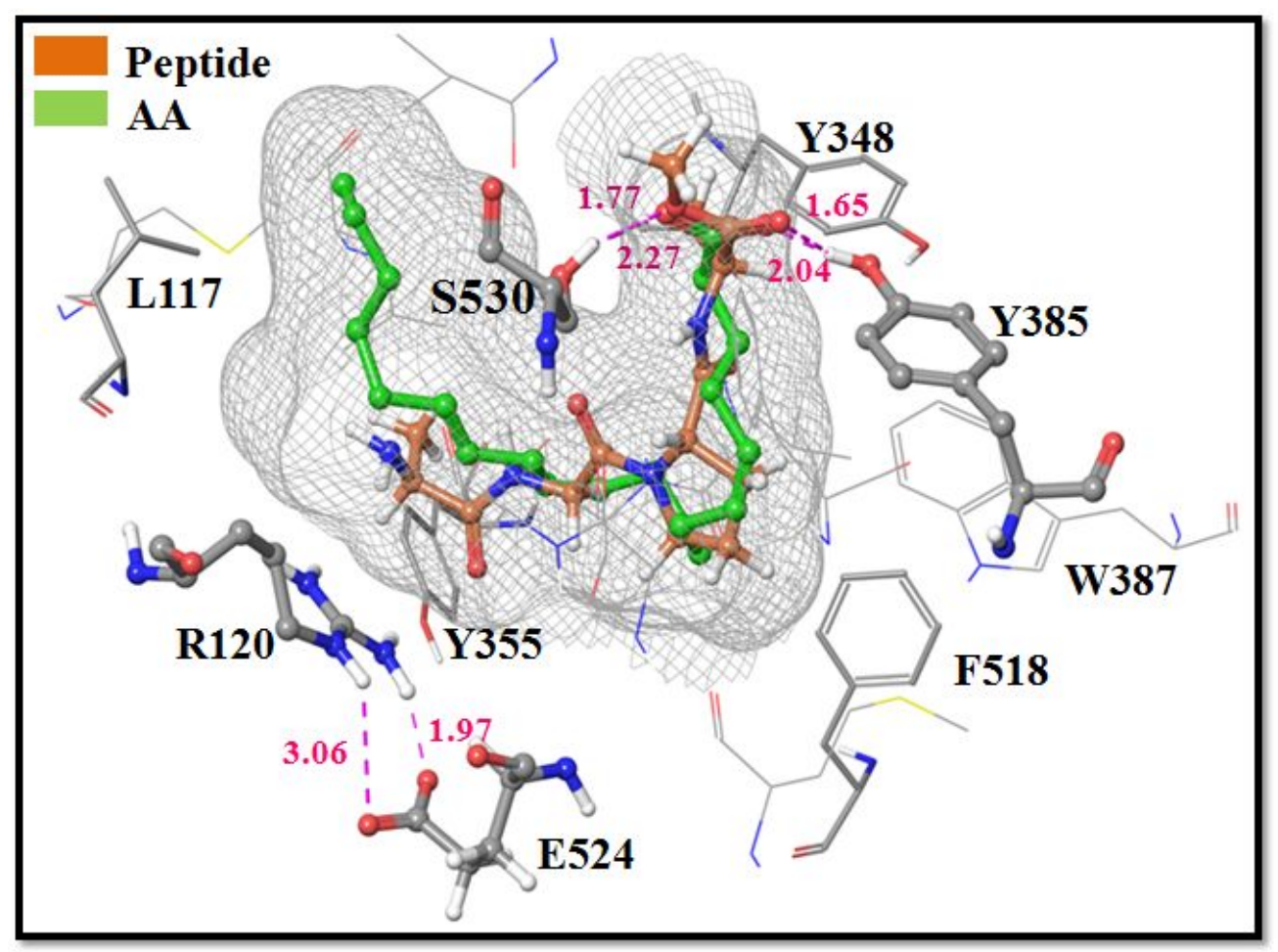

Figure S2. Molecular docking of peptide 1 in the active site pocket of COX-2 (pdb ID 1CVU). 


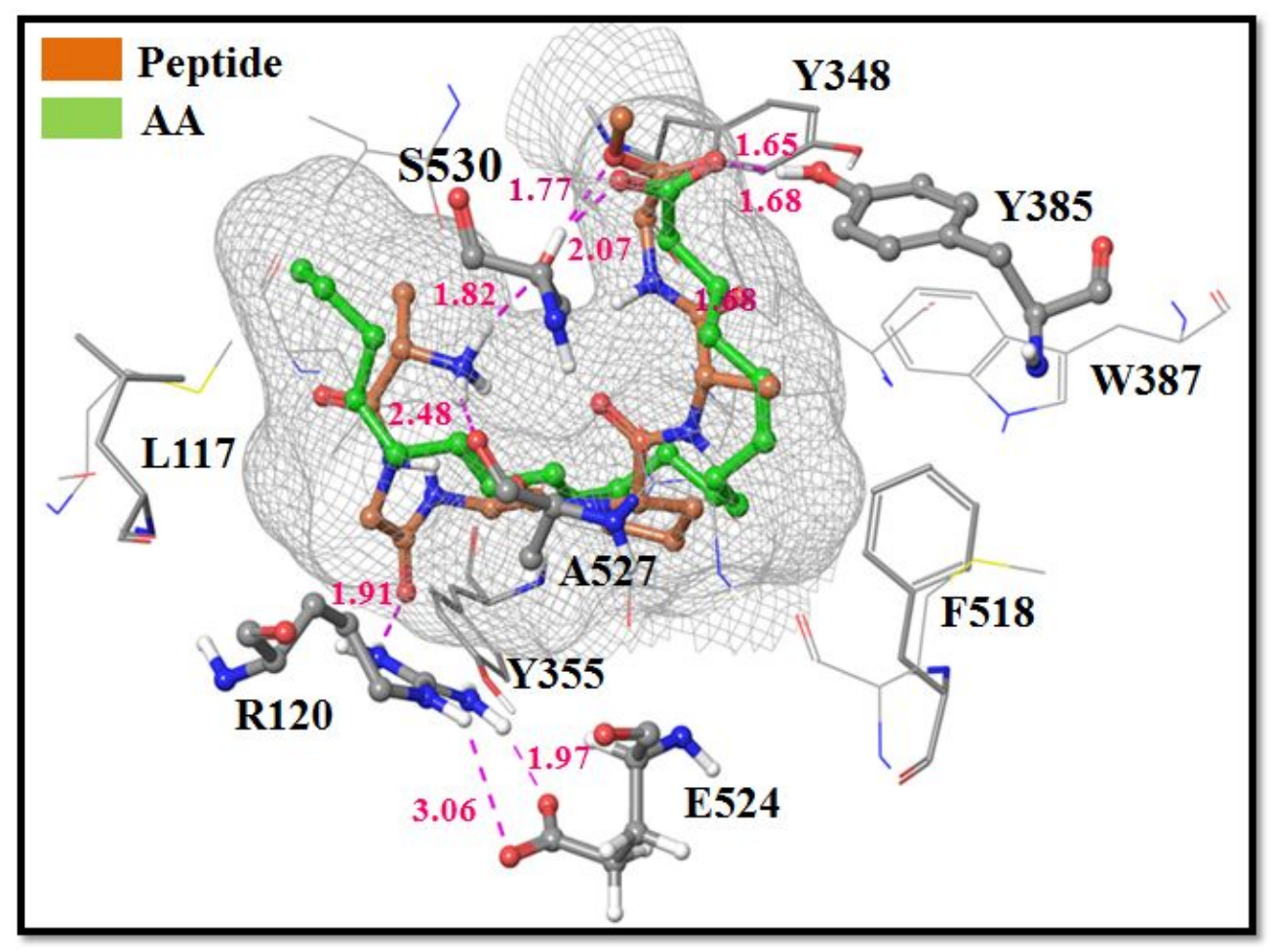

Figure S3. Molecular docking of peptide 3 in the active site pocket of COX-2 (pdb ID 1CVU).

\section{Reference}

1. Kiefer, J. R.; Pawlitz, J. L.; Moreland, K. L.; Stegeman, R. A.; Hood, W. F.; Gierse, J. K.; Stevens, A. M.; Goodwin, D. C.; Rowlinson, S. W.; Marnett, L. J.; Stallings, W. C.; Kurumbail, R. G. Structural insights into the stereochemistry of the cyclooxygenase reaction Nature 2000, 405, 97- 101. 

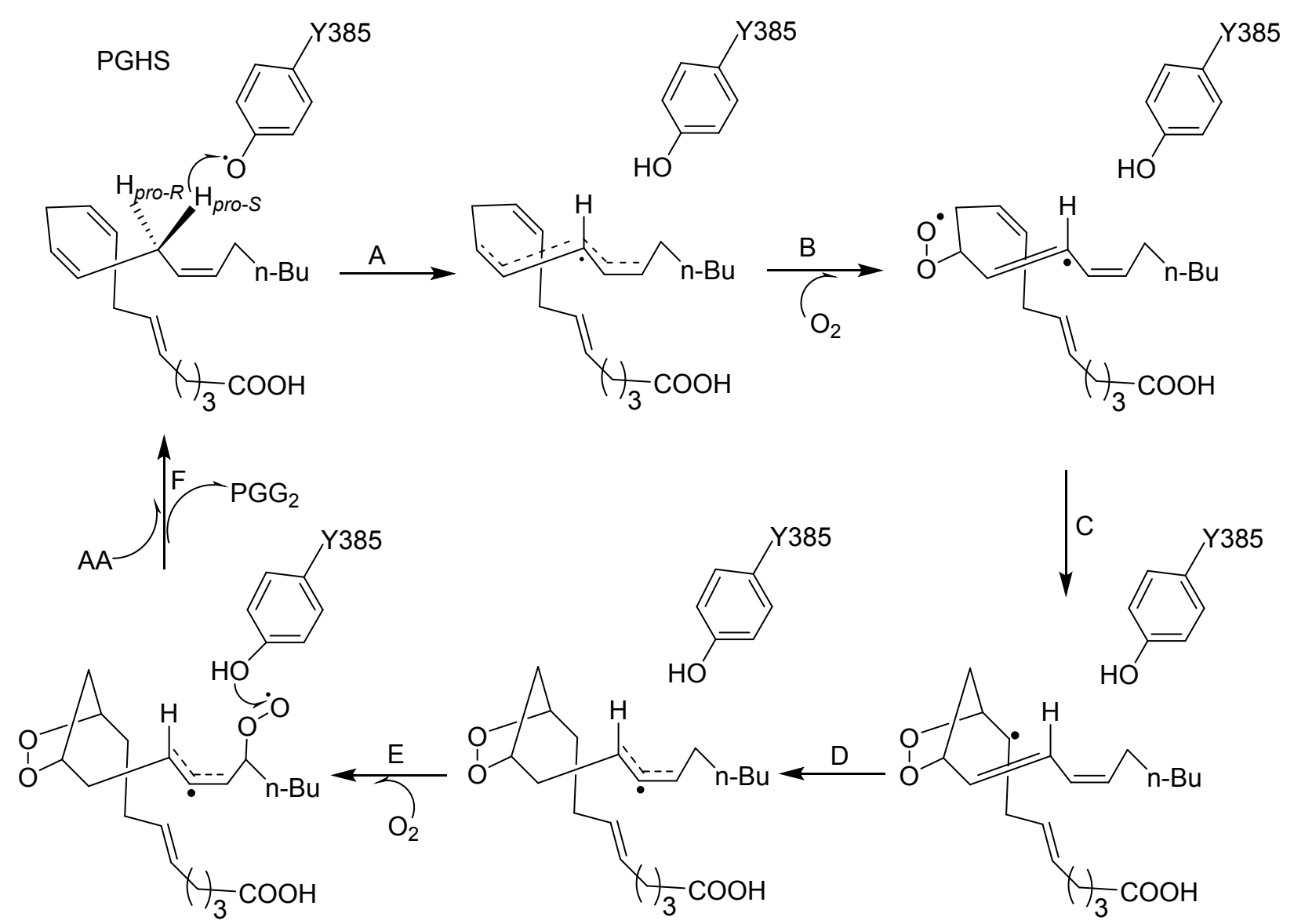

Scheme S1. Proposed mechanism for COX-2 mediated breakdown of arachidonic acid., ${ }^{2,3}$

\section{References}

2. Wu, G.; Lu, J.-M.; Donk, W. A. V. D.; Kulmacz, R. J.; Tsai, A.-L. Cyclooxygenase reaction mechanism of prostaglandin $\mathrm{H}$ synthase from deuterium kinetic isotope effects, $J$. Inorg. Biochem. 2011, 105, 382-390.

3. Hamberg, M.; Samuelsson, B. On the Mechanism of the Biosynthesis of Prostaglandins $\mathrm{E}_{1}$ and $\mathrm{F}_{1 \alpha}{ }^{*}$ J. Biol. Chem. 1967, 242, 5336-5343. 


\section{${ }^{1}$ H NMR Spectra:}

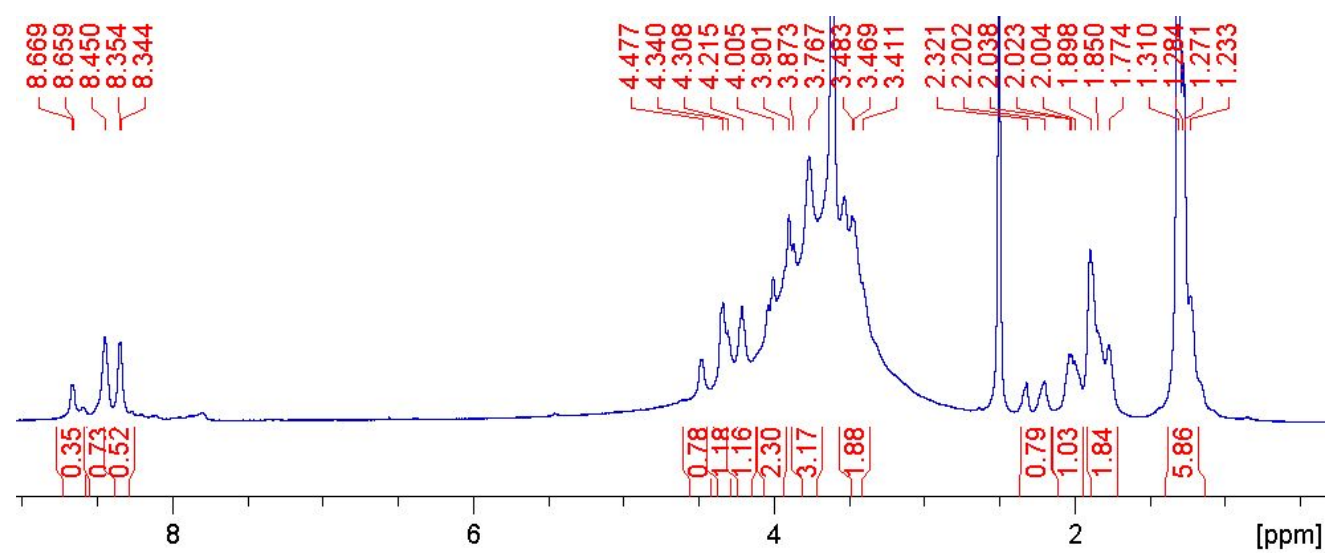

Figure S4. ${ }^{1} \mathrm{H}$ NMR spectrum of Ala-Gly-Pro-Ala-OMe (1) in DMSO- $d_{6}$.

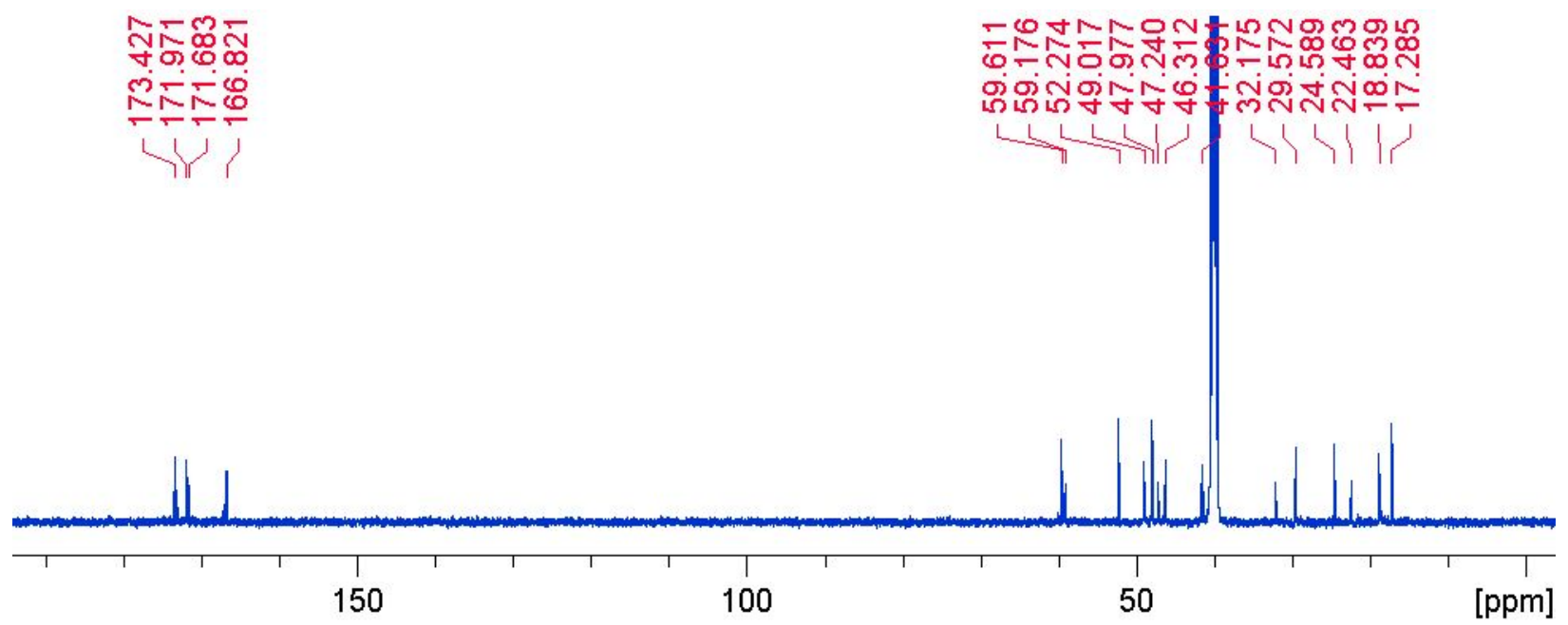

Figure S5. ${ }^{13} \mathrm{C}$ NMR spectrum of Ala-Gly-Pro-Ala-OMe (1) in DMSO- $d_{6}$. 


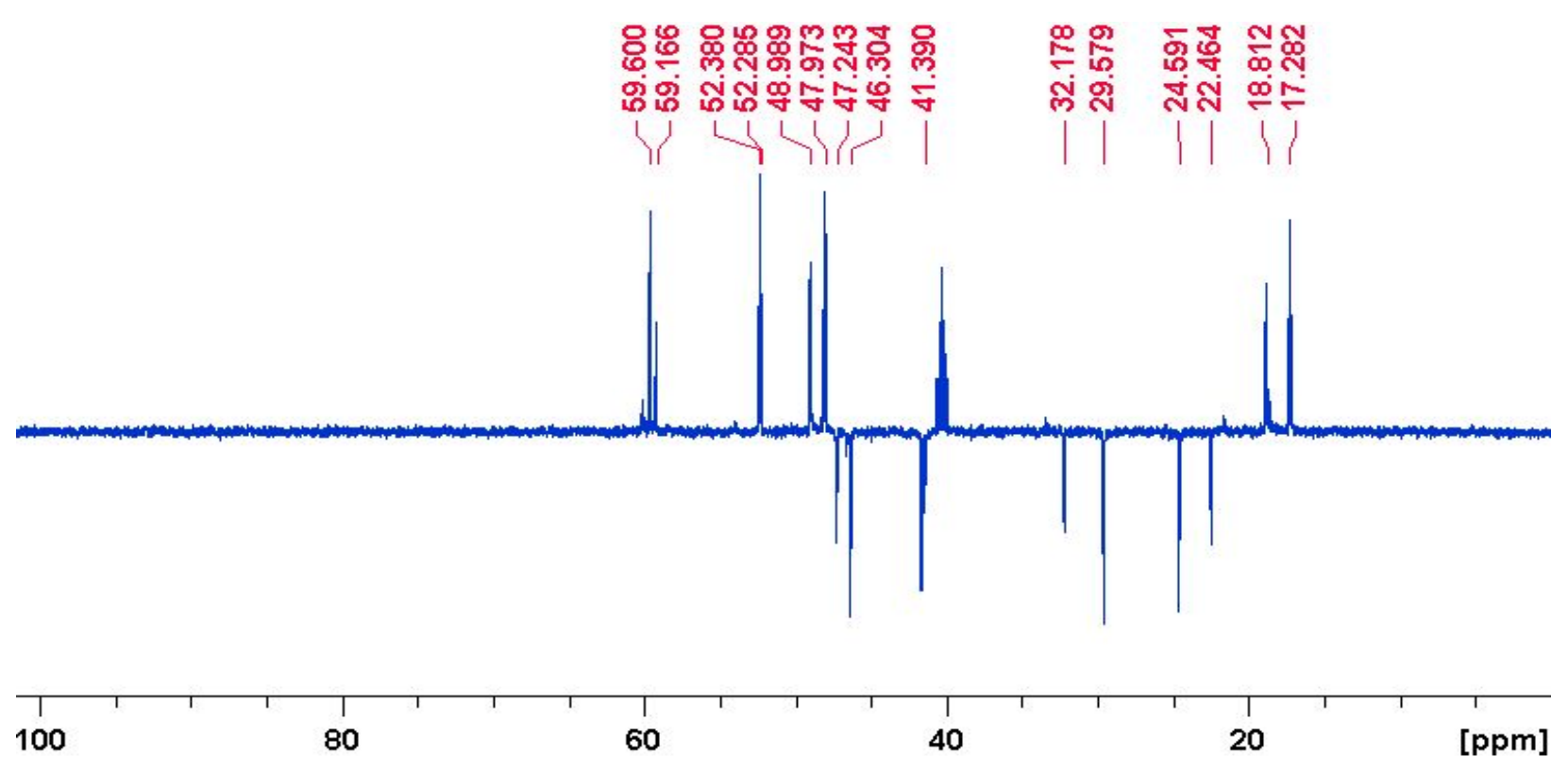

Figure S6. DEPT-135 NMR spectrum of compound Ala-Gly-Pro-Ala-OMe (1) in DMSO- $d_{6}$.

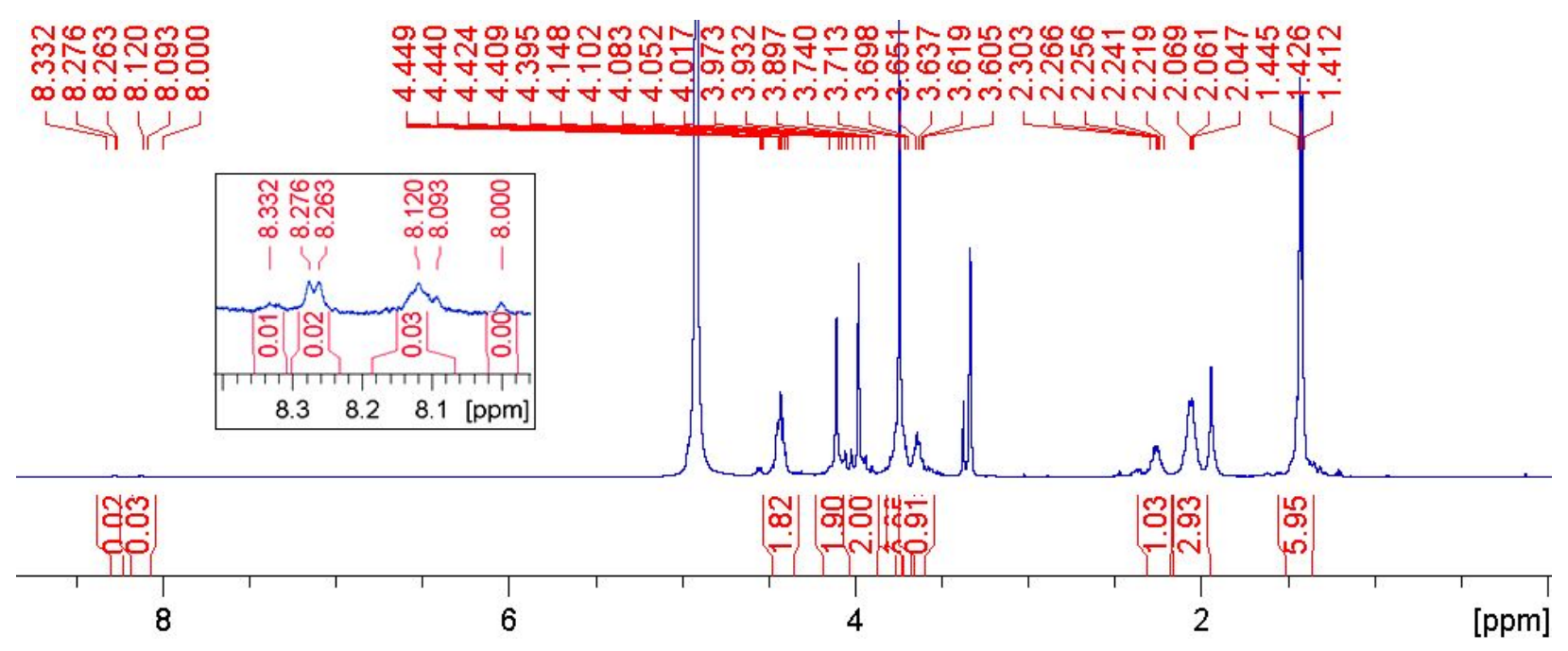

Figure S7. ${ }^{1} \mathrm{H}$ NMR spectrum of Ala-Gly-Pro-Ala-Gly-OMe (2) in methanol- $d_{4}$. 


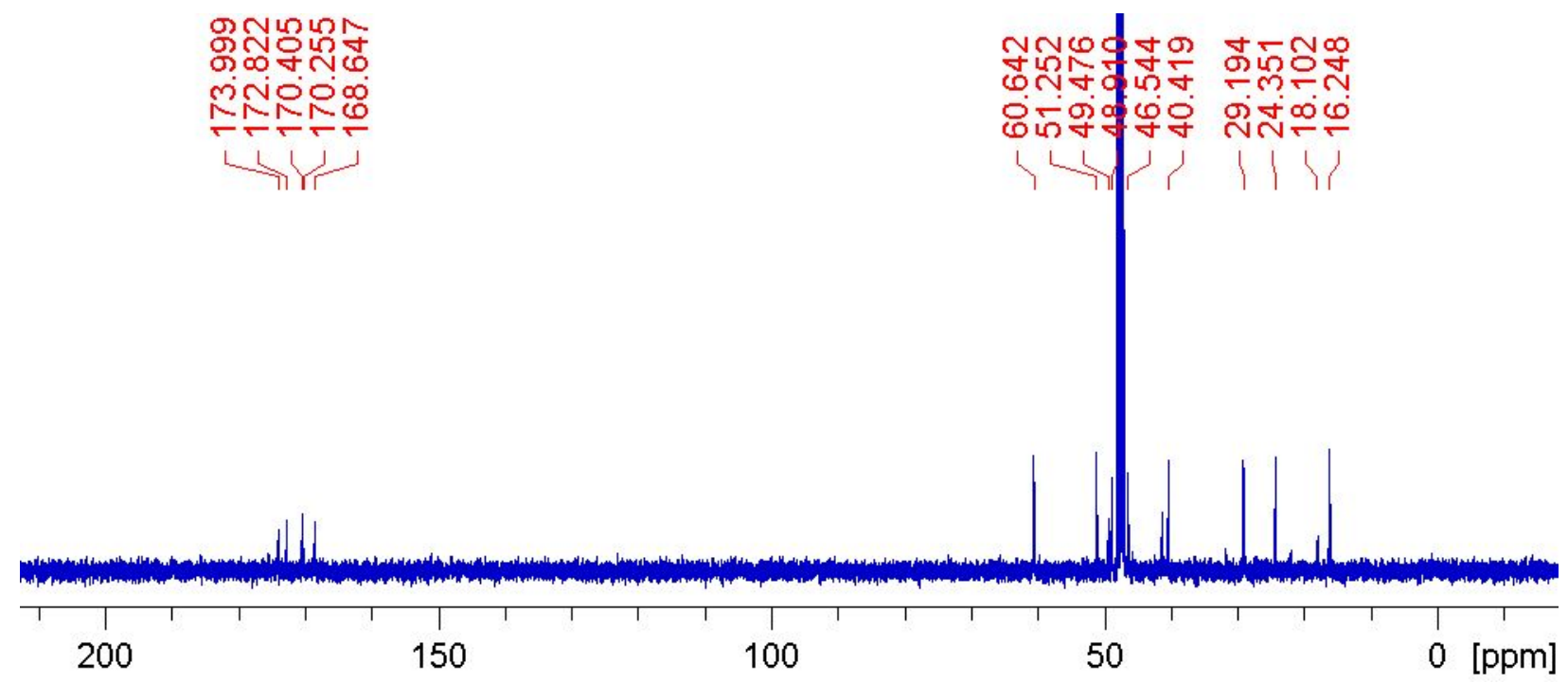

Figure S8. ${ }^{13} \mathrm{C}$ NMR spectrum of Ala-Gly-Pro-Ala-Gly-OMe (2) in methanol- $d_{4}$.

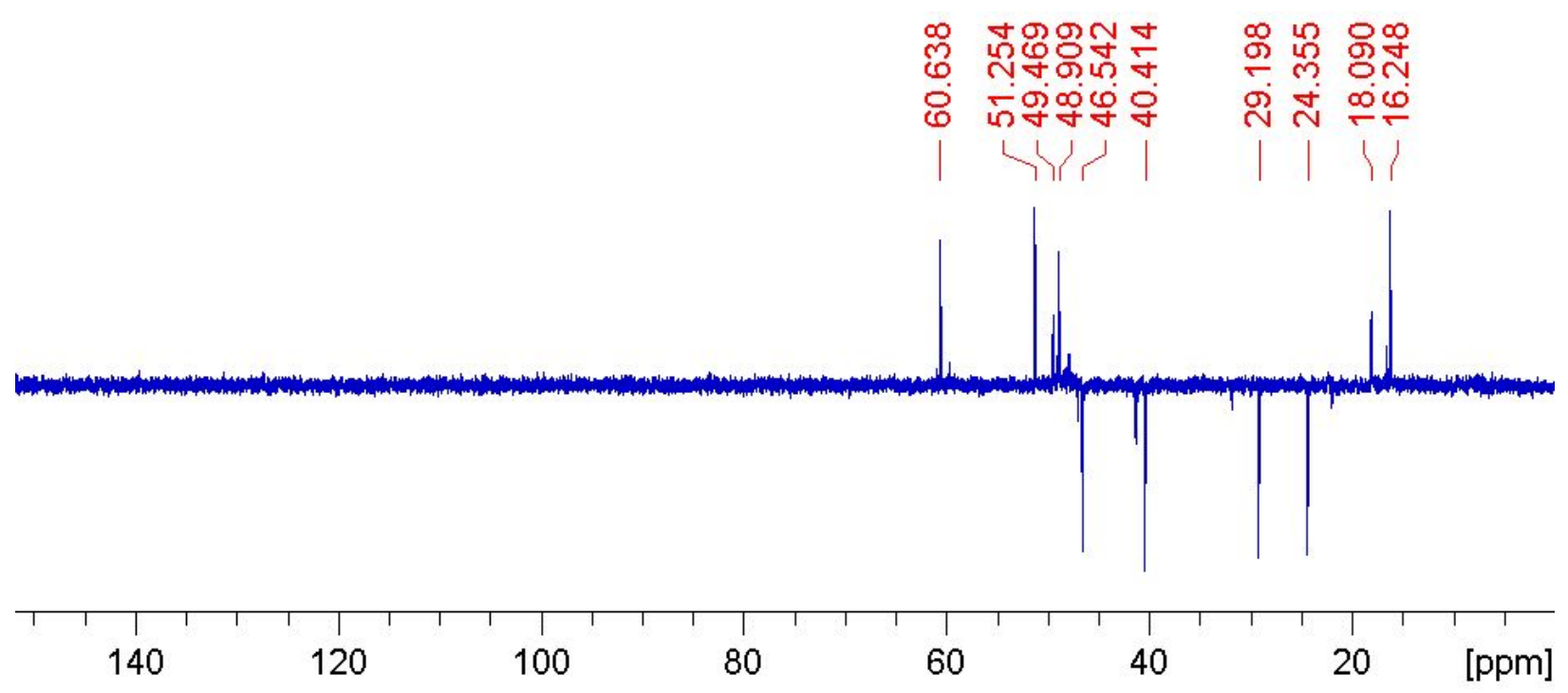

Figure S9. DEPT-135 NMR spectrum of Ala-Gly-Pro-Ala-Gly-OMe (2) in methanol- $d_{4}$. 


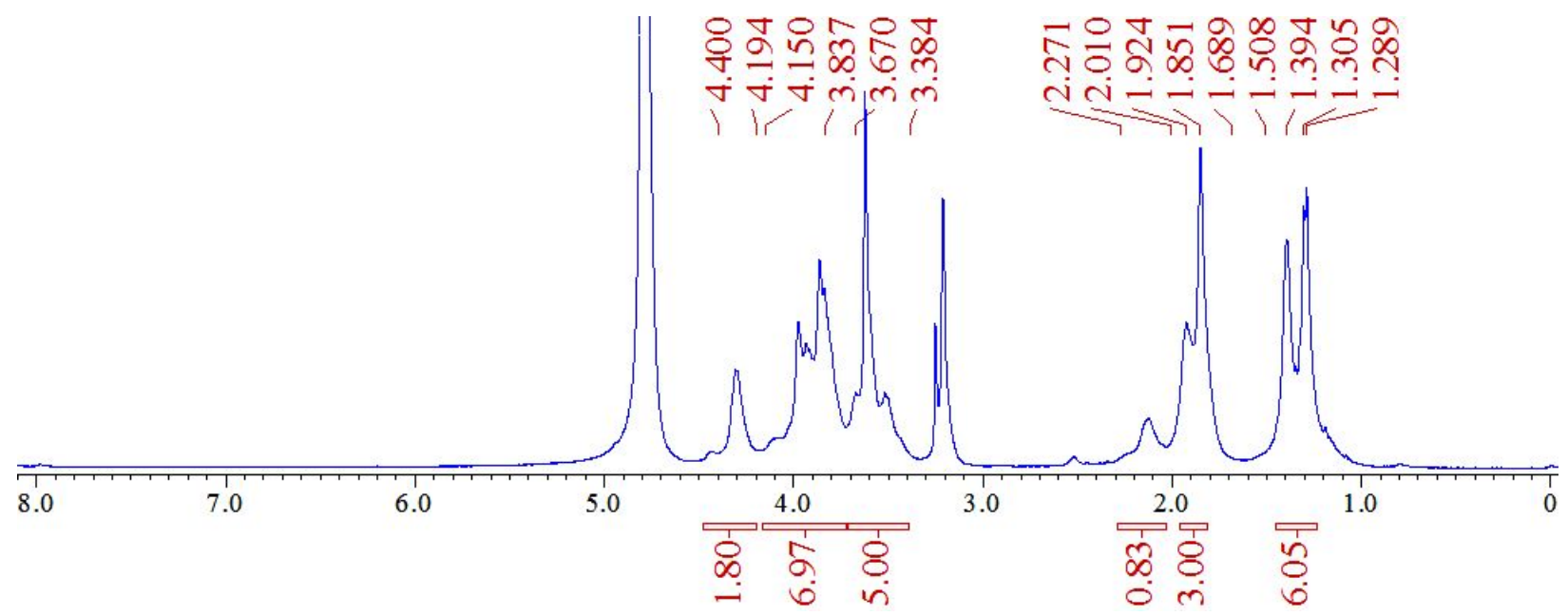

Figure S10. ${ }^{1} \mathrm{H}$ NMR spectrum of Ala-Gly-Gly-Pro-Ala-Gly-OMe (3) in Methanol- $d_{4}$.
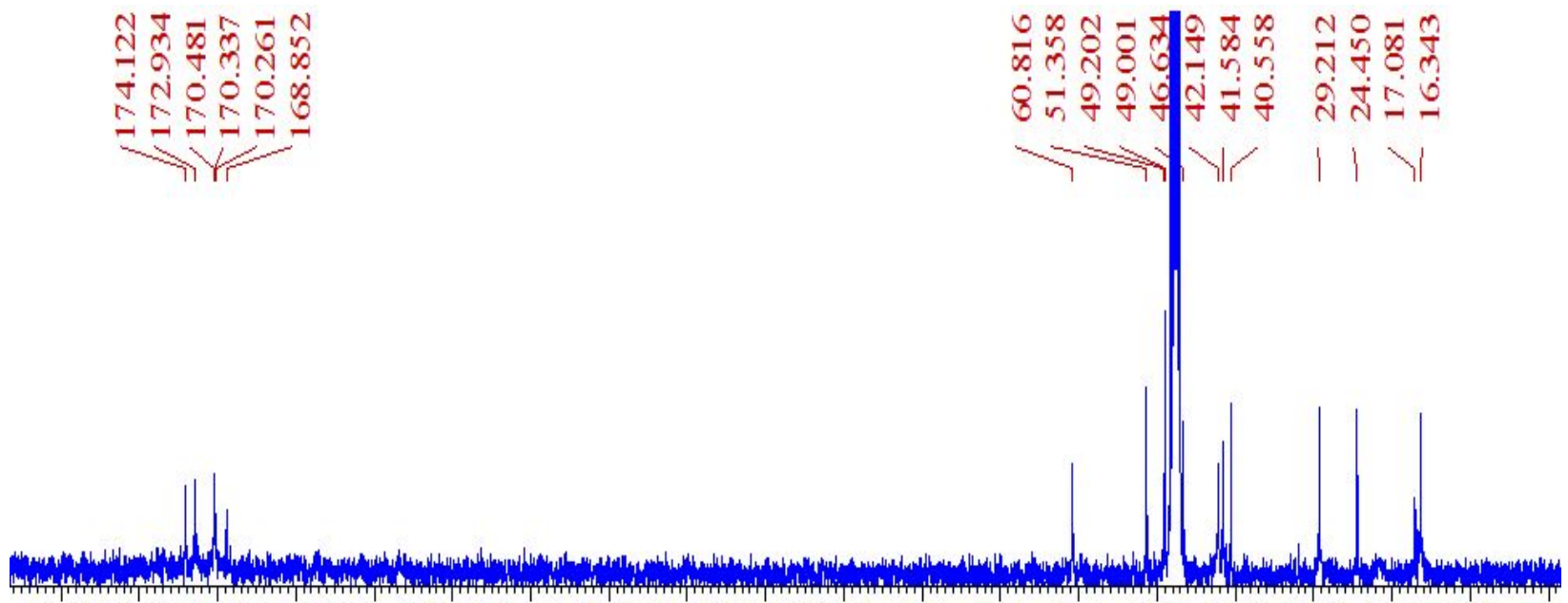

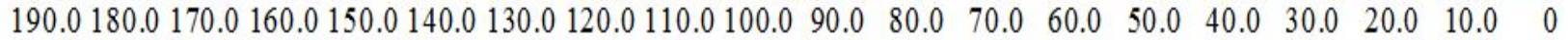

Figure S11. ${ }^{13} \mathrm{C}$ NMR spectrum of 3 in Methanol- $d_{4}$. 


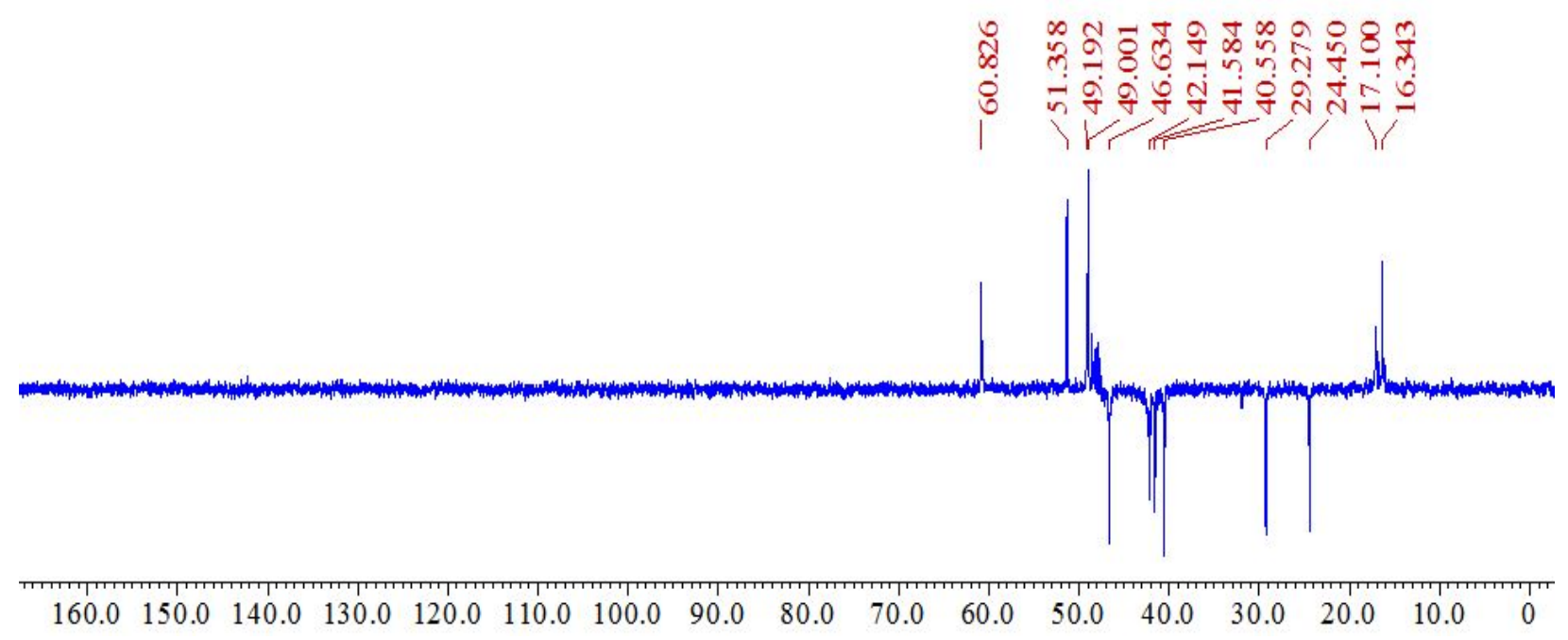

Figure S12. DEPT-135 NMR spectrum of $\mathbf{3}$ in Methanol- $d_{4}$.
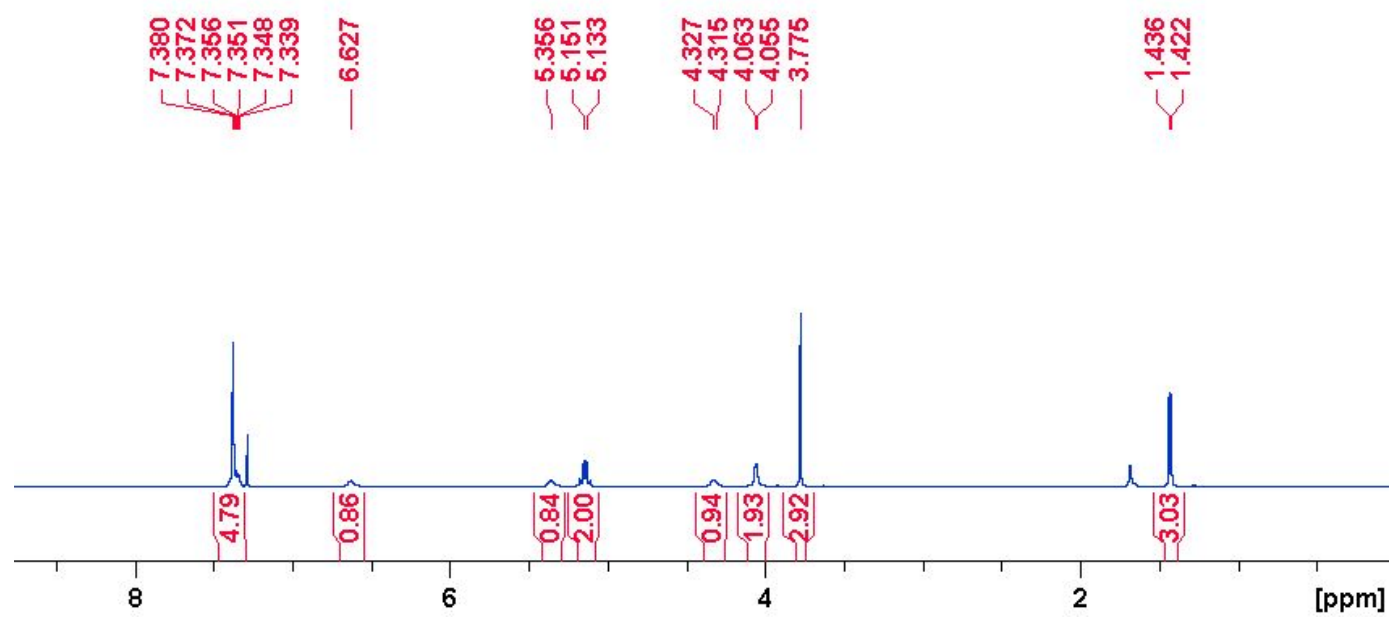

Figure S13. ${ }^{1} \mathrm{H}$ NMR spectrum of N-Cbz-Ala-Gly-OMe (5) in $\mathrm{CDCl}_{3}$. 

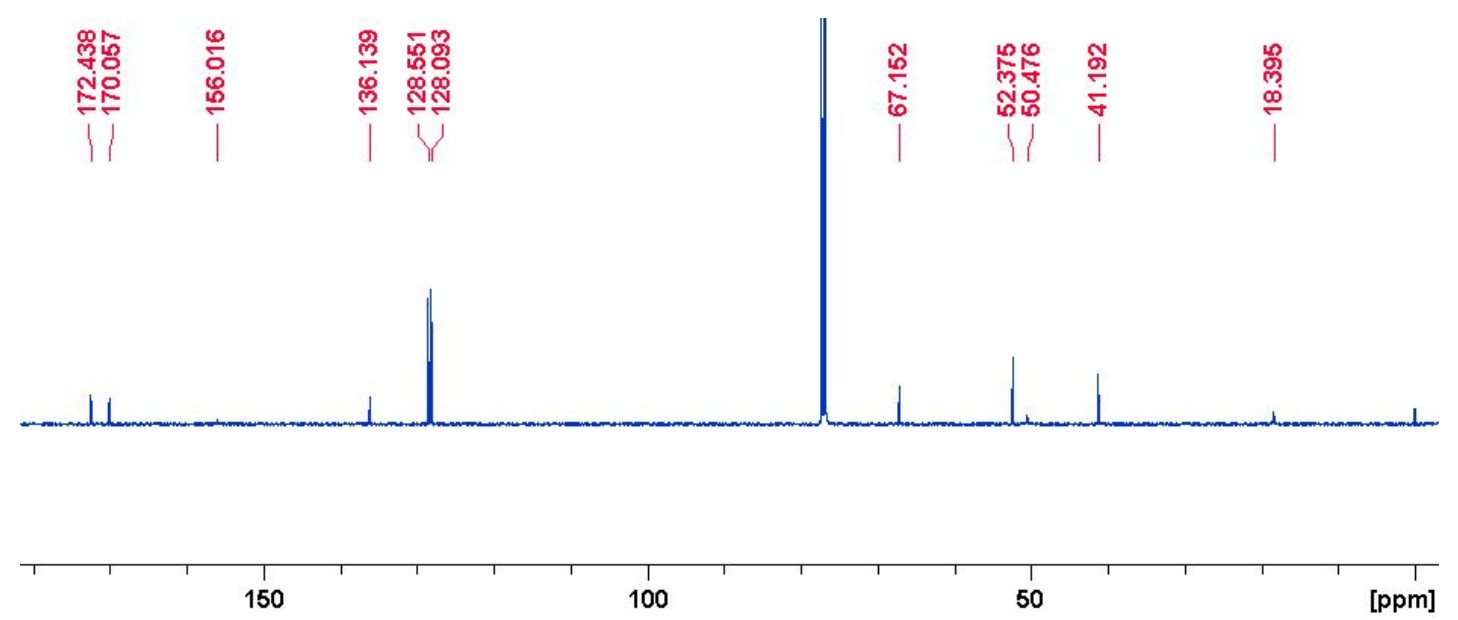

Figure S14. ${ }^{13} \mathrm{C}$ NMR spectrum 5 in $\mathrm{CDCl}_{3}$.
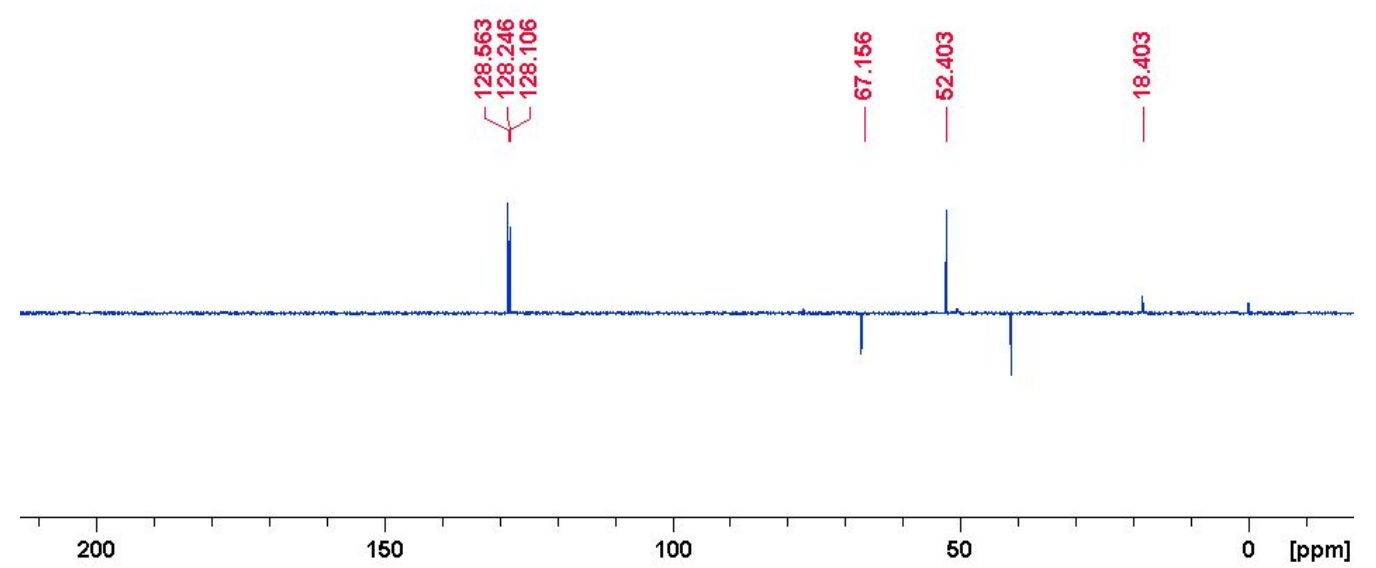

Figure S15. DEPT-135 NMR spectrum of 5 in $\mathrm{CDCl}_{3}$.
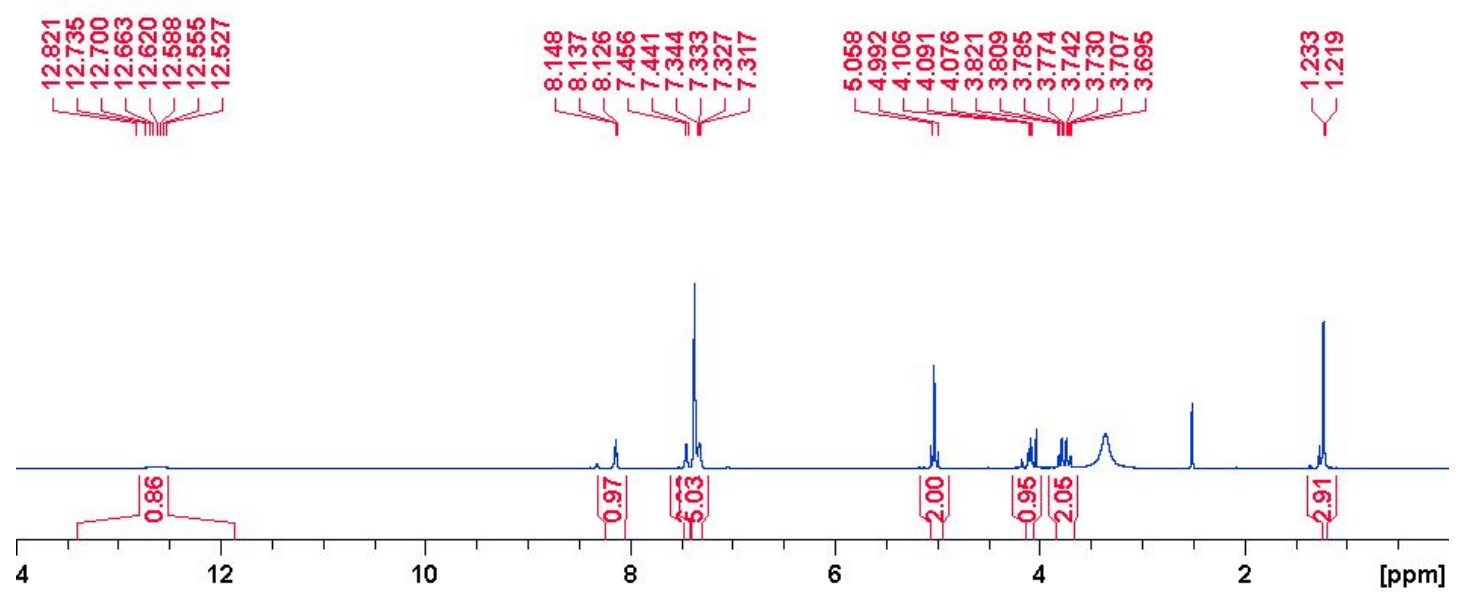

Figure S16. ${ }^{1} \mathrm{H}$ NMR spectrum of 6 in DMSO- $d_{6}$. 


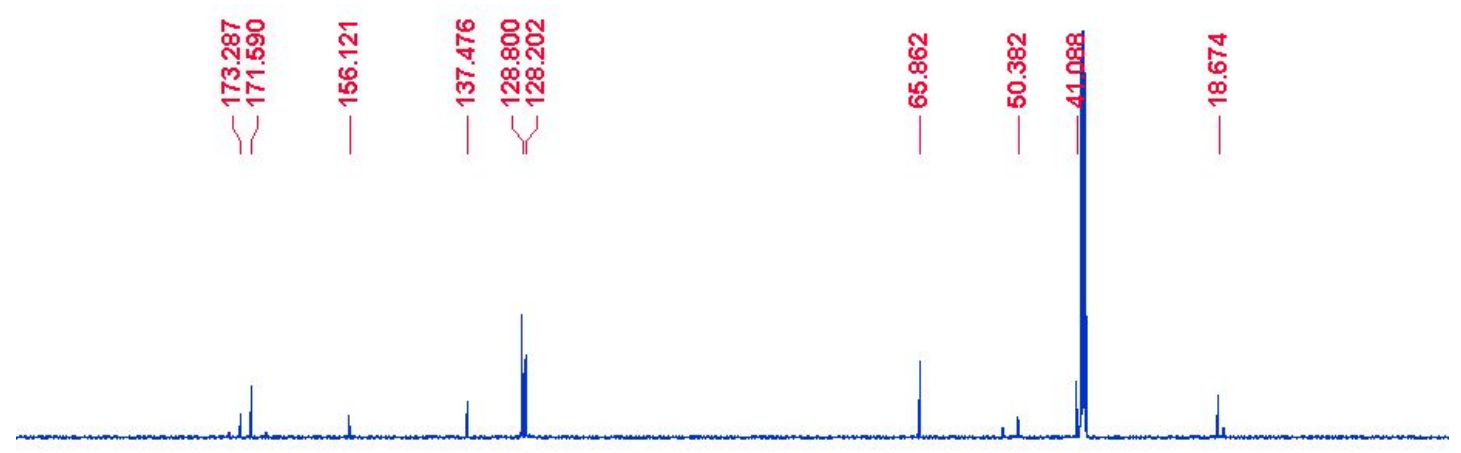

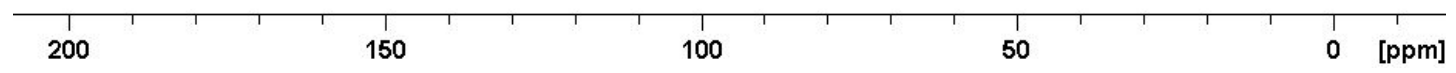

Figure S17. ${ }^{13} \mathrm{C}$ NMR spectrum of N-Cbz-Ala-Gly-OH (6) in DMSO- $d_{6}$.

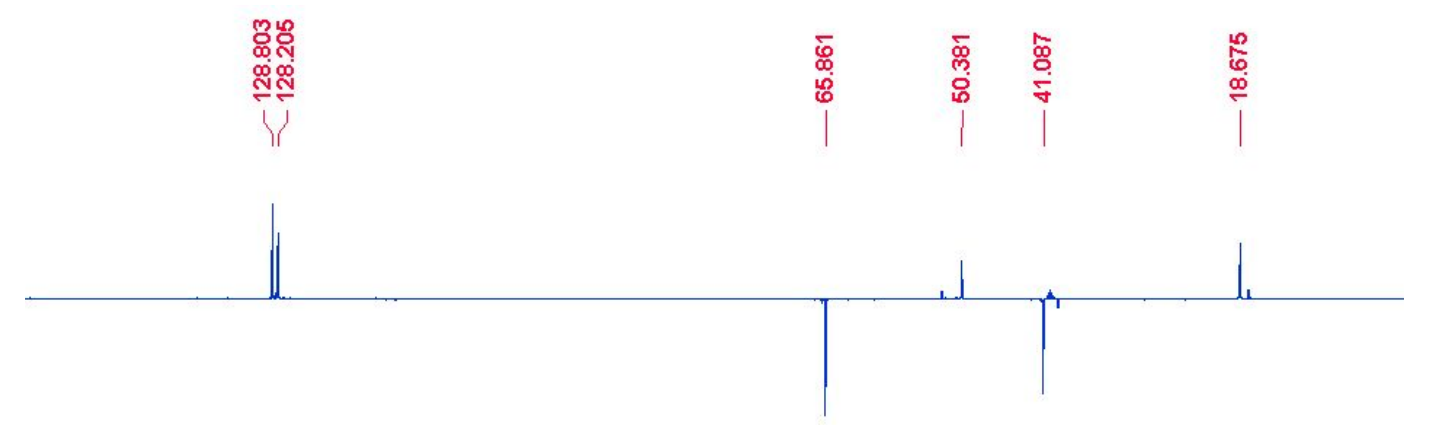

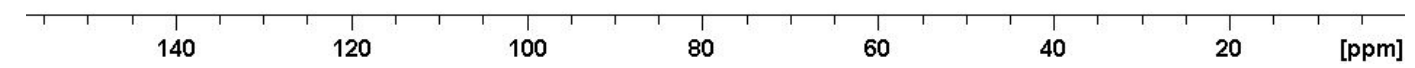

Figure S18. DEPT-135 NMR spectrum of N-Cbz-Ala-Gly-OH (6) in DMSO- $d_{6}$.

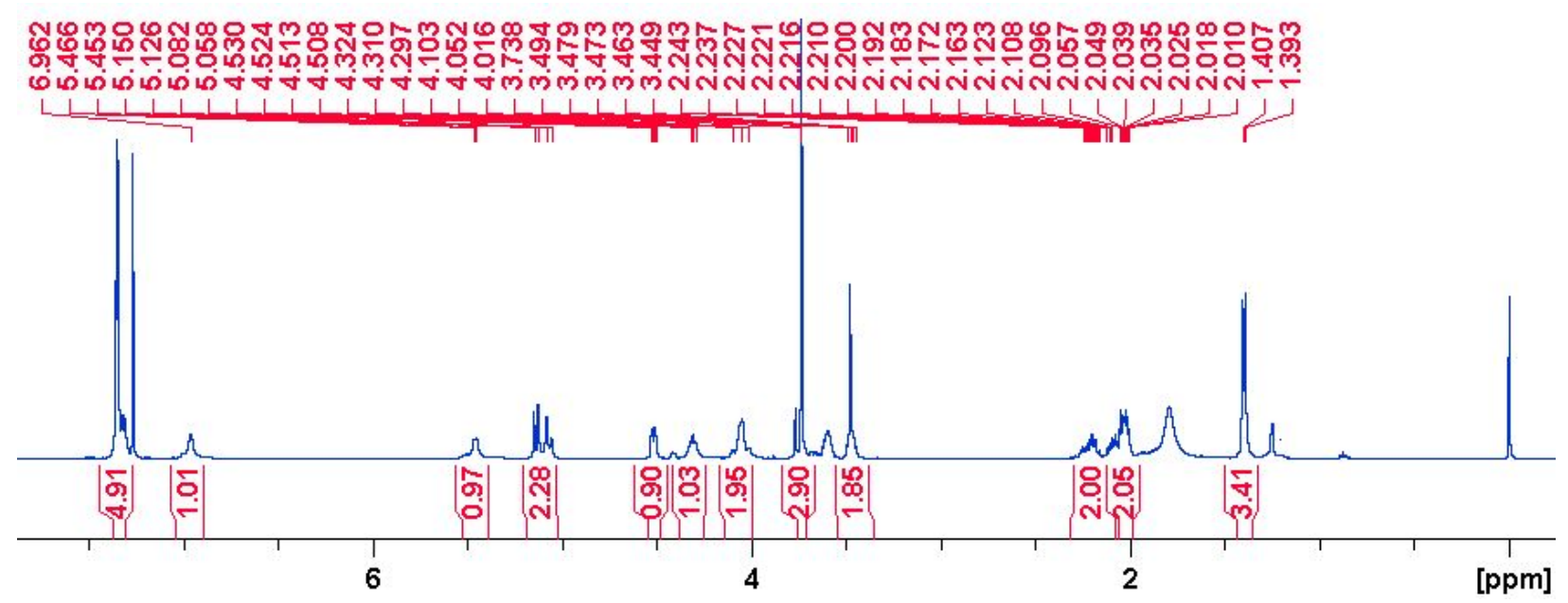

Figure S19. ${ }^{1} \mathrm{H}$ NMR spectrum of N-Cbz-Ala-Gly-Pro-OMe (7) in $\mathrm{CDCl}_{3}$. 


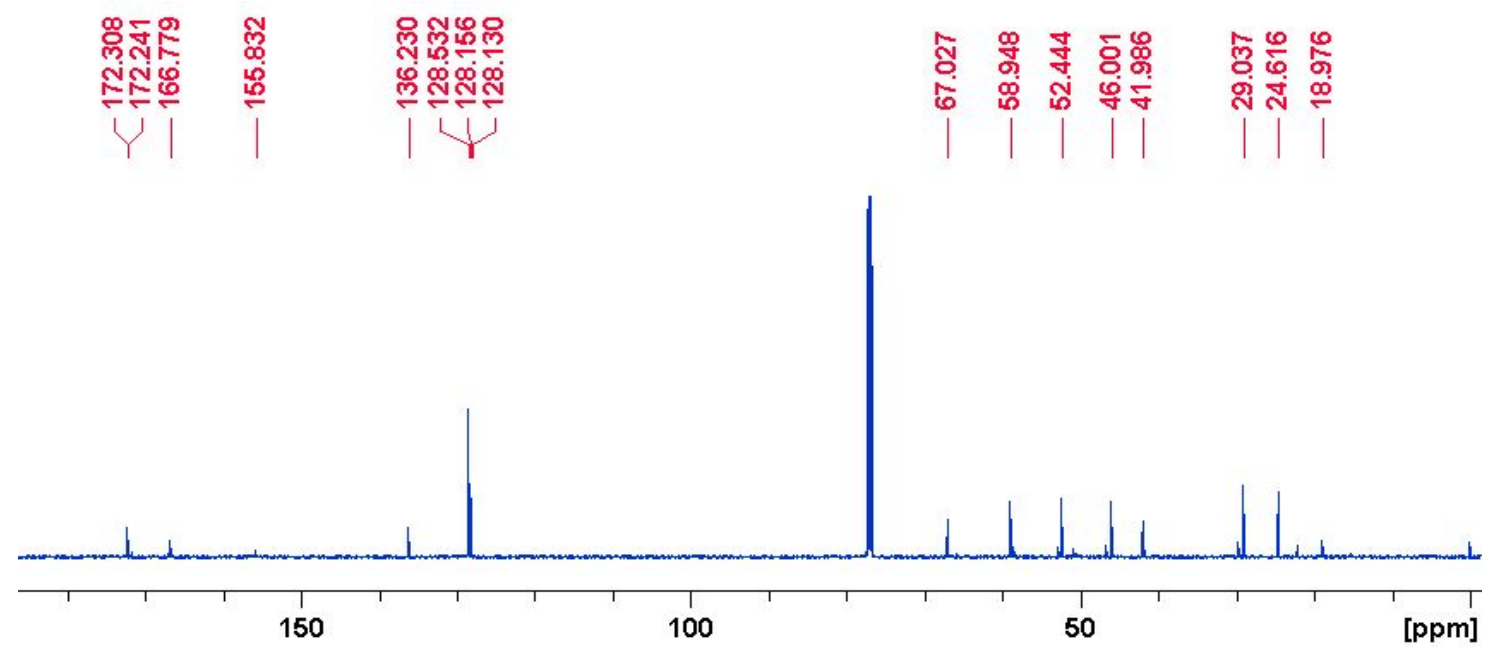

Figure S20. ${ }^{13} \mathrm{C}$ NMR spectrum of N-Cbz-Ala-Gly-Pro-OMe (7) in $\mathrm{CDCl}_{3}$.
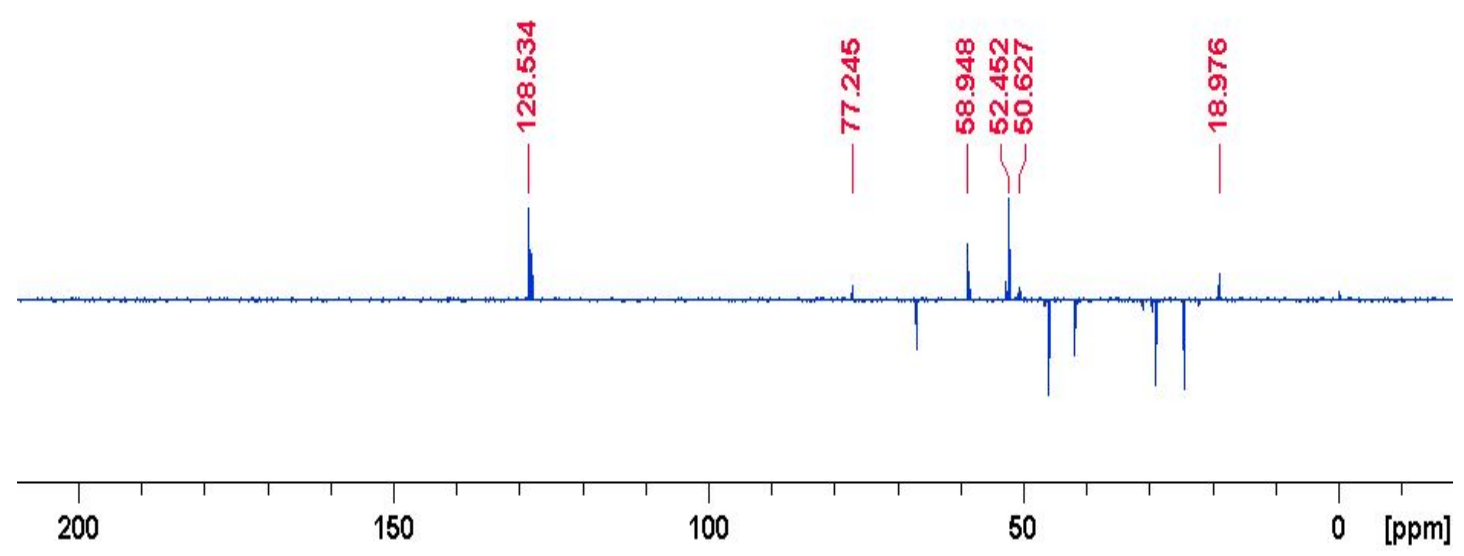

Figure S21. DEPT-135 NMR spectrum of N-Cbz-Ala-Gly-Pro-OMe (7) in $\mathrm{CDCl}_{3}$.

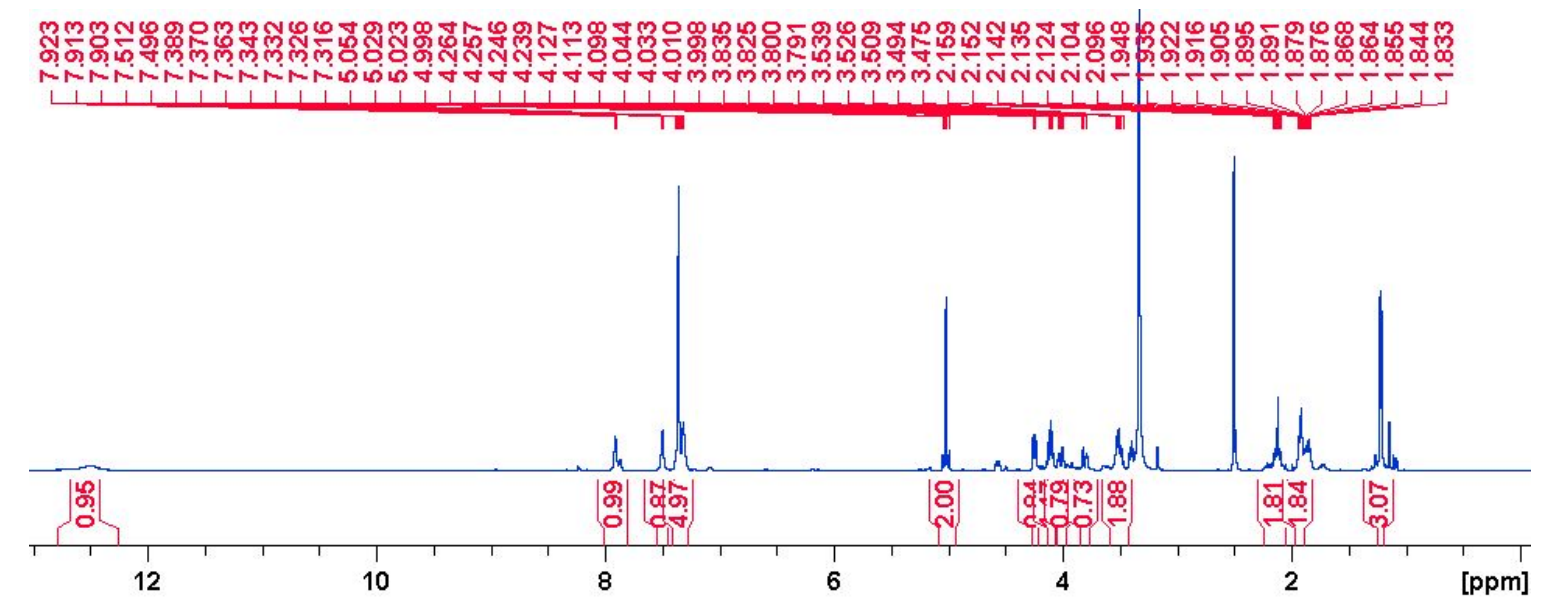

Figure S22. ${ }^{1} \mathrm{H}$ NMR spectrum of N-Cbz-Ala-Gly-Pro-OH (8) in DMSO- $d_{6}$. 


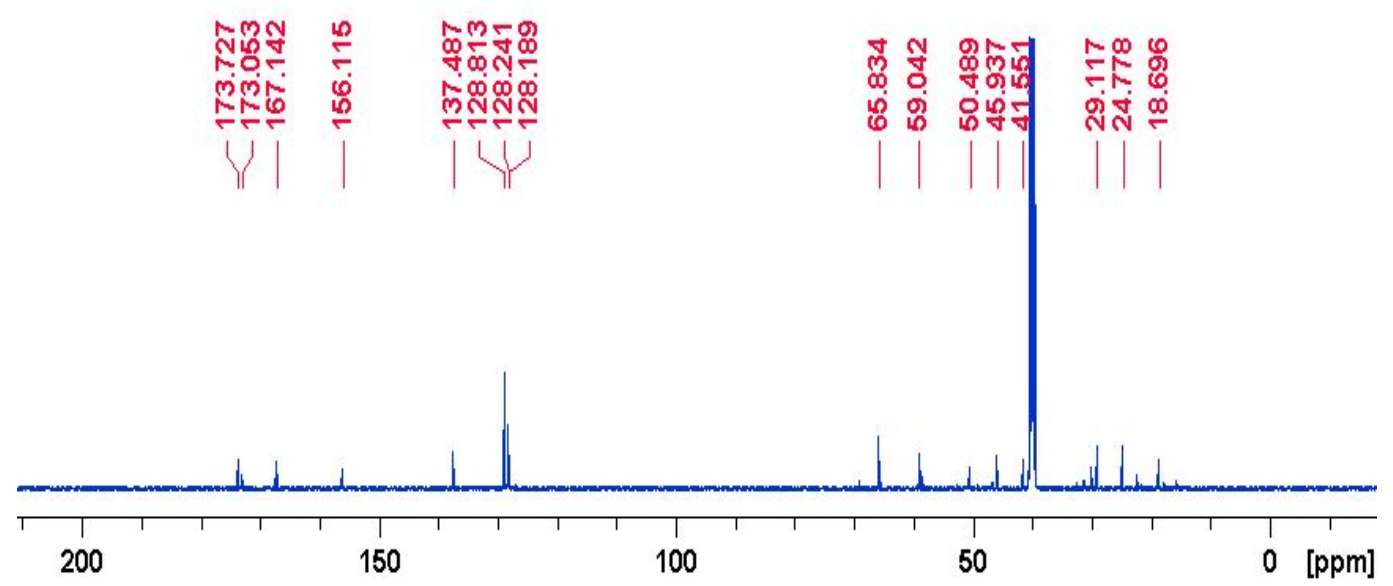

Figure S23. ${ }^{13} \mathrm{C}$ NMR spectrum of N-Cbz-Ala-Gly-Pro-OH (8) in DMSO- $d_{6}$.

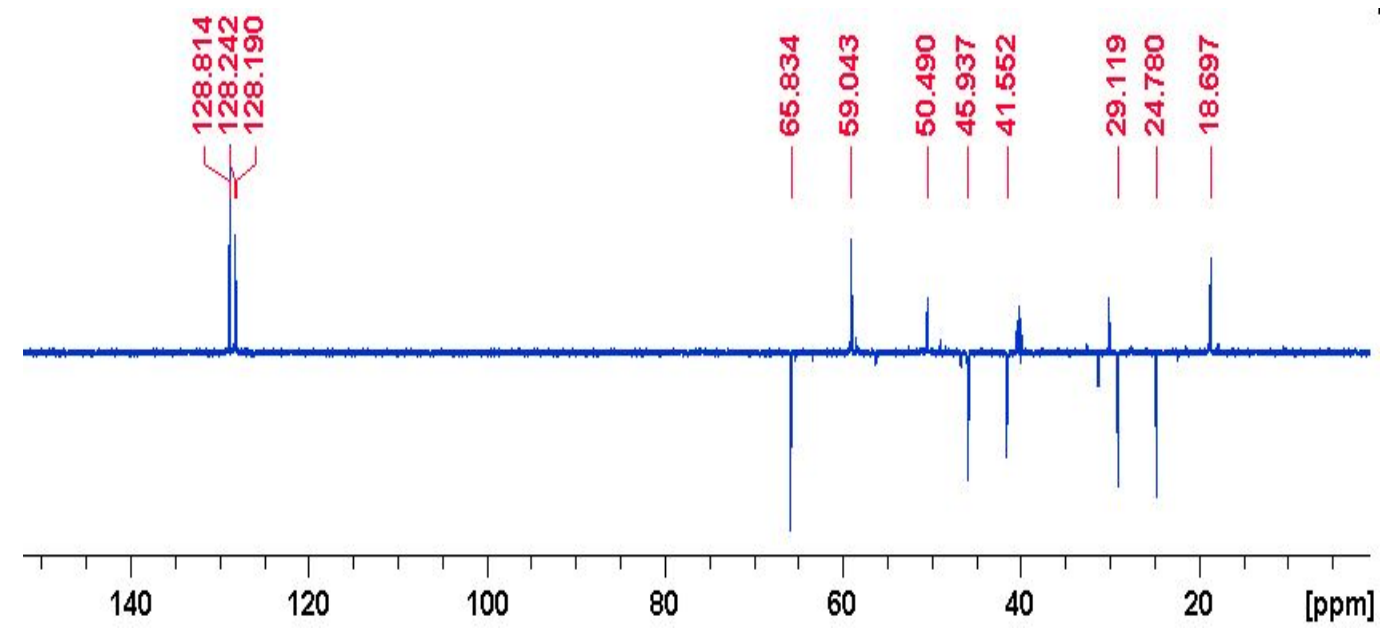

Figure S24. DEPT-135 NMR spectrum of N-Cbz-Ala-Gly-Pro-OH (8) in DMSO- $d_{6}$.

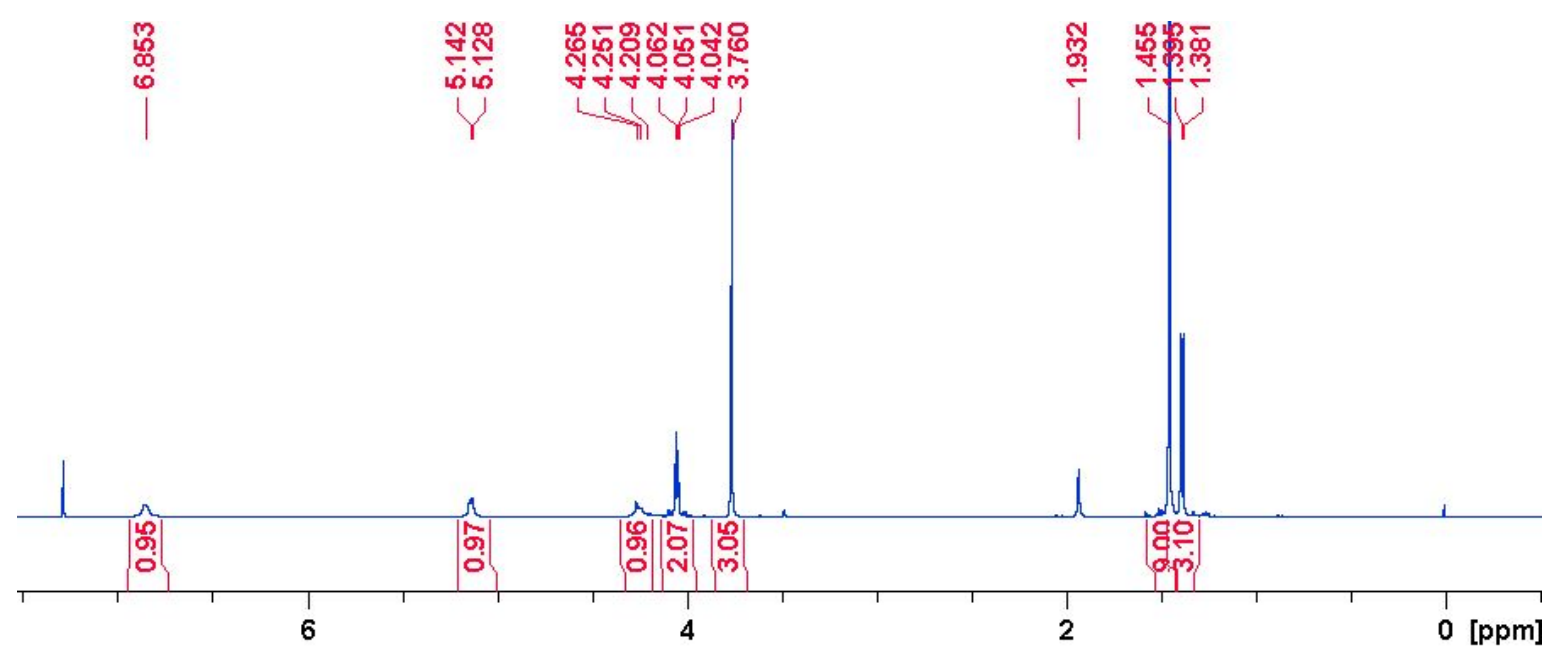

Figure S25. ${ }^{1} \mathrm{H}$ NMR spectrum of N-Boc-Ala-Gly-OMe (10) in $\mathrm{CDCl}_{3}$. 


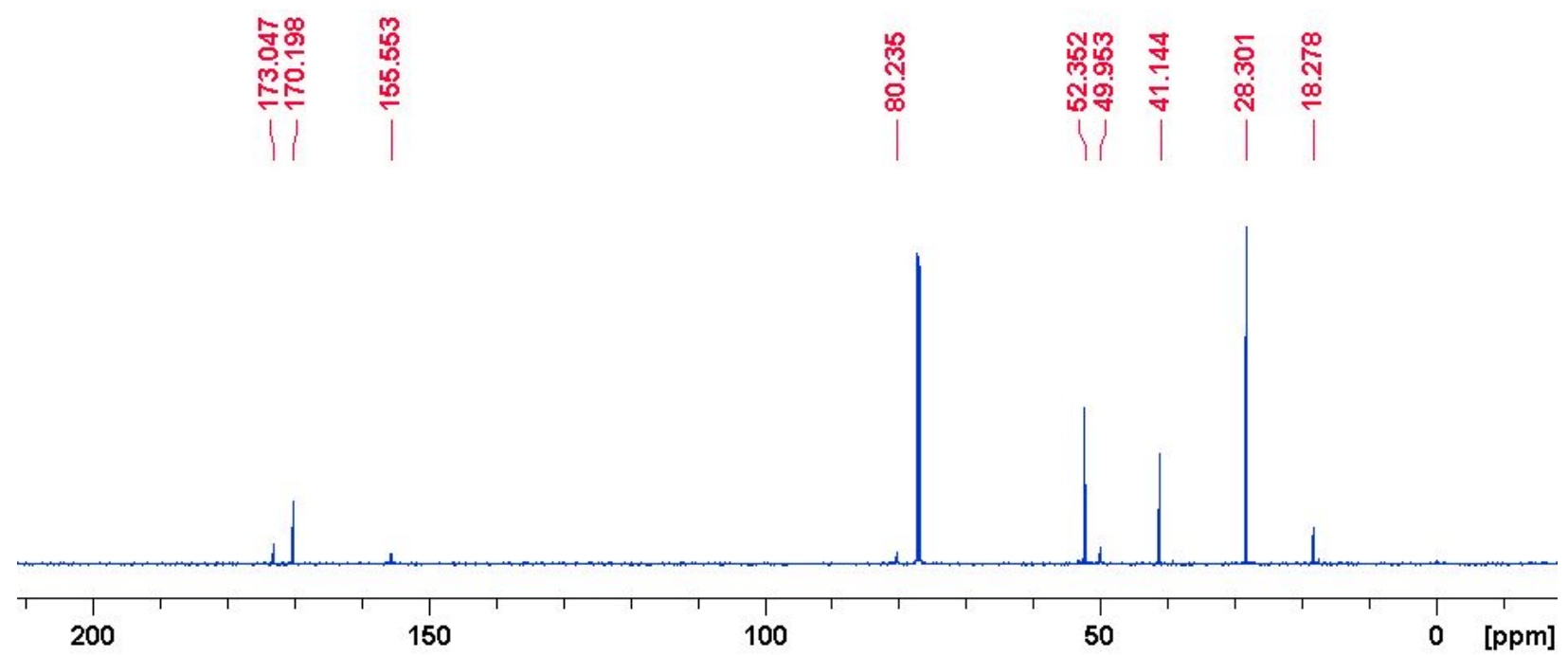

Figure S26. ${ }^{13} \mathrm{C}$ NMR spectrum of N-Boc-Ala-Gly-OMe (10) in $\mathrm{CDCl}_{3}$.
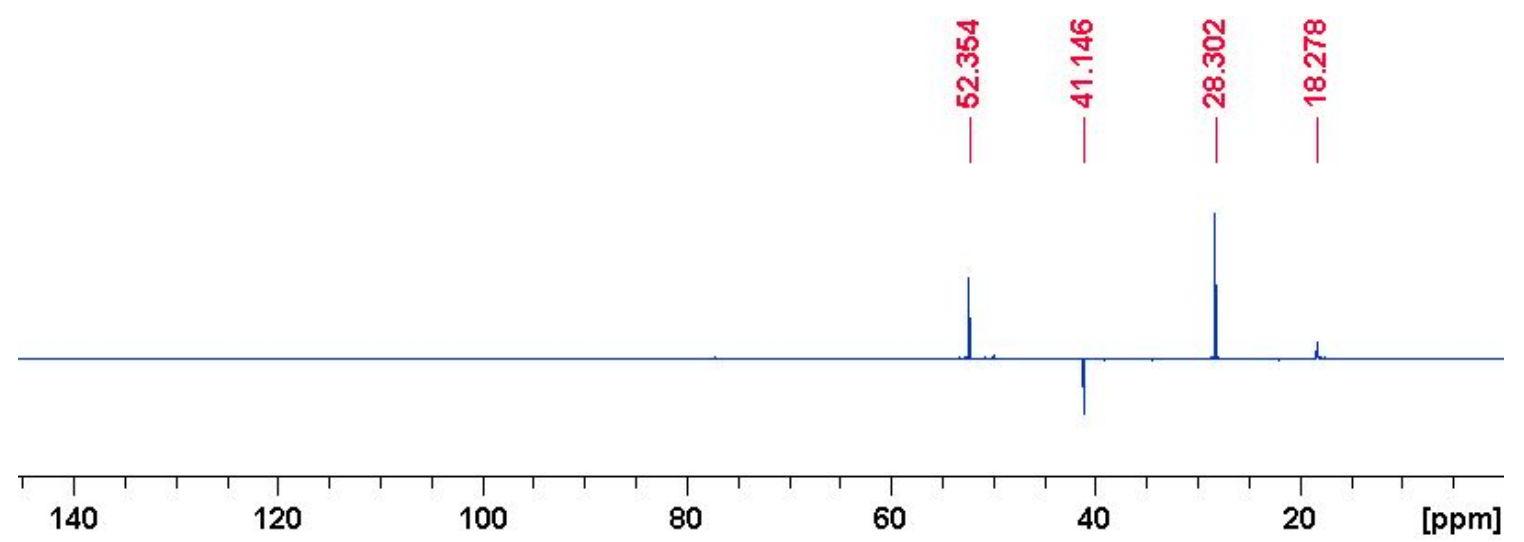

Figure S27. DEPT-135 NMR spectrum of N-Boc-Ala-Gly-OMe (10) in $\mathrm{CDCl}_{3}$.

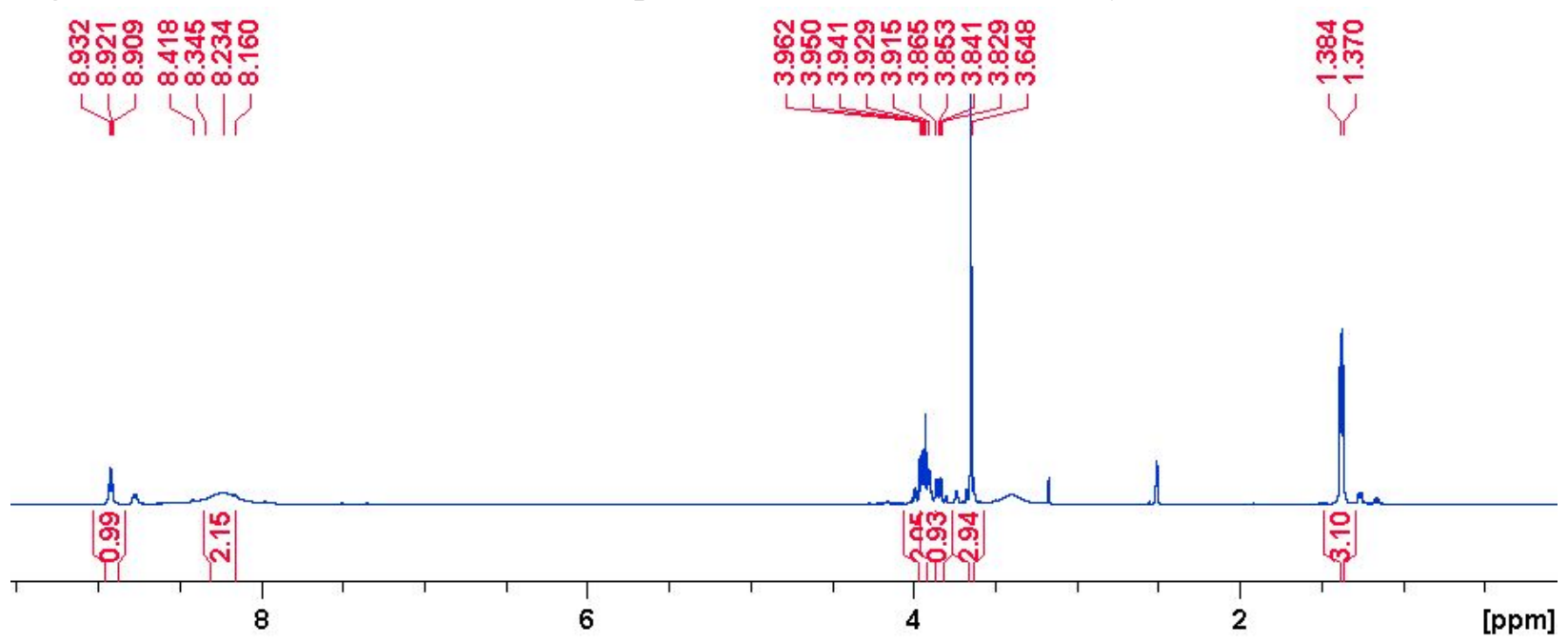

Figure S28. ${ }^{1} \mathrm{H}$ NMR spectrum of Ala-Gly-OMe (11) in DMSO- $d_{6}$. 


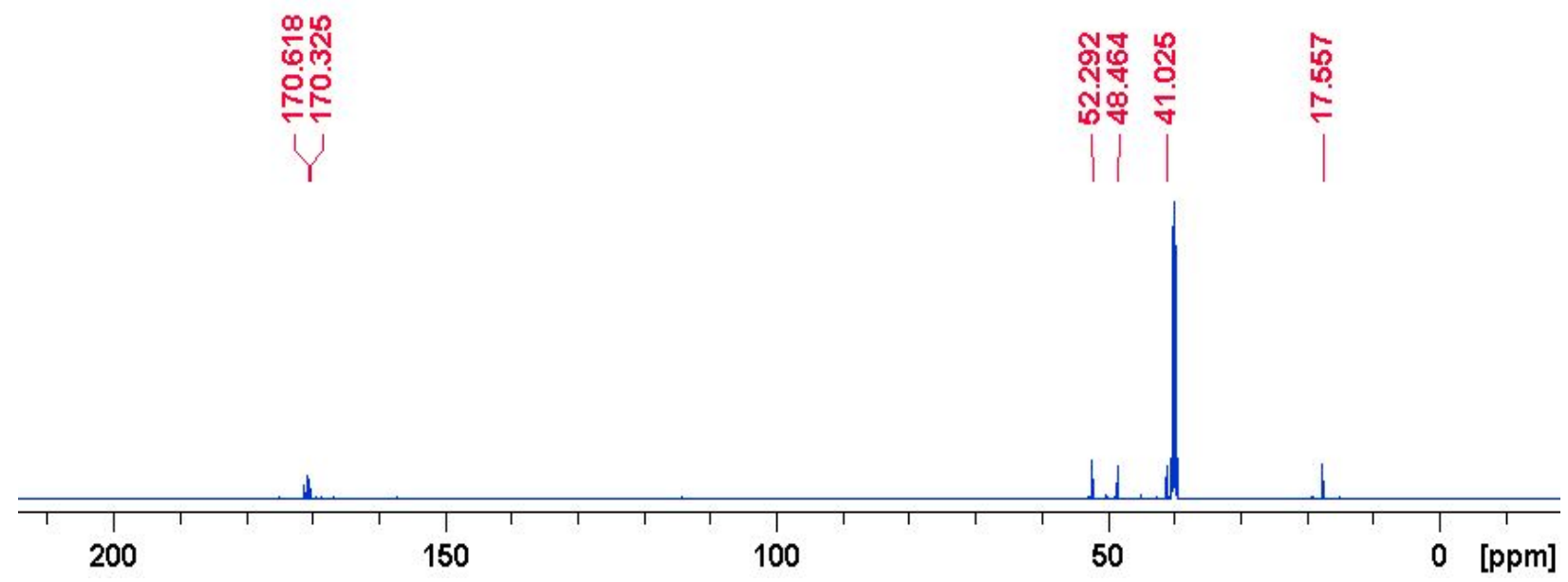

Figure S29. ${ }^{13} \mathrm{C}$ NMR spectrum of Ala-Gly-OMe (11) in DMSO- $d_{6}$.

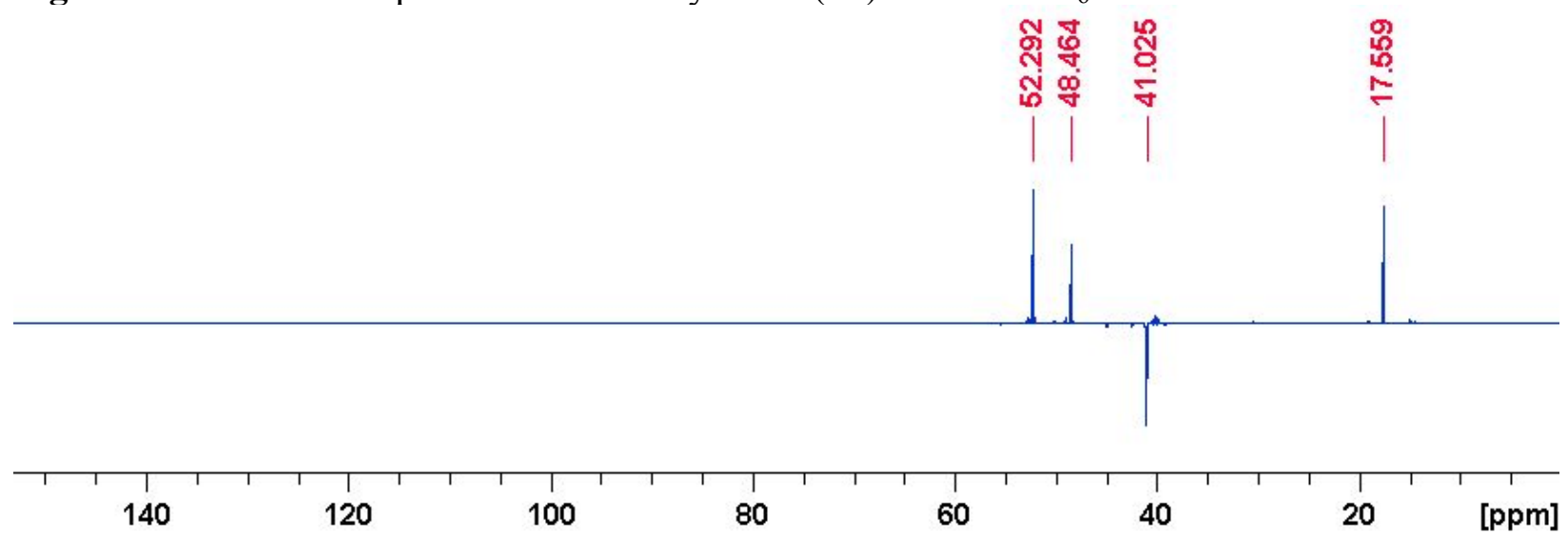

Figure S30. DEPT-135 NMR spectrum of Ala-Gly-OMe (11) in DMSO- $d_{6}$.

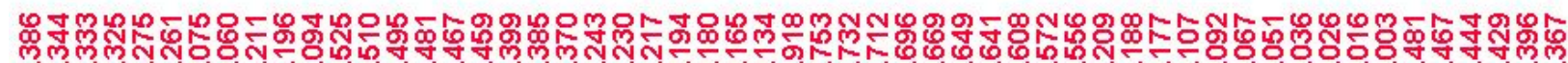
MNM M M

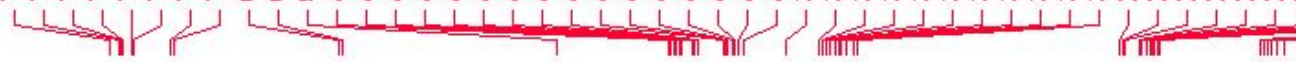

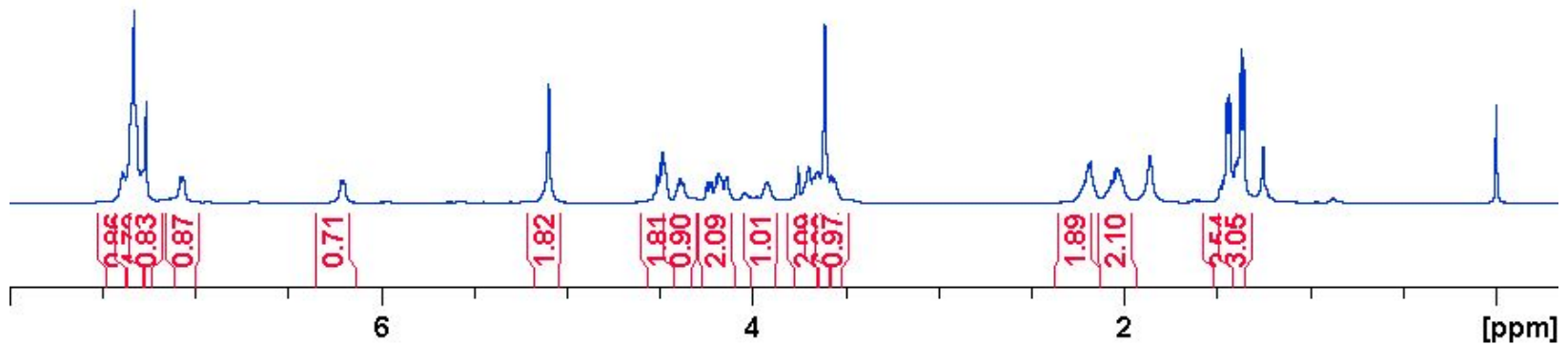

Figure S31. ${ }^{1} \mathrm{H}$ NMR spectrum of N-Cbz-Ala-Gly-Pro-Ala-Gly-OMe (12) in $\mathrm{CDCl}_{3}$. 


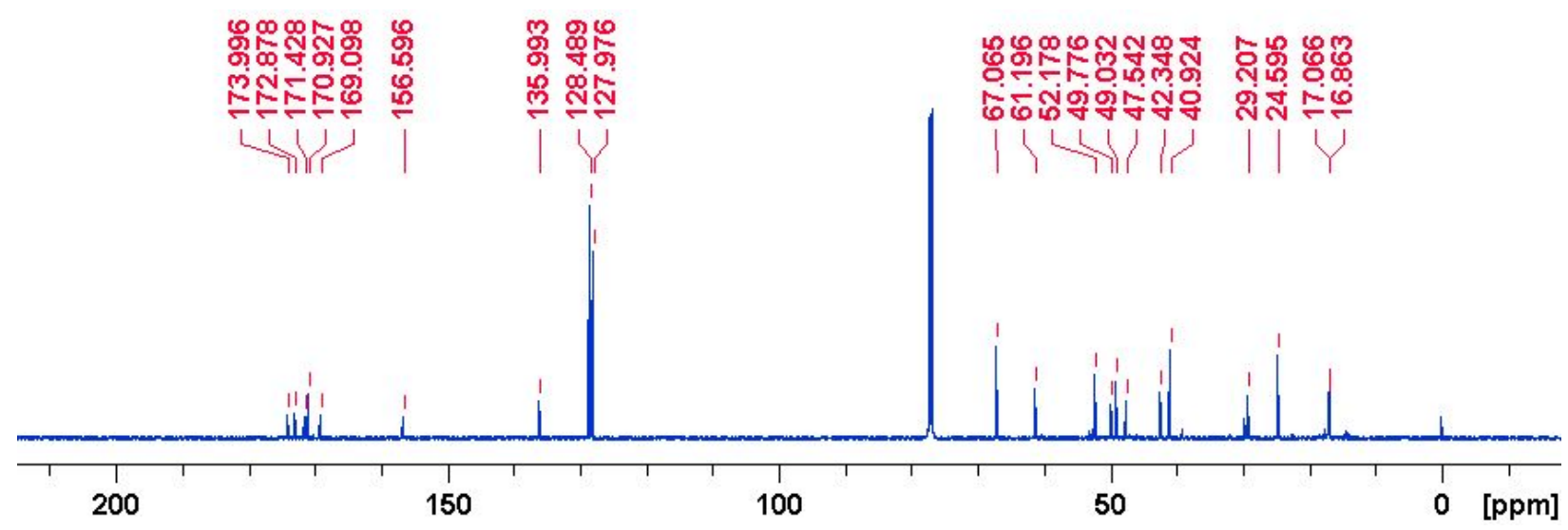

Figure S32. ${ }^{13} \mathrm{C}$ NMR spectrum of N-Cbz-Ala-Gly-Pro-Ala-Gly-OMe (12) in $\mathrm{CDCl}_{3}$.

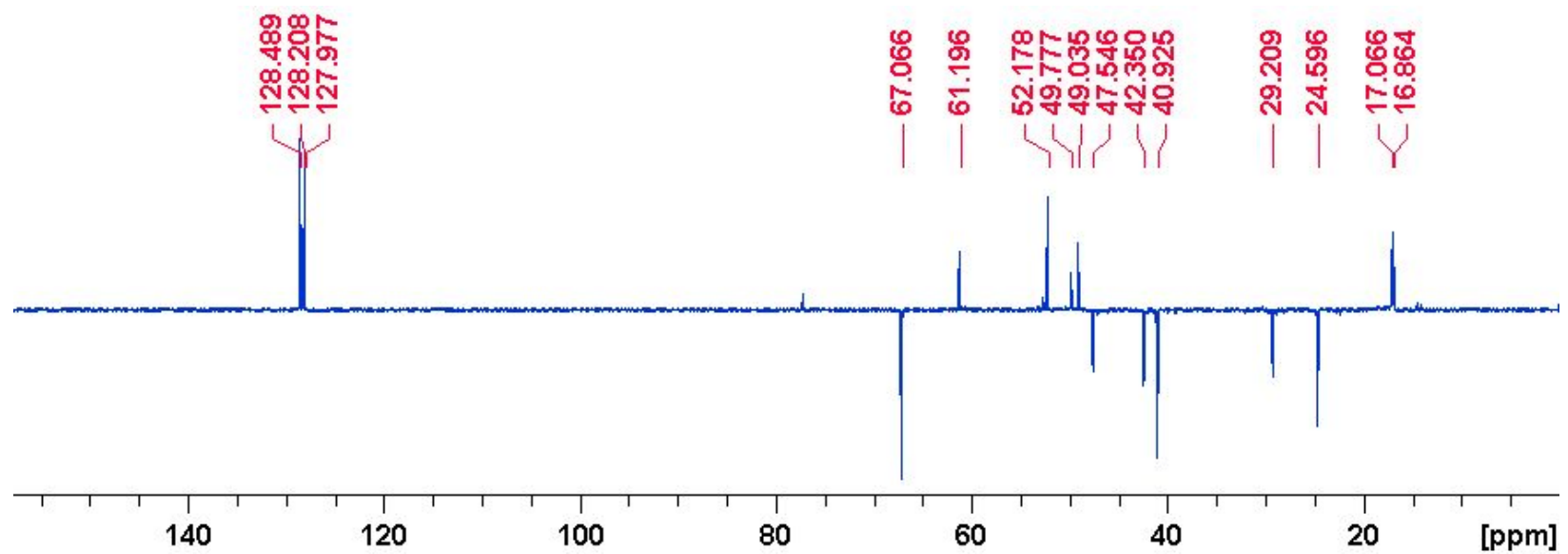

Figure S33. DEPT-135 NMR spectrum of N-Cbz-Ala-Gly-Pro-Ala-Gly-OMe (12) in $\mathrm{CDCl}_{3}$. 


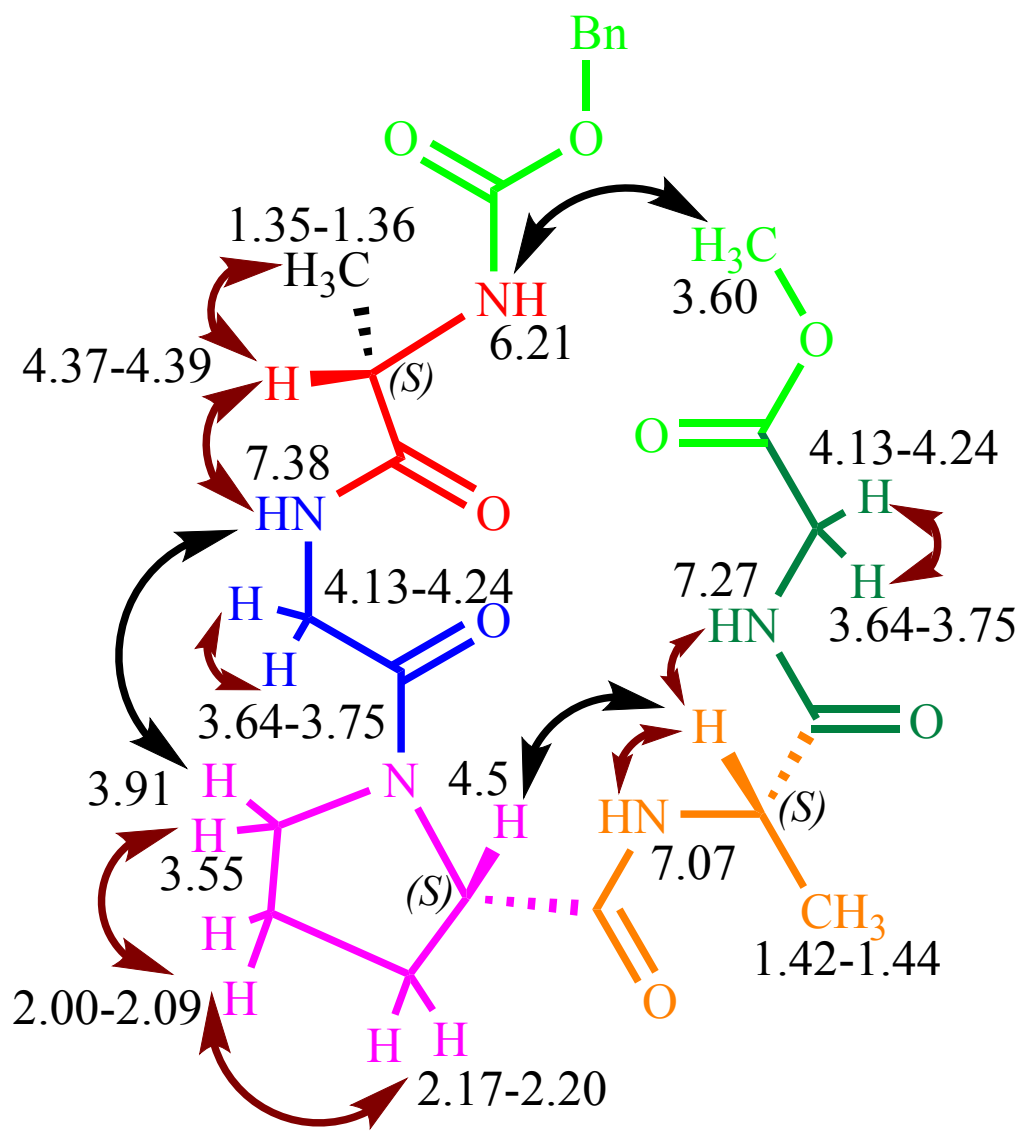

Figure S34. Configuration of compound $\mathbf{1 2}$ as depicted from the ROESY and COSY cross peaks. 


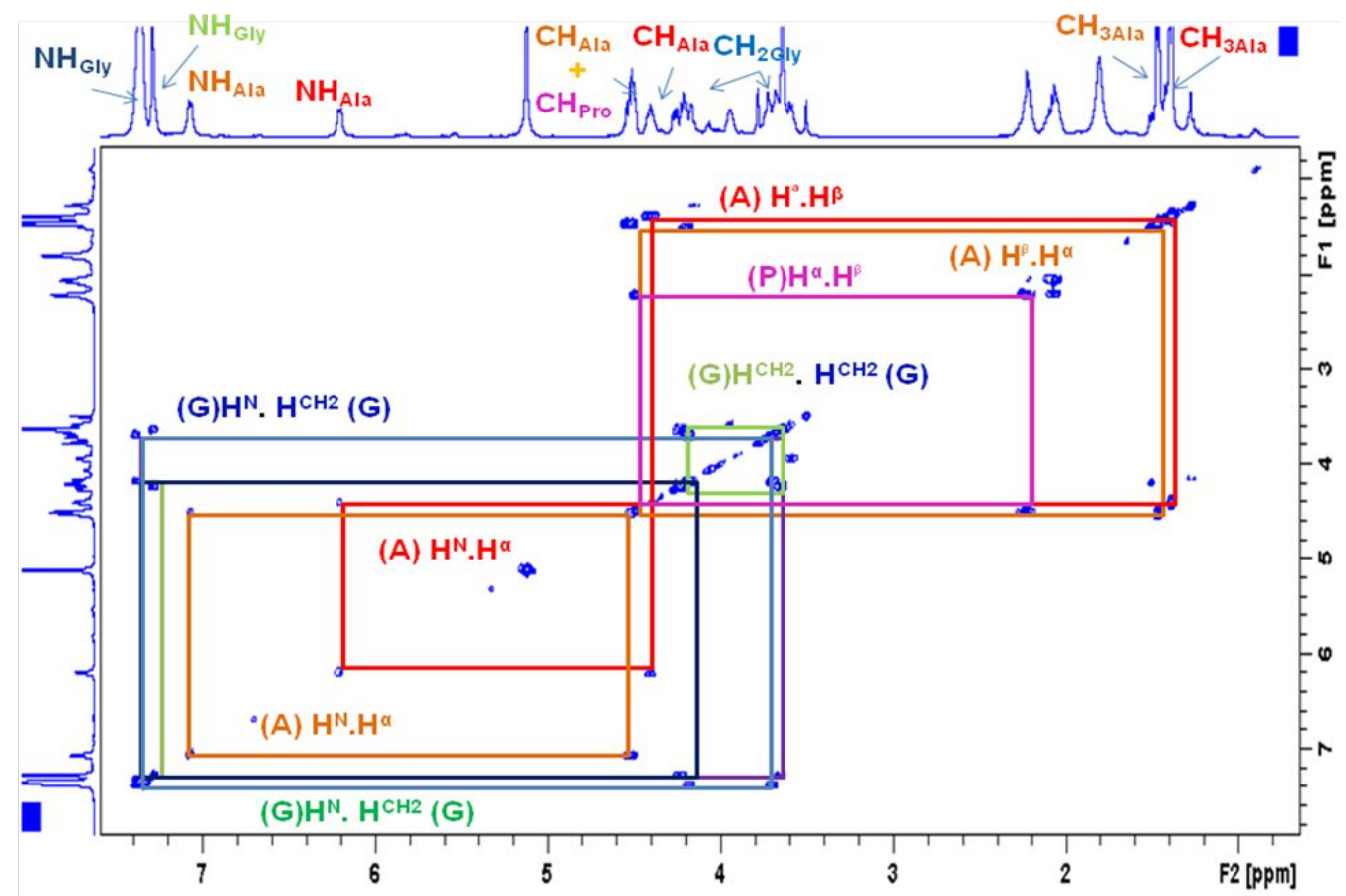

Figure S35. ${ }^{1} \mathrm{H}-{ }^{1} \mathrm{H}$ COSY spectrum of N-Cbz-AGPAG-OMe (12).

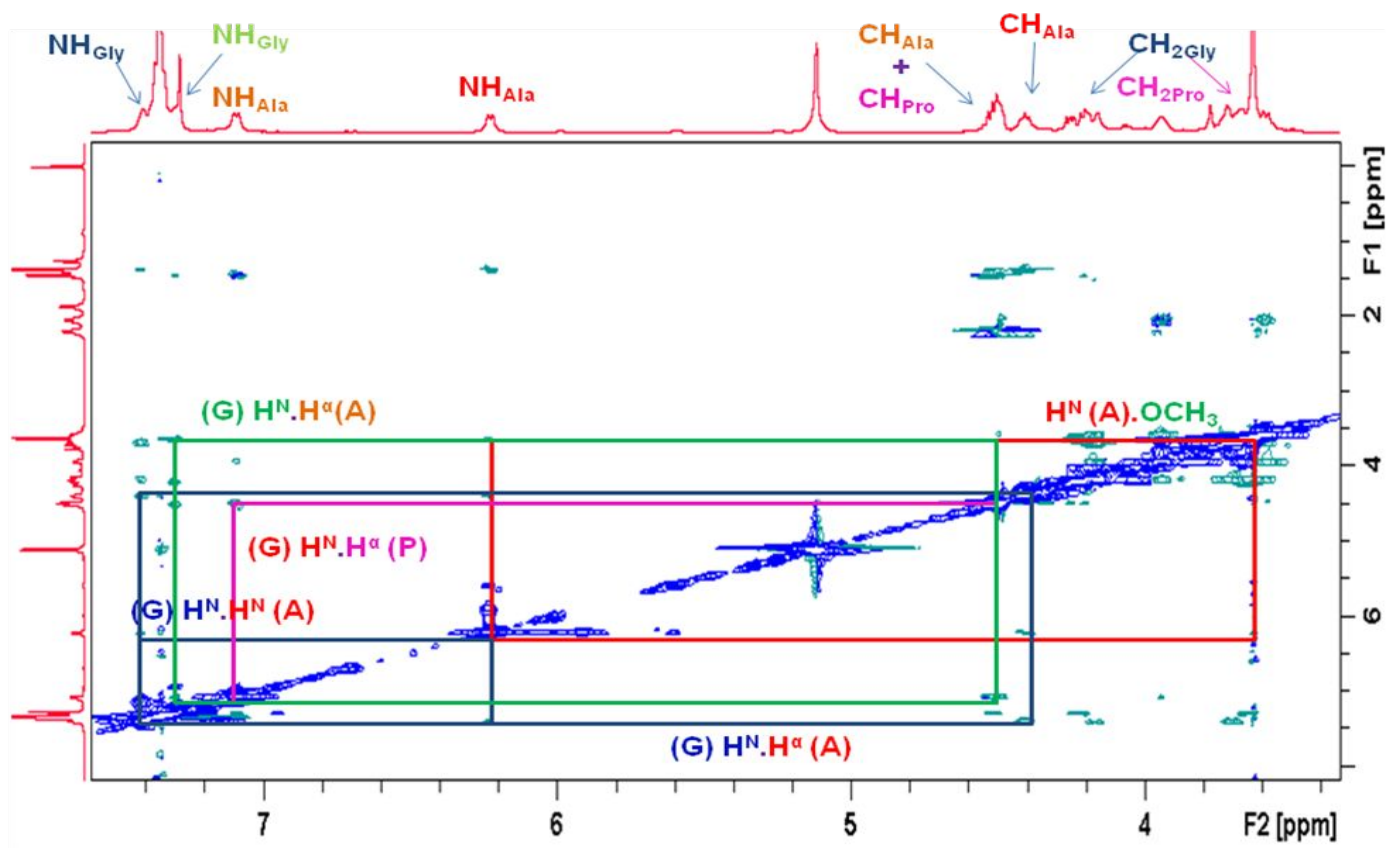

Figure S36. ${ }^{1} \mathrm{H}-{ }^{1} \mathrm{H}$ NOESY spectrum of N-Cbz AGPAG-OMe (12). 


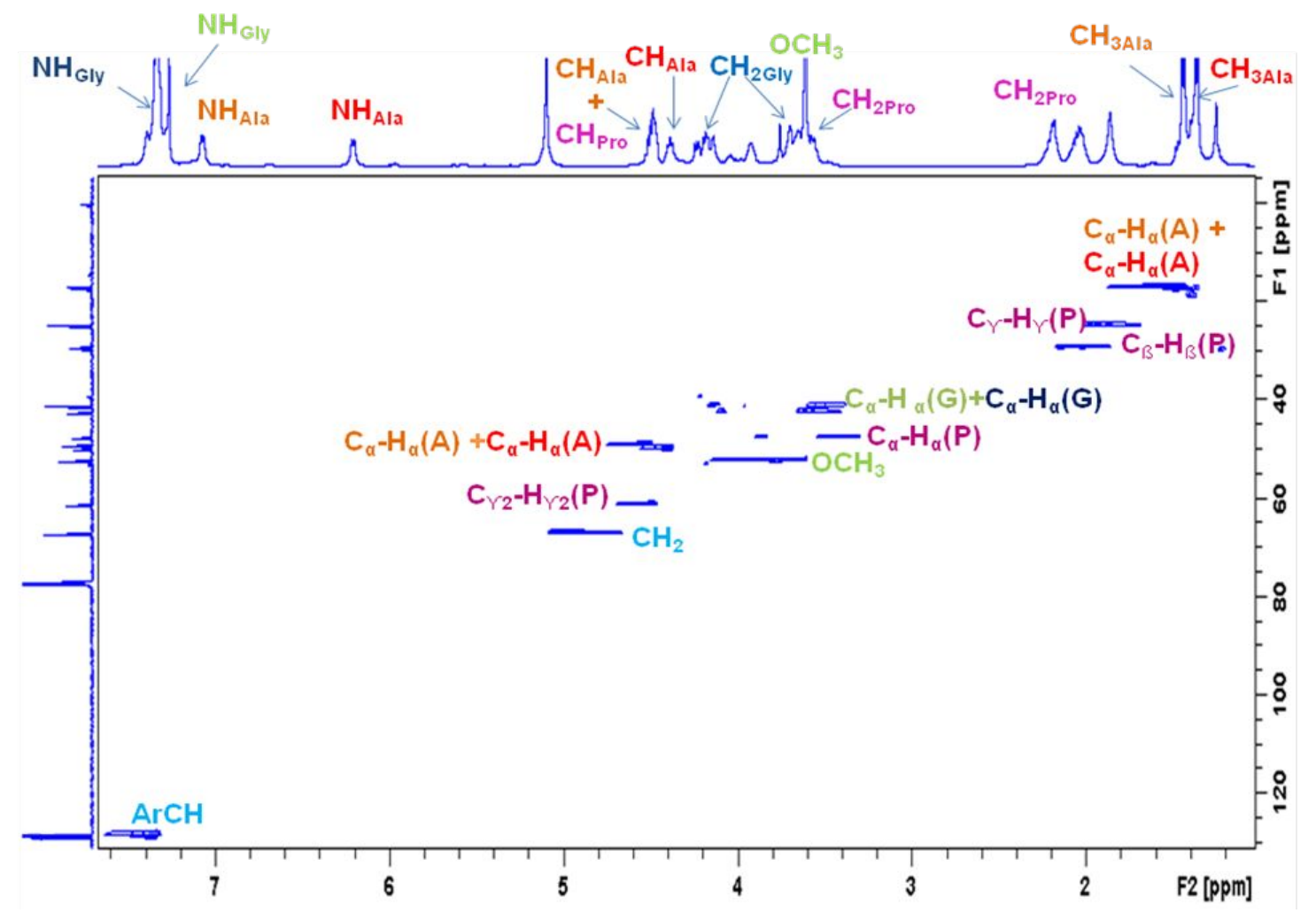

Figure S37. HSQC spectrum of N-Cbz-AGPAG-OMe (12).

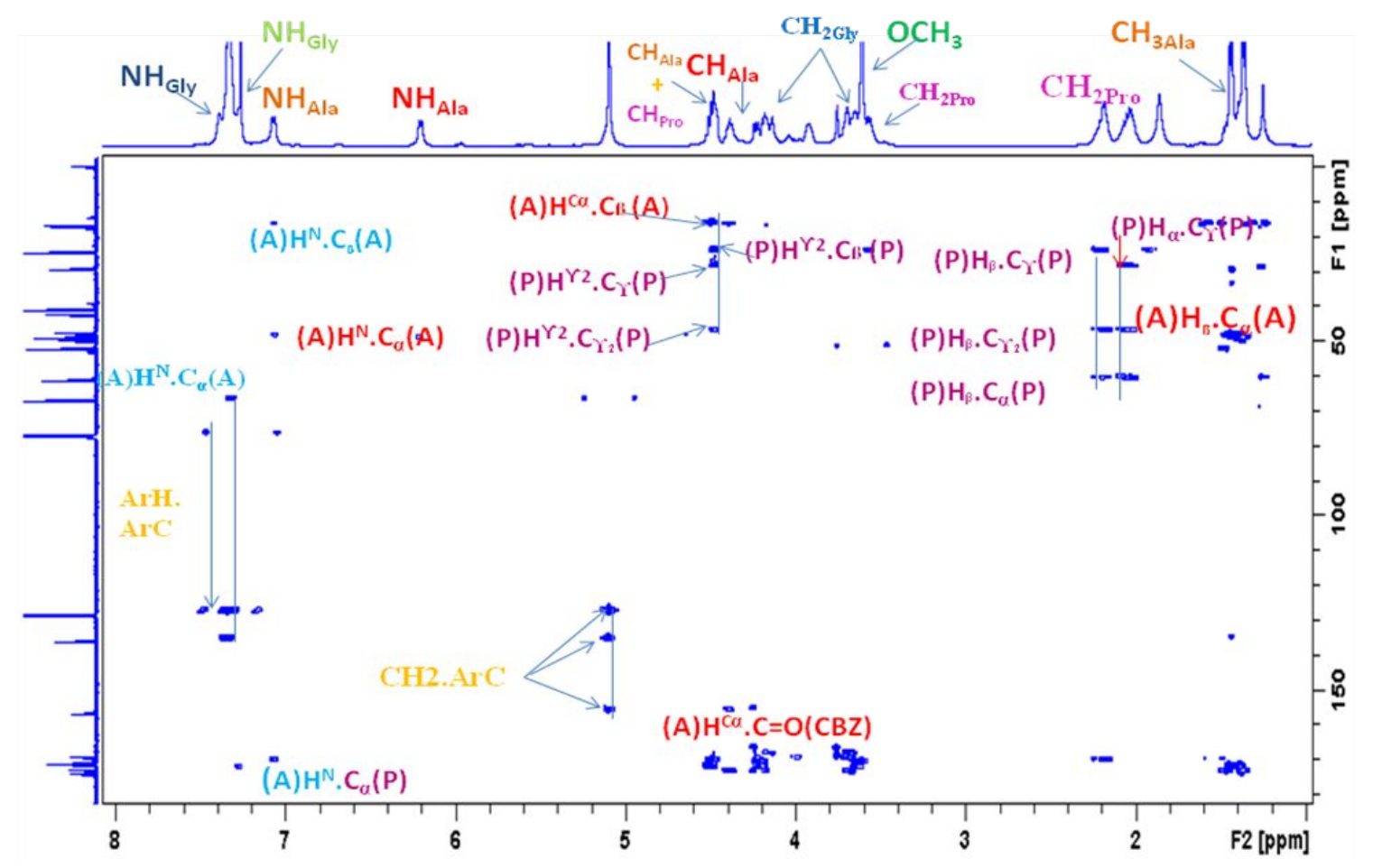

Figure S38. HMBC spectrum of N-Cbz-AGPAG-OMe (12). 


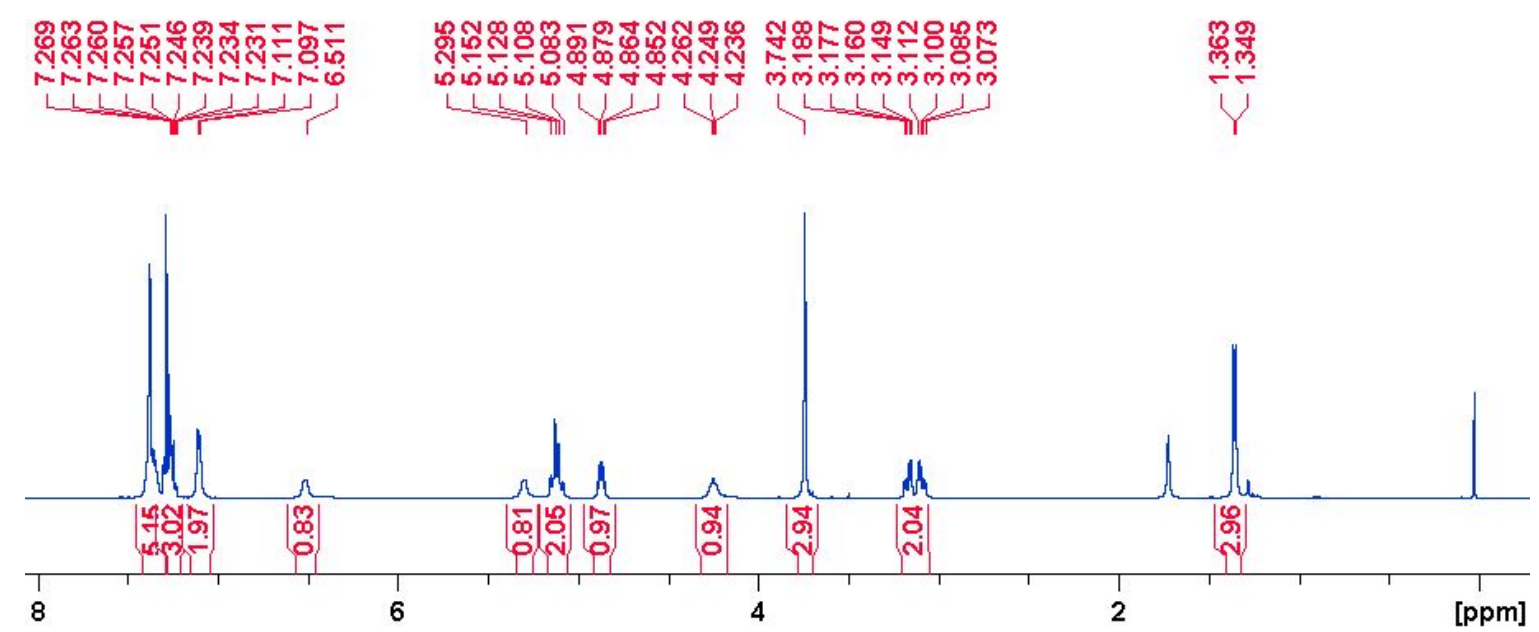

Figure S39. ${ }^{1} \mathrm{H}$ NMR spectrum of N-Cbz-Ala-Phe-OMe (13) in $\mathrm{CDCl}_{3}$.

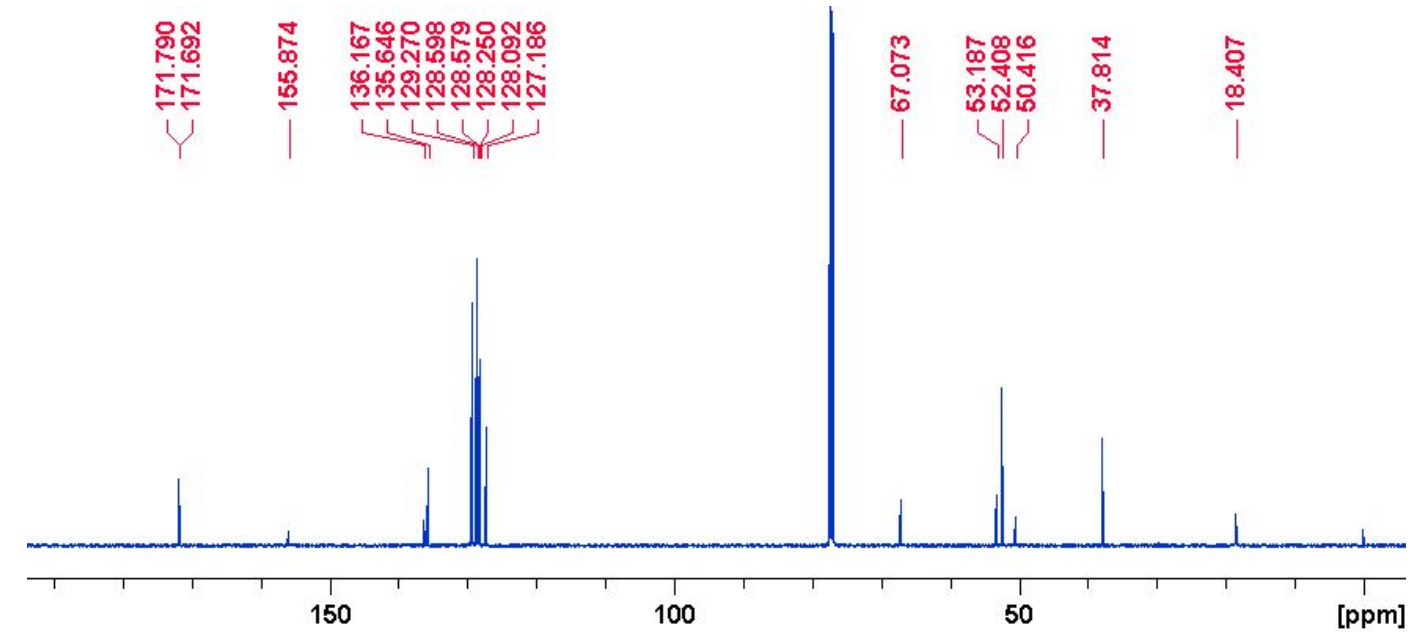

Figure S40. ${ }^{13} \mathrm{C}$ NMR spectrum of N-Cbz-Ala-Phe-OMe (13) in $\mathrm{CDCl}_{3}$.
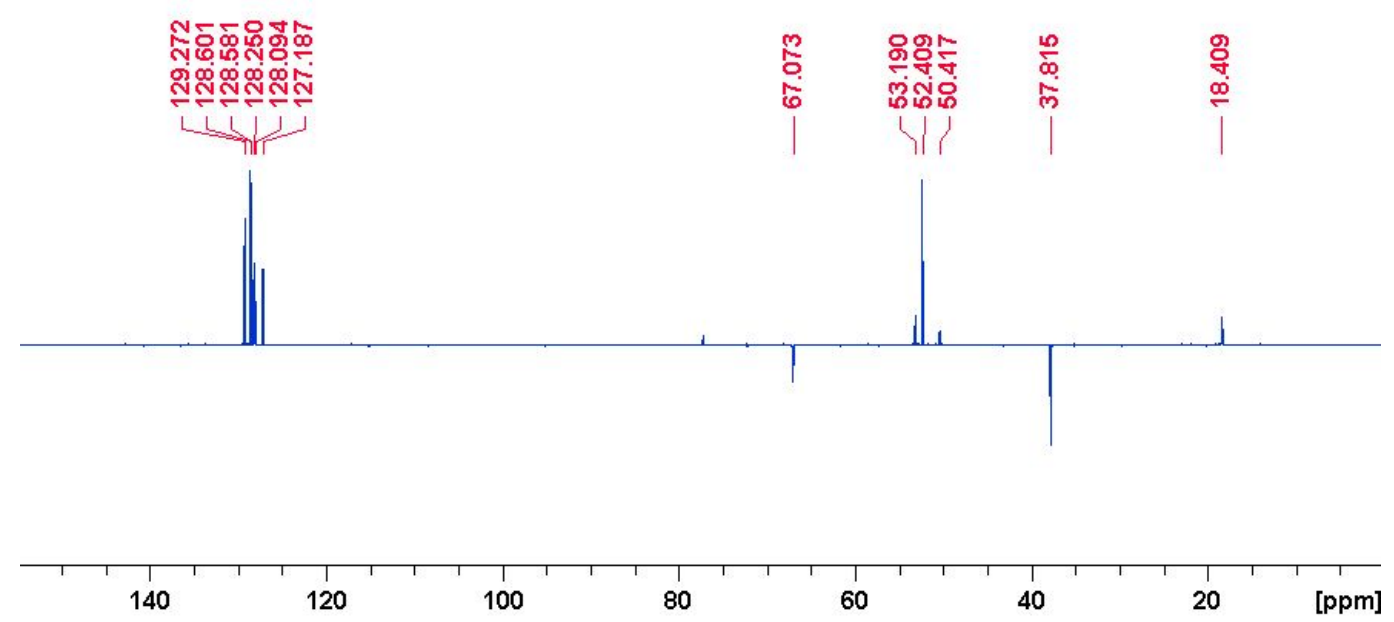

Figure S41. DEPT-135 NMR spectrum of N-Cbz-Ala-Phe-OMe (13) in $\mathrm{CDCl}_{3}$. 


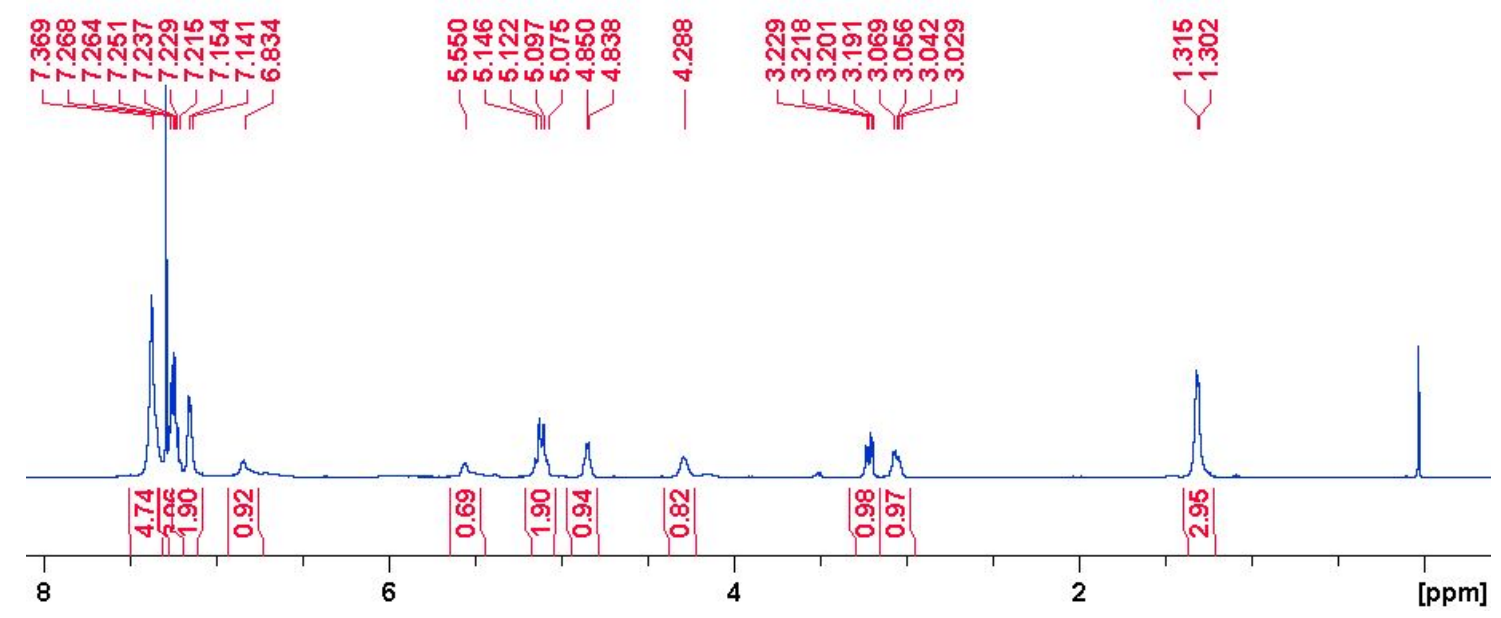

Figure S42. ${ }^{1} \mathrm{H}$ NMR spectrum of N-Cbz-Ala-Phe-OH (14) in $\mathrm{CDCl}_{3}$.

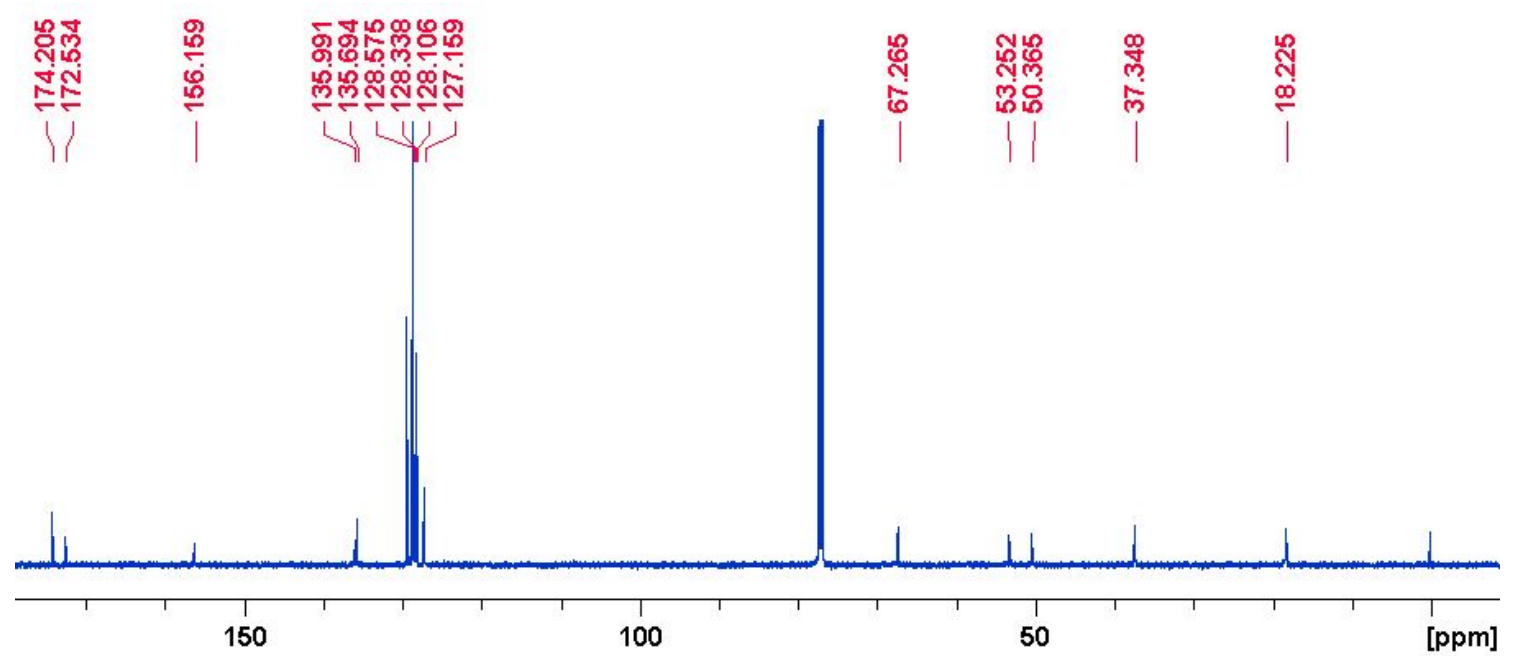

Figure S43. ${ }^{13} \mathrm{C}$ NMR spectrum of N-Cbz-Ala-Phe-OH (14) in $\mathrm{CDCl}_{3}$.
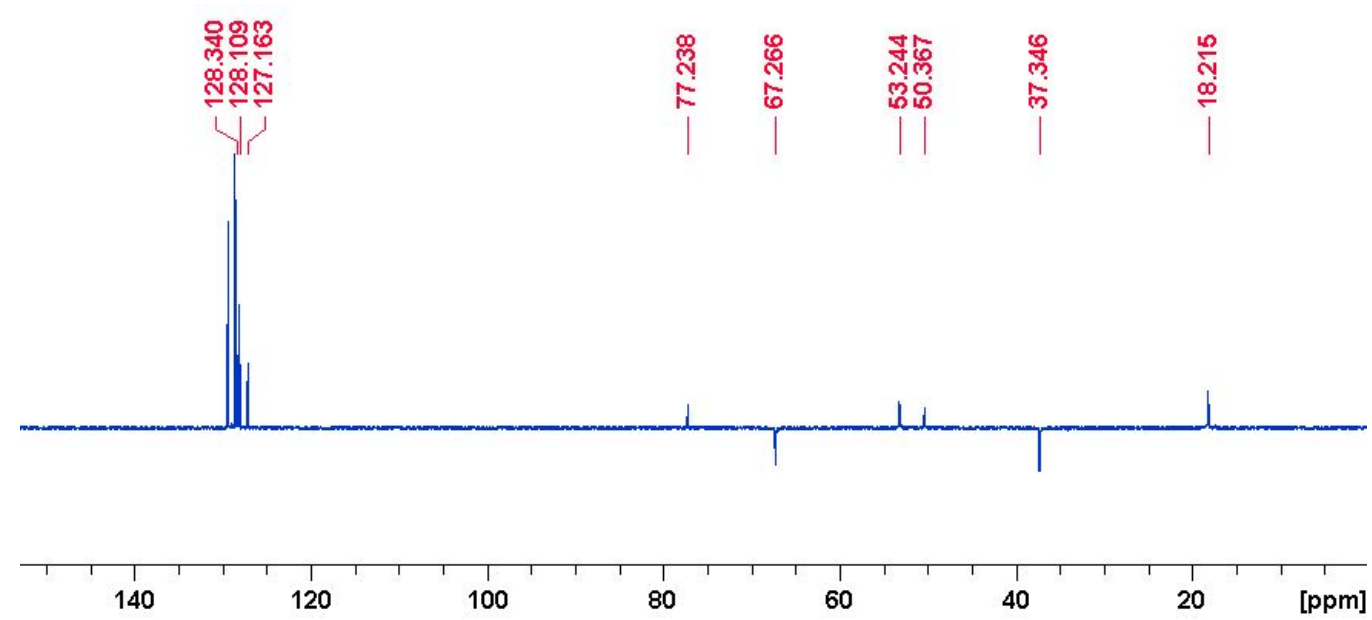

Figure S44. DEPT-135 NMR spectrum of N-Cbz-Ala-Phe-OH (14) in $\mathrm{CDCl}_{3}$. 


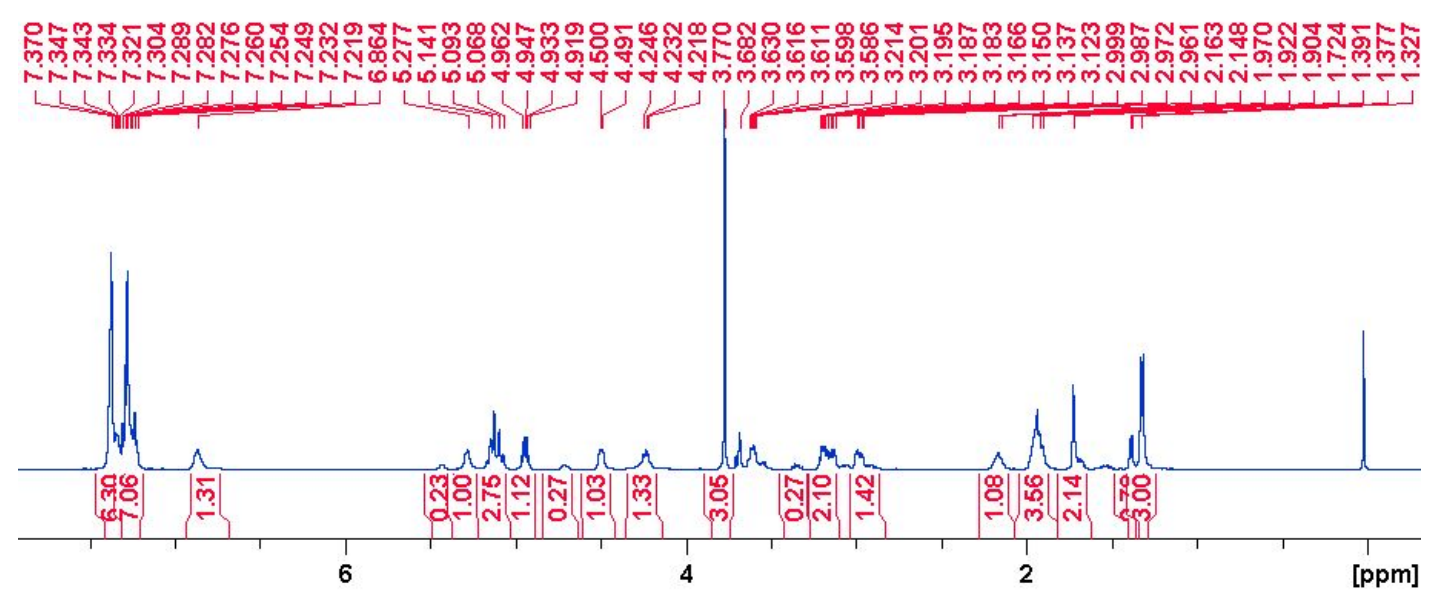

Figure S45. ${ }^{1} \mathrm{HNMR}$ spectrum of N-Cbz-Ala-Phe-Pro-OMe (15) in $\mathrm{CDCl}_{3}$.

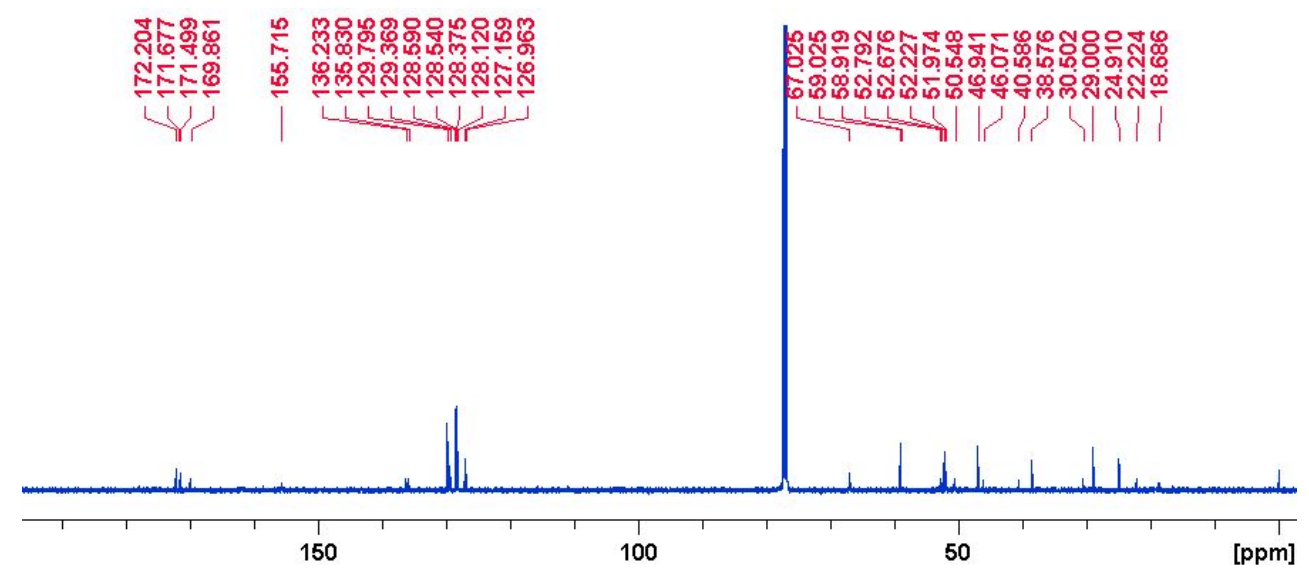

Figure S46. ${ }^{13} \mathrm{C}$ NMR spectrum of $\mathrm{N}-\mathrm{Cbz}-\mathrm{Ala}-\mathrm{Phe}-\mathrm{Pro}-\mathrm{OMe}(\mathbf{1 5})$ in $\mathrm{CDCl}_{3}$.

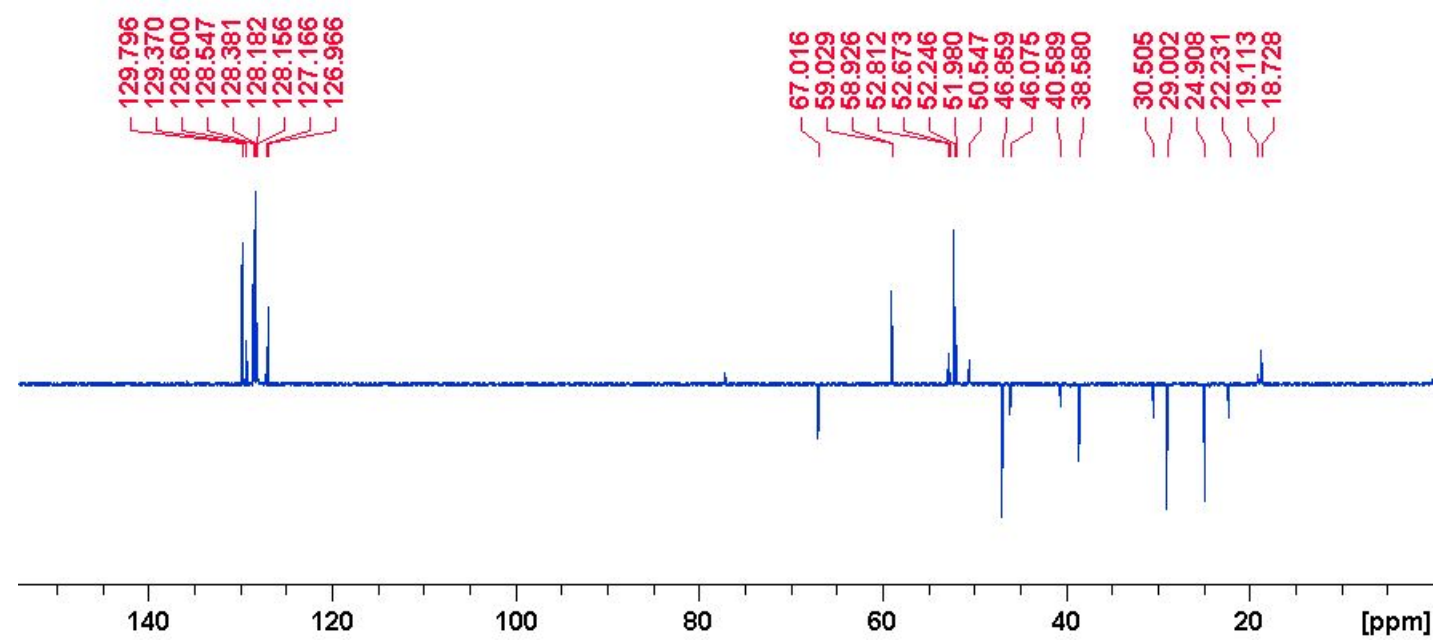

Figure S47. DEPT-135 NMR spectrum of N-Cbz-Ala-Phe-Pro-OMe (15) in $\mathrm{CDCl}_{3}$. 

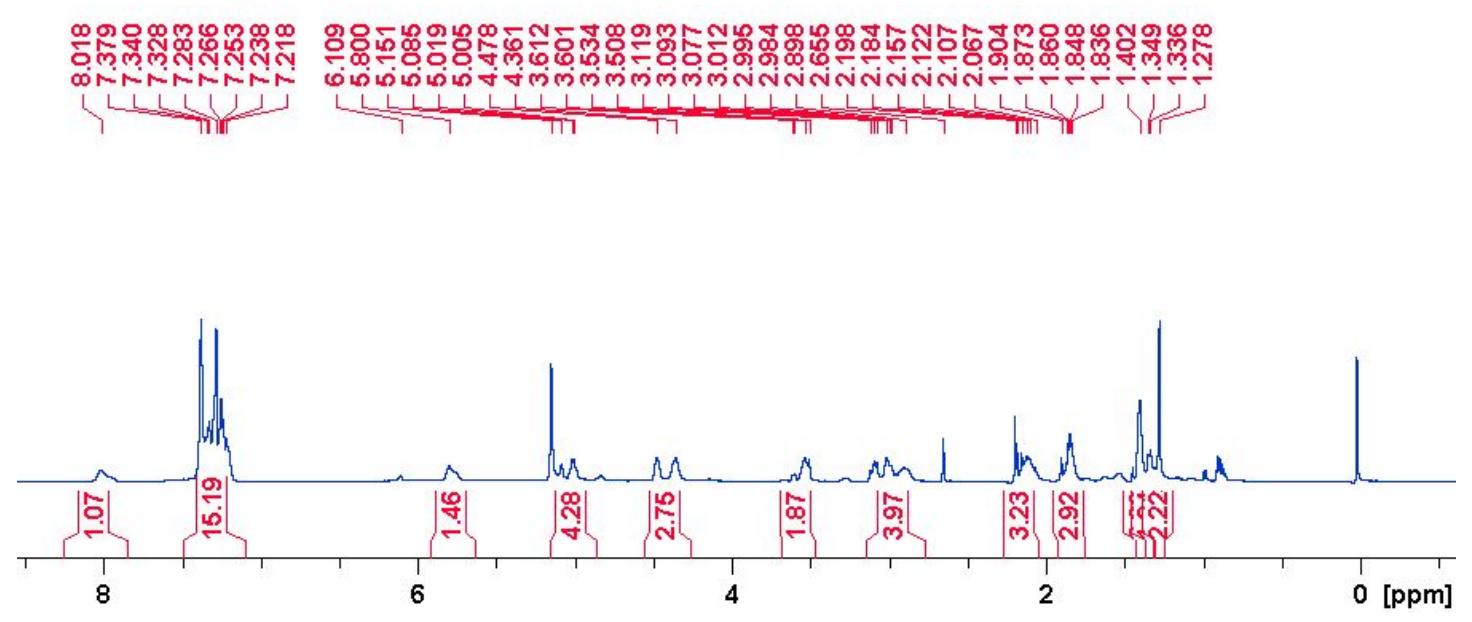

Figure S48. ${ }^{1} \mathrm{H}$ NMR spectrum of N-Cbz-Ala-Phe-Pro-OH (16) in $\mathrm{CDCl}_{3}$.

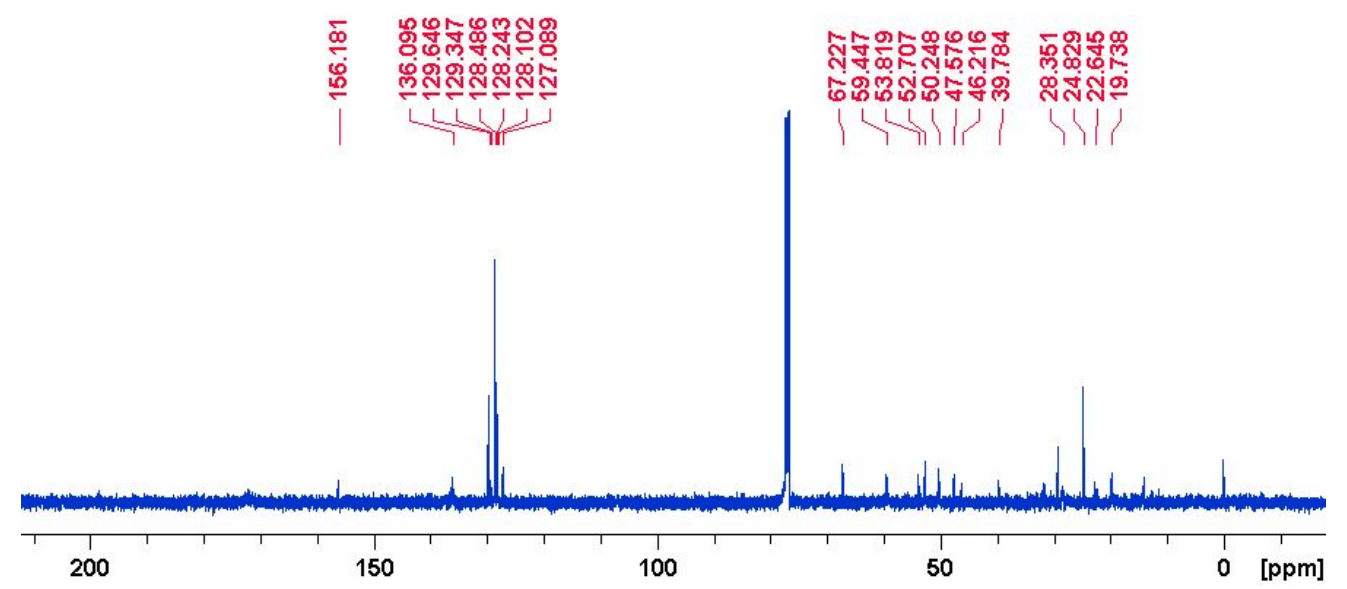

Figure S49. ${ }^{13} \mathrm{C}$ NMR spectrum of N-Cbz-Ala-Phe-Pro-OH (16) in $\mathrm{CDCl}_{3}$.

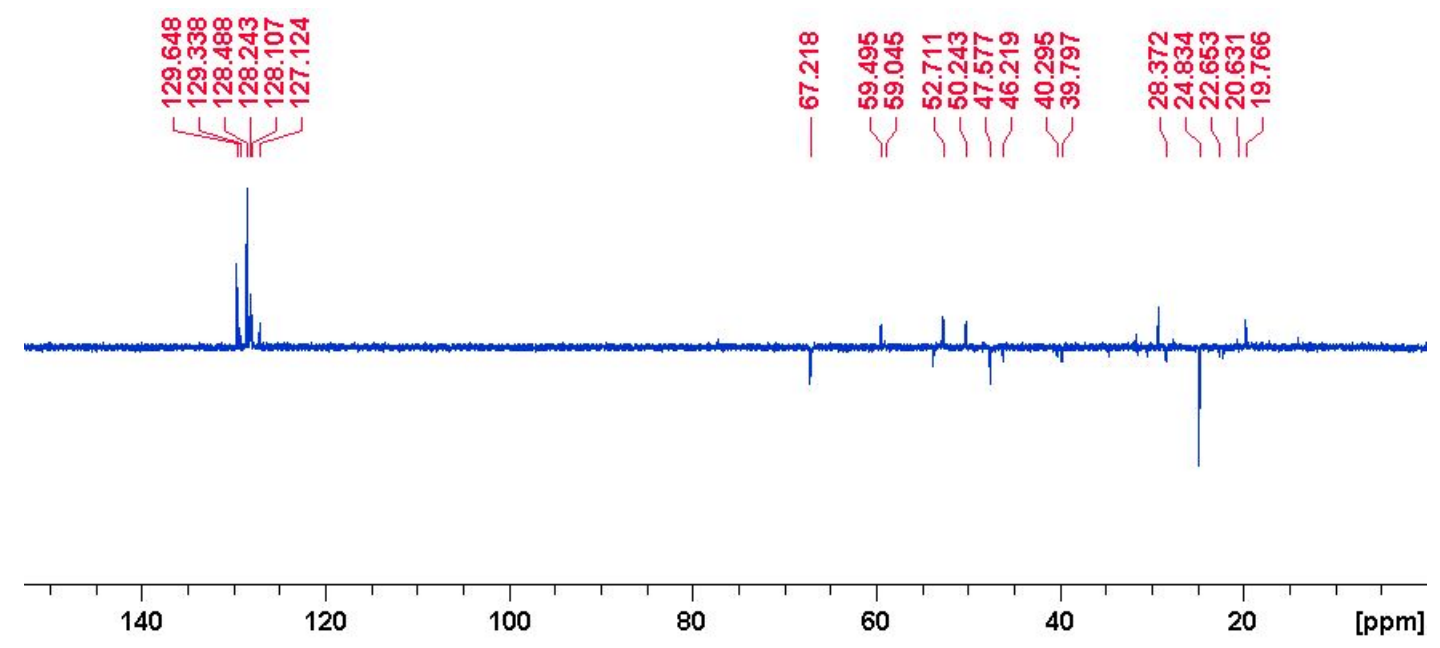

Figure S50. DEPT-135 NMR spectrum of N-Cbz-Ala-Phe-Pro-OH (16) in $\mathrm{CDCl}_{3}$. 


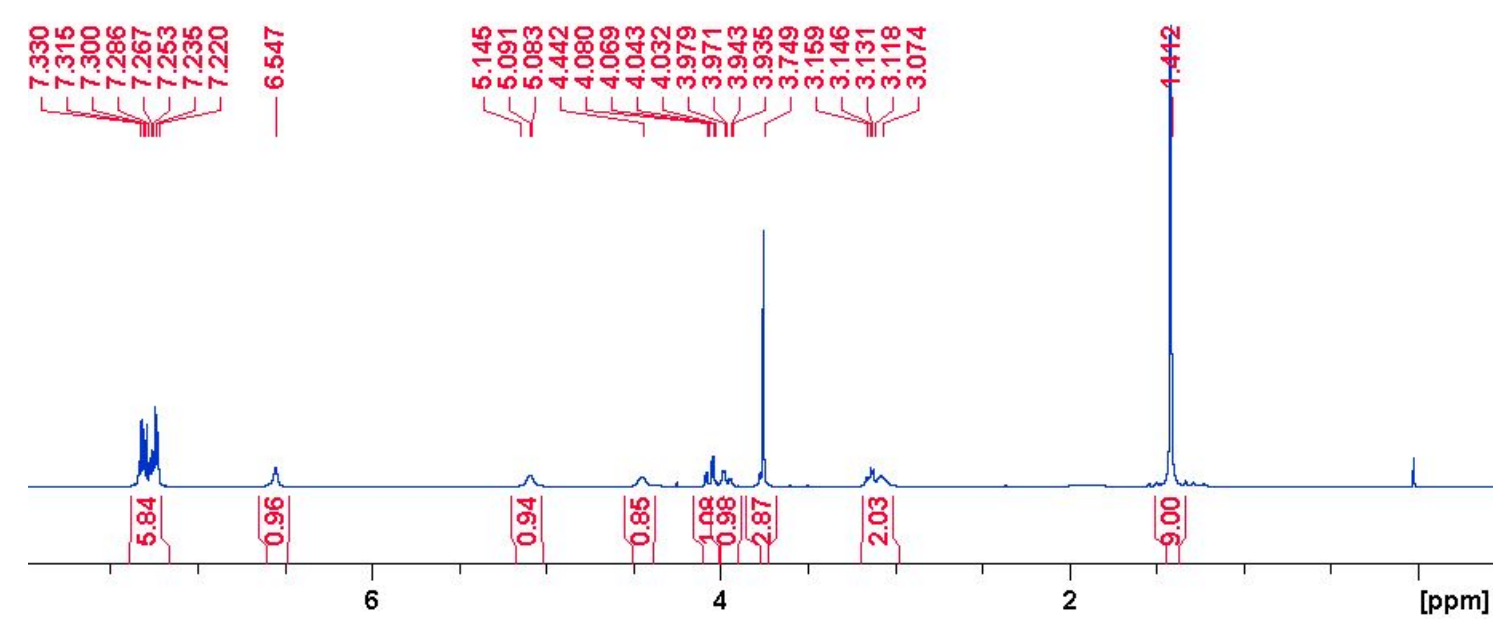

Figure S51. ${ }^{1} \mathrm{H}$ NMR spectrum of N-Boc-Phe-Gly-OMe (18) in $\mathrm{CDCl}_{3}$.

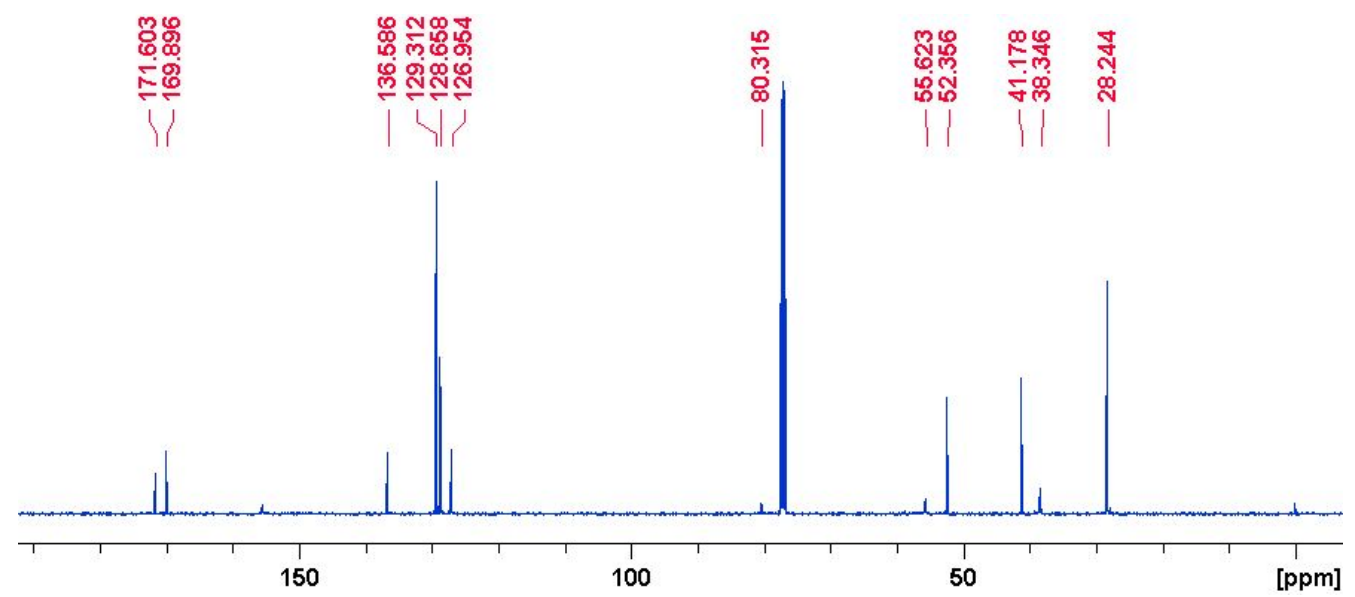

Figure S52. ${ }^{13} \mathrm{C}$ NMR spectrum of N-Boc-Phe-Gly-OMe (18) in $\mathrm{CDCl}_{3}$.

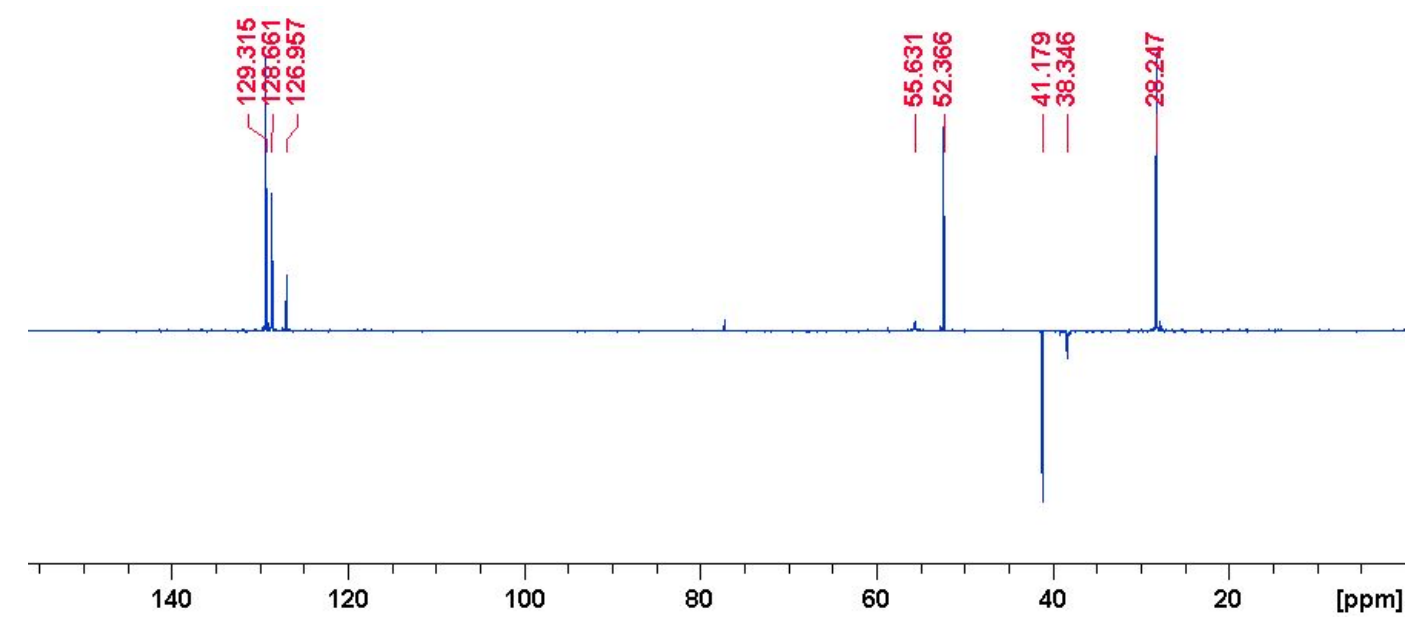

Figure S53. DEPT-135 NMR spectrum of N-Boc-Phe-Gly-OMe (18) in $\mathrm{CDCl}_{3}$. 


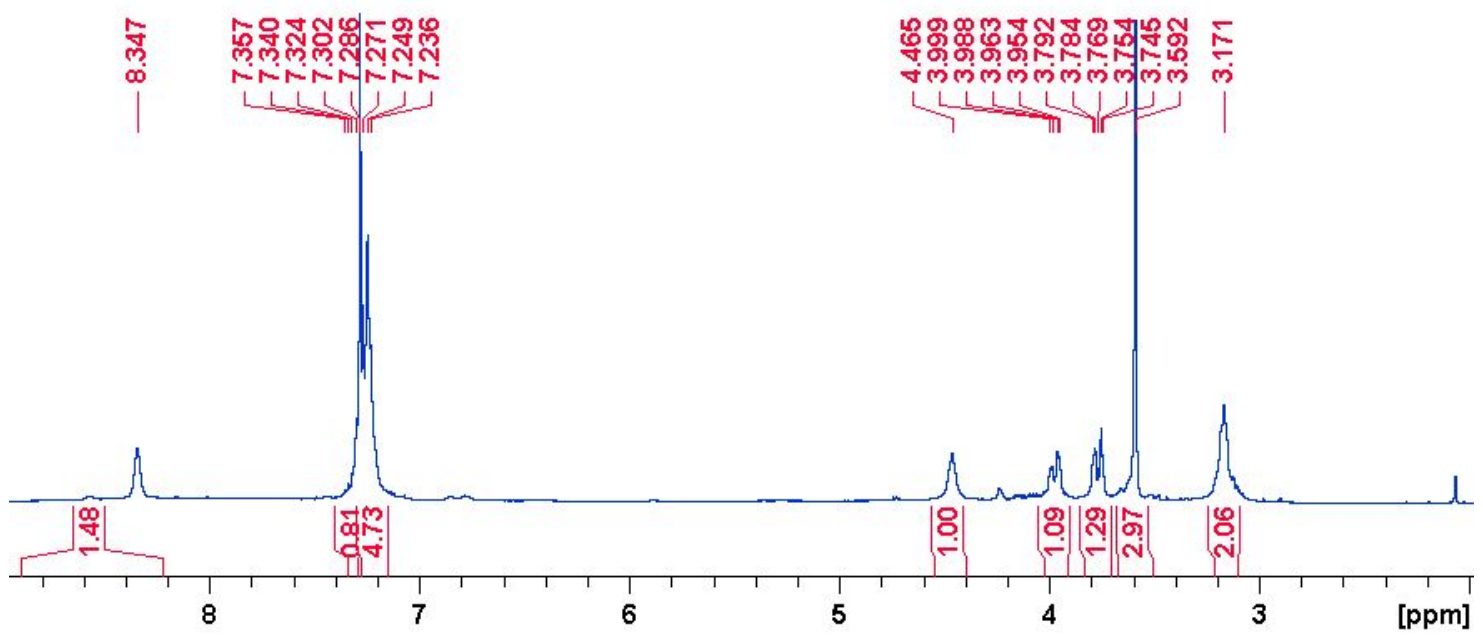

Figure S54. ${ }^{1} \mathrm{H}$ NMR spectrum of Phe-Gly-OMe (19) in $\mathrm{CDCl}_{3}$.

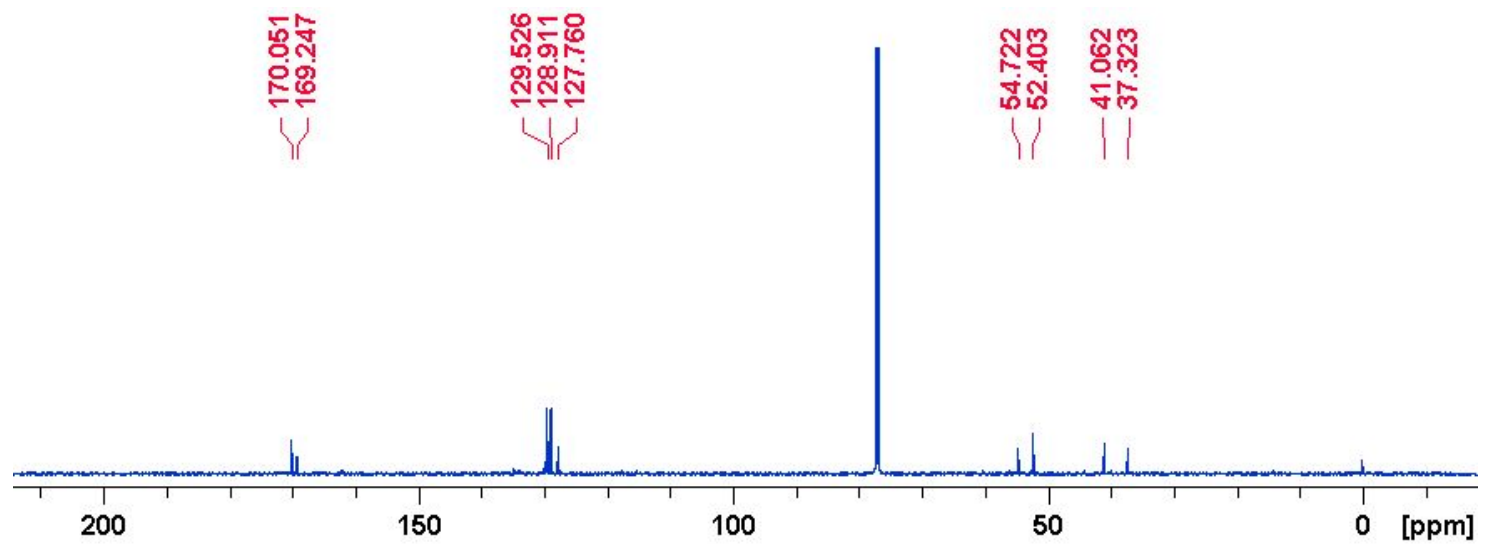

Figure S55. ${ }^{13} \mathrm{C}$ NMR spectrum of Phe-Gly-OMe (19) in $\mathrm{CDCl}_{3}$.

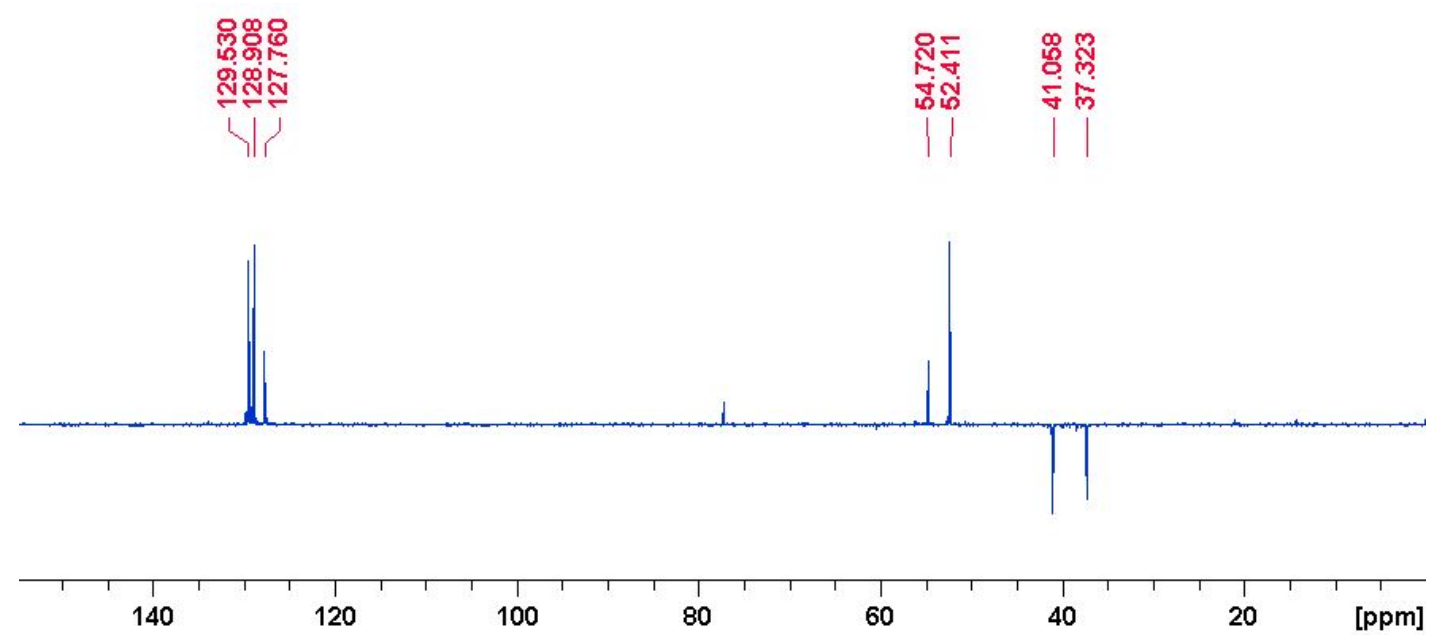

Figure S56. DEPT-135 NMR spectrum of Phe-Gly-OMe (19) in $\mathrm{CDCl}_{3}$. 


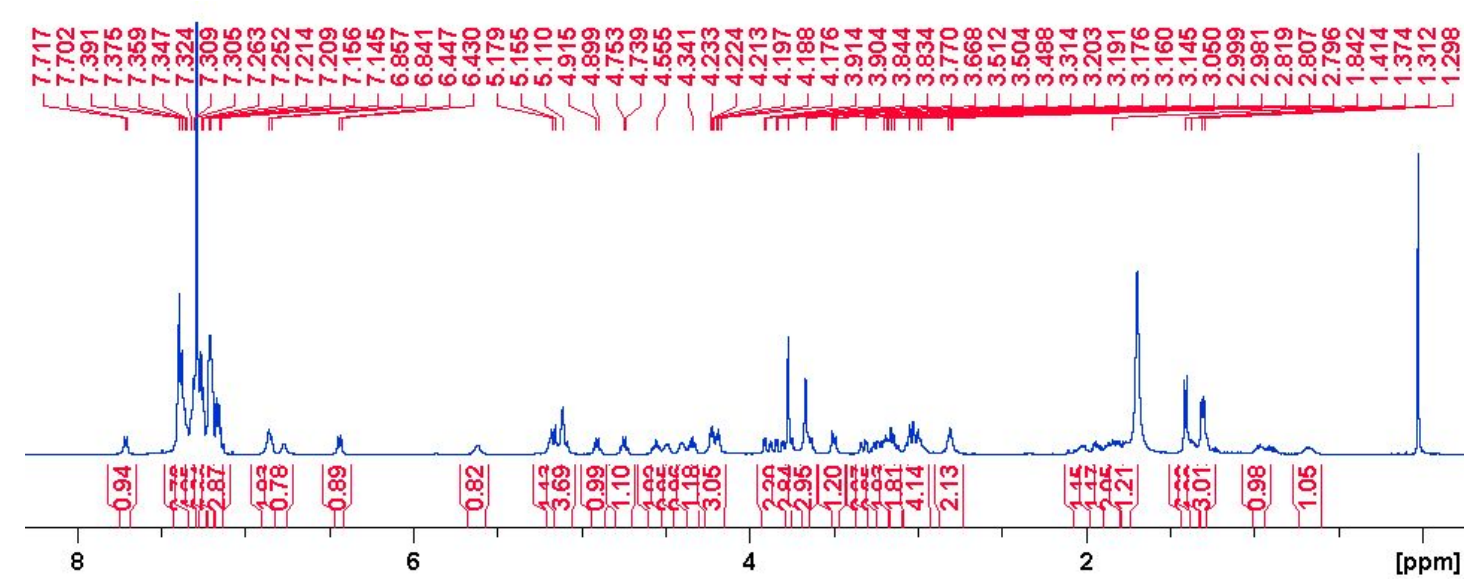

Figure S57. ${ }^{1} \mathrm{H}$ NMR spectrum of N-Cbz-Ala-Phe-Pro-Phe-Gly-OMe (20) in $\mathrm{CDCl}_{3}$.

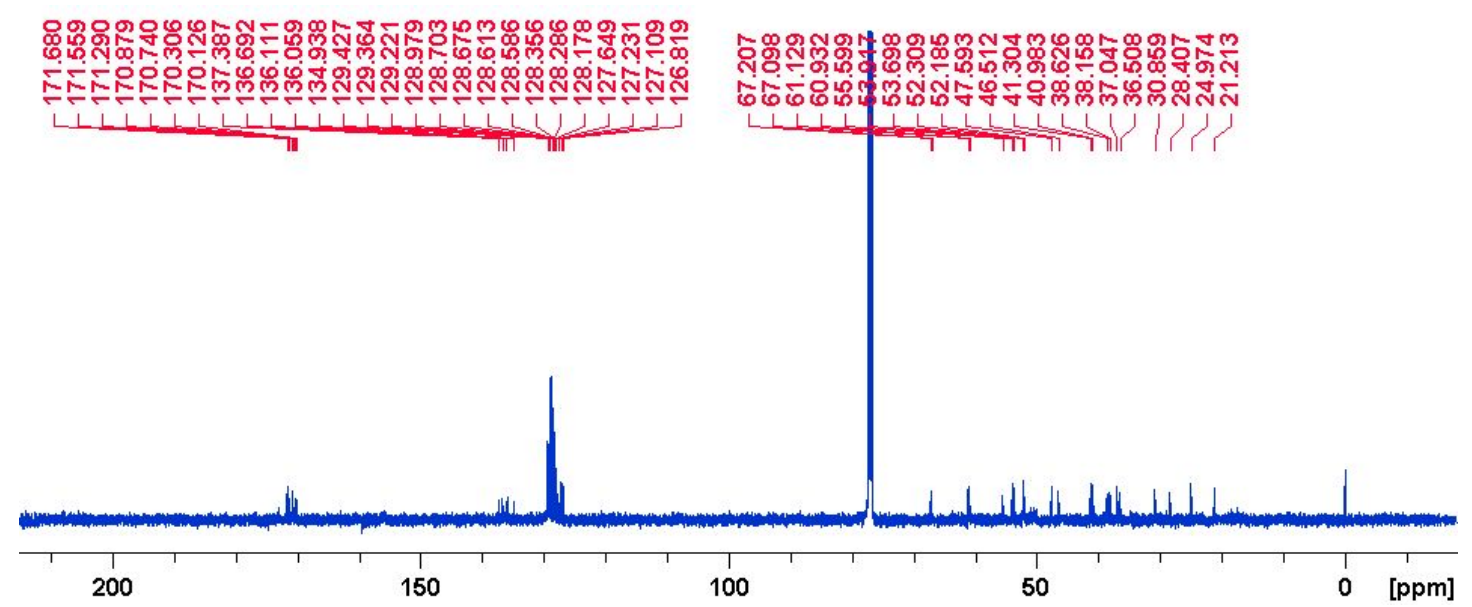

Figure S58. ${ }^{13} \mathrm{C}$ NMR spectrum of N-Cbz-Ala-Phe-Pro-Phe-Gly-OMe (20) in $\mathrm{CDCl}_{3}$.

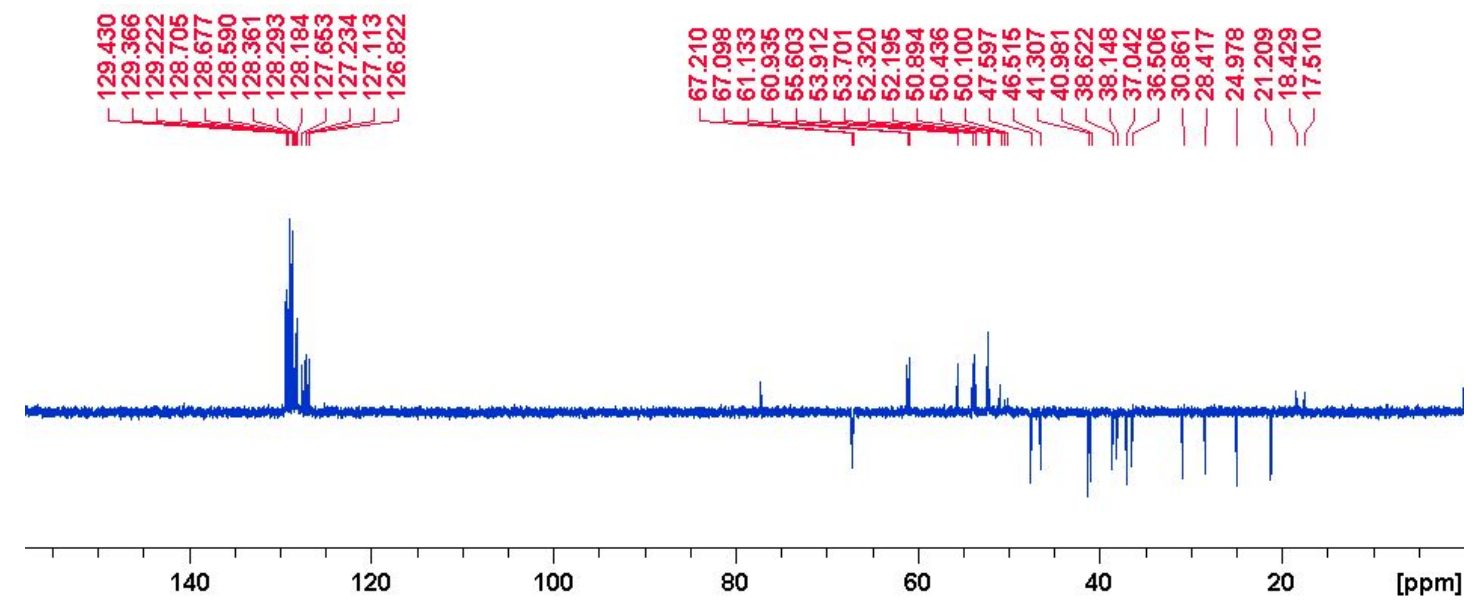

Figure S59. DEPT-135 NMR spectrum of N-Cbz-Ala-Phe-Pro-Phe-Gly-OMe (20) in $\mathrm{CDCl}_{3}$. 


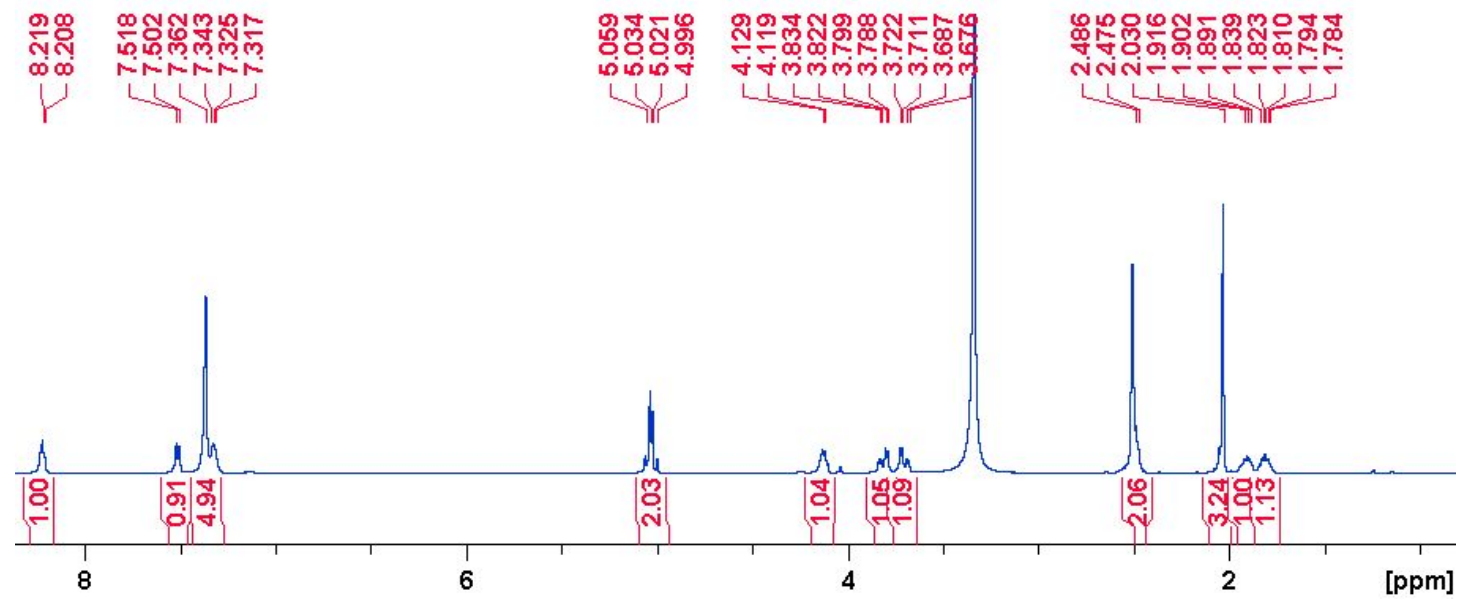

Figure S60. ${ }^{1} \mathrm{H}$ NMR spectrum of N-Cbz-Met-Gly-OH (21) in DMSO- $d_{6}$.
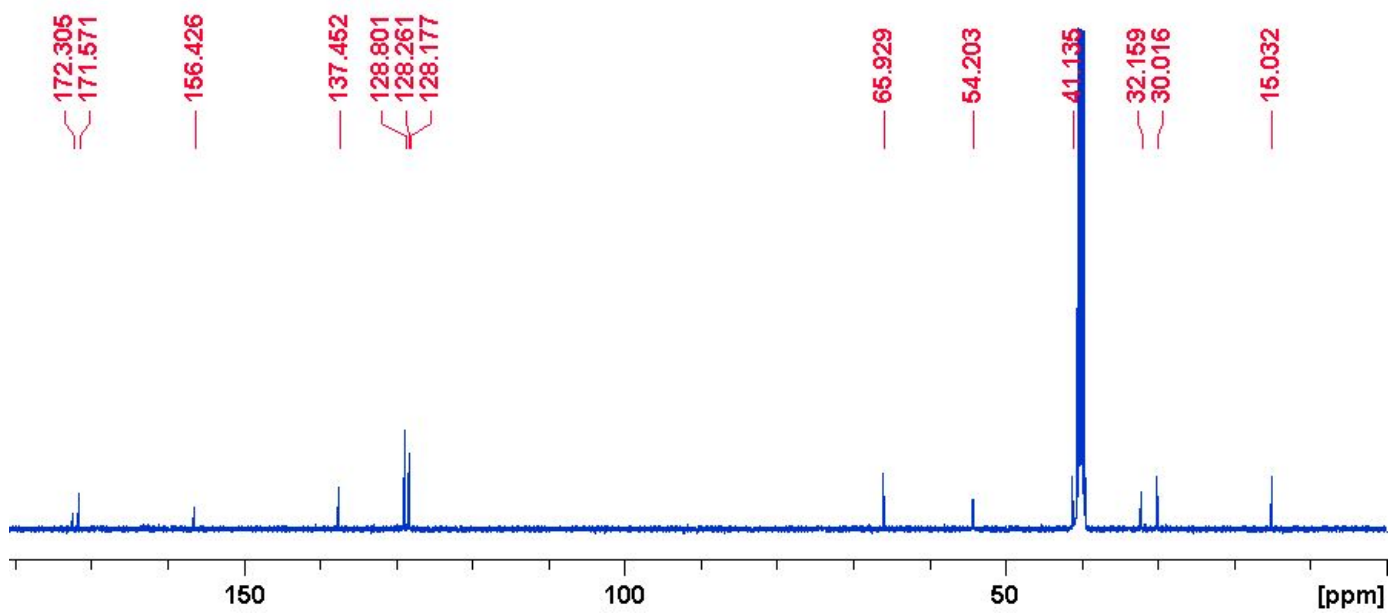

Figure S61. ${ }^{13} \mathrm{C}$ NMR spectrum of N-Cbz-Met-Gly-OH (21) in DMSO- $d_{6}$.

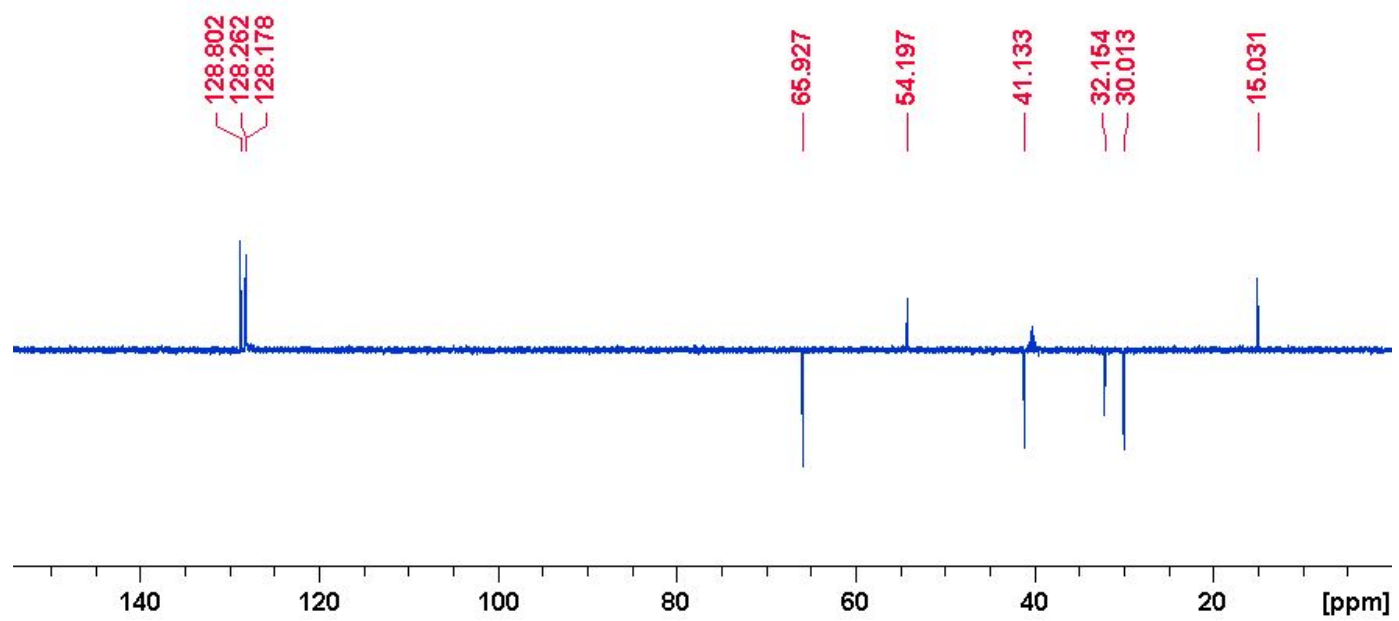

Figure S62. ${ }^{13} \mathrm{C}$ NMR spectrum of N-Cbz-Met-Gly-OH (21) in DMSO- $d_{6}$. 


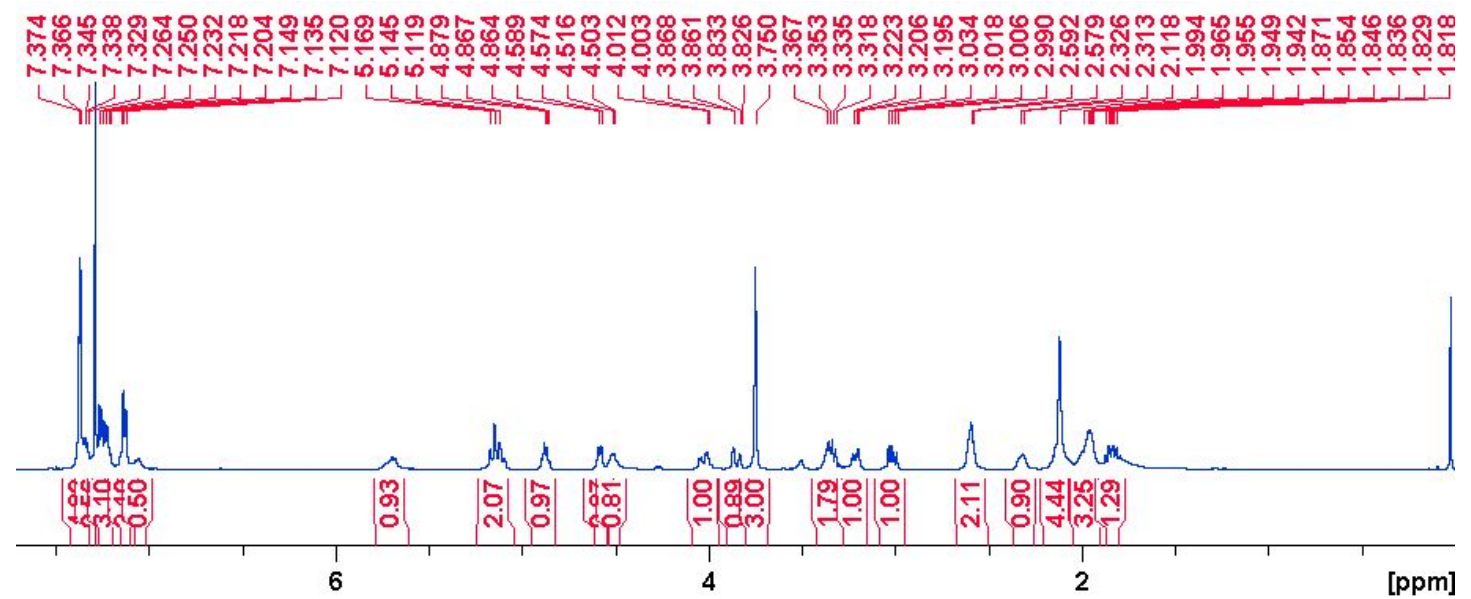

Figure S63. ${ }^{1} \mathrm{H}$ NMR spectrum of N-Cbz-Met-Gly-Pro-Phe-OMe (23) in $\mathrm{CDCl}_{3}$.

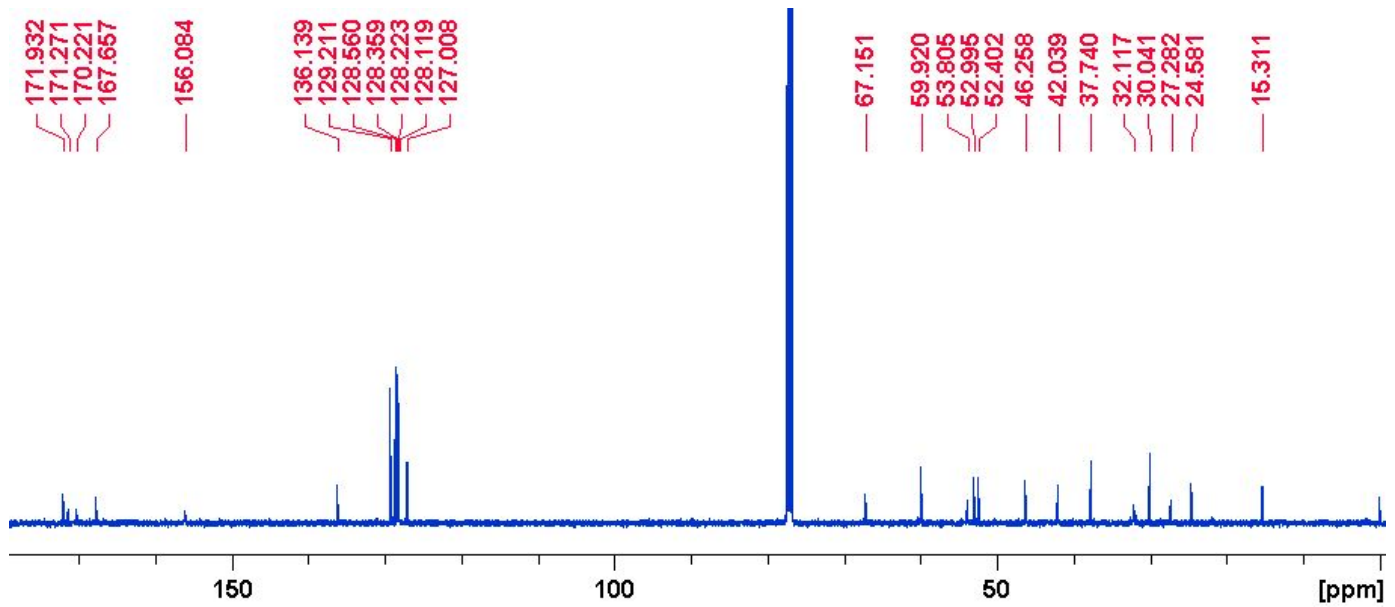

Figure S64. ${ }^{13} \mathrm{C}$ NMR spectrum of N-Cbz-Met-Gly-Pro-Phe-OMe (23) in $\mathrm{CDCl}_{3}$.
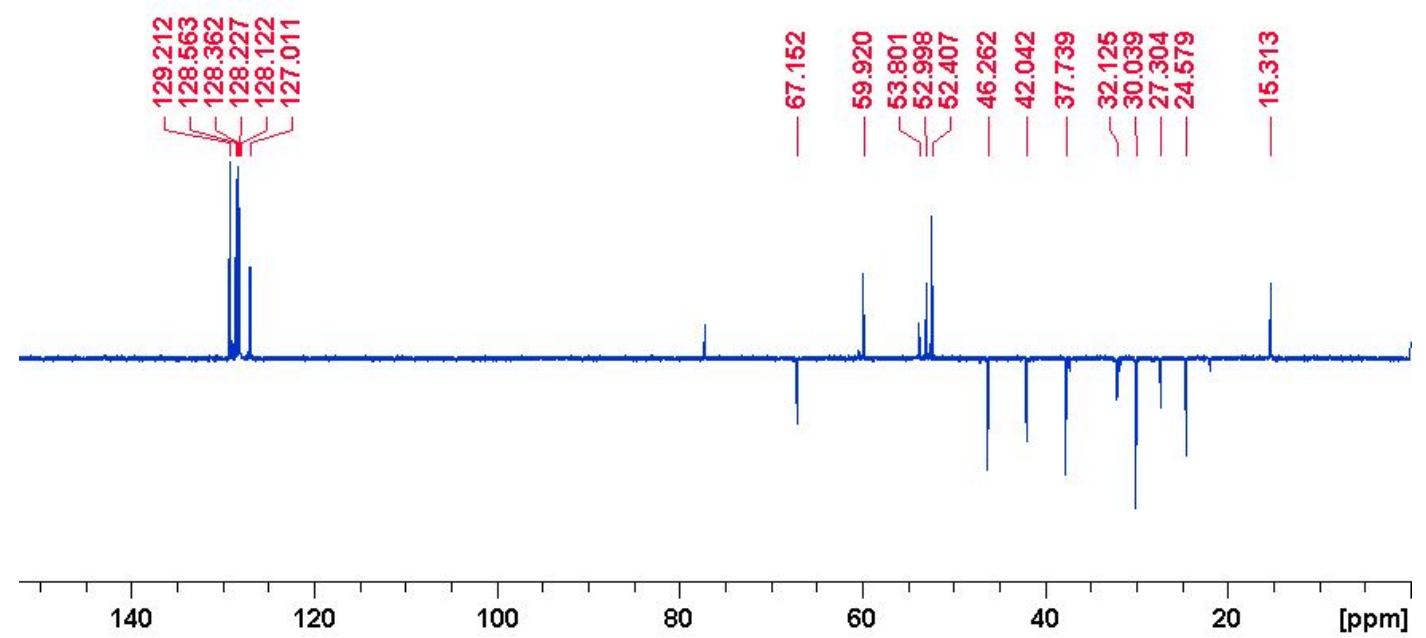

Figure S65. DEPT-135 NMR spectrum of N-Cbz-Met-Gly-Pro-Phe-OMe (23) in $\mathrm{CDCl}_{3}$. 

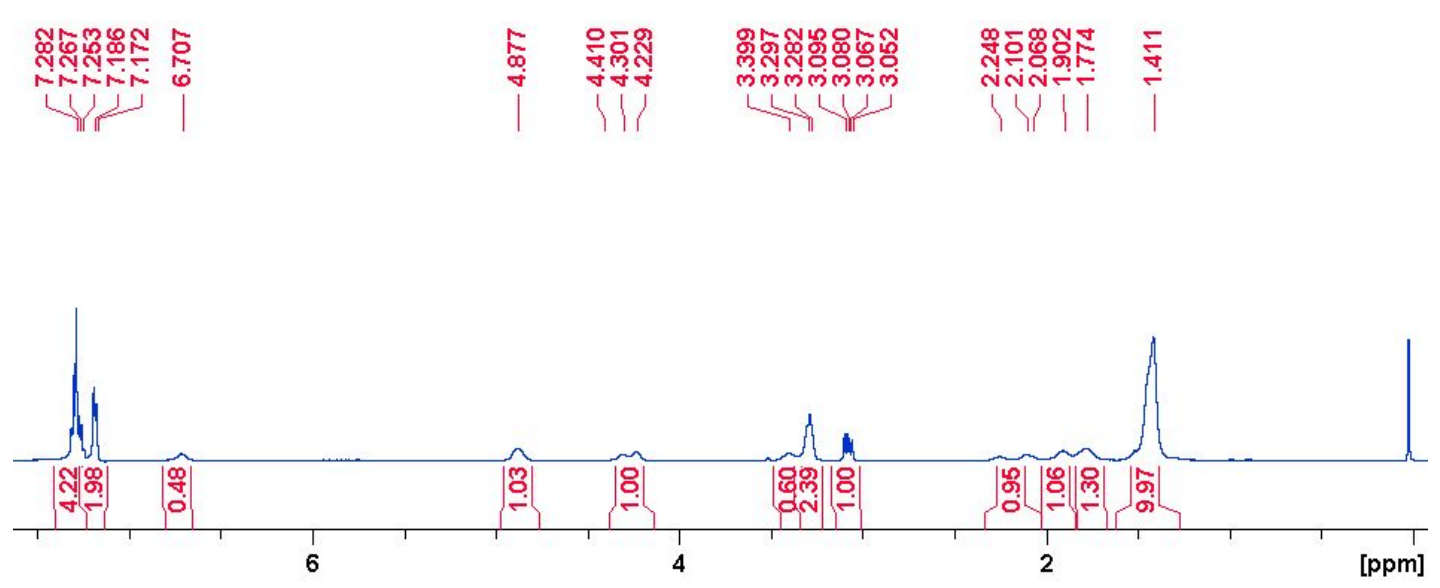

Figure S66. ${ }^{1} \mathrm{H}$ NMR spectrum of N-Boc-Pro-Phe-OH (24) in $\mathrm{CDCl}_{3}$.

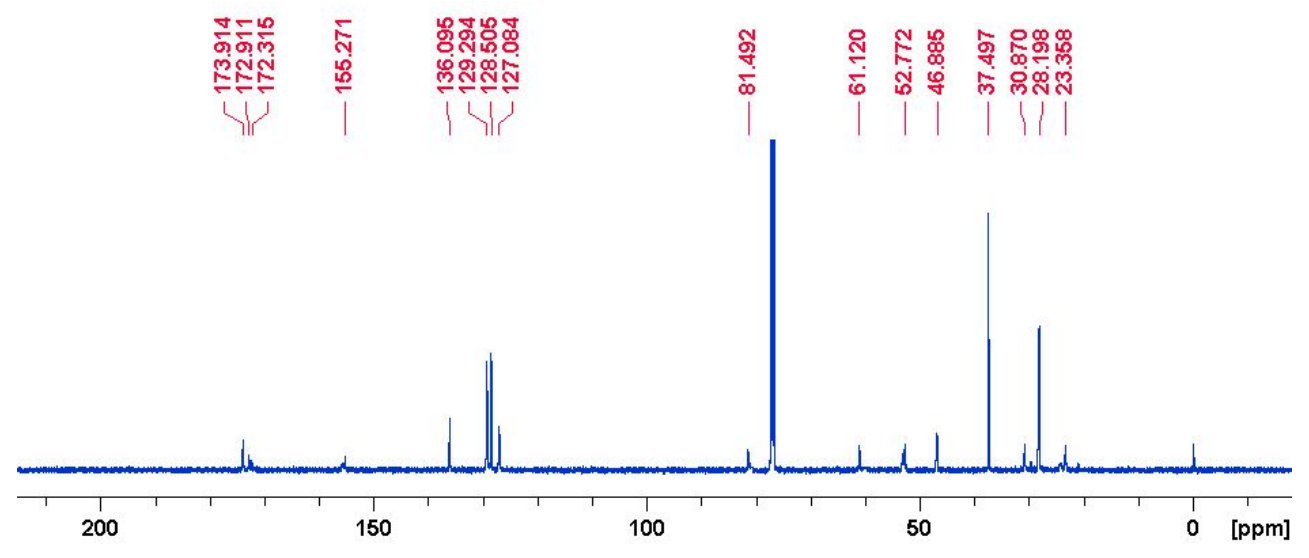

Figure S67. ${ }^{13} \mathrm{C}$ NMR spectrum of N-Boc-Pro-Phe-OH (24) in $\mathrm{CDCl}_{3}$.

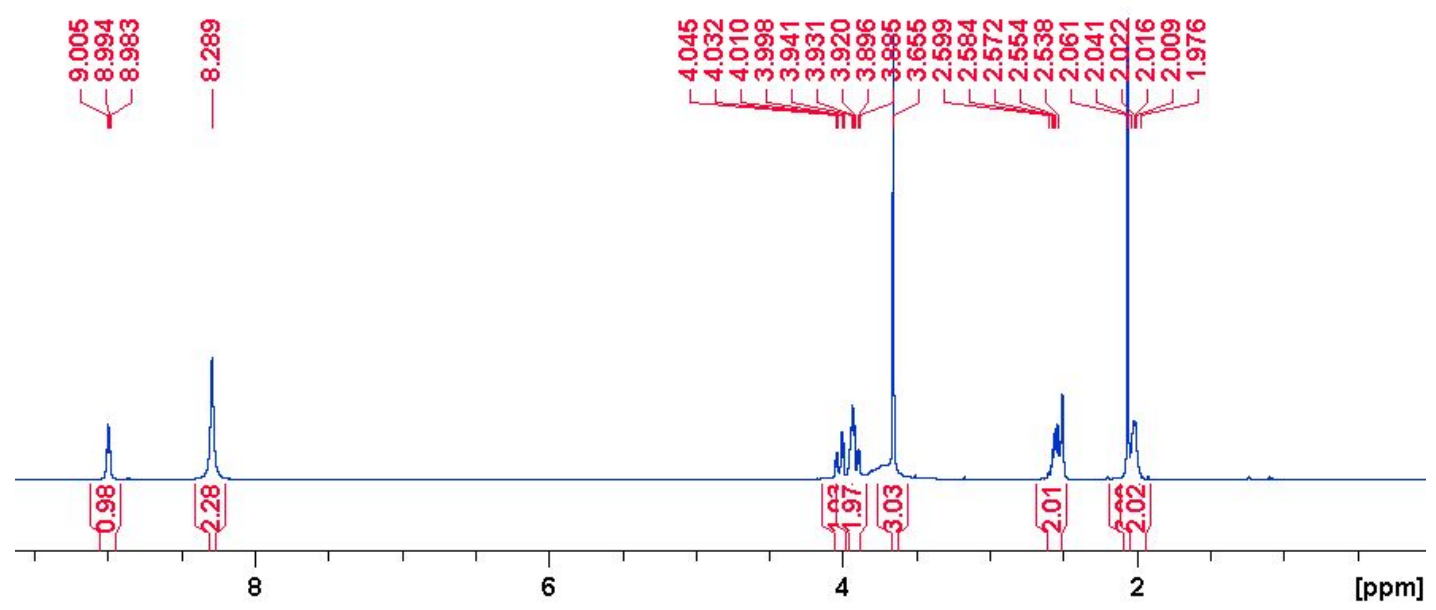

Figure S68. ${ }^{1} \mathrm{H}$ NMR spectrum of Met-Gly-OMe (25) in DMSO-d 6 . 


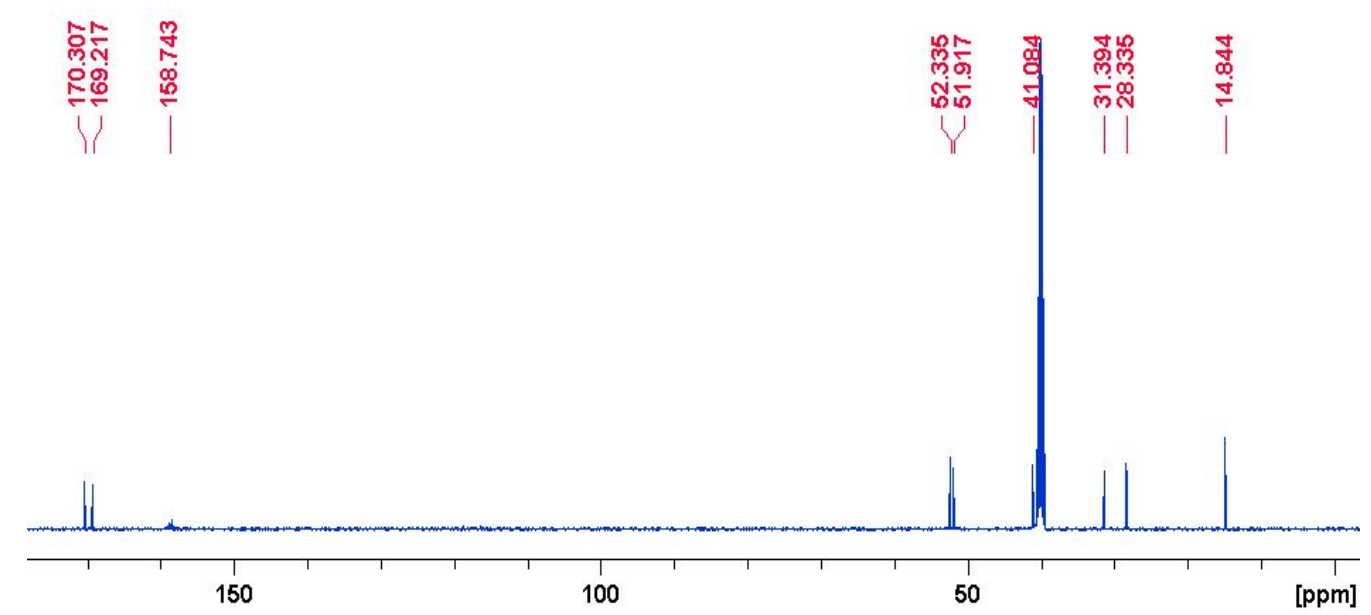

Figure S69. ${ }^{13} \mathrm{C}$ NMR spectrum of Met-Gly-OME (25) in DMSO- $d_{6}$.

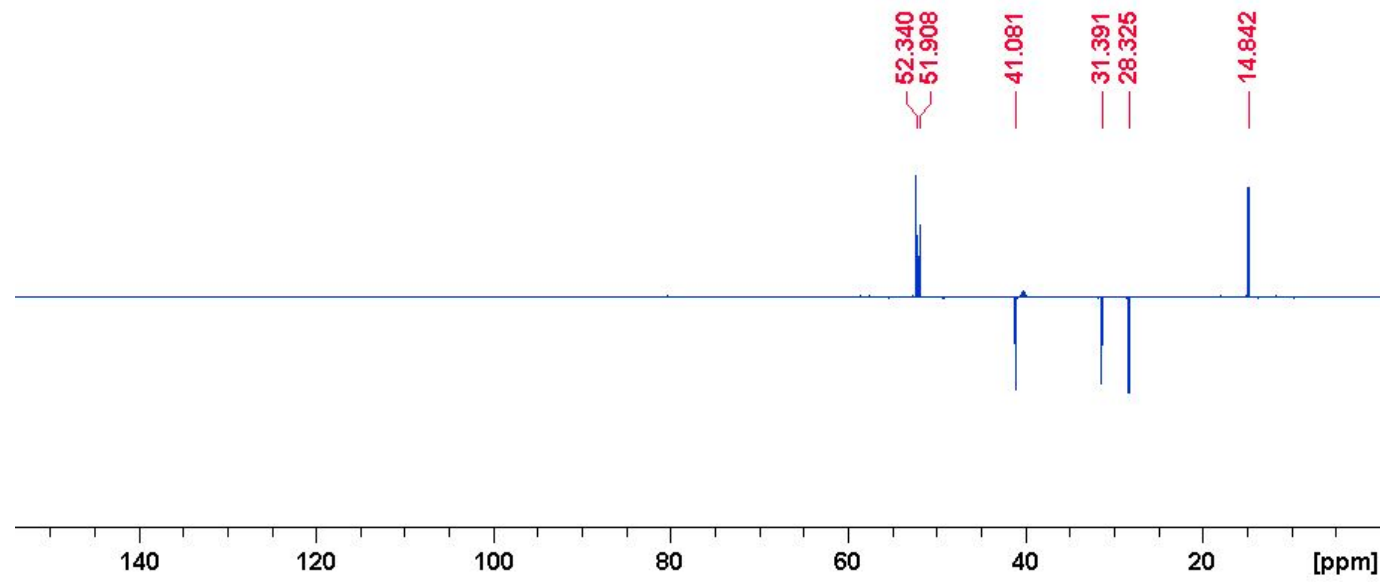

Figure S70. DEPT-135 NMR spectrum of Met-Gly-OME (25) in DMSO- $d_{6}$.
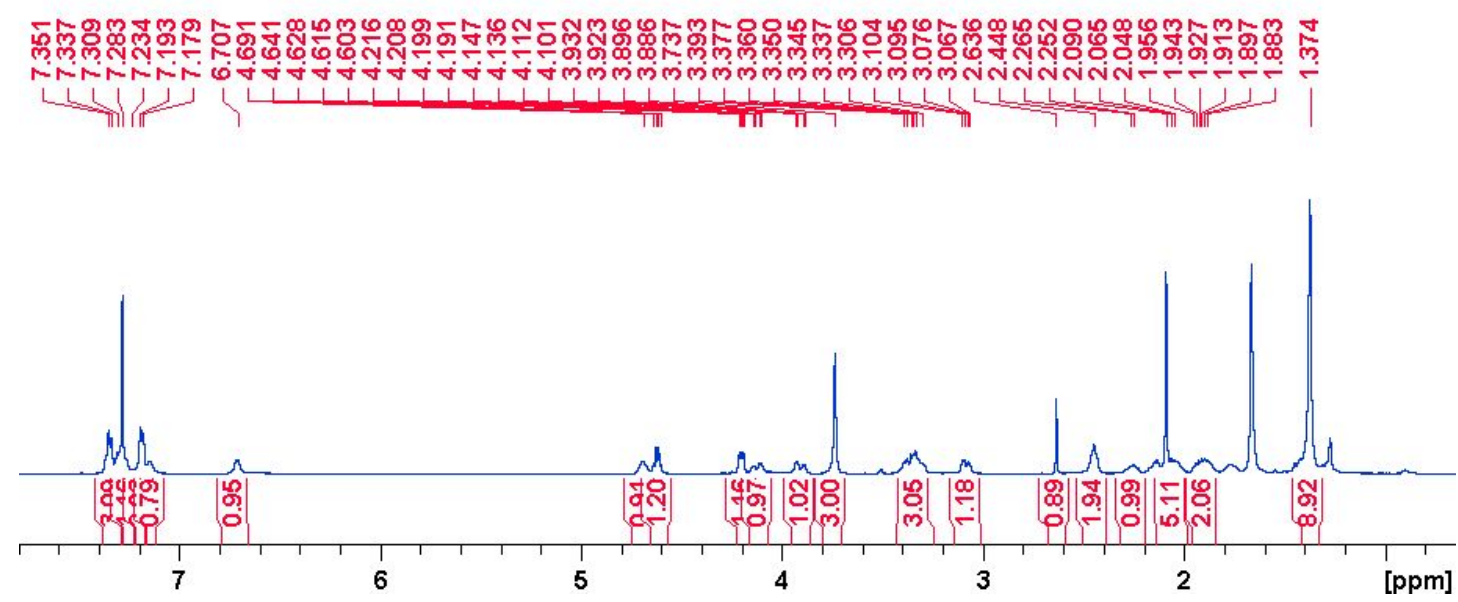

Figure S71. ${ }^{1} \mathrm{H}$ NMR spectrum of N-Boc-Pro-Phe-Met-Gly-OMe (26) in $\mathrm{CDCl}_{3}$. 


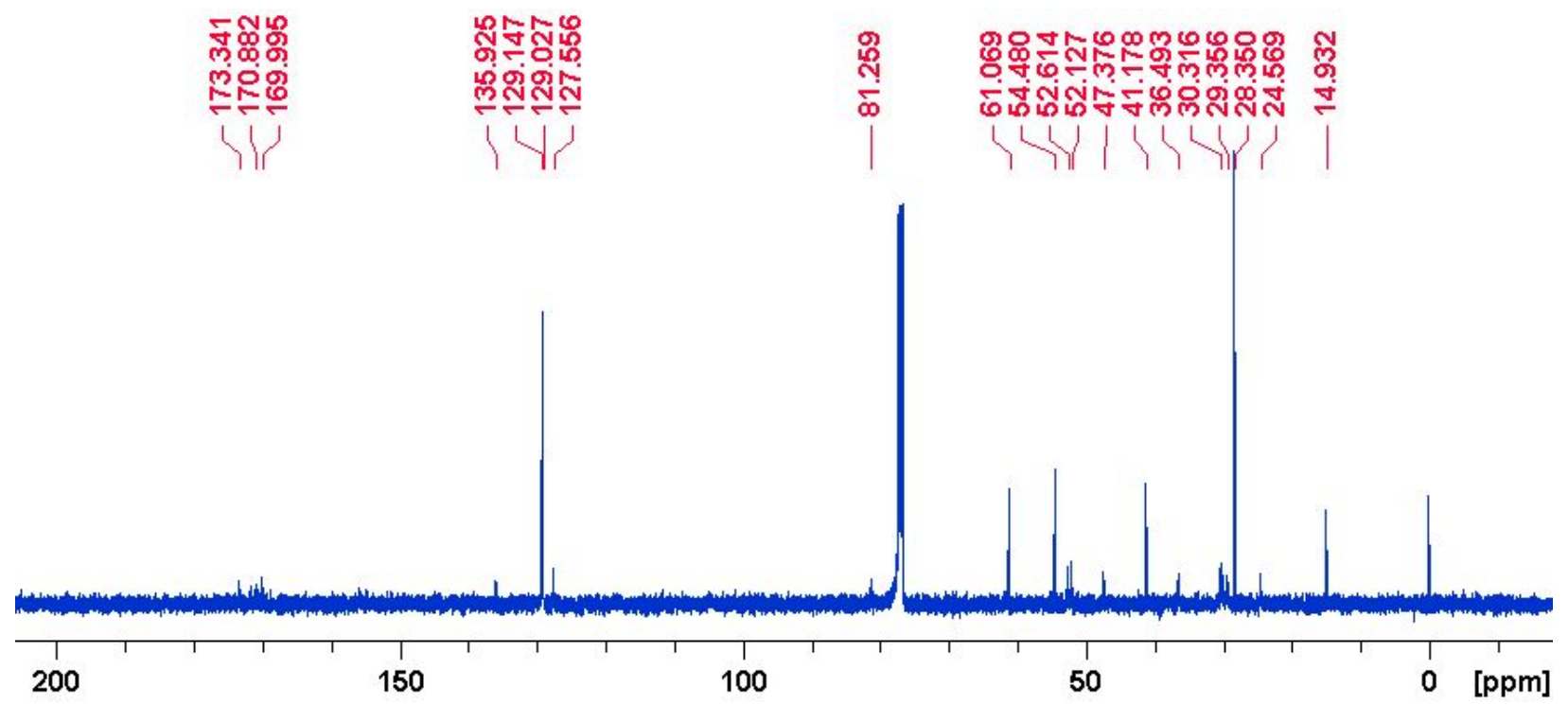

Figure S72. ${ }^{13} \mathrm{C}$ NMR spectrum of N-Boc-Pro-Phe-Met-Gly-OMe (26) in $\mathrm{CDCl}_{3}$.

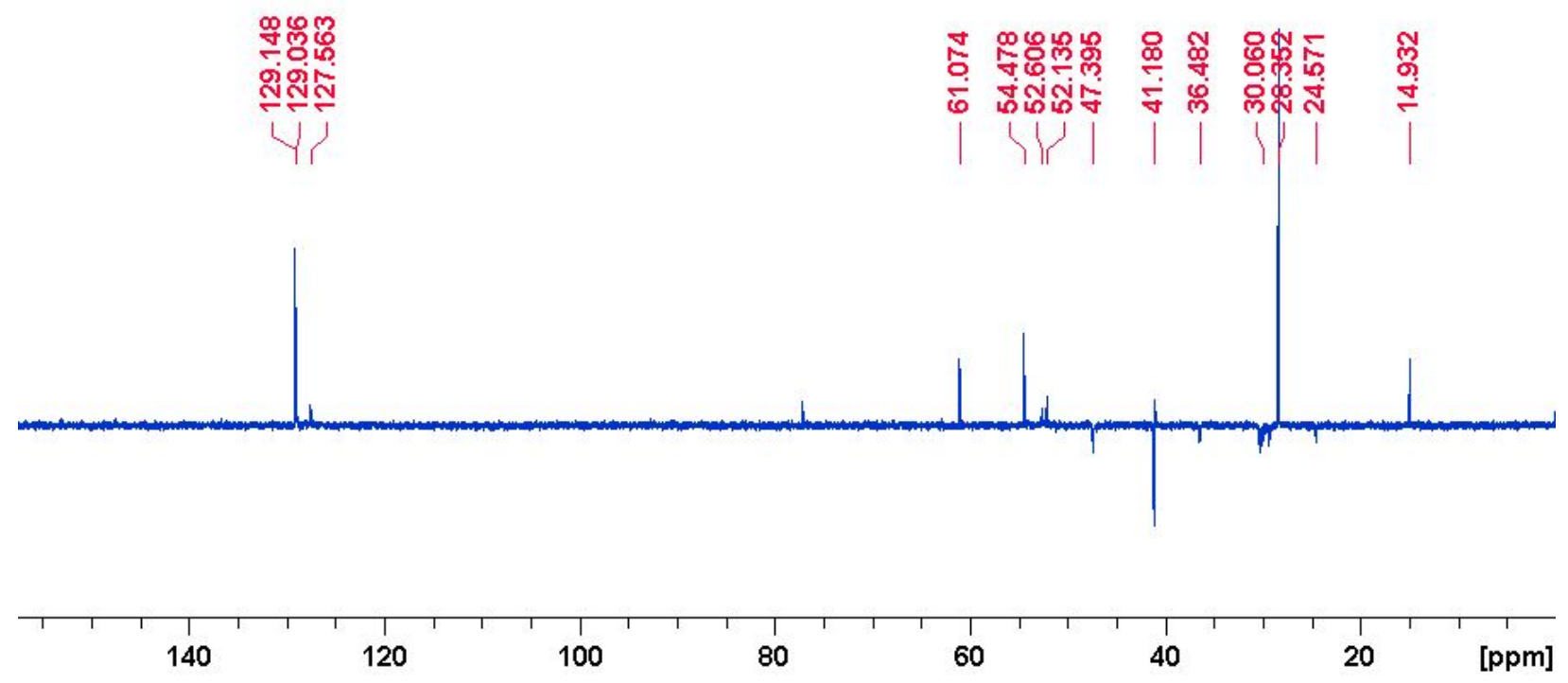

Figure S73. DEPT-135 NMR spectrum of N-Boc-Pro-Phe-Met-Gly-OMe (26) in $\mathrm{CDCl}_{3}$. 


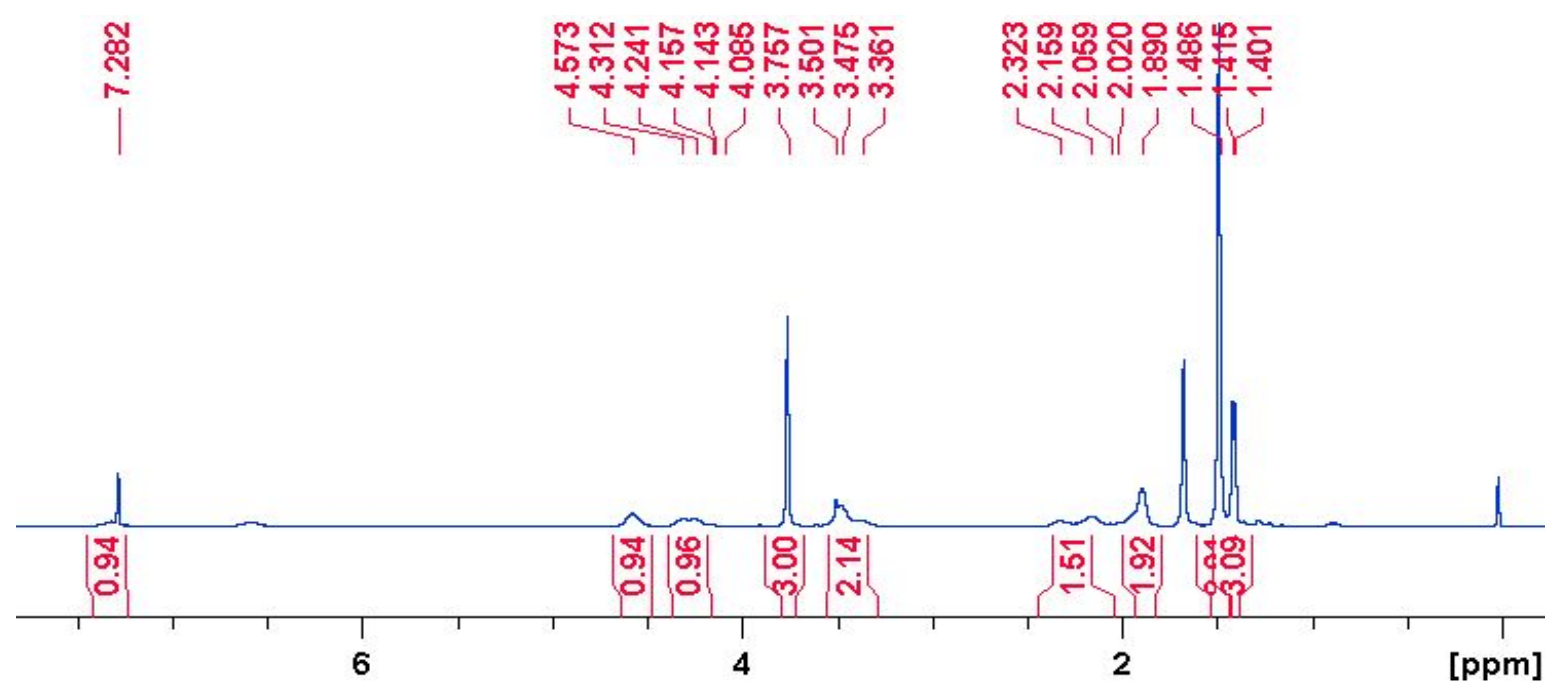

Figure S74. ${ }^{1} \mathrm{H}$ NMR spectrum of N-Boc-Pro-Ala-OMe (27) in $\mathrm{CDCl}_{3}$.

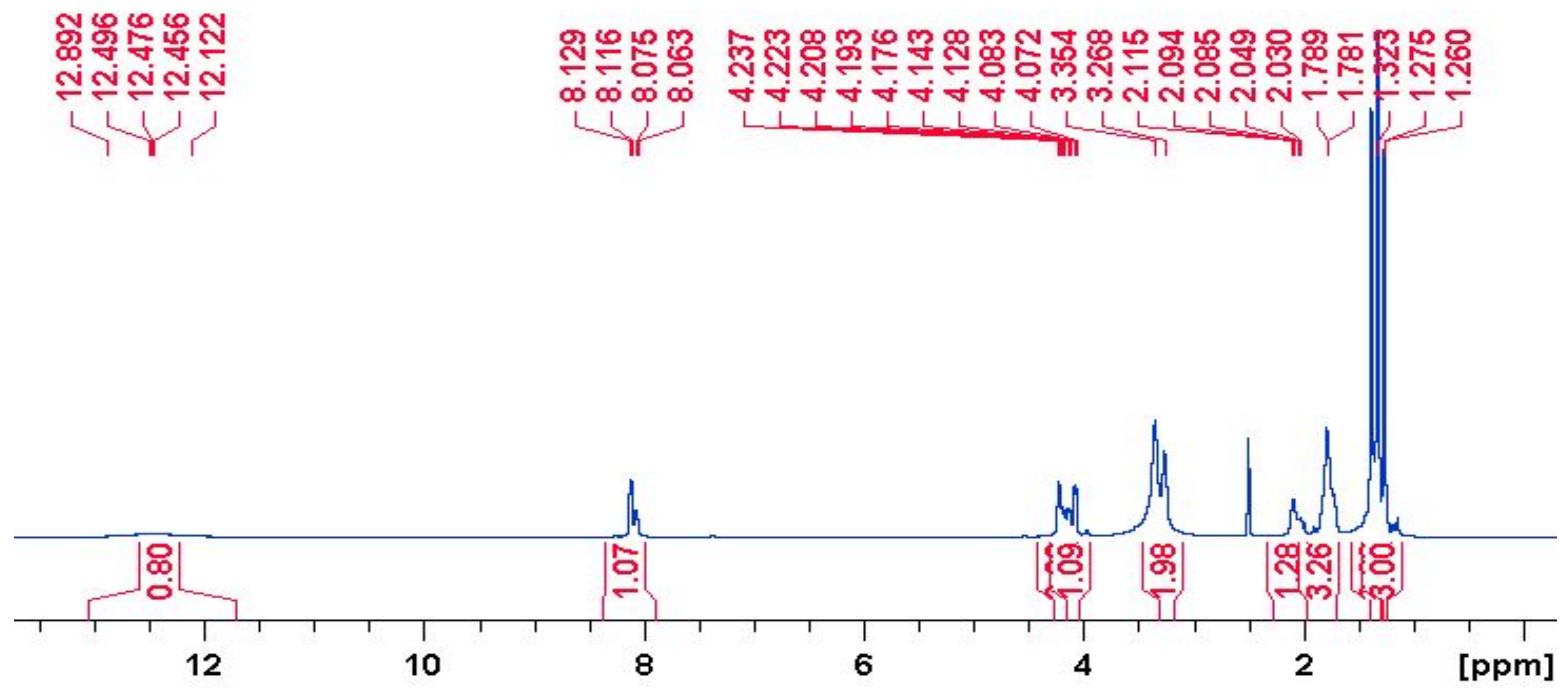

Figure S75. ${ }^{1} \mathrm{H}$ NMR spectrum of N-Boc-Pro-Ala-OH (28) in DMSO- $d_{6}$. 


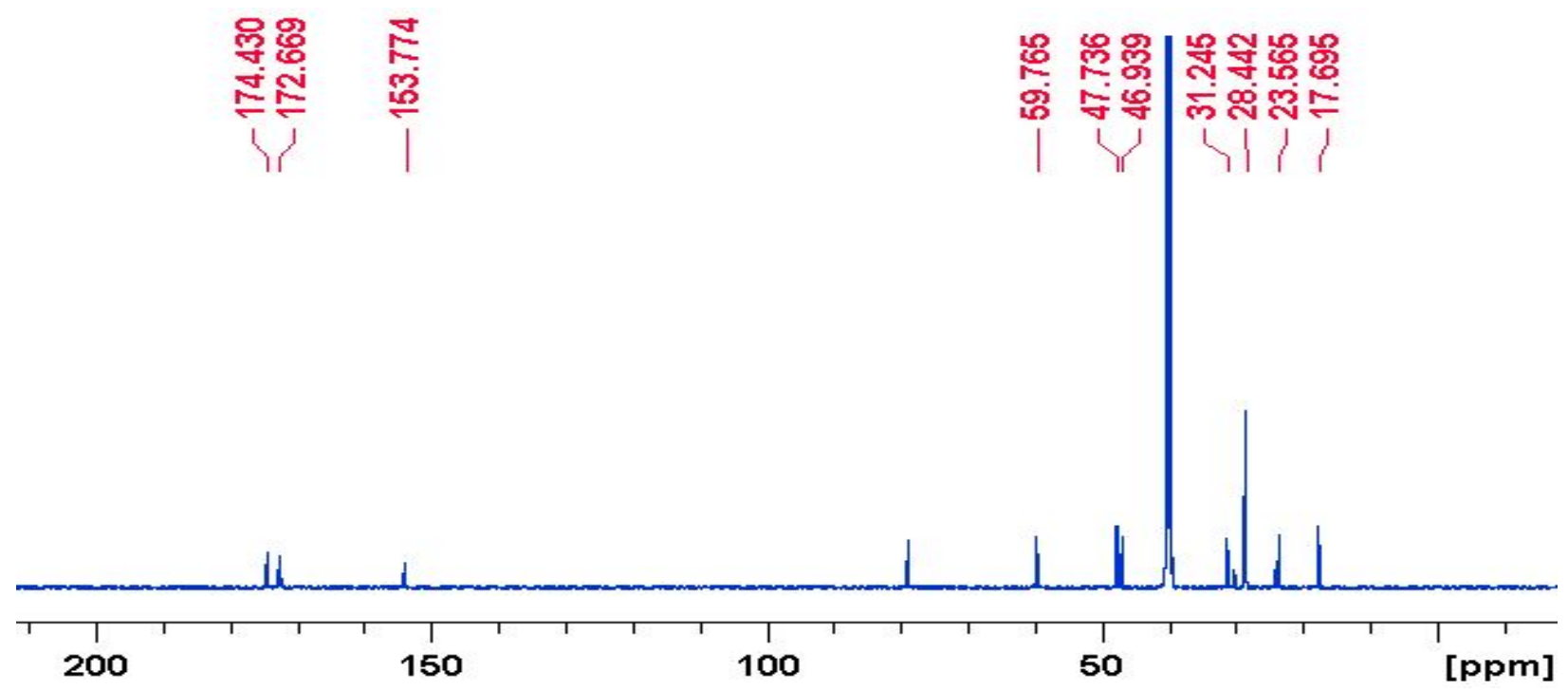

Figure S76. ${ }^{13} \mathrm{C}$ NMR spectrum of N-Boc-Pro-Ala-OH (28) in DMSO- $d_{6}$.

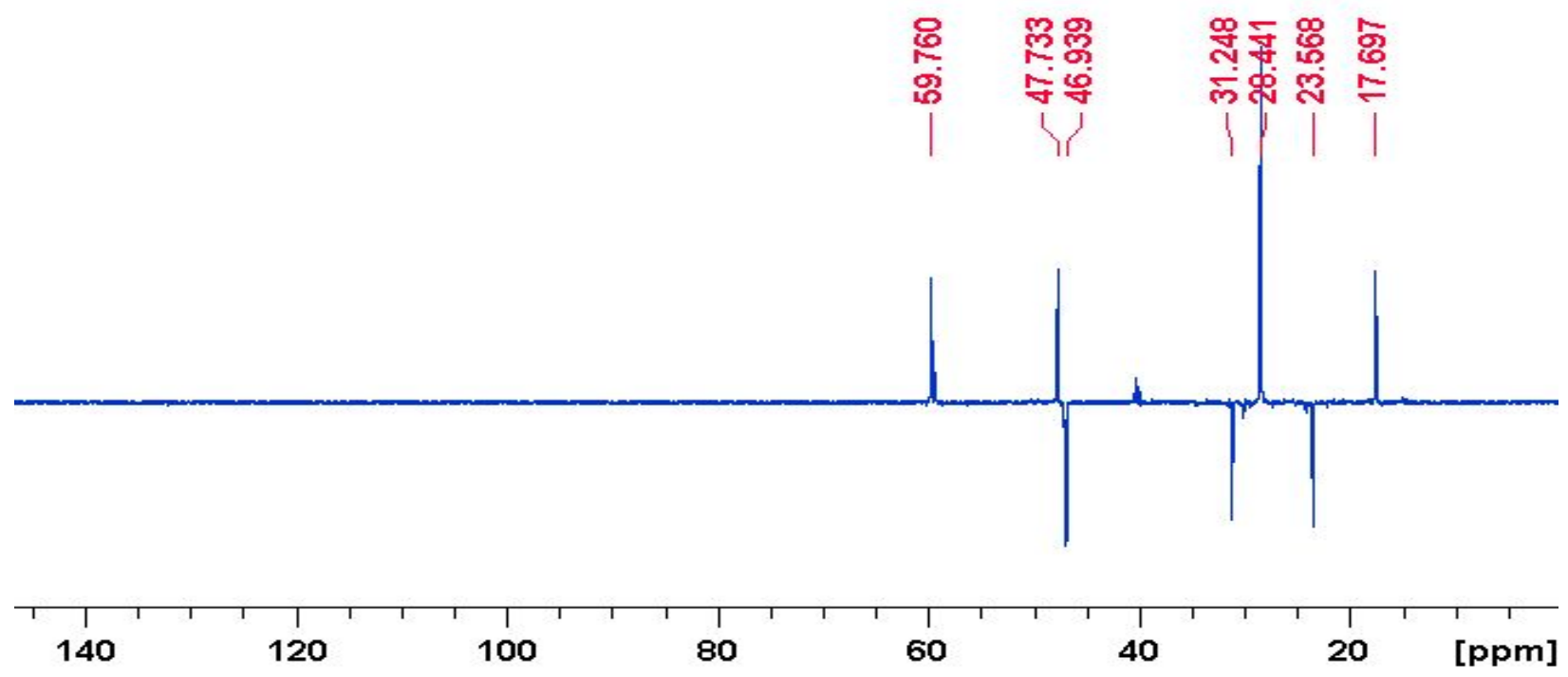

Figure S77. DEPT-135 NMR spectrum of N-Boc-Pro-Ala-OH (28) in DMSO- $d_{6}$. 


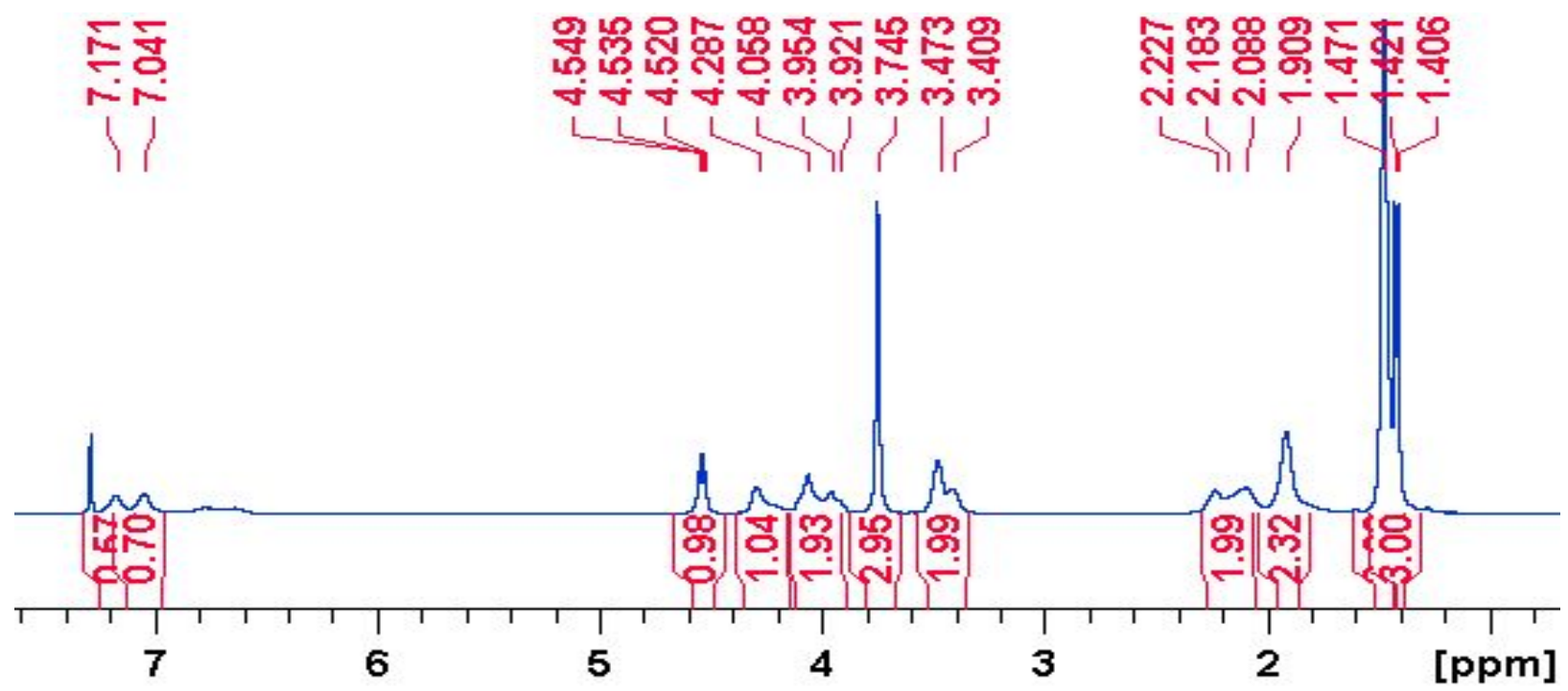

Figure S78. ${ }^{1} \mathrm{H}$ NMR spectrum of N-Boc-Pro-Ala-Gly-OMe (29) in $\mathrm{CDCl}_{3}$.

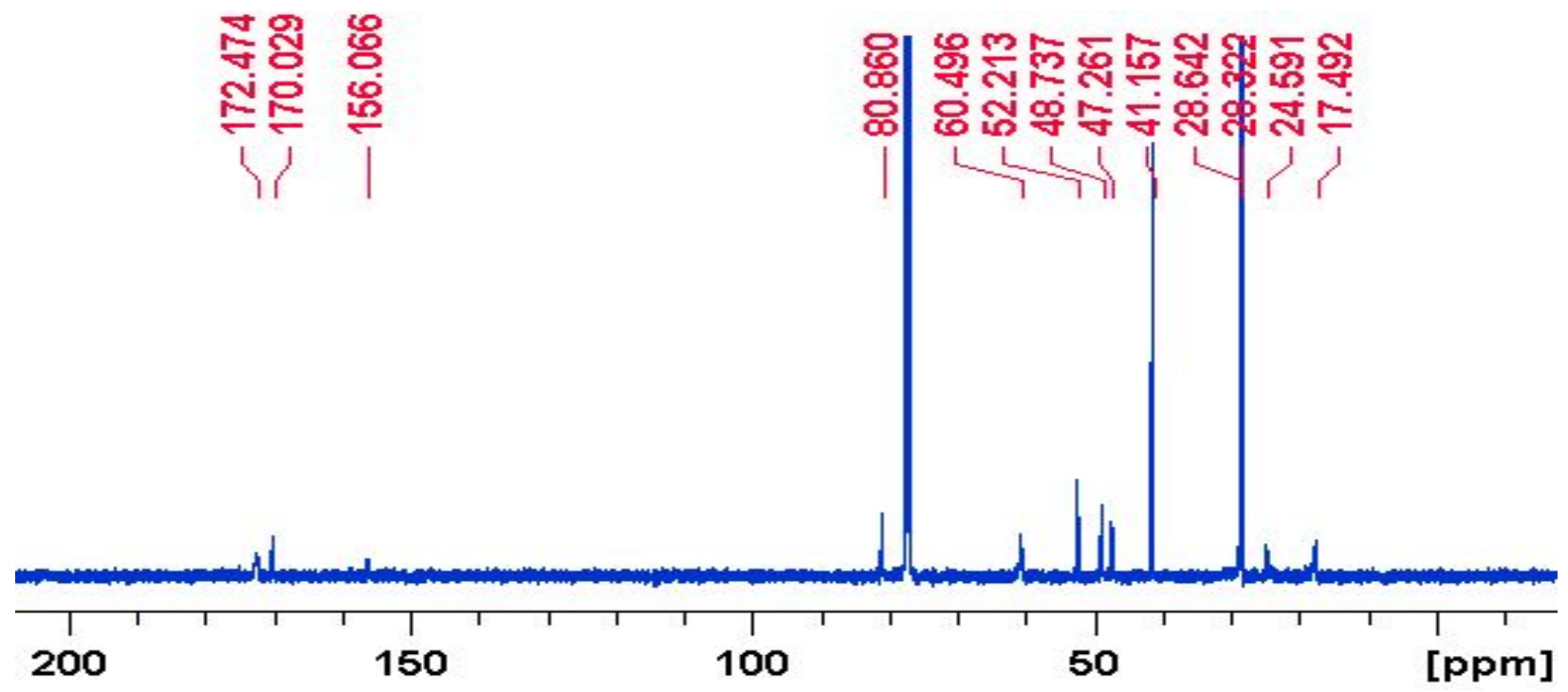

Figure S79. ${ }^{13} \mathrm{C}$ NMR spectrum of N-Boc-Pro-Ala-Gly-OMe (29) in $\mathrm{CDCl}_{3}$. 


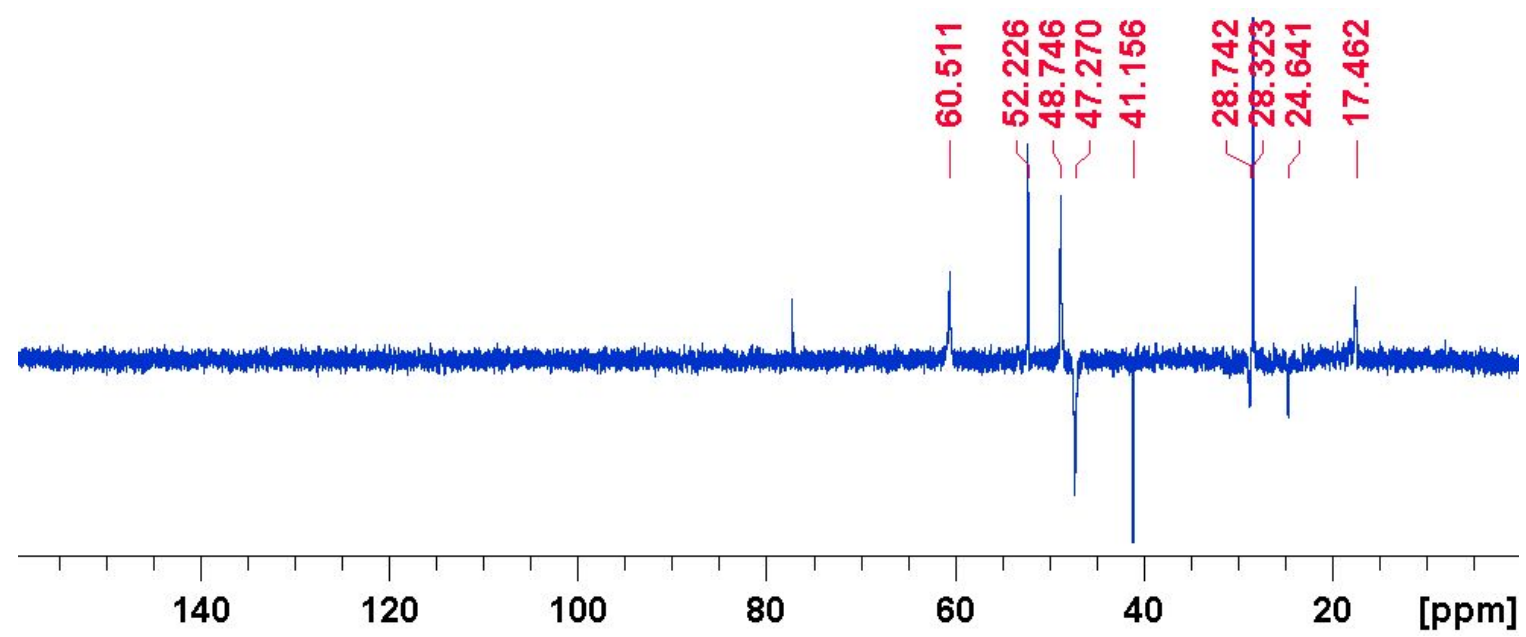

Figure S80. DEPT-135 NMR spectrum of N-Boc-Pro-Ala-Gly-OMe (29) in $\mathrm{CDCl}_{3}$.

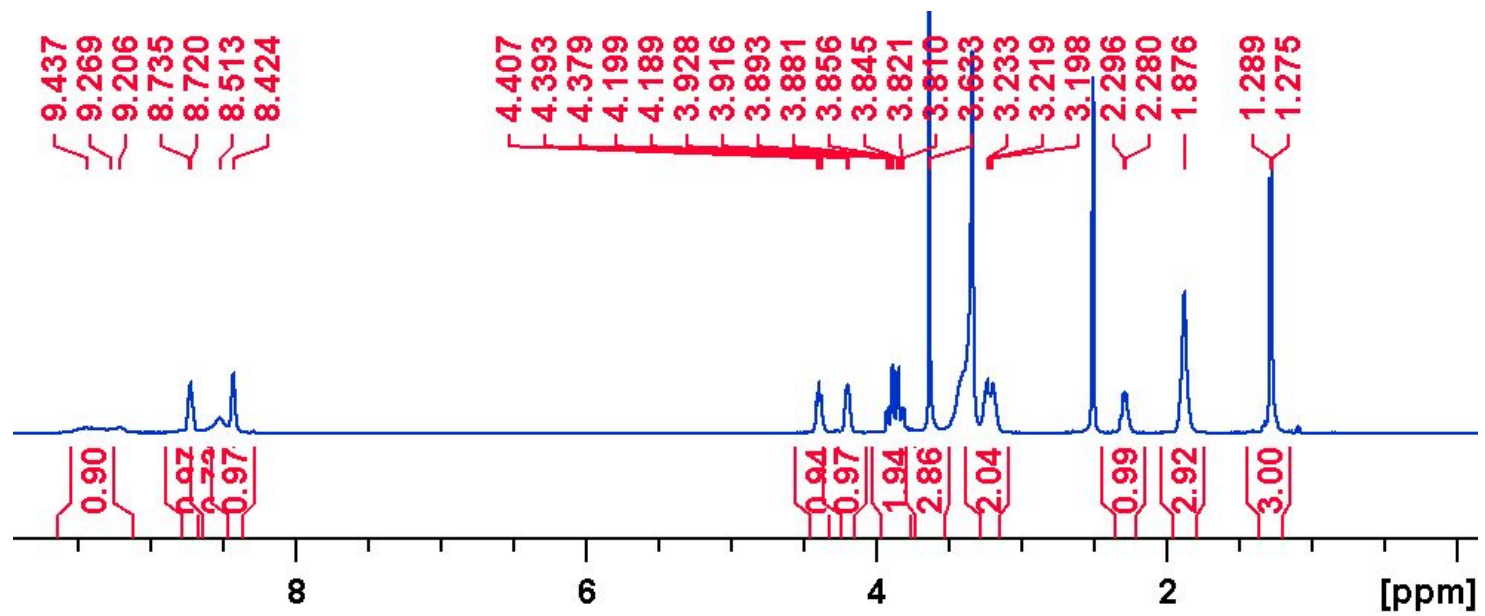

Figure S81. ${ }^{1} \mathrm{H}$ NMR spectrum of Pro-Ala-Gly-OMe (30) in DMSO- $d_{6}$. 


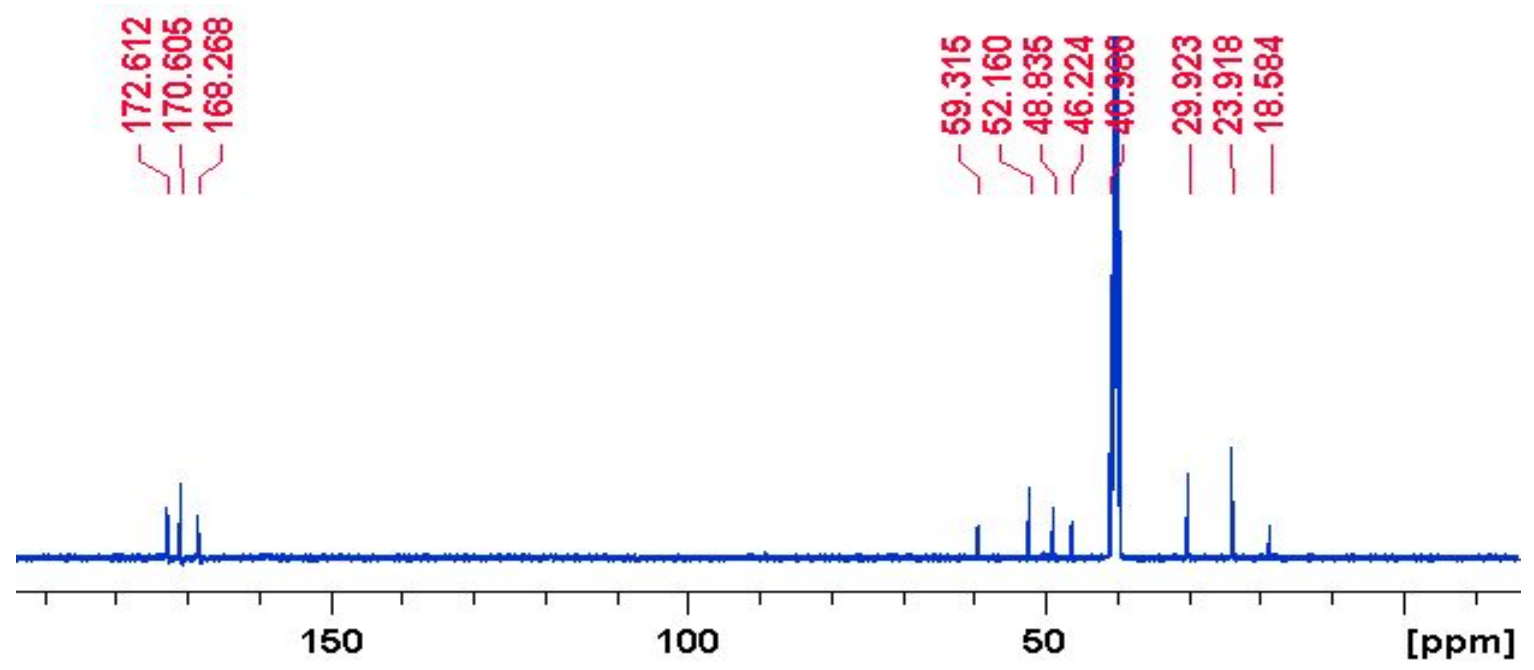

Figure S82. ${ }^{13} \mathrm{C}$ NMR spectrum of Pro-Ala-Gly-OMe (30) in DMSO- $d_{6}$.

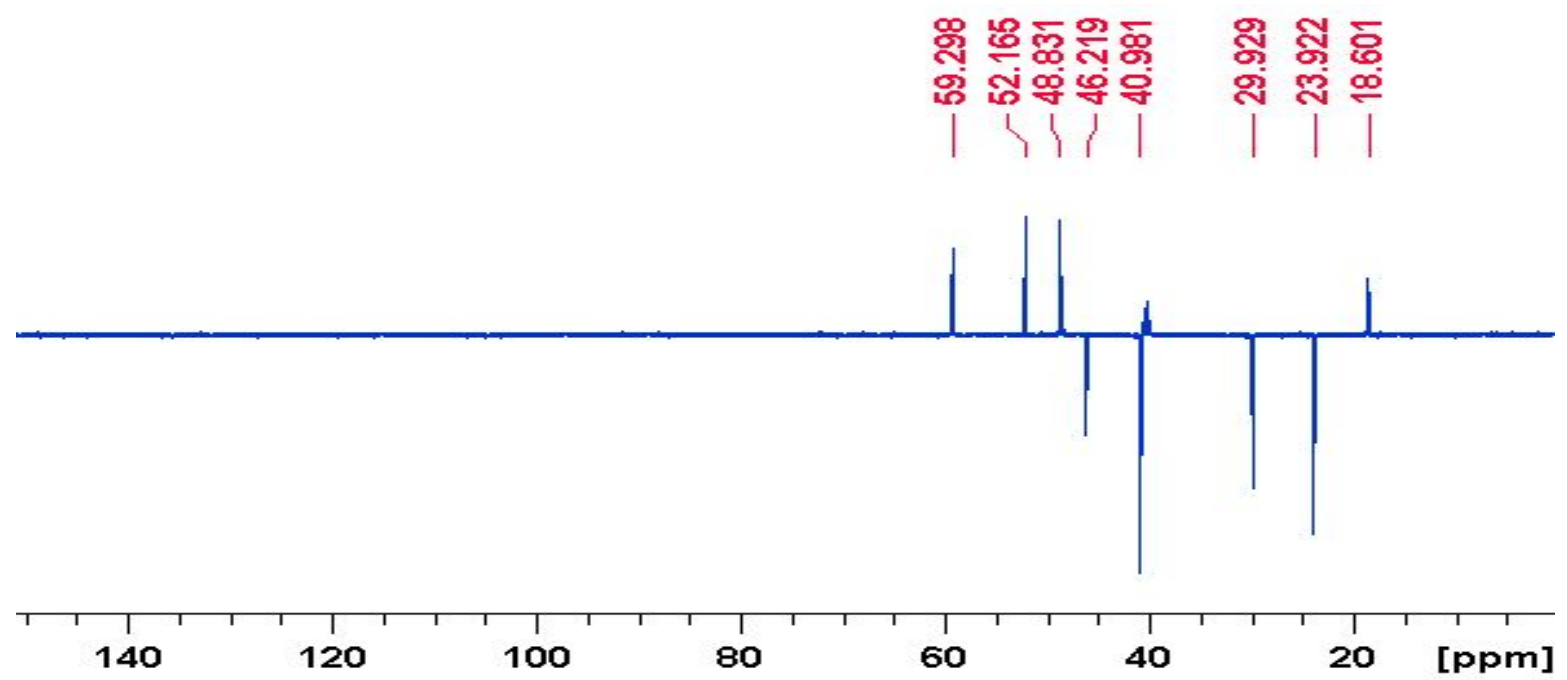

Figure S83. DEPT-135 NMR spectrum of Pro-Ala-Gly-OMe (30) in DMSO- $d_{6}$. 


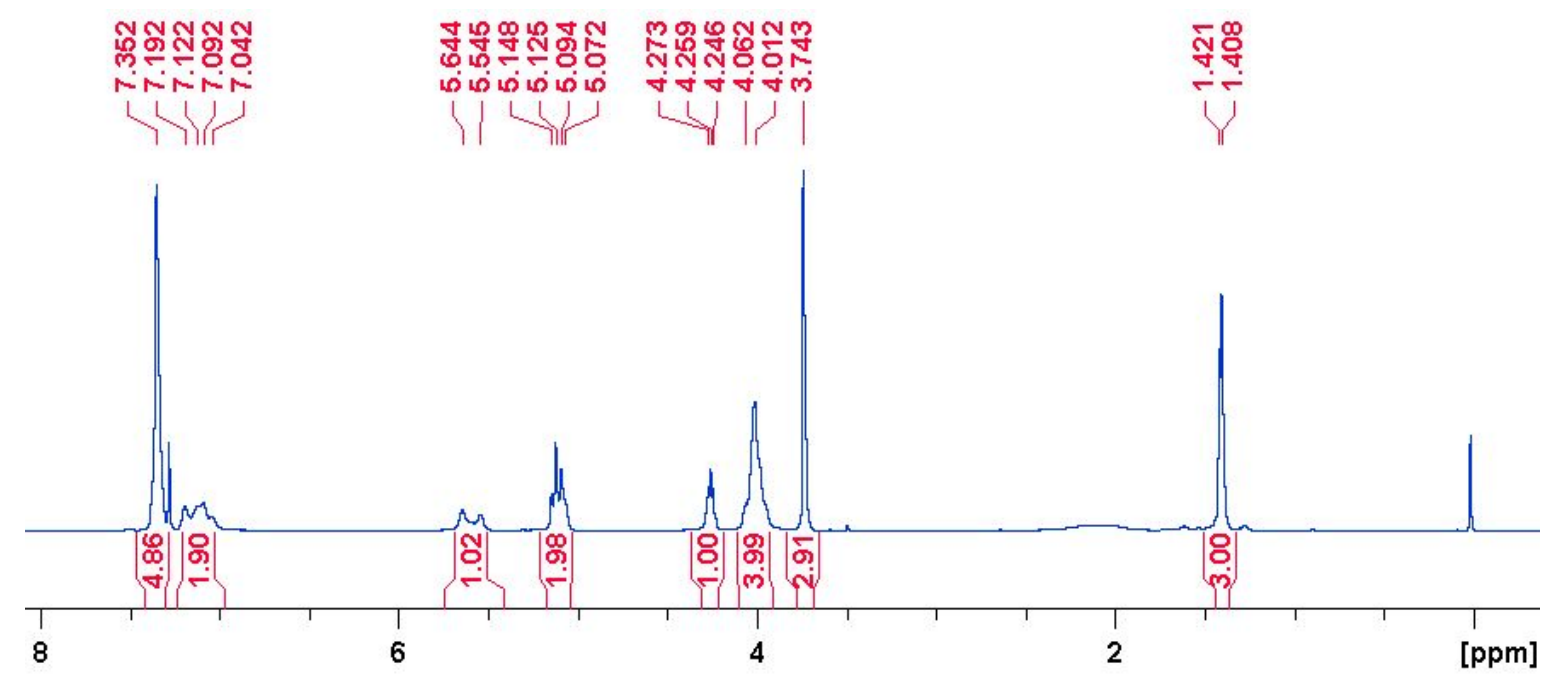

Figure S84. ${ }^{1} \mathrm{H}$ NMR spectrum of N-Cbz-Ala-Gly-Gly-OMe (31) in $\mathrm{CDCl}_{3}$.

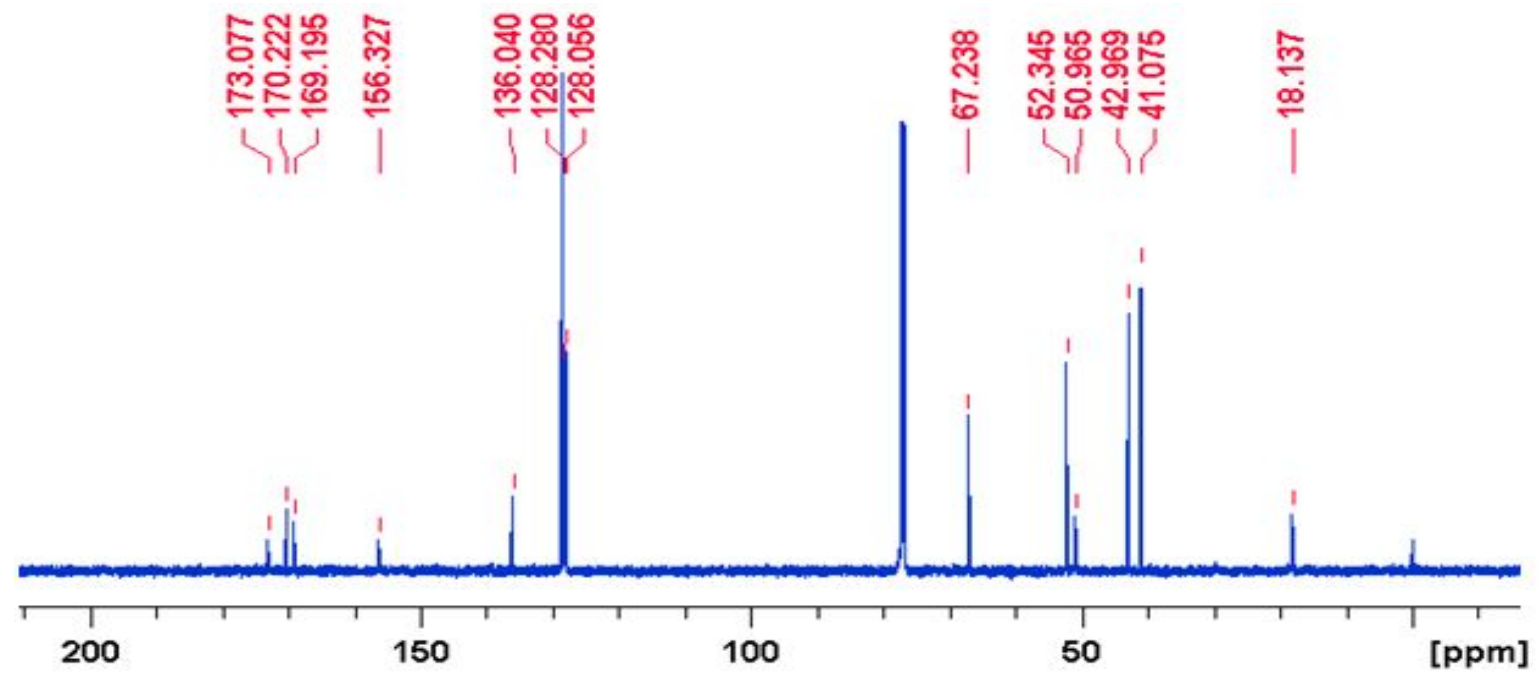

Figure S85. ${ }^{13} \mathrm{C}$ NMR spectrum of N-Cbz-Ala-Gly-Gly-OMe (31) in $\mathrm{CDCl}_{3}$. 


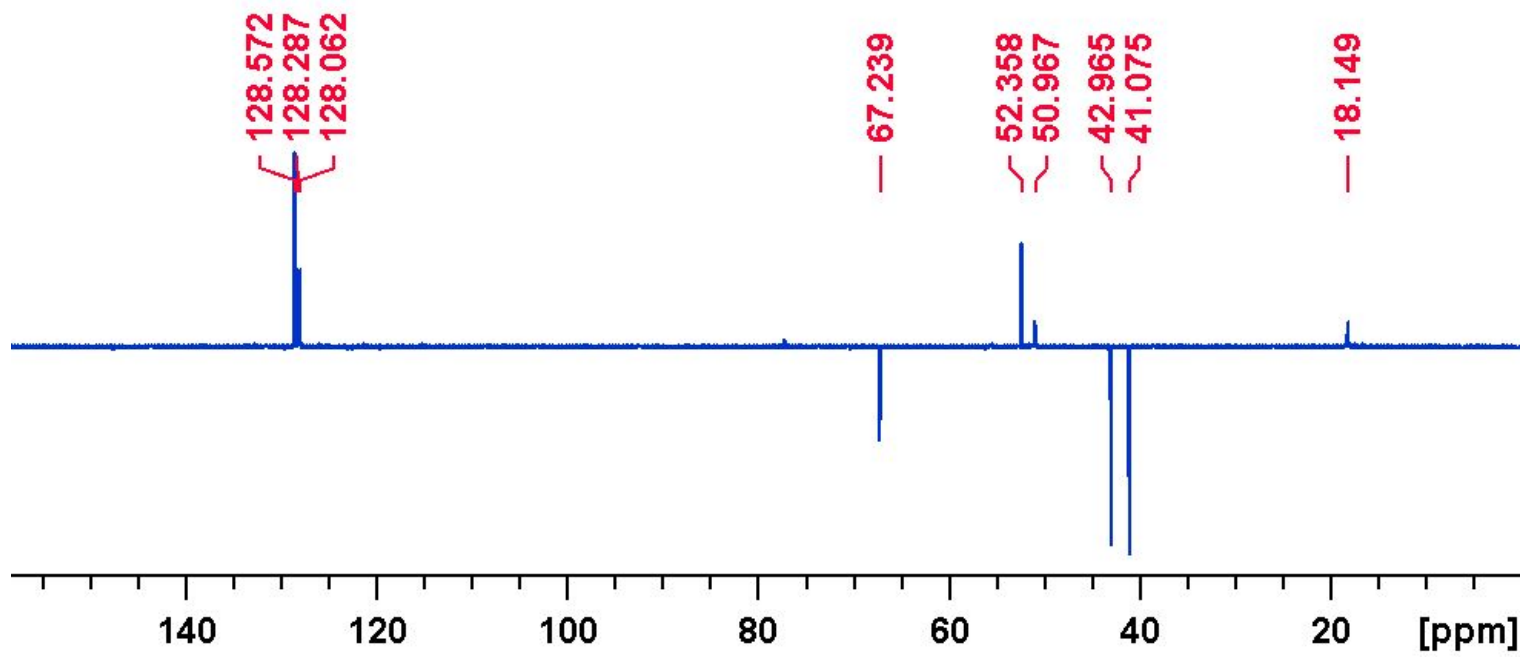

Figure S86. DEPT-135 NMR spectrum of N-Cbz-Ala-Gly-Gly-OMe (31) in $\mathrm{CDCl}_{3}$.

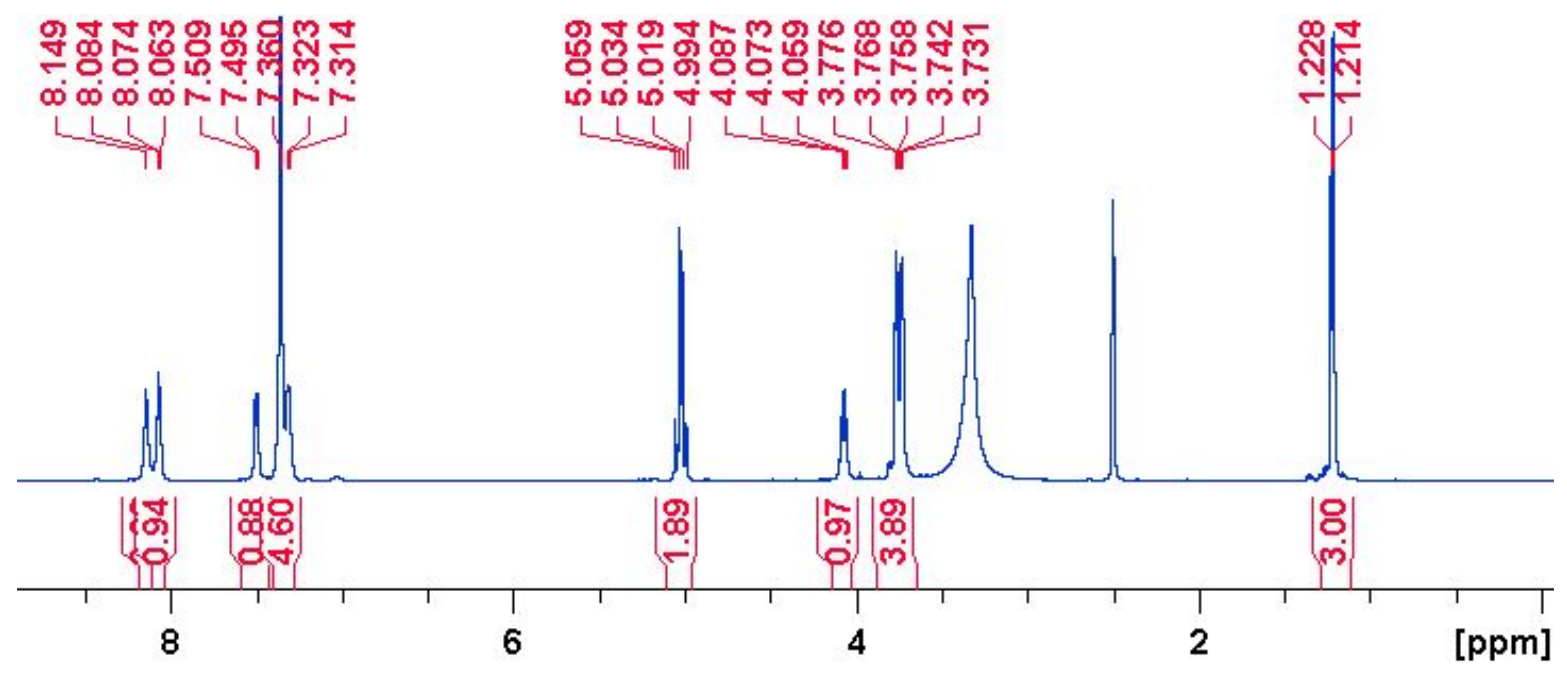

Figure S87. ${ }^{1} \mathrm{H}$ NMR spectrum of N-Cbz-Ala-Gly-Gly-OH (32) in DMSO- $d_{6}$. 


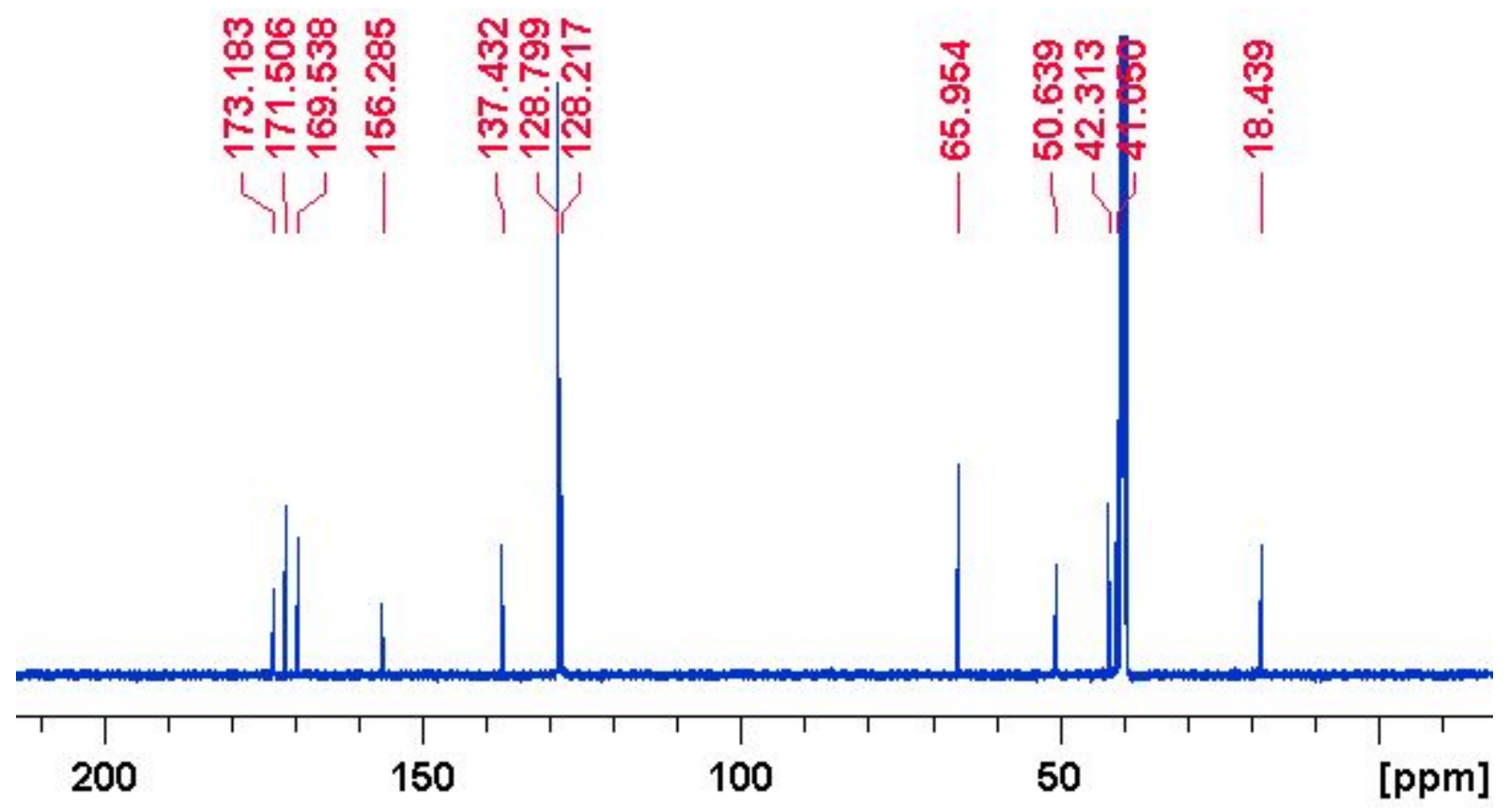

Figure S88. ${ }^{13} \mathrm{C}$ NMR spectrum of N-Cbz-Ala-Gly-Gly-OH (32) in DMSO- $d_{6}$.

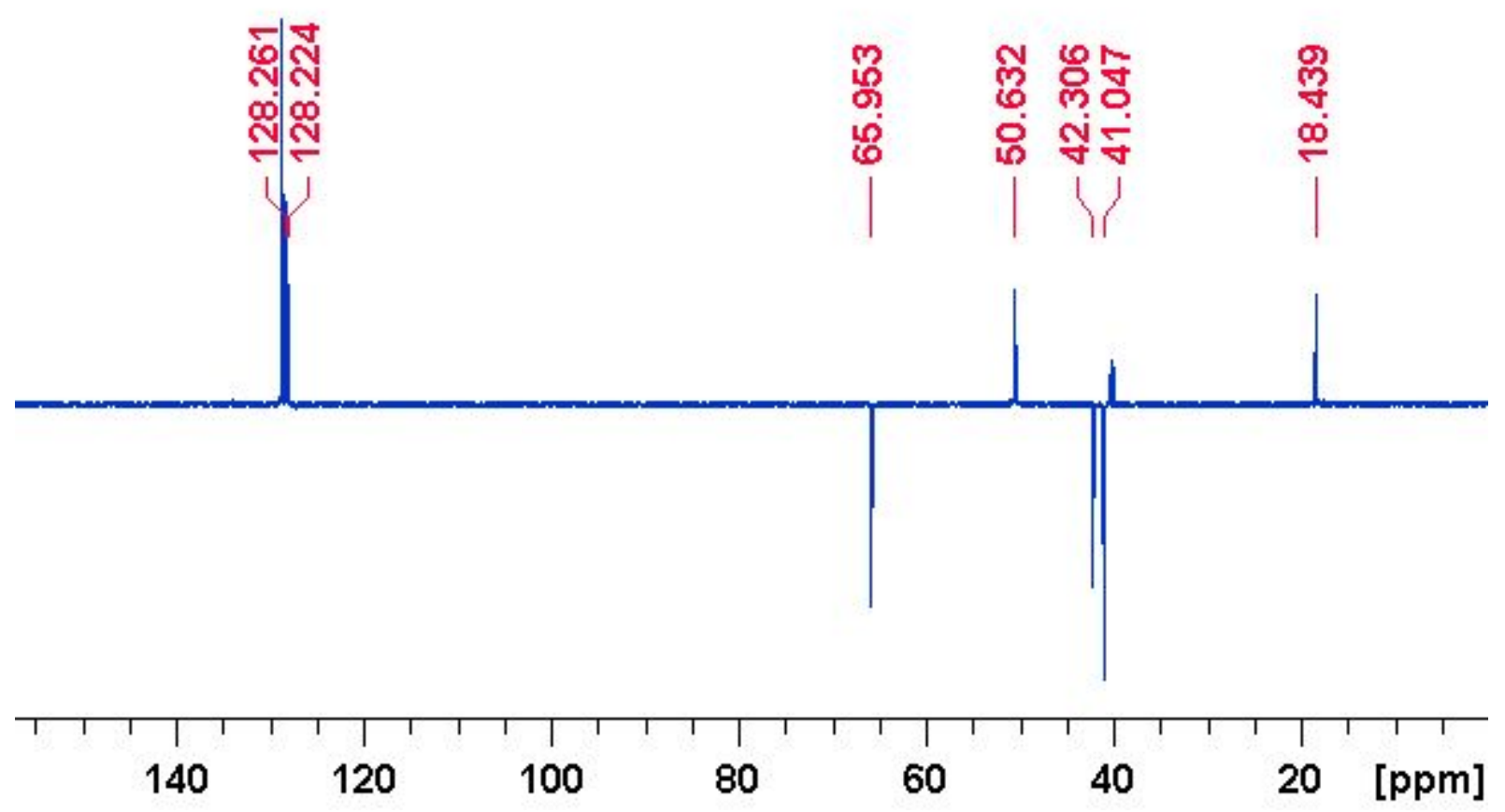

Figure S89. DEPT-135 NMR spectrum of N-Cbz-Ala-Gly-Gly-OH (32) in DMSO- $d_{6}$. 


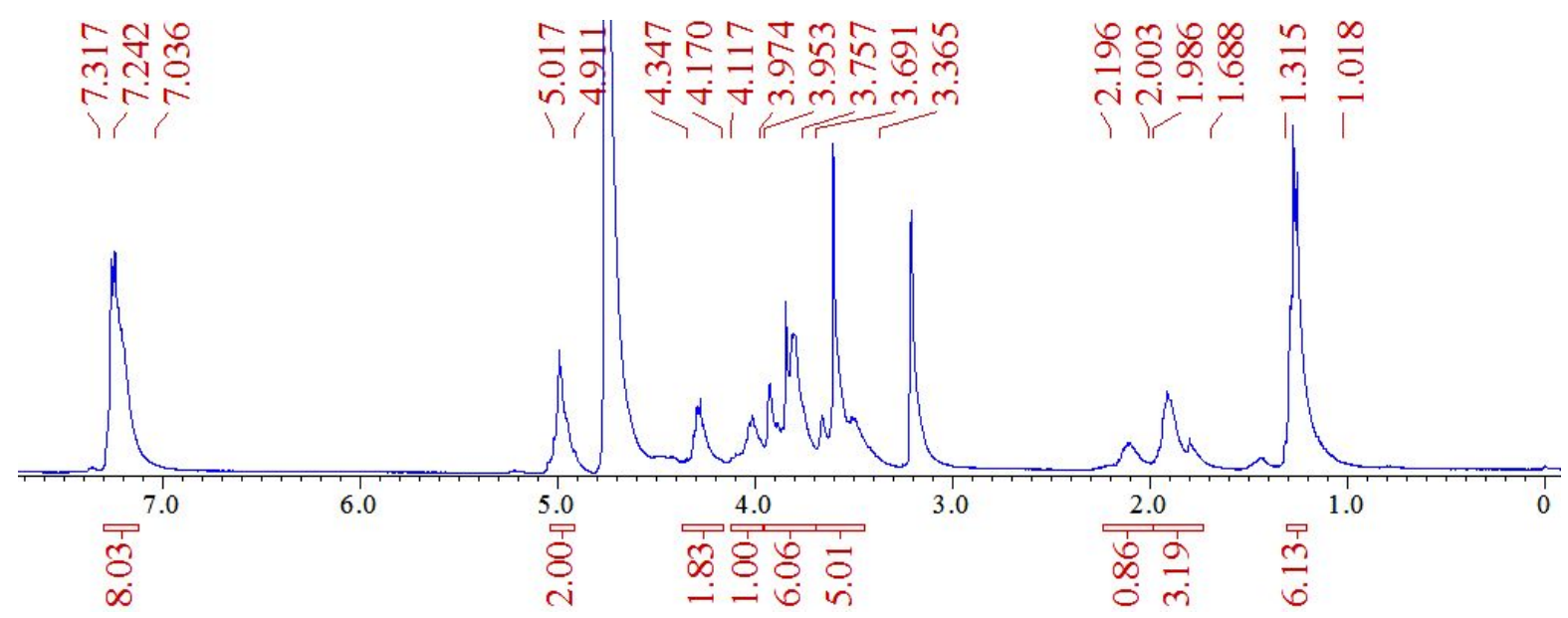

Figure S90. ${ }^{1} \mathrm{H}$ NMR spectrum of Cbz-Ala-Gly-Gly-Pro-Ala-Gly-OMe (33) in methanol- $d_{4}$.

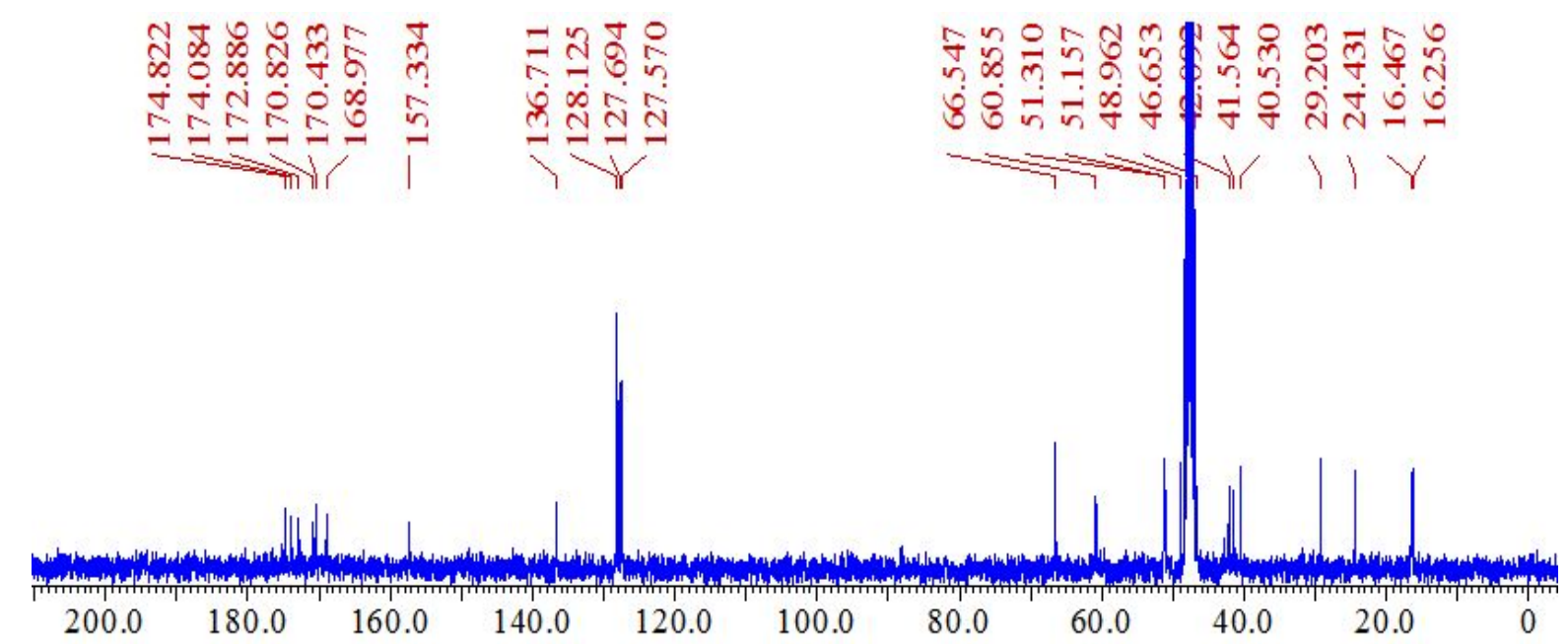

Figure S91. ${ }^{13} \mathrm{C}$ NMR spectrum of Cbz-Ala-Gly-Gly-Pro-Ala-Gly-OMe (33) in methanol- $d_{4}$. 


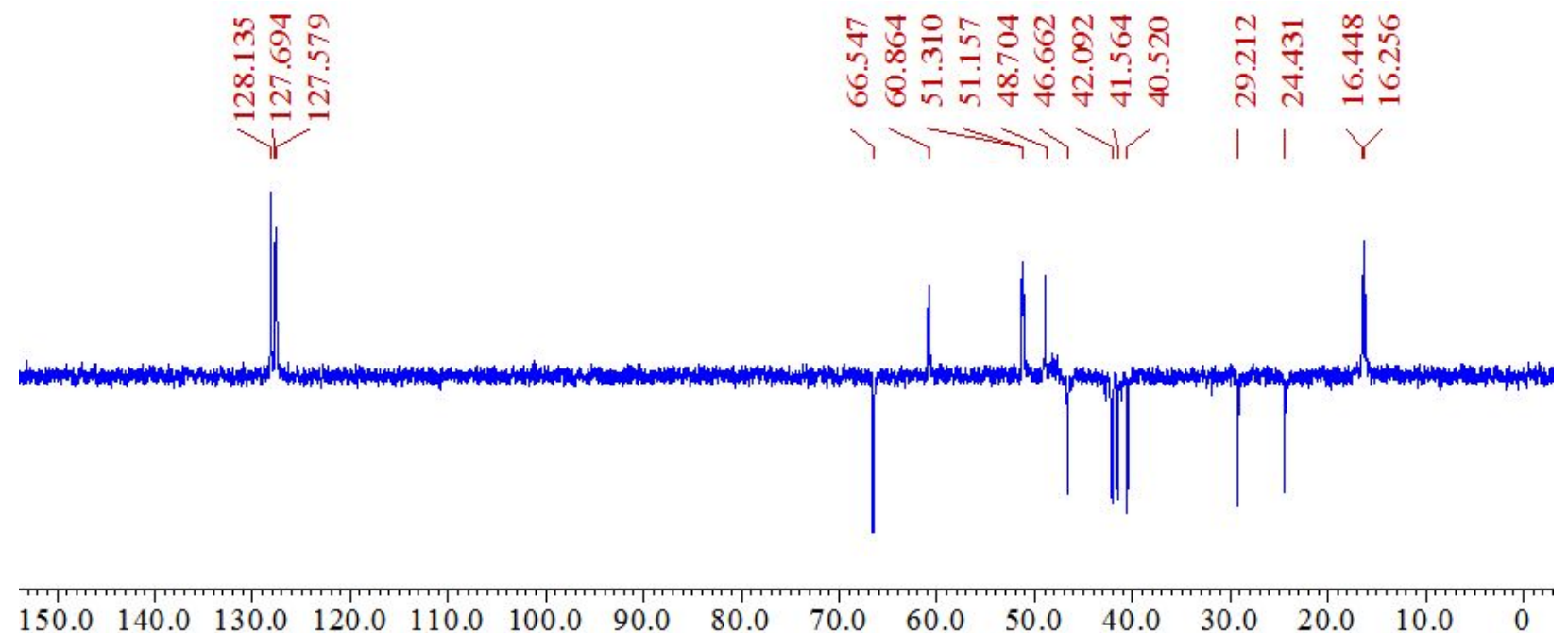

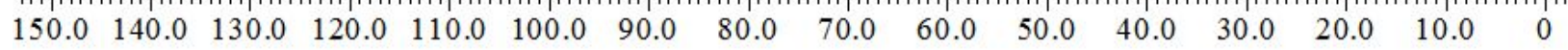

Figure S92. DEPT-135 NMR spectrum of Cbz-Ala-Gly-Gly-Pro-Ala-Gly-OMe (33) in methanol- $d_{4}$.

\section{$q^{1}$ HNMR of N-Cbz-Ala-Gly-Pro-Ala-Gly-OMe (12).}

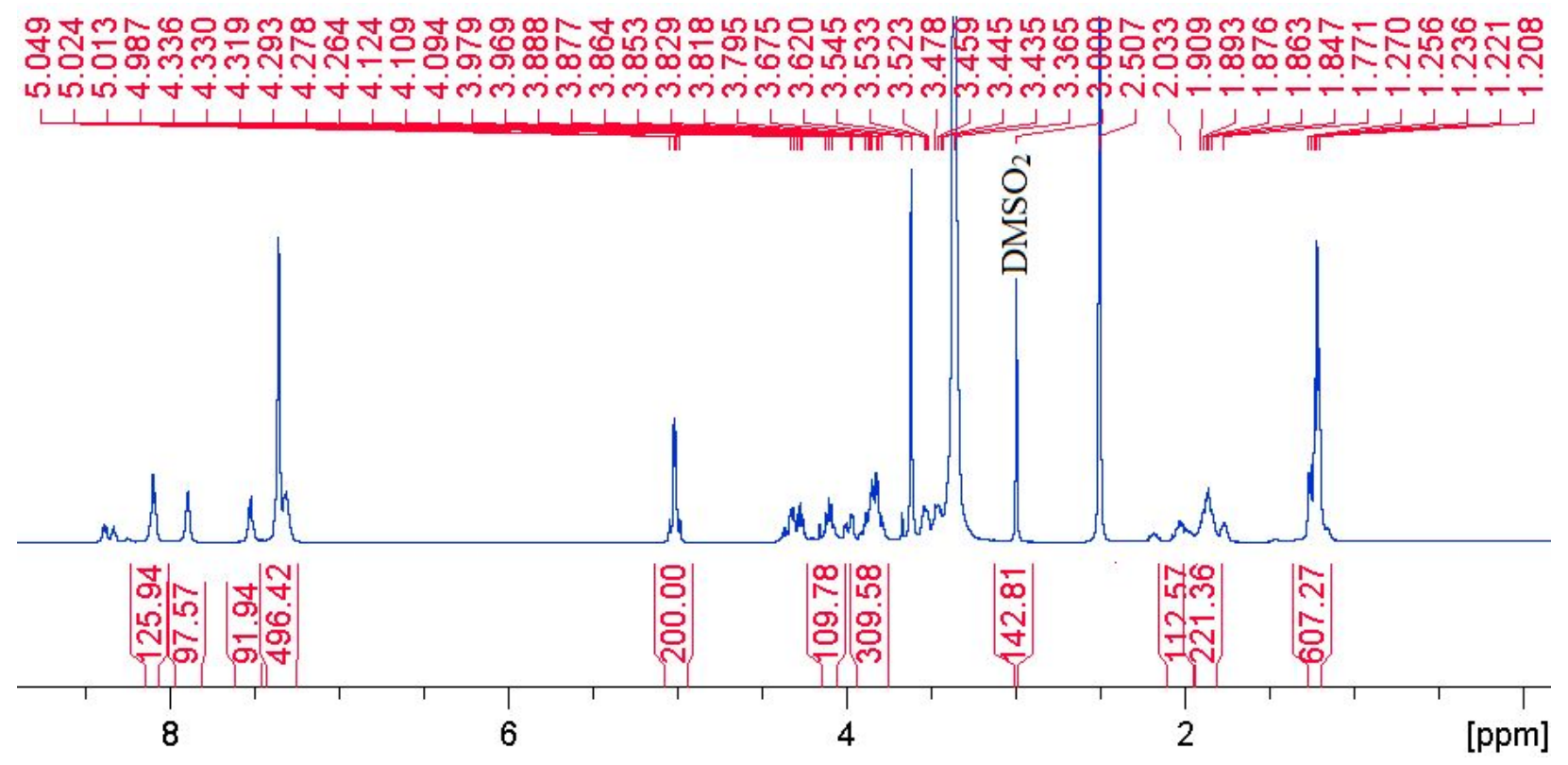

Figure S93. $\mathrm{q}^{1} \mathrm{H}$ NMR of compound 12 in DMSO-d6 with the Dimethylsulfone as Internal Calibrant (99.4\% pure).

Percentage purity [P \%] of the compound 12 was calculated using the following equation 
$\mathrm{P}[\%]=\frac{n_{I C} \cdot \operatorname{Int}_{t} \cdot M W_{t} \cdot m_{I C}}{n_{t} \cdot \operatorname{Int}_{I C} \cdot M W_{I C} \cdot m_{s}} \cdot P_{I C}$

$\mathrm{n}=$ no of protons giving rise to a given NMR signal

Int $=$ integral, $\mathrm{IC}=$ internal calibrant, $\mathrm{t}=$ target analyte or compound

$\mathrm{MW}_{\mathrm{t}}=$ molecular weight of compound

$\mathrm{MW}_{\mathrm{IC}}=$ molecular weight of internal calibrant

$\mathrm{m}_{\mathrm{IC}}=$ amount of internal calibrant

$\mathrm{m}_{\mathrm{S}}=$ amount of compound

$\mathrm{P}_{\mathrm{IC}}=$ purity of internal calibrant

In the given $\mathrm{q}^{1} \mathrm{HNMR}$ experiment,

$\mathrm{n}_{\mathrm{t}}=1, \mathrm{n}_{\mathrm{IC}}=6, \mathrm{Int}_{\mathrm{t}}=103.14^{\mathrm{a}}, \mathrm{Int}_{\mathrm{IC}}=142.81, \mathrm{MW}_{\mathrm{t}}=519 \mathrm{~g} / \mathrm{mol}$,

$\mathrm{MW}_{\mathrm{IC}}=94.13 \mathrm{~g} / \mathrm{mol}, \mathrm{m}_{\mathrm{S}}=5 \mathrm{mg}, \mathrm{m}_{\mathrm{IC}}=0.207 \mathrm{mg}, \mathrm{P}_{\mathrm{IC}}=99.4 \%$

a The integral of compound was calculated as the average of integration of all the integrated signals in the given ${ }^{1} \mathrm{H}$ NMR spectrum.

Percentage purity of compound $\mathbf{1 2}$ was $98.32 \%$. 


\section{Mass Spectra}

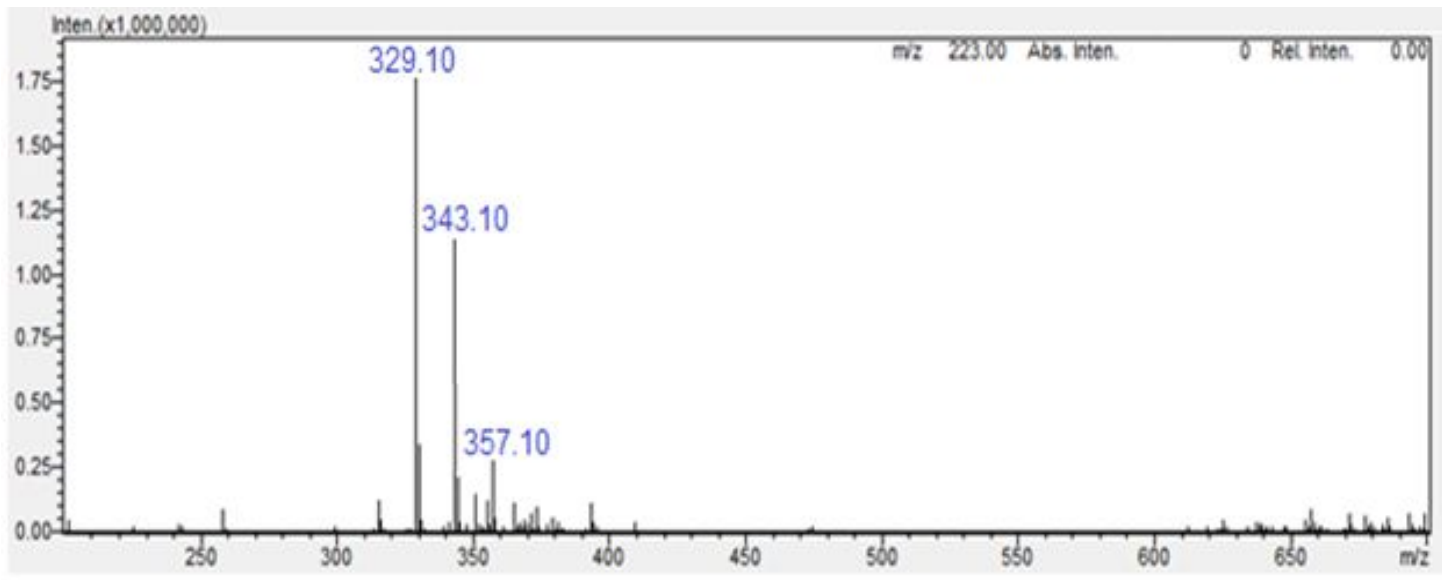

Figure S94. MS of Ala-Gly-Pro-Ala-OMe (1) $\left(\right.$ calcd $\left.m / z 329.18[\mathrm{M}+\mathrm{H}]^{+}\right)$.

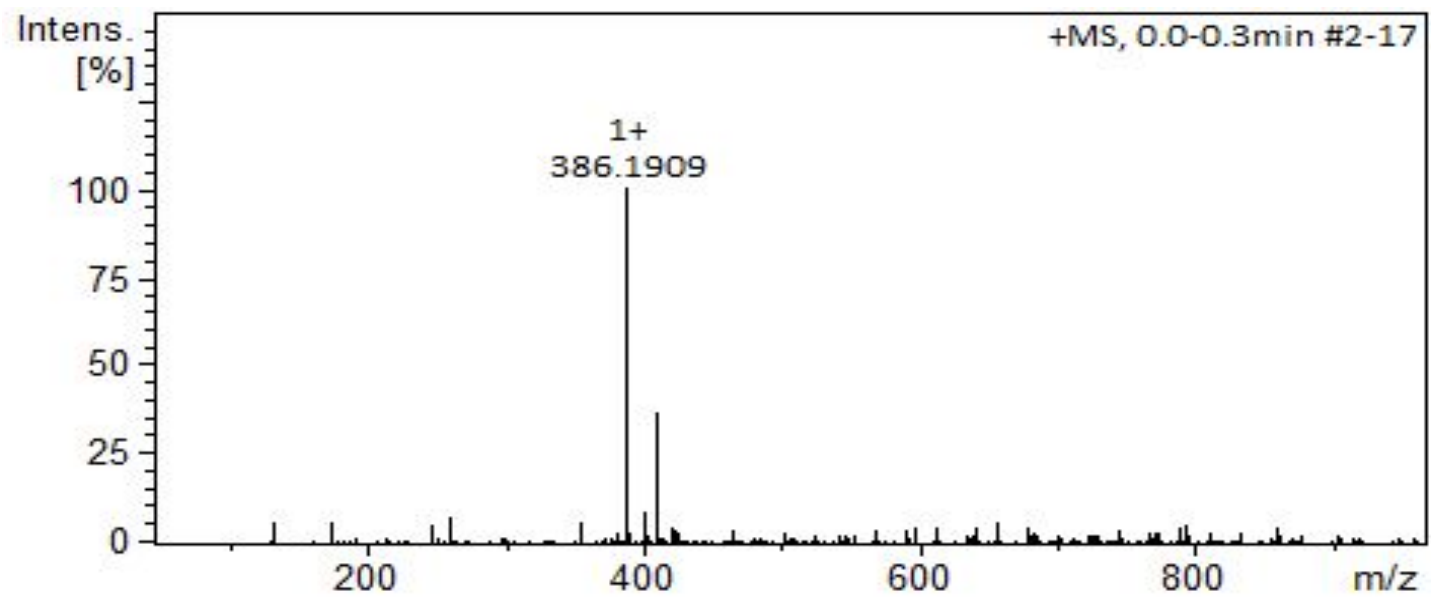

Figure S95. HRMS of Ala-Gly-Pro-Ala-Gly-OMe (2) (calcd m/z $\left.386.2034[\mathrm{M}+\mathrm{H}]^{+}\right)$.

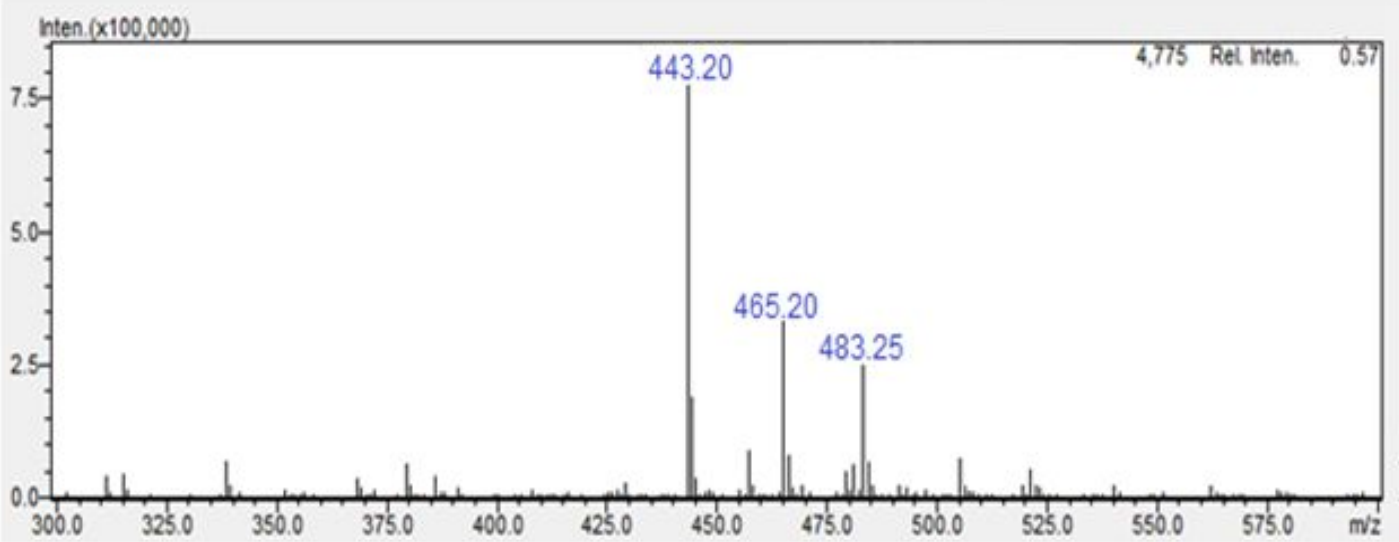

Figure S96. MS of Ala-Gly-Gly-Pro-Ala-Gly-OMe (3) (calcd $\left.m / z 443.12[\mathrm{M}+\mathrm{H}]^{+}\right)$. 


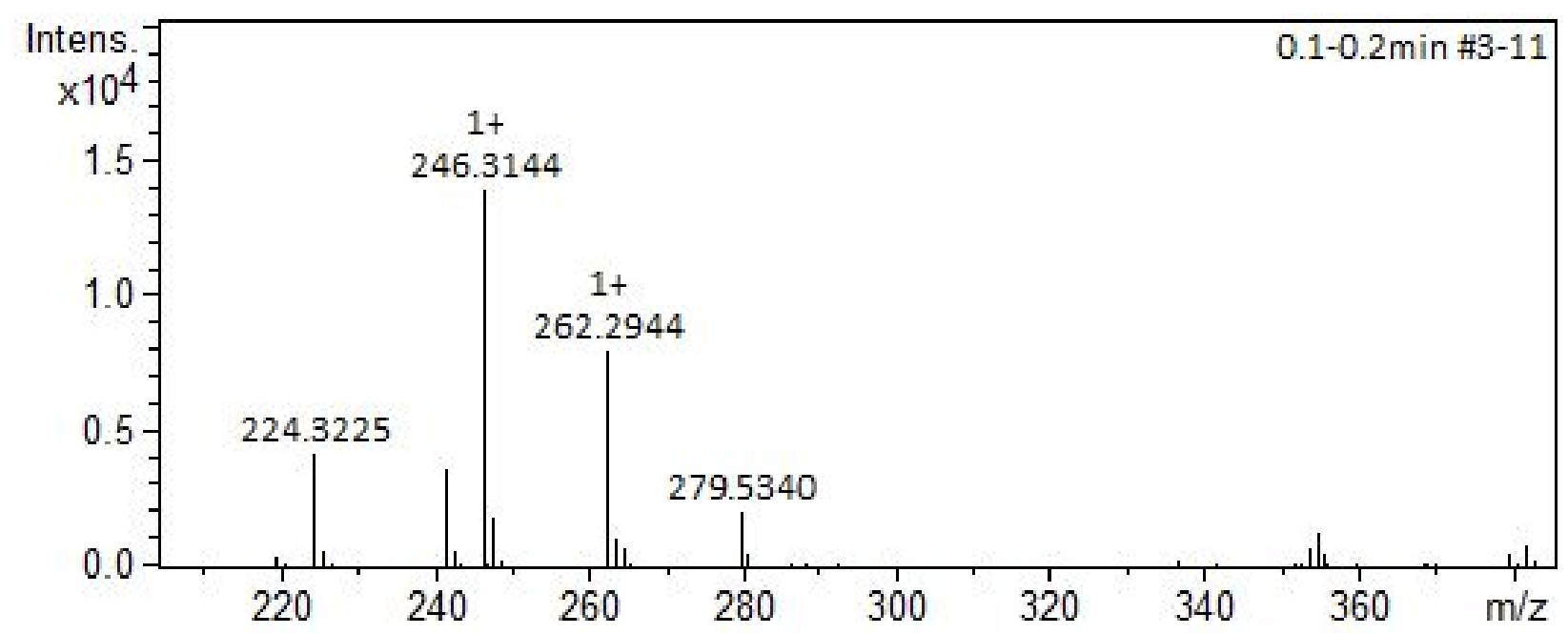

Figure S97. MS of Cbz-Ala-OH (4) (calcd $\left.m / z 246.0736[\mathrm{M}+\mathrm{Na}]^{+}\right)$.

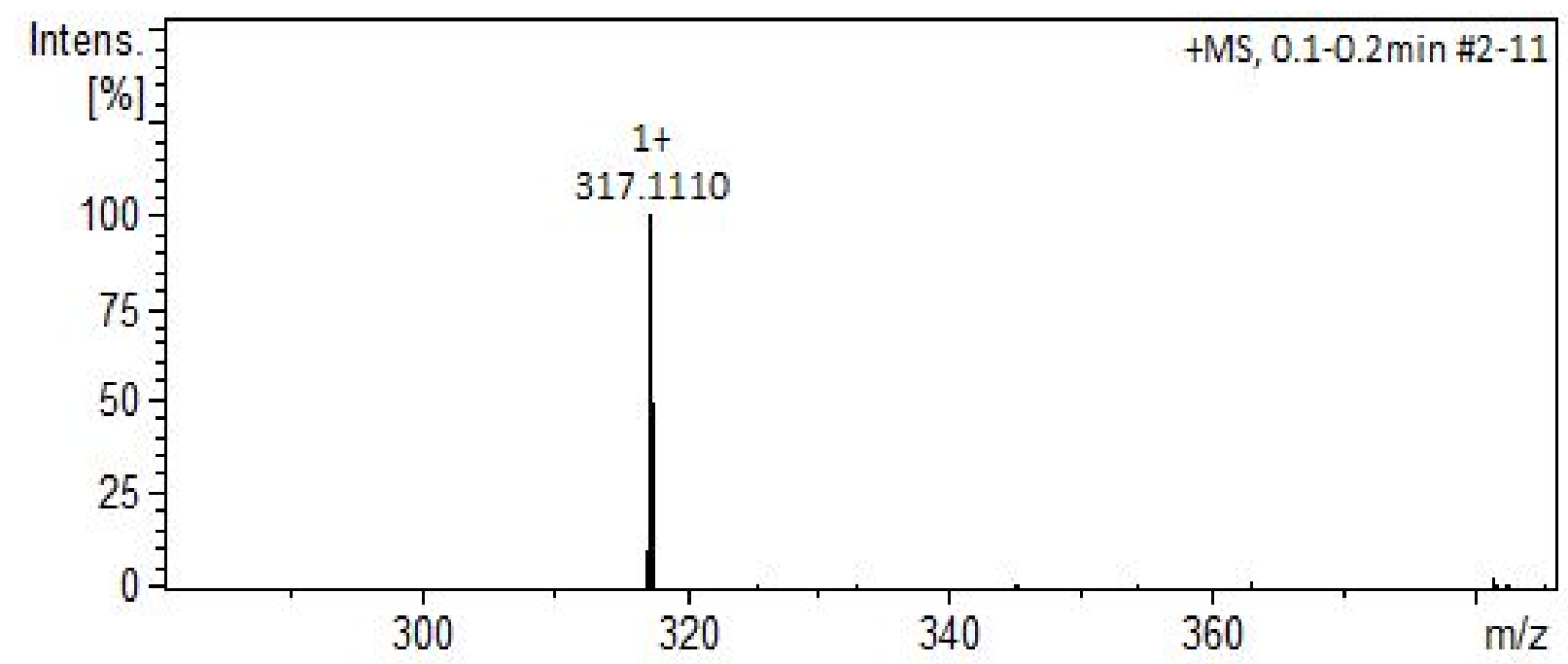

Figure 98. HRMS of N-Cbz-Ala-Gly-OMe (5) (calcd m/z 317.1107 [M+Na $]^{+}$). 


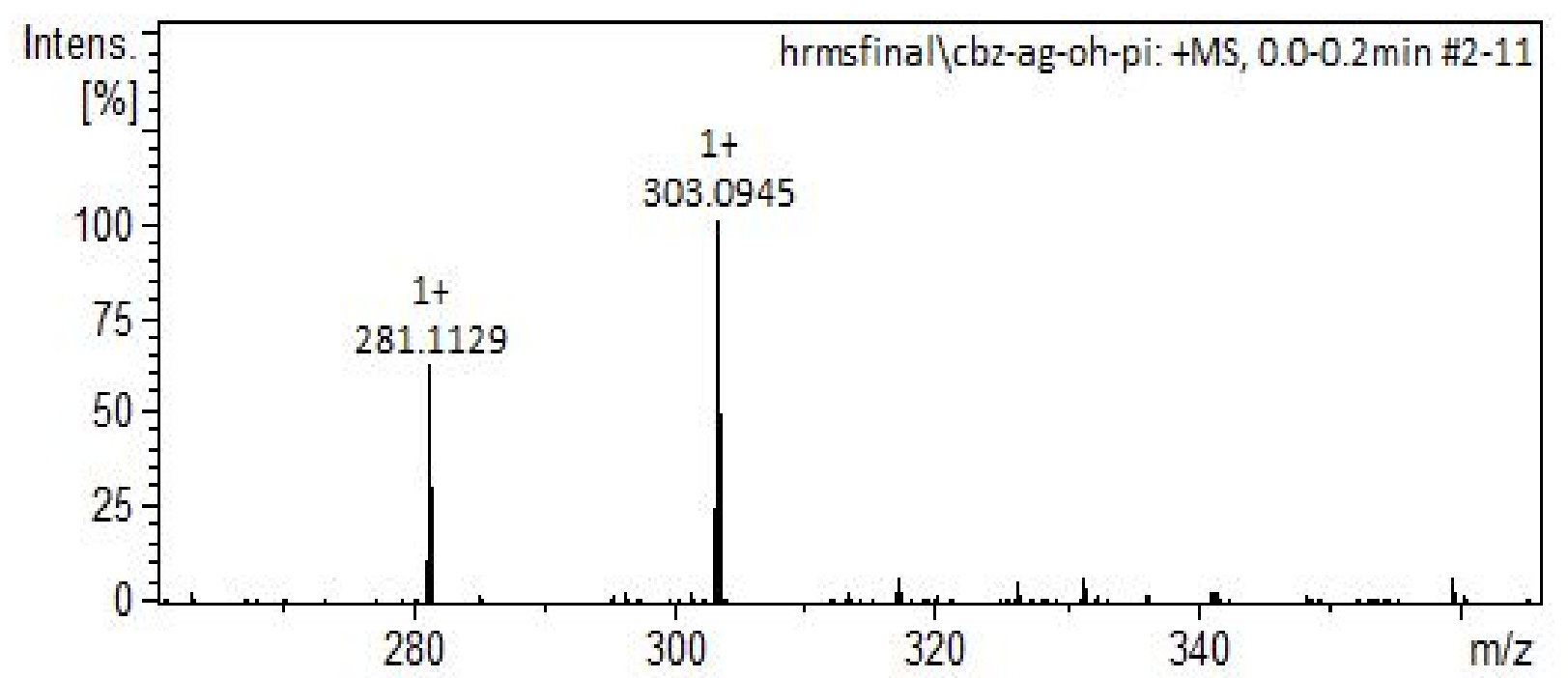

Figure S99. HRMS of N-Cbz-Ala-Gly-OH (6) (calcd m/z 281.1131 [M+H] $]^{+}$).

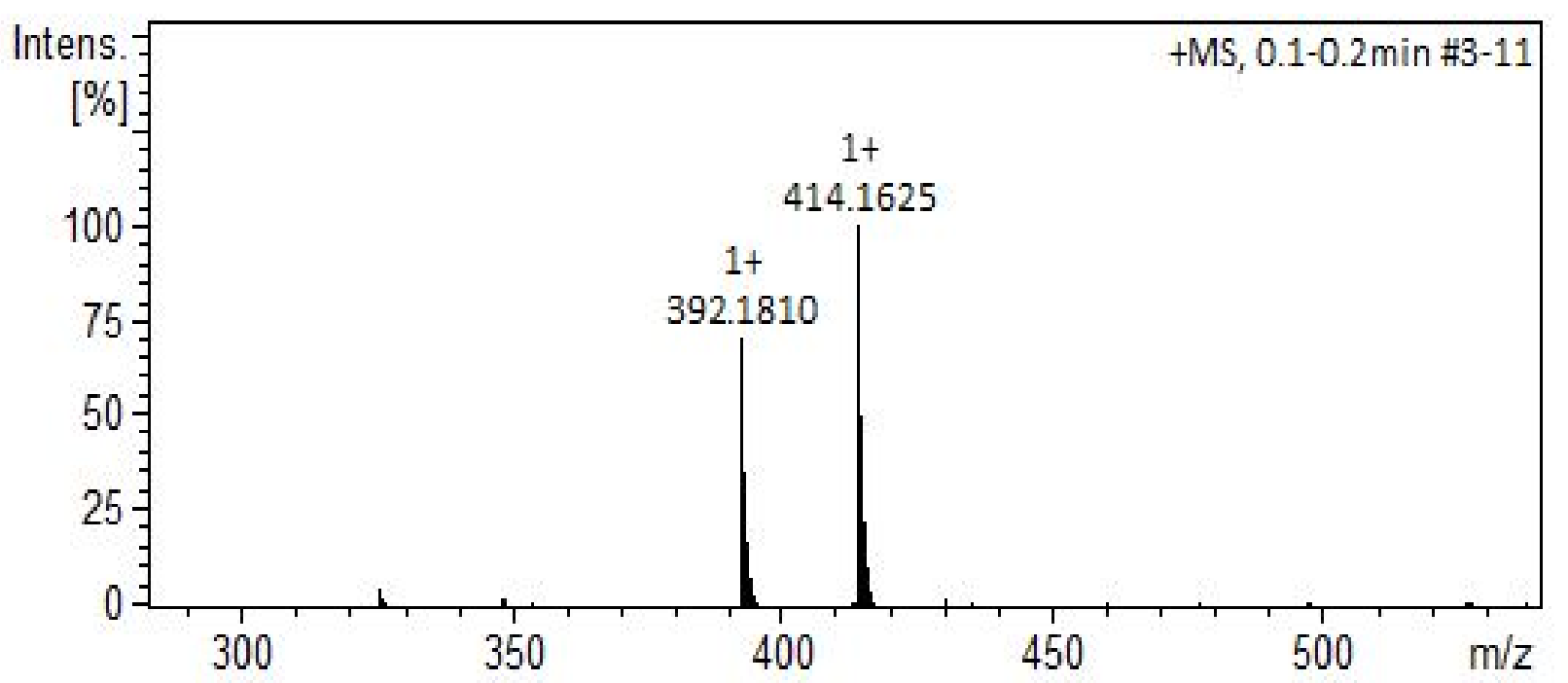

Figure S100. HRMS of N-Cbz-Ala-Gly-Pro-OMe (7) (calcd m/z $\left.392.1816[\mathrm{M}+\mathrm{H}]^{+}\right)$. 


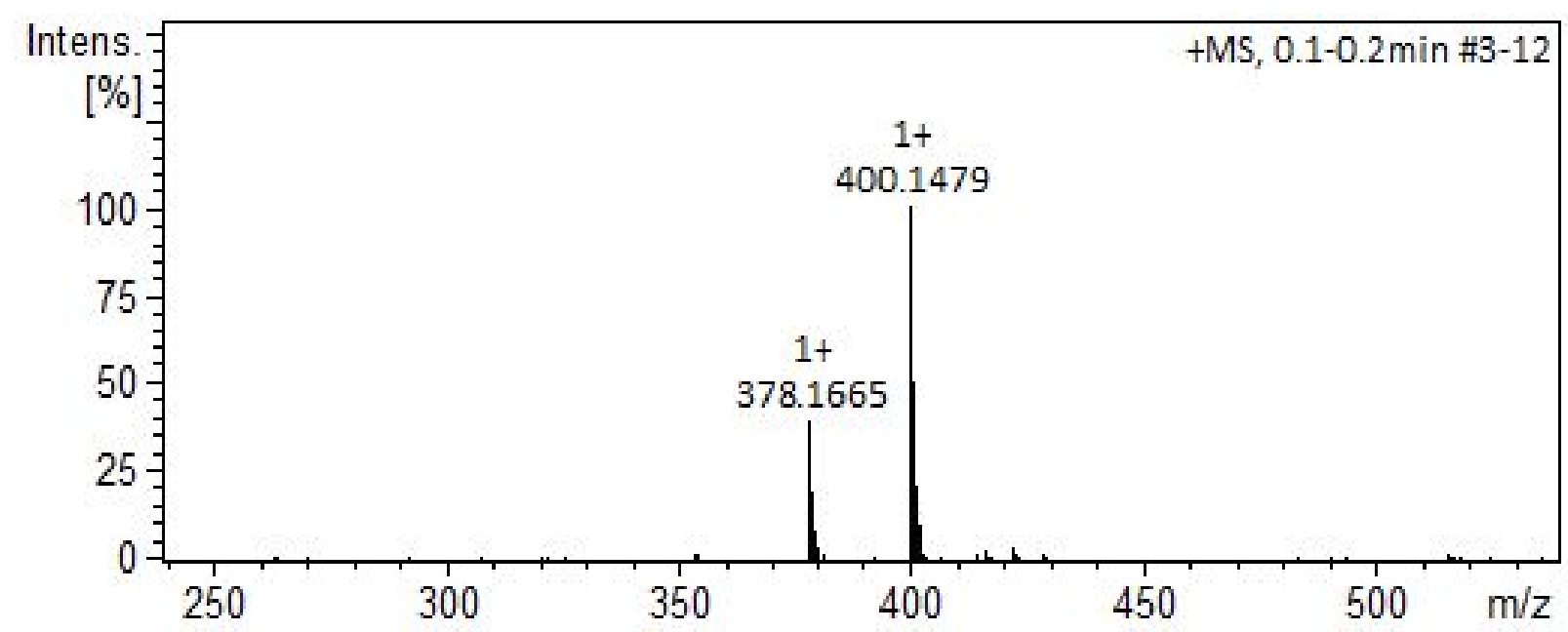

Figure S101. HRMS of N-Cbz-Ala-Gly-Pro-OH (8) $\left(\right.$ calcd $\left.m / z 378.1659[\mathrm{M}+\mathrm{H}]^{+}\right)$.

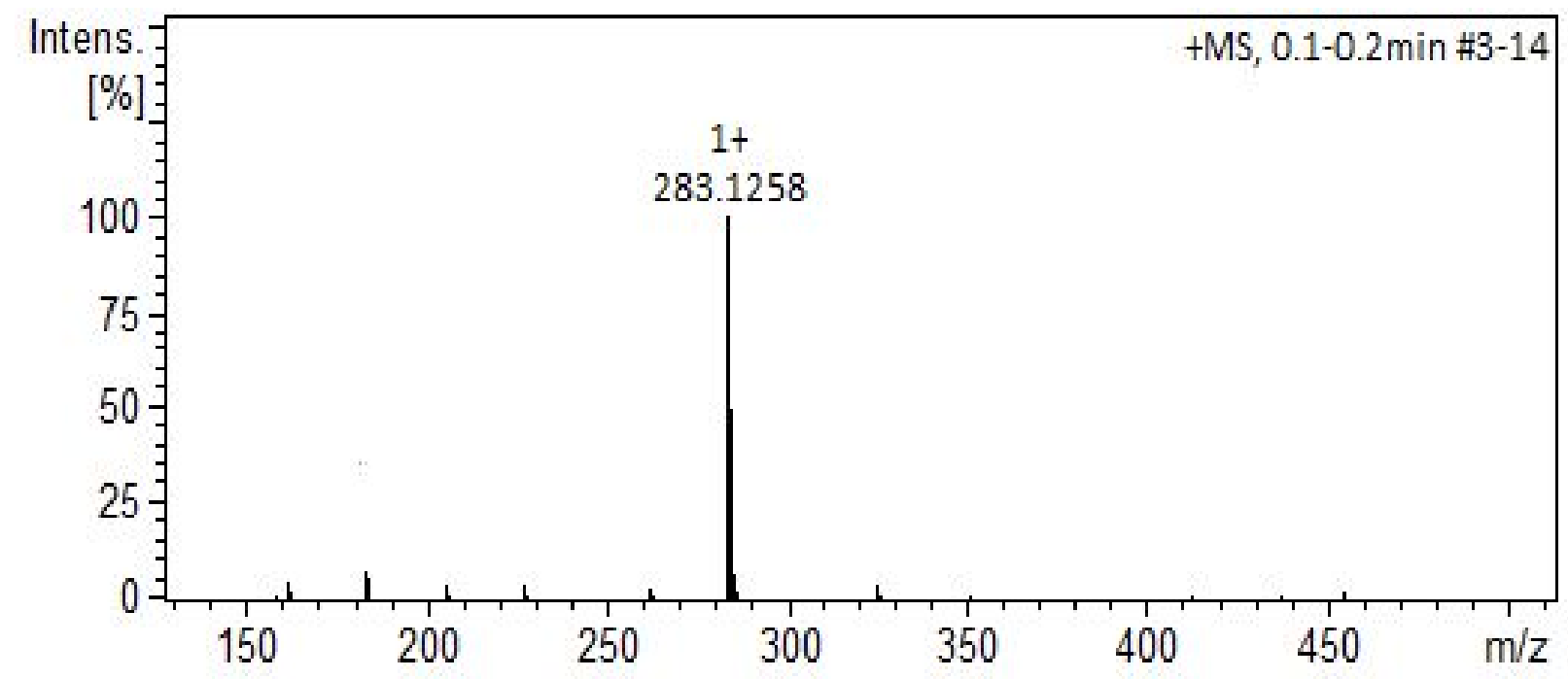

Figure S102. HRMS of N-Boc-Ala-Gly-OMe (10) $\left(\right.$ calcd $\left.m / z 283.1264[\mathrm{M}+\mathrm{Na}]^{+}\right)$. 


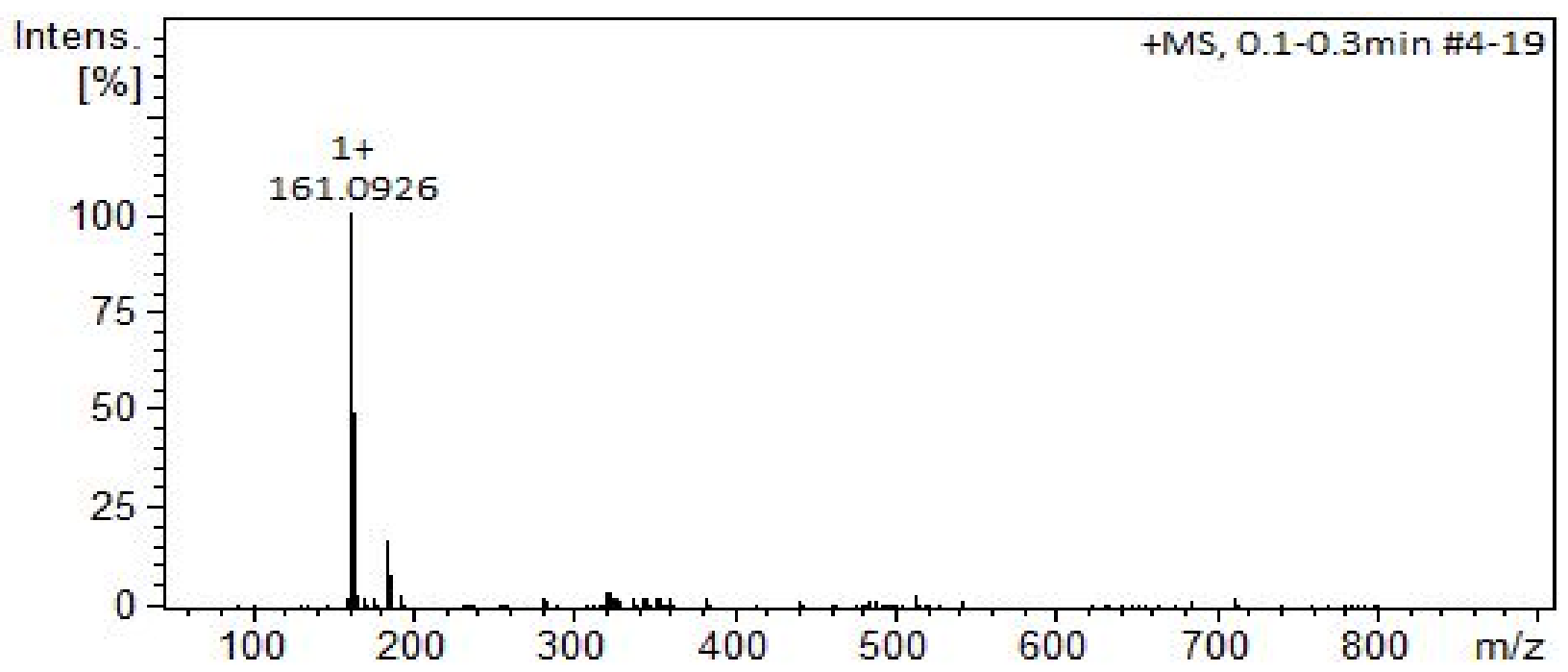

Figure S103. HRMS of Ala-Gly-OMe (11) (calcd m/z $\left.161.0920[\mathrm{M}+\mathrm{H}]^{+}\right)$.

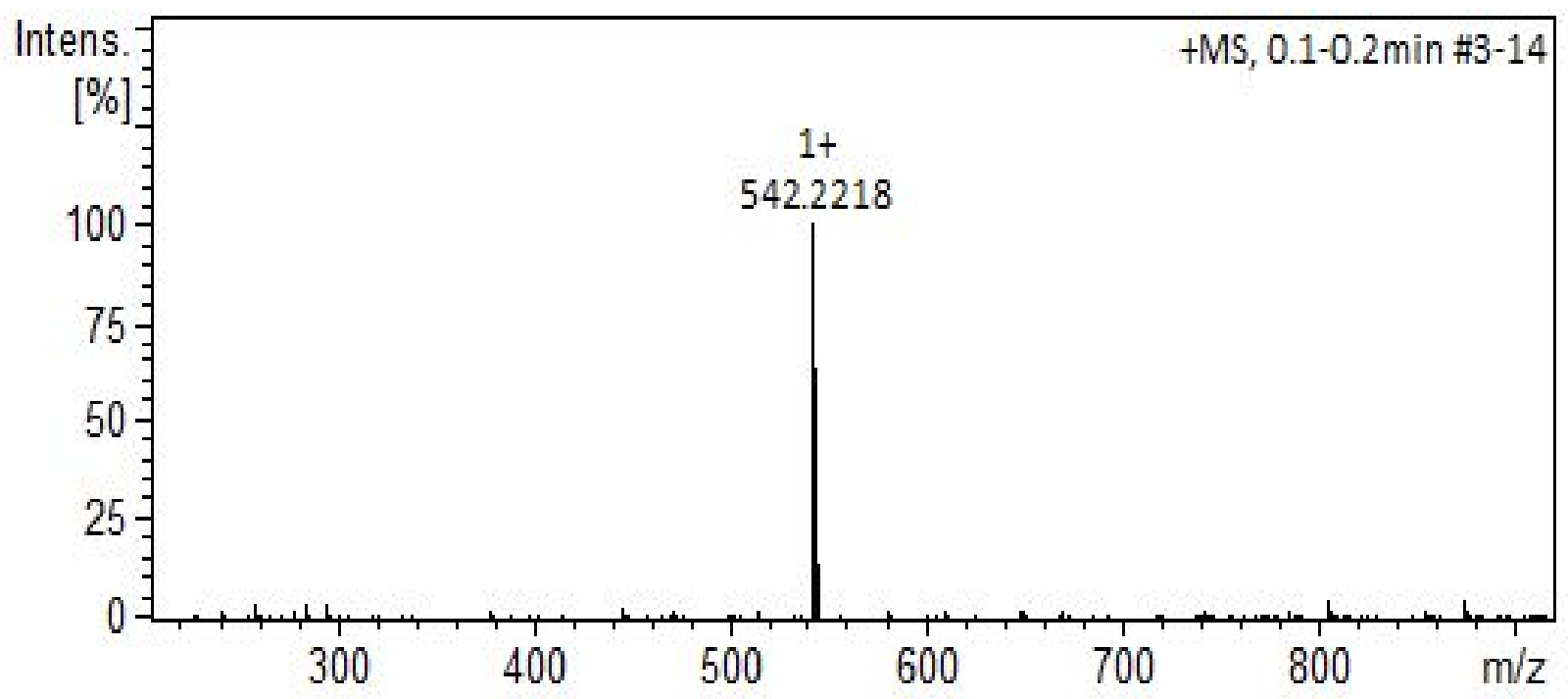

Figure S104. HRMS of N-Cbz-Ala-Gly-Pro-Ala-Gly-OMe (12) (calcd $\mathrm{m} / z \quad 542.2221$

$\left.[\mathrm{M}+\mathrm{Na}]^{+}\right)$. 


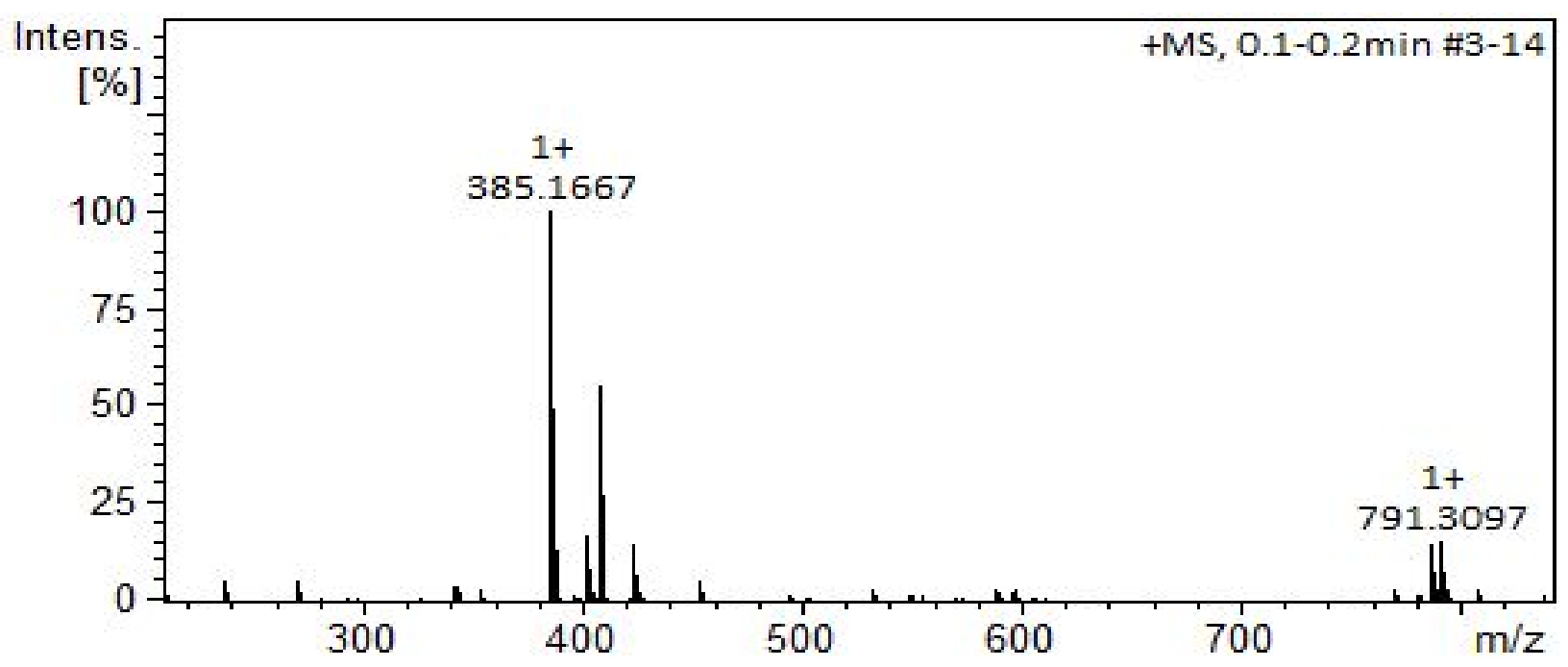

Figure S105. HRMS of N-Cbz -Ala-Phe-OMe (13) $\left(\operatorname{calcd} m / z \quad 385.1757[\mathrm{M}+\mathrm{H}]^{+}\right)$.

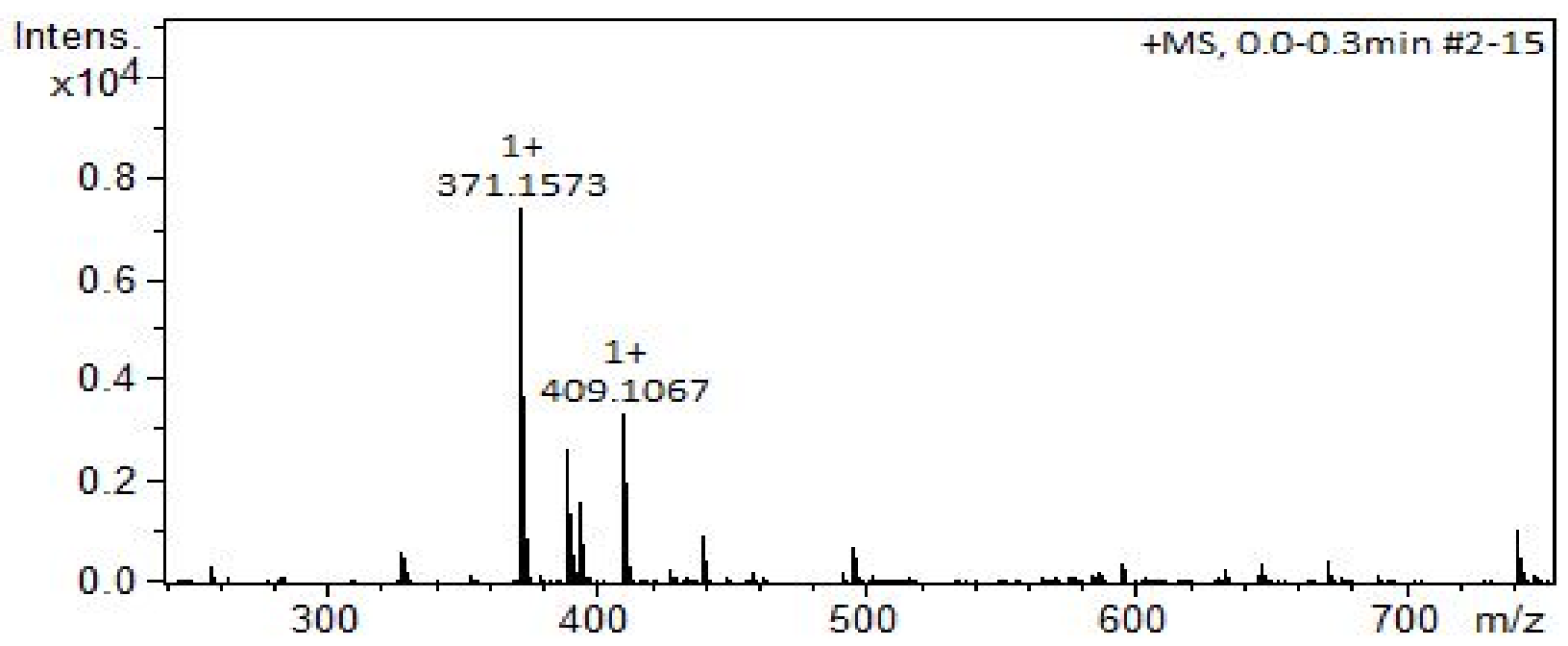

Figure S106. HRMS of N-Cbz -Ala-Phe-OH (14) (calcd m/z $\left.371.1601[\mathrm{M}+\mathrm{H}]^{+}\right)$. 


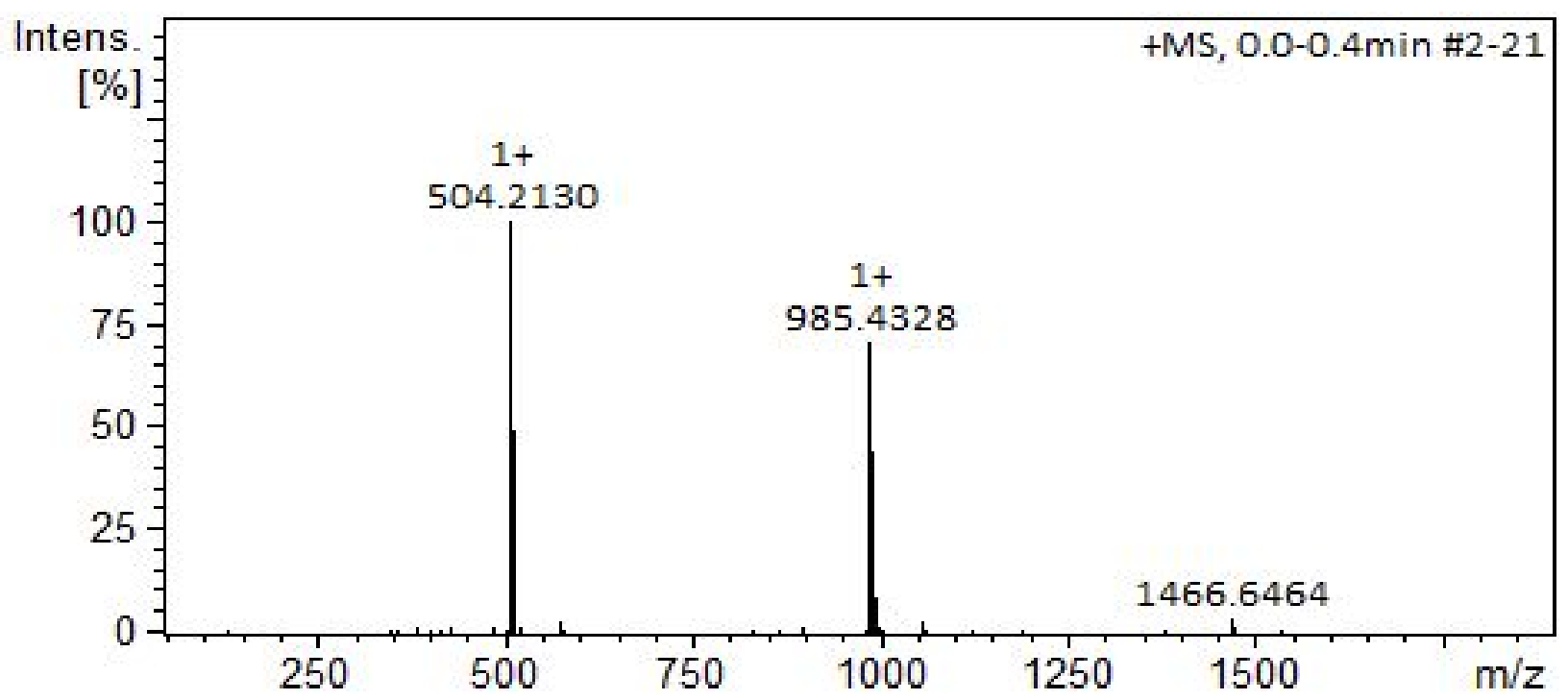

Figure S107. HRMS of N-Cbz -Ala-Phe-Pro-OMe (15) (calcd m/z $504.2105[\mathrm{M}+\mathrm{Na}]^{+}$).

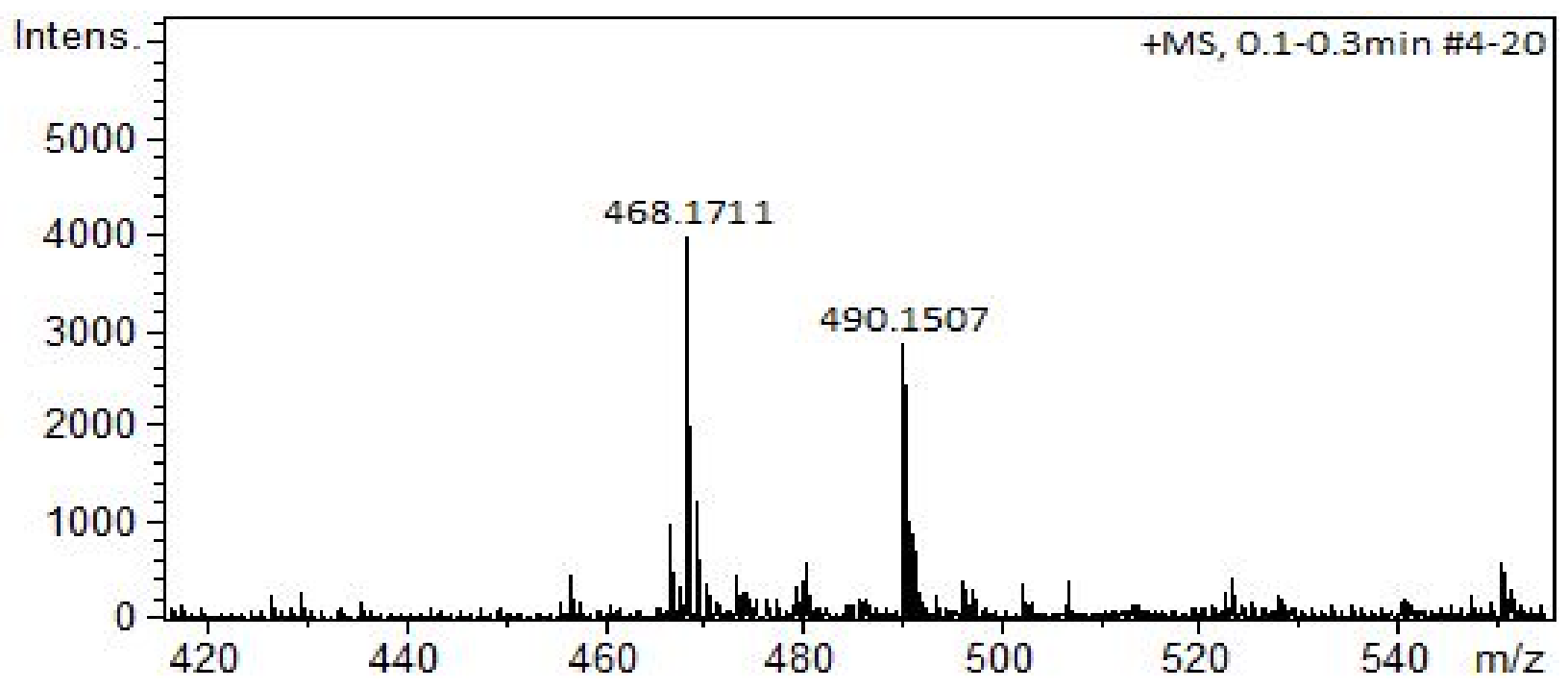

Figure S108. HRMS of N-Cbz -Ala-Phe-Pro-OH (16) (calcd m/z $\left.468.2129[\mathrm{M}+\mathrm{H}]^{+}\right)$. 


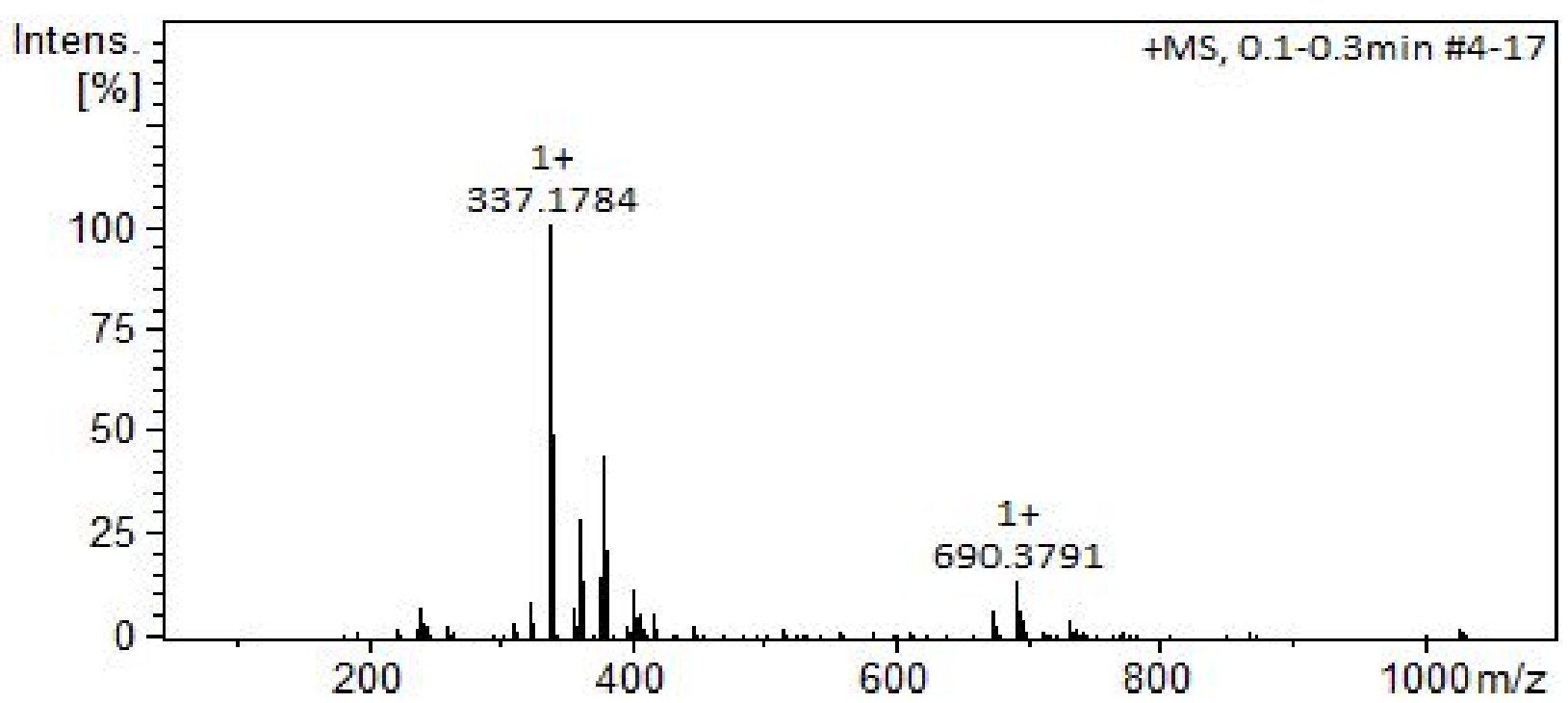

Figure S109. HRMS of Boc-Phe-Gly-OMe (18) (calcd m/z $\left.337.1757[\mathrm{M}+\mathrm{H}]^{+}\right)$.

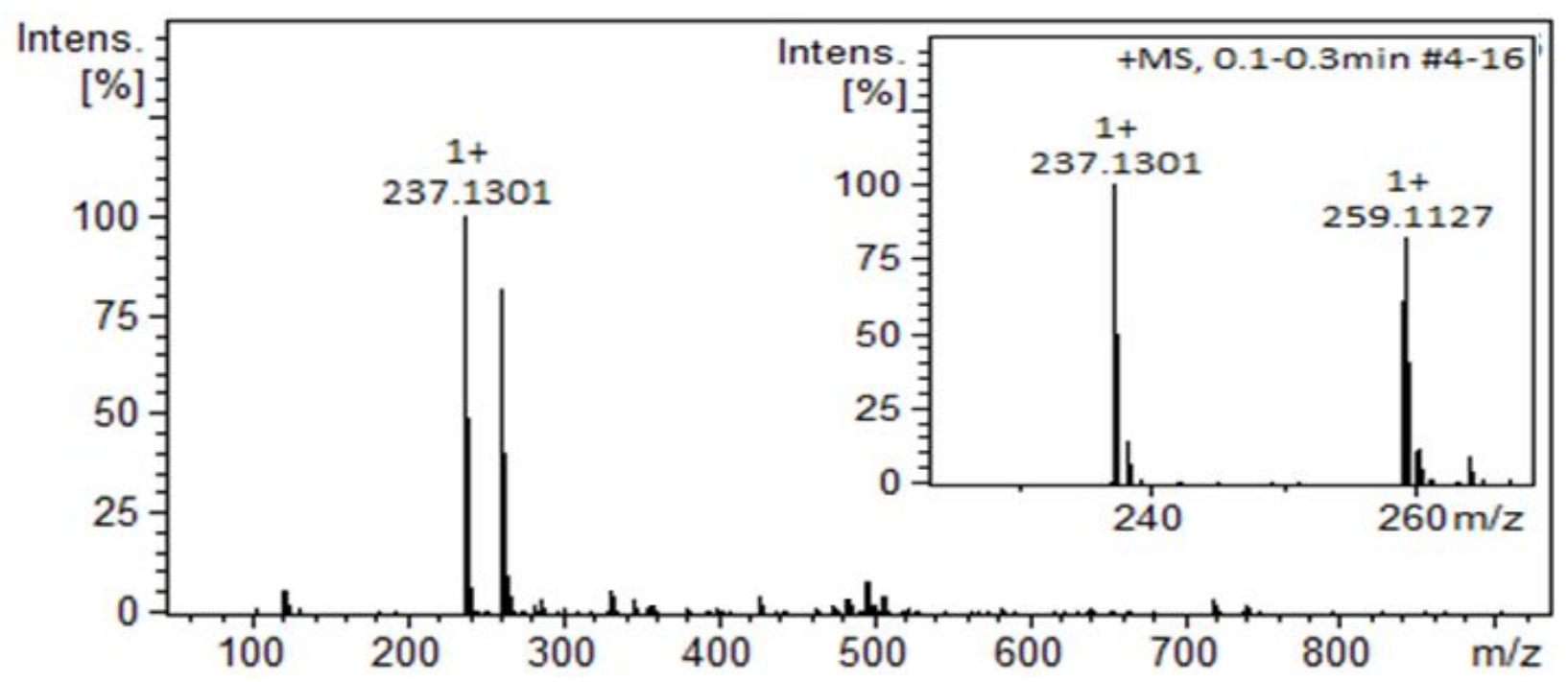

Figure S110. HRMS of Phe-Gly-OMe (19) (calcd $\left.m / z 237.1233[\mathrm{M}+\mathrm{H}]^{+}\right)$. 


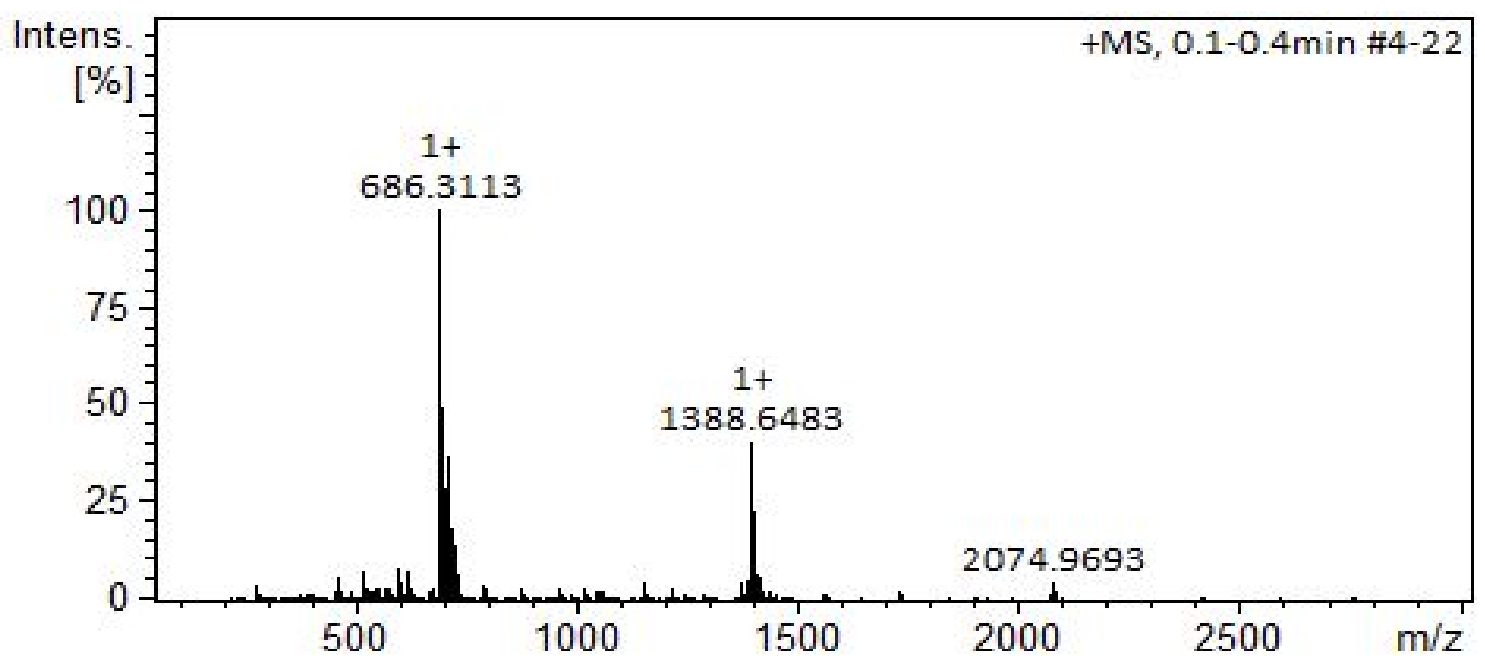

Figure S111. HRMS of N-Cbz-Ala-Phe-Pro-Phe-Gly-OMe (20) (calcd m/z 686.3184[M+H] $]^{+}$).

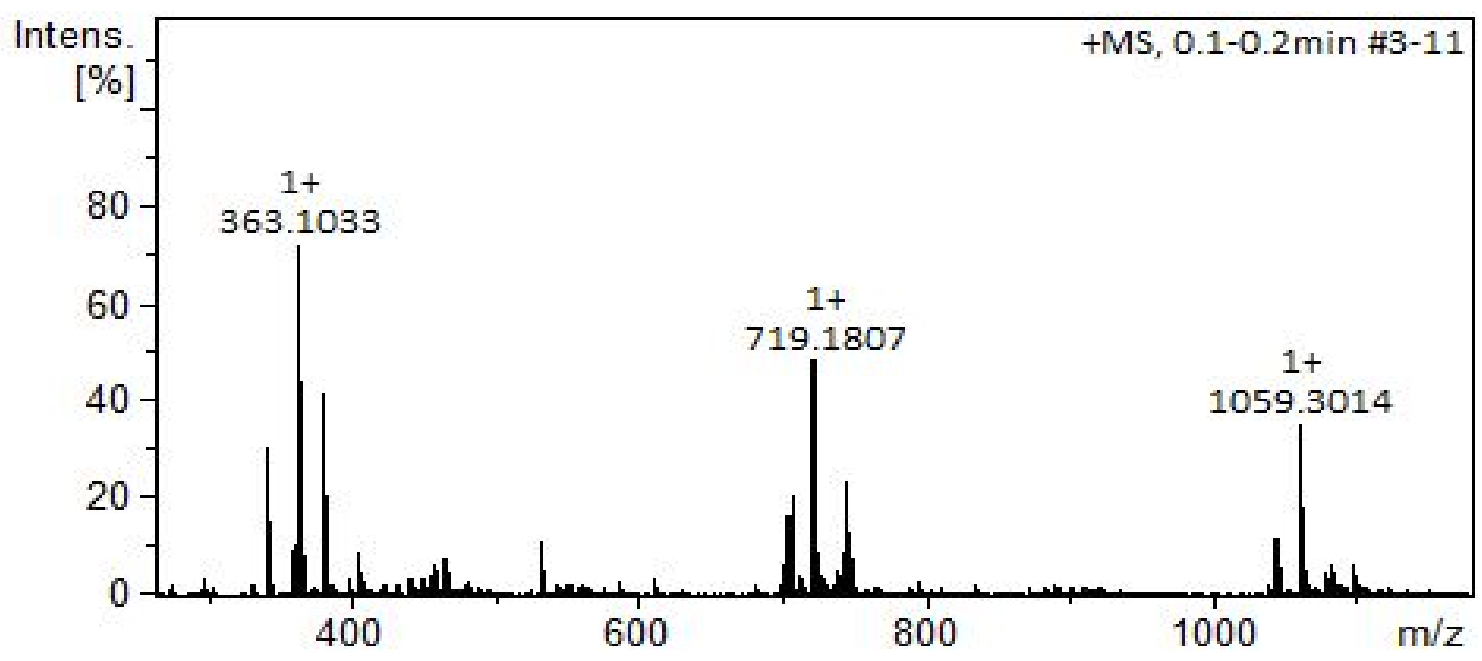

Figure S112. HRMS of N-Cbz -Met-Gly-OH (21) (calcd $\left.m / z 363.0985[\mathrm{M}+\mathrm{Na}]^{+}\right)$. 


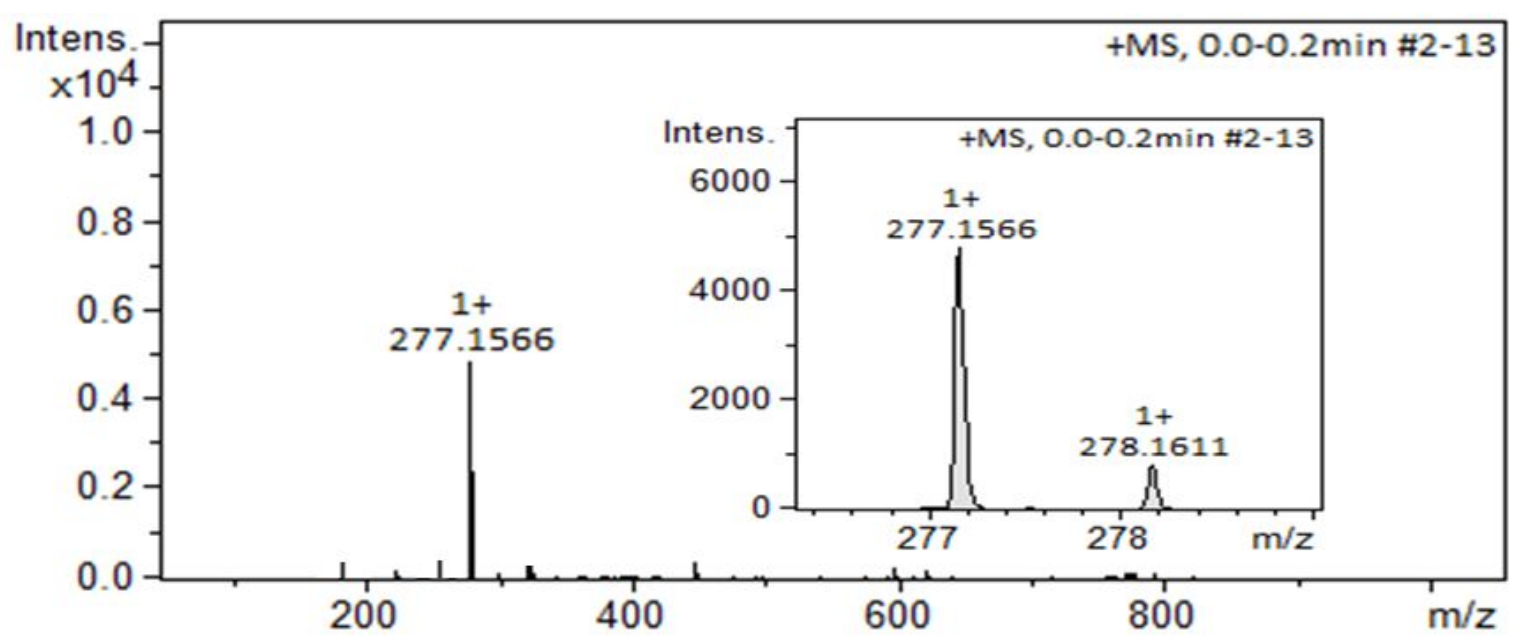

Figure S113. HRMS of Pro-Phe-OMe (22) (calcd $\left.m / z \quad 277.1546[\mathrm{M}+\mathrm{H}]^{+}\right)$.

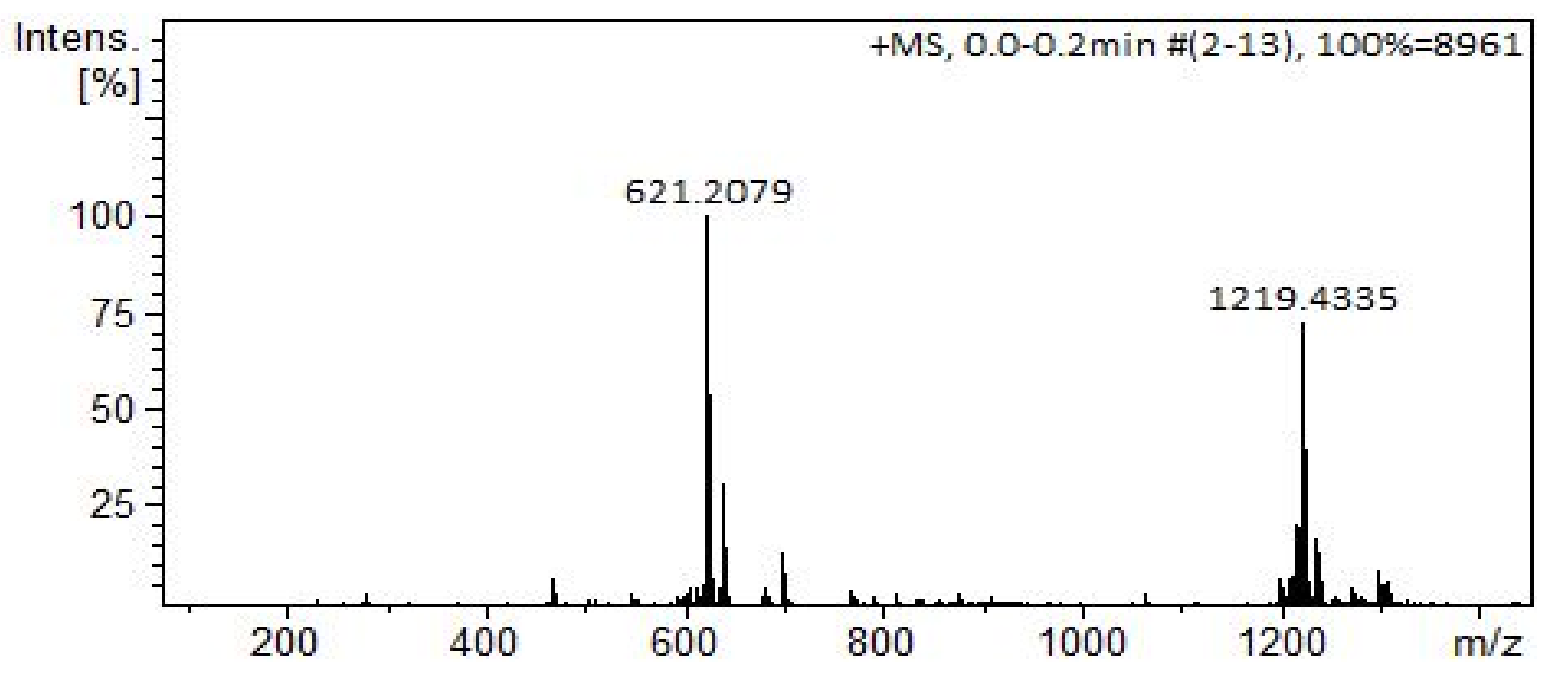

Figure S114. HRMS of N-Cbz -Met-Gly-Pro-Phe-OMe (23) (calcd m/z 621.2353 [M+Na] $]^{+}$). 


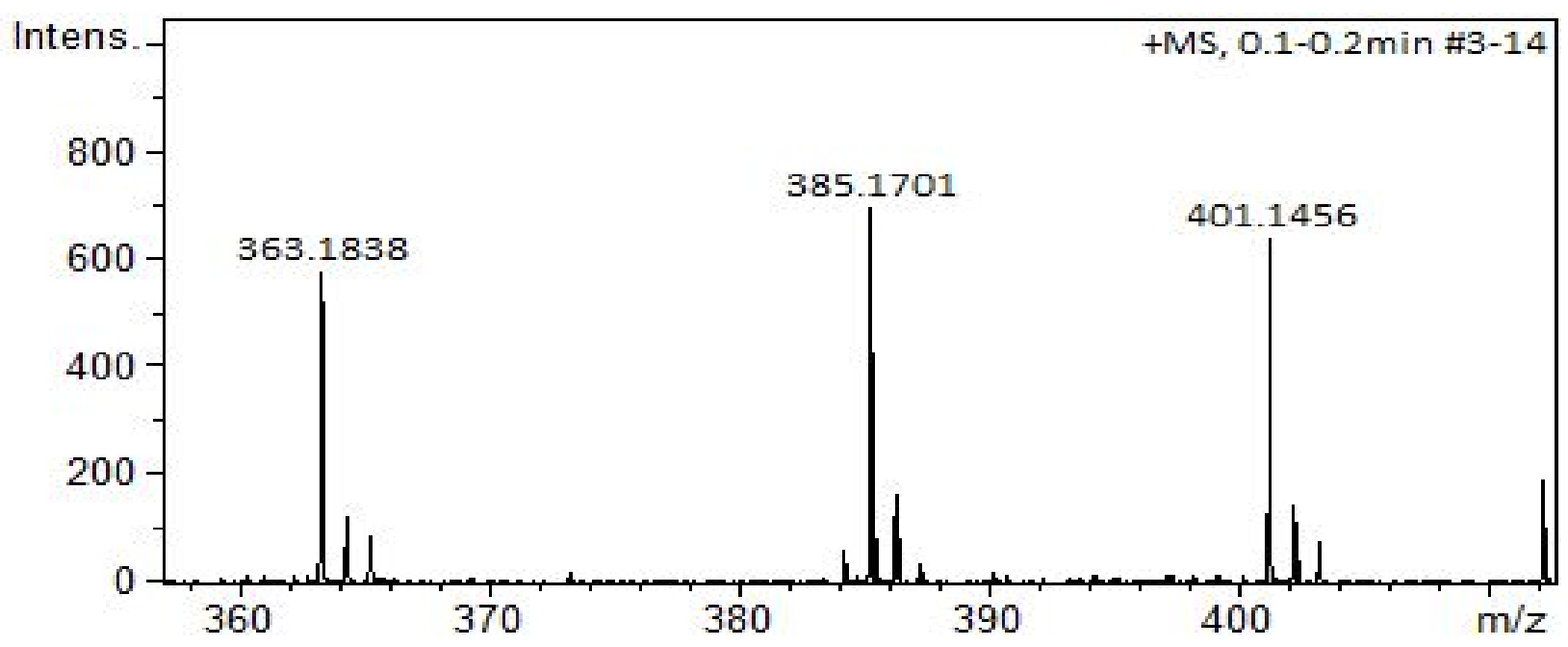

Figure S115. HRMS of N-Boc-Pro-Phe-OH (24) (calcd m/z $\left.385.1733[\mathrm{M}+\mathrm{Na}]^{+}\right)$.

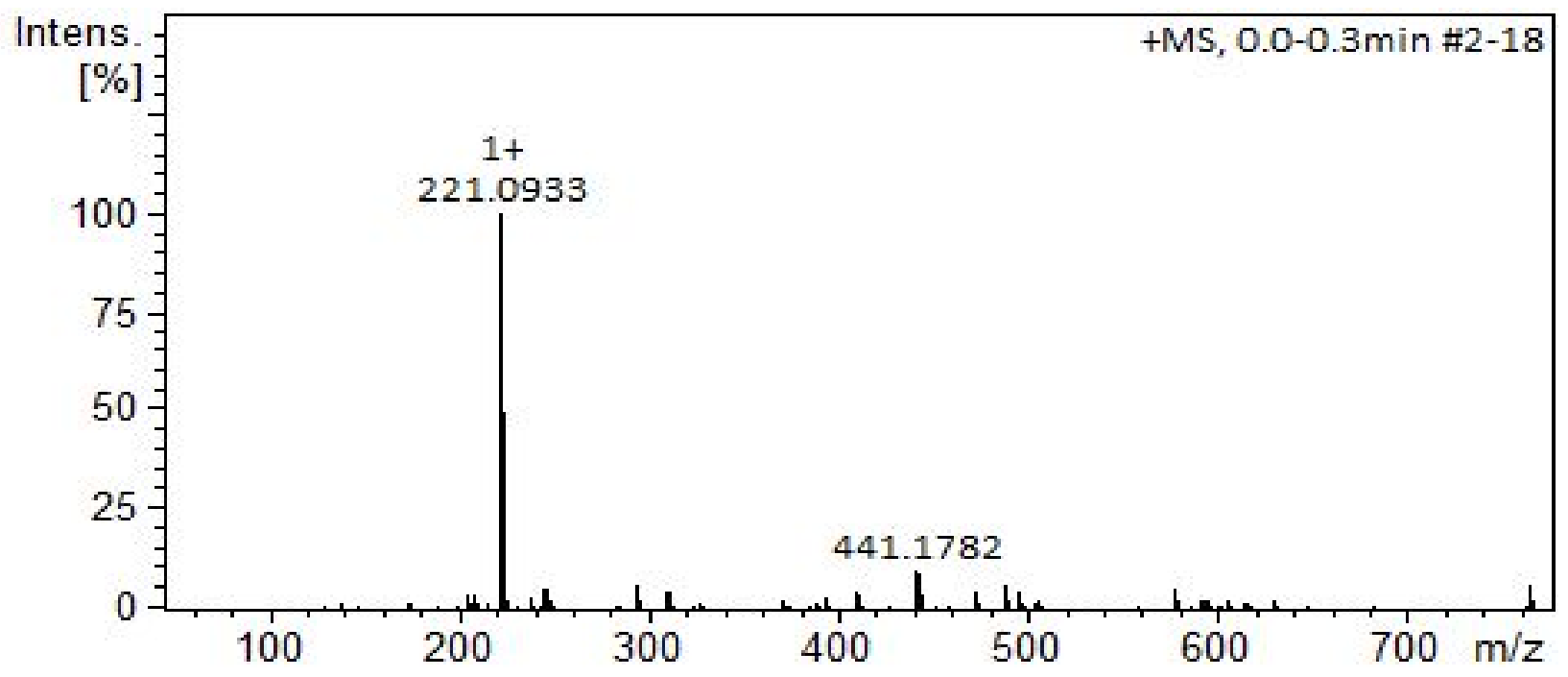

Figure S116. HRMS of Met-Gly-OMe (25) (calcd m/z 221.0954 [M+H] $]^{+}$). 


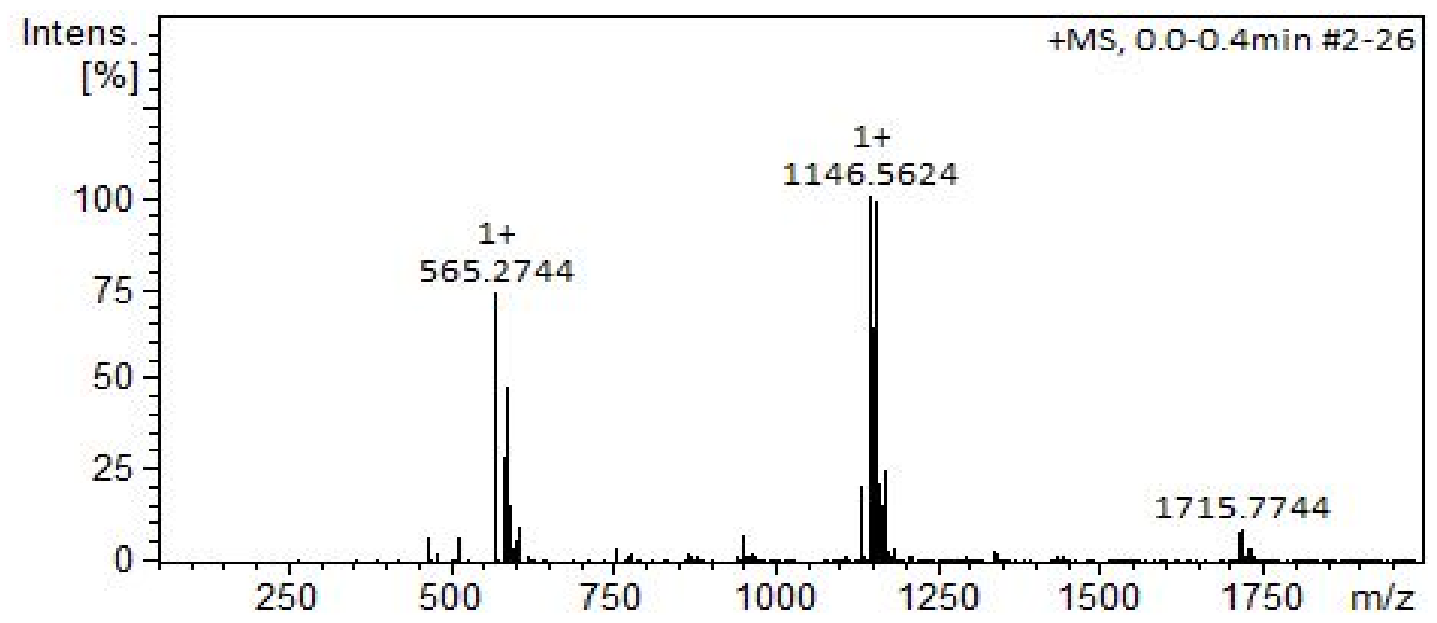

Figure S117. HRMS of N-Boc-Pro-Phe-Met-Gly-OMe (26) (calcd $\left.\mathrm{m} / z \quad 565.2690[\mathrm{M}+\mathrm{Na}]^{+}\right)$.

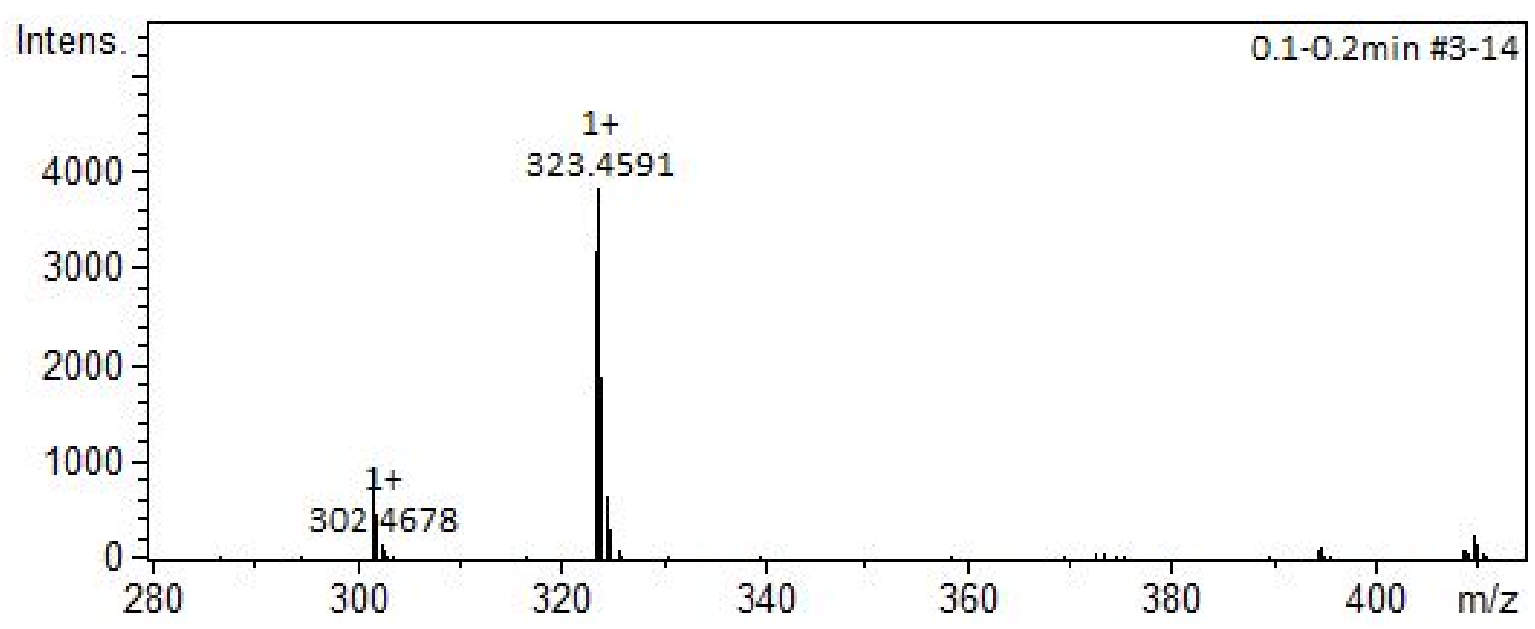

Figure S118. HRMS of Boc-Pro-Ala-OMe (27) (calcd m/z $\left.323.1577[\mathrm{M}+\mathrm{Na}]^{+}\right)$.

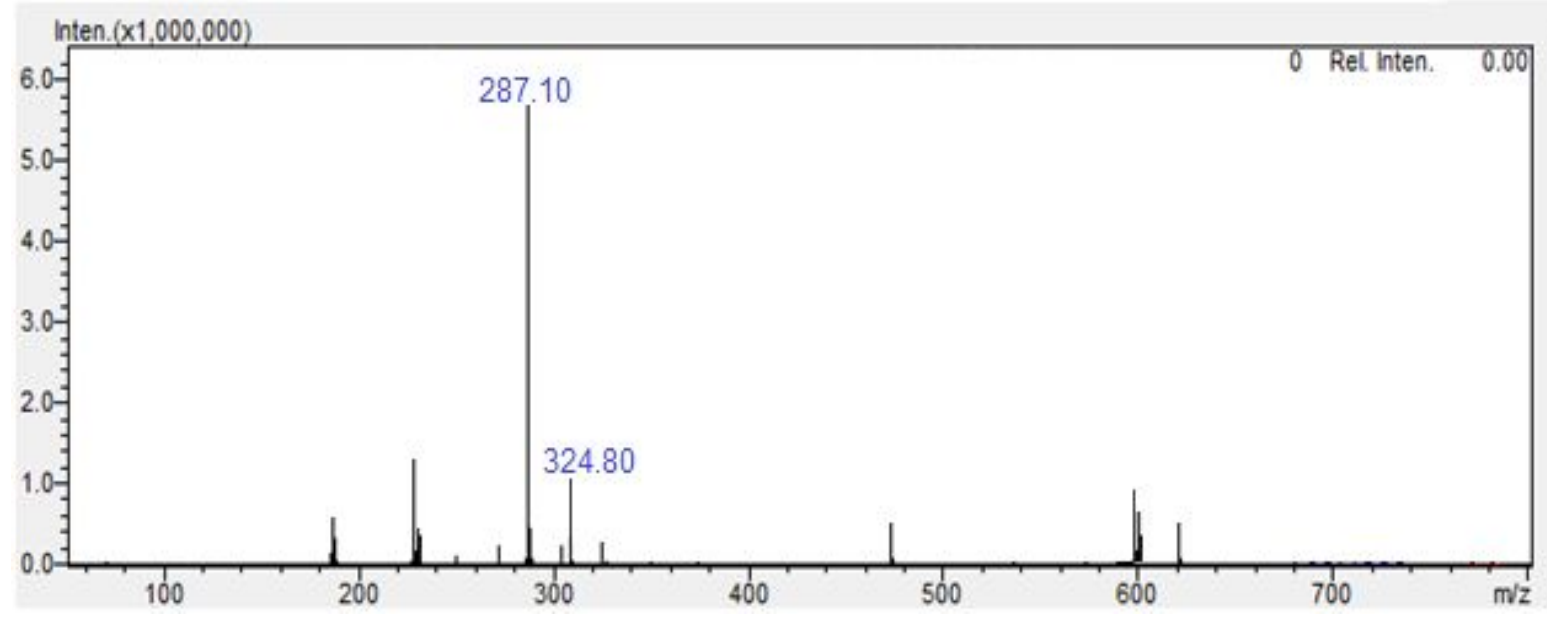

Figure S119. MS of Boc-Pro-Ala-OH (28) (calcd $\left.m / z 287.16[\mathrm{M}+\mathrm{H}]^{+}\right)$. 


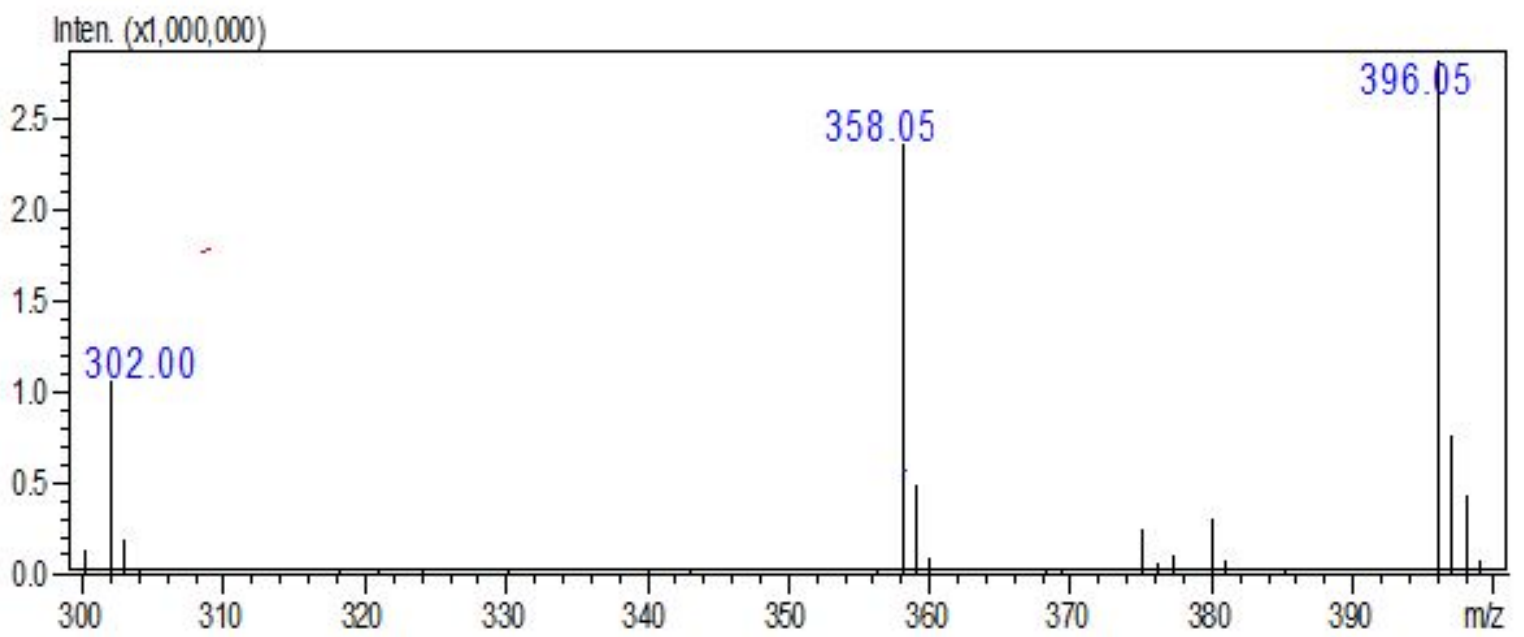

Figure S120. MS of Boc-Pro-Ala-GlyOMe (29) (calcd m/z $\left.358.19[\mathrm{M}+\mathrm{H}]^{+}\right)$.

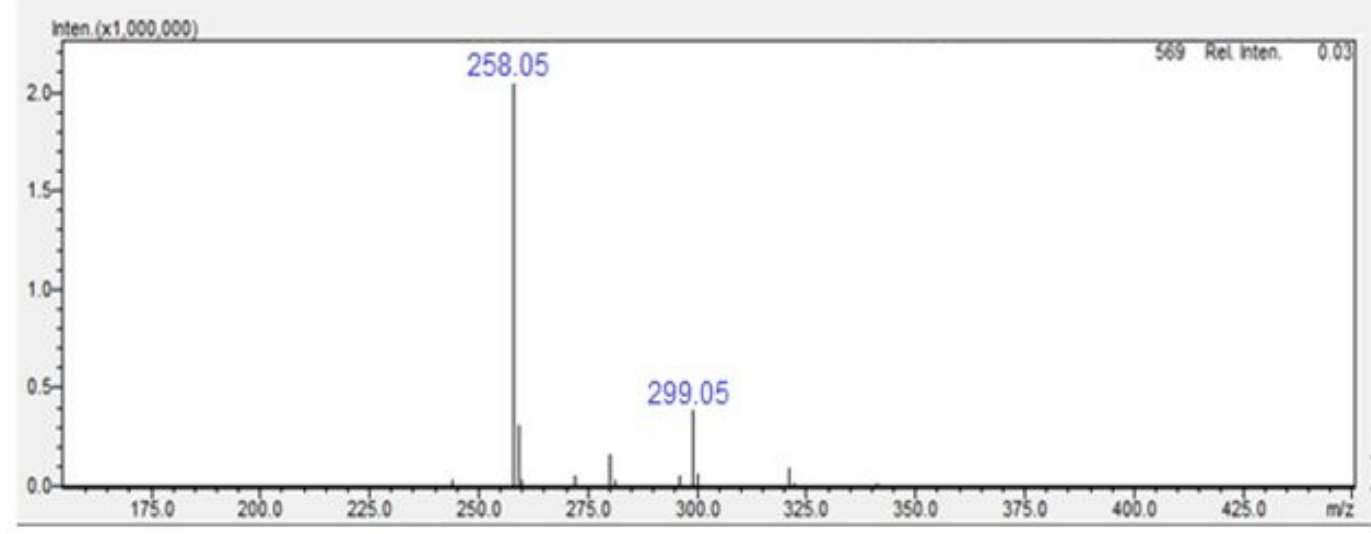

Figure S121. MS of Pro-Ala-Gly-OMe (30) (calcd $\left.m / z 258.14[\mathrm{M}+\mathrm{H}]^{+}\right)$.

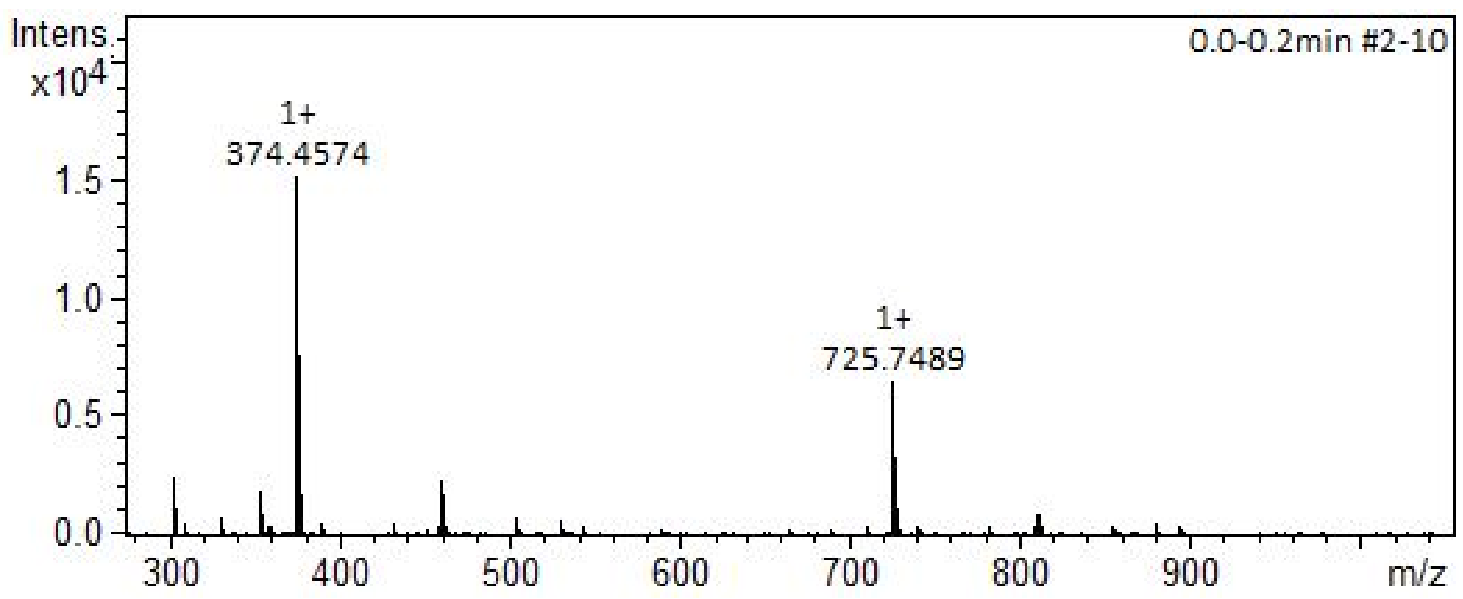

Figure S122. HRMS of N-Cbz-Ala-Gly-Gly-OMe (31) (calcd m/z $\left.374.1322[\mathrm{M}+\mathrm{Na}]^{+}\right)$. 


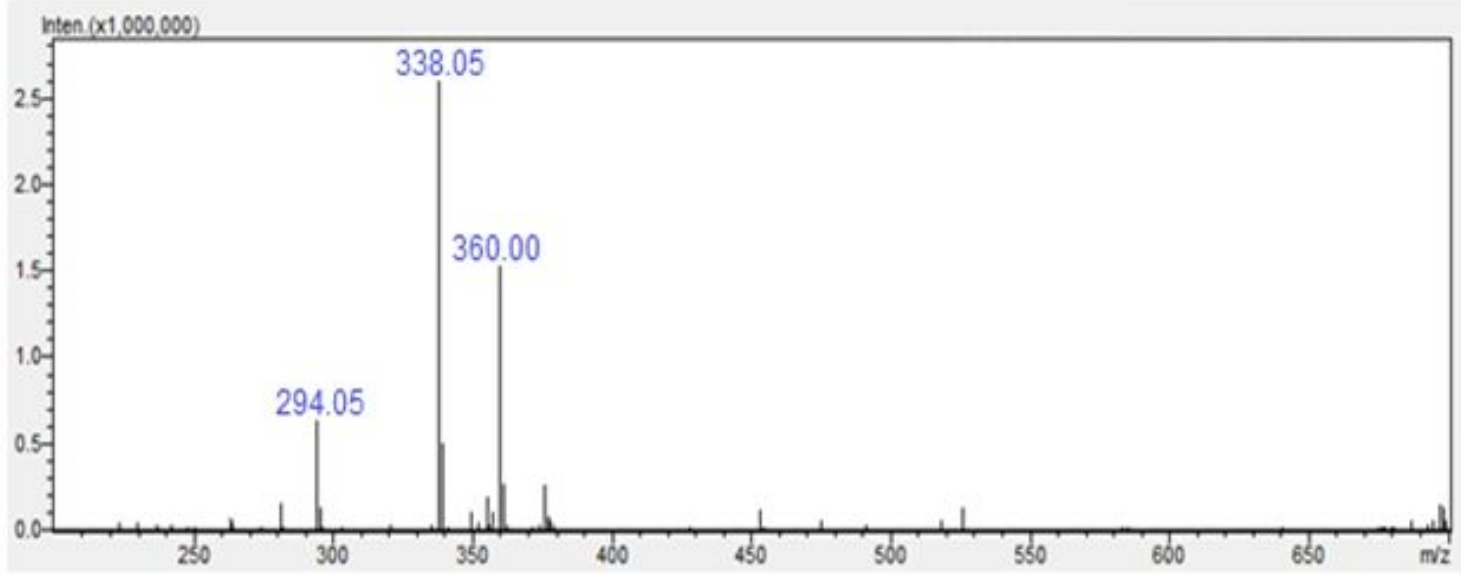

Figure S123. MS of N-Cbz-Ala-Gly-Gly-OH (32) (calcd $\left.m / z 338.13[\mathrm{M}+\mathrm{H}]^{+}\right)$.

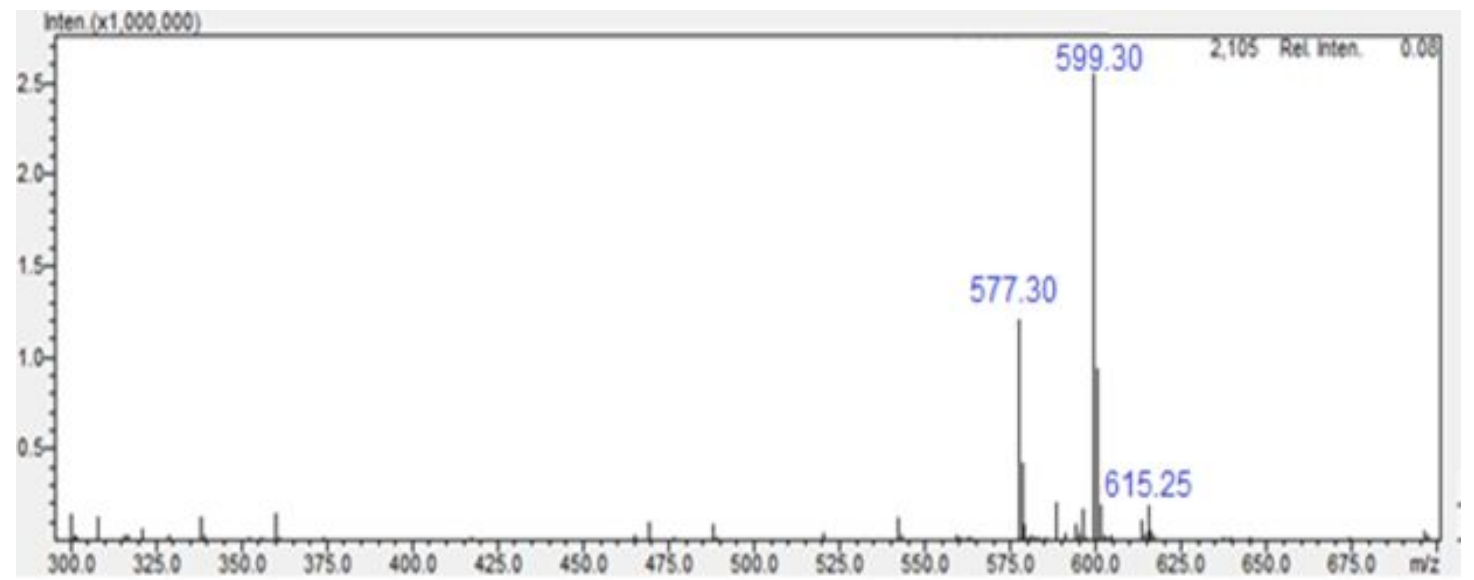

Figure S124. MS of N-Cbz-Ala-Gly-Gly-Pro-Ala-Gly-OMe (33) (calcd m/z $\left.577.26[\mathrm{M}+\mathrm{H}]^{+}\right)$. 


\section{IR Spectra:}

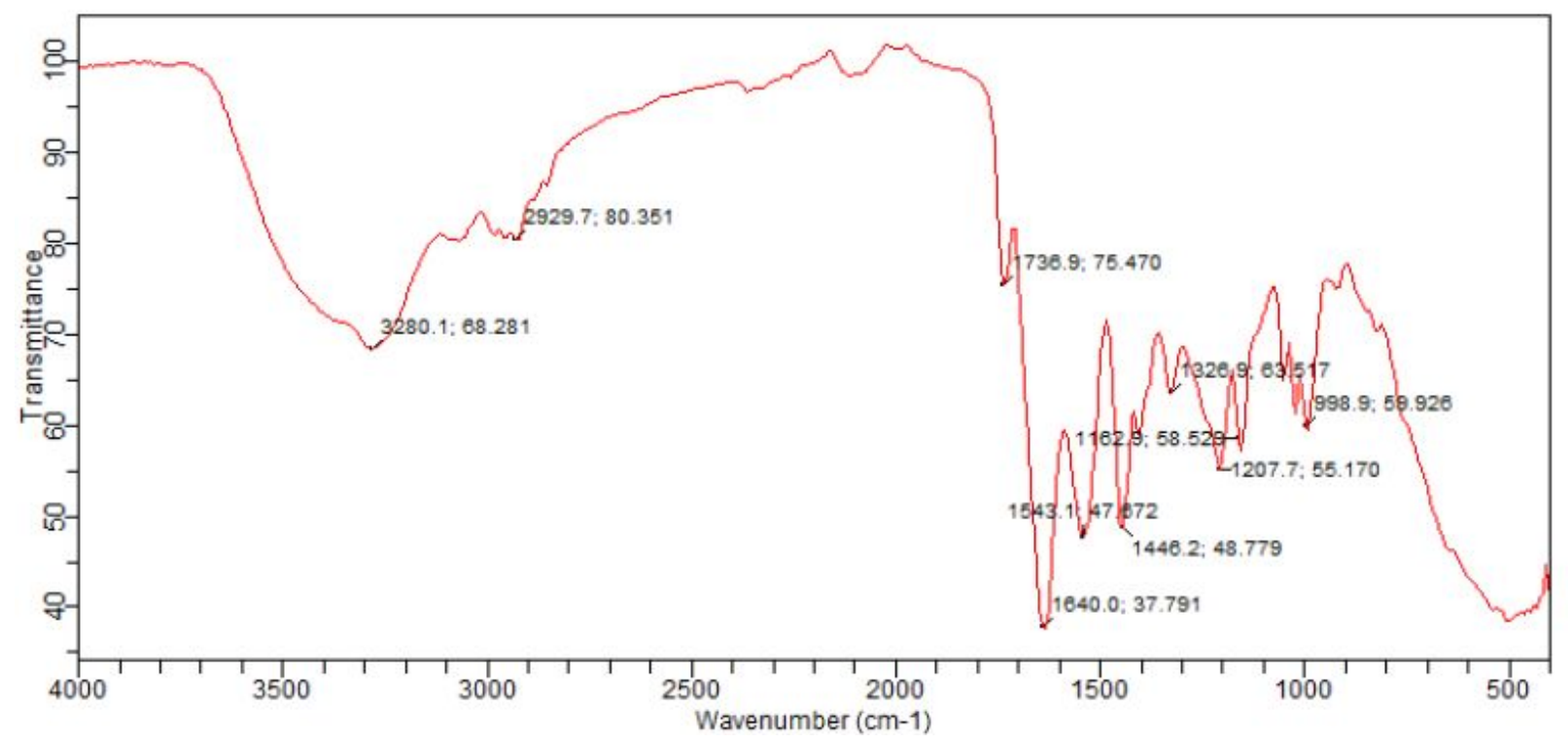

Figure S125. IR spectrum of compound 1.

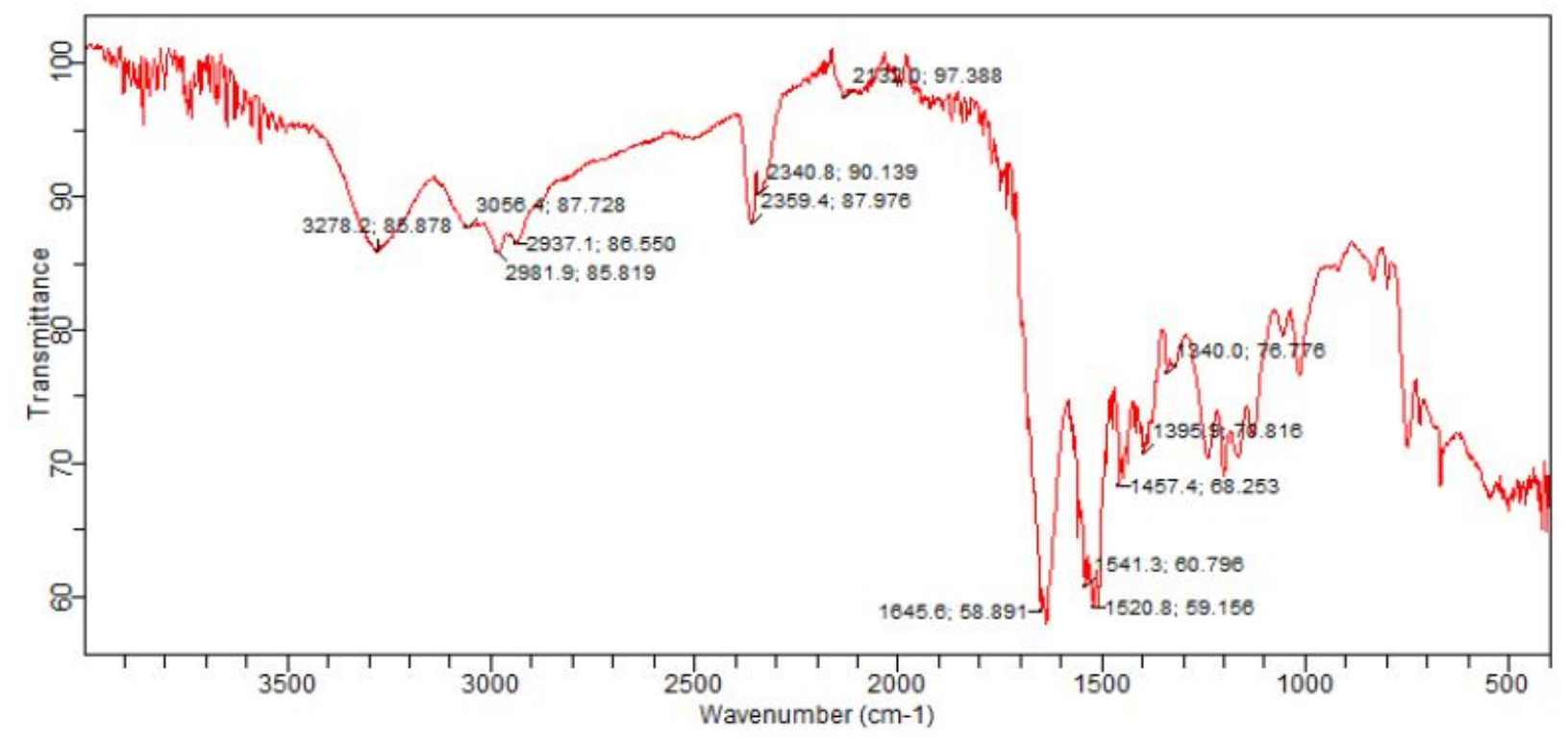

Figure S126. IR spectrum of compound 2. 


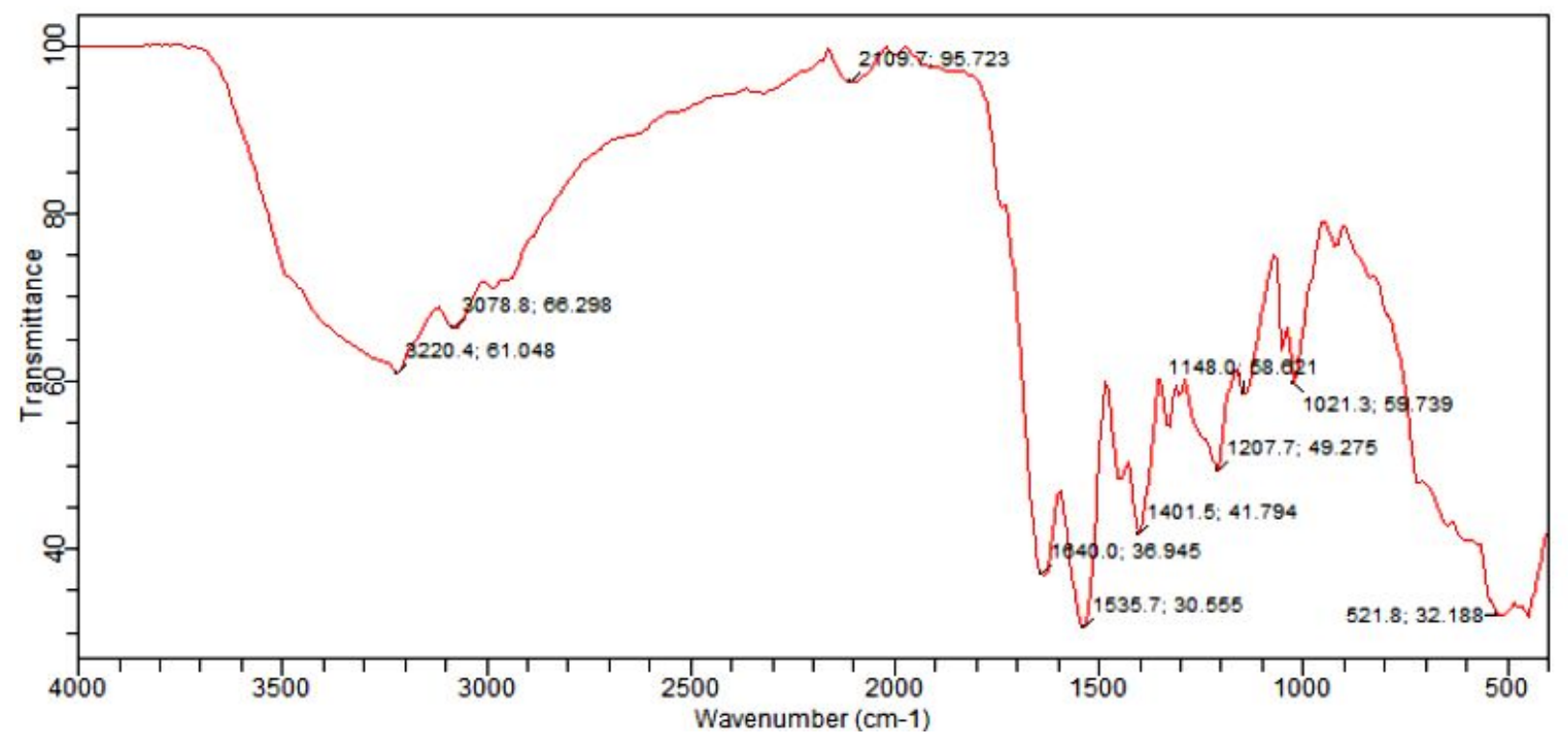

Figure S127. IR spectrum of compound 3.

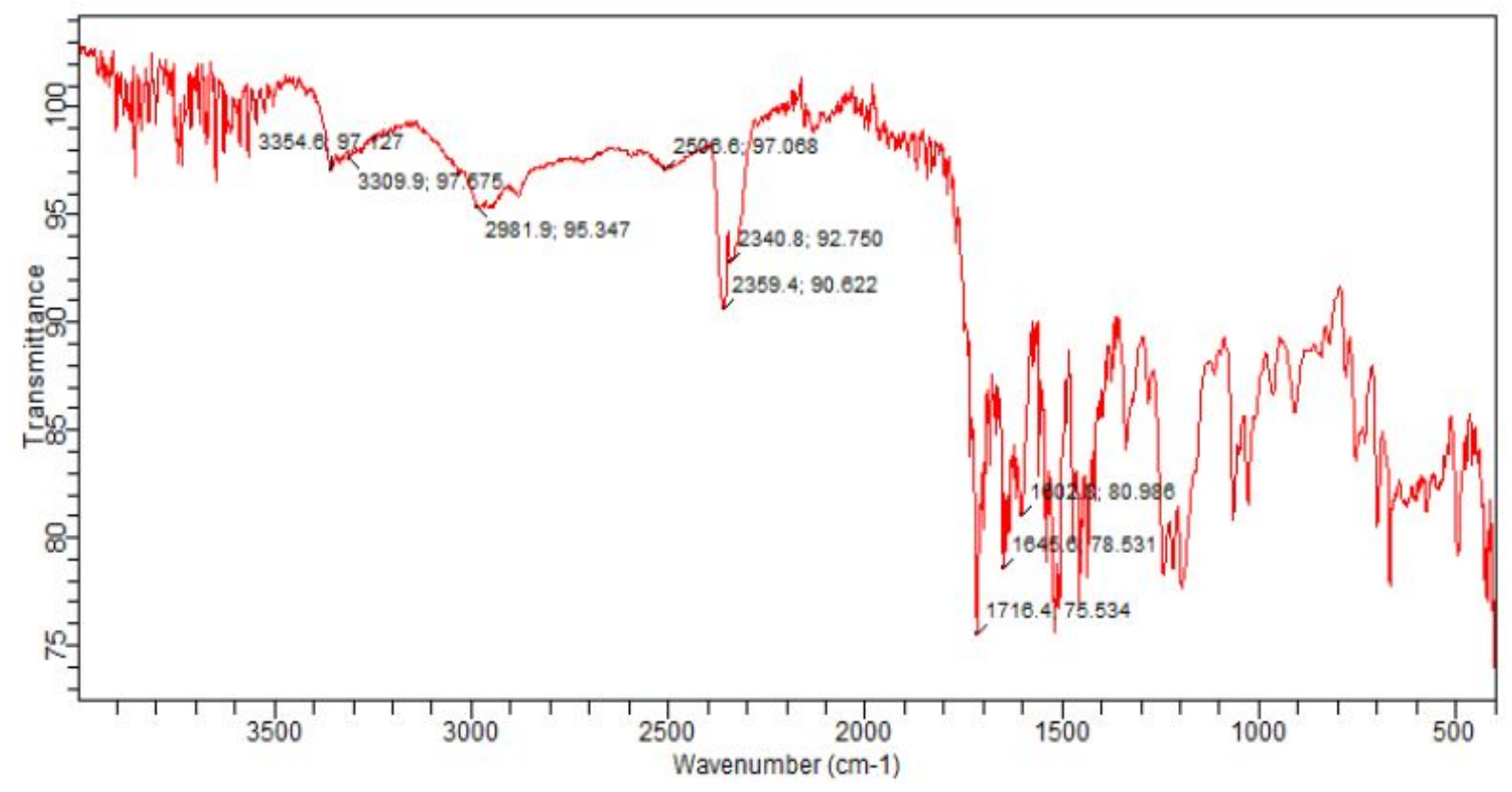

Figure S128. IR spectrum of compound 5. 


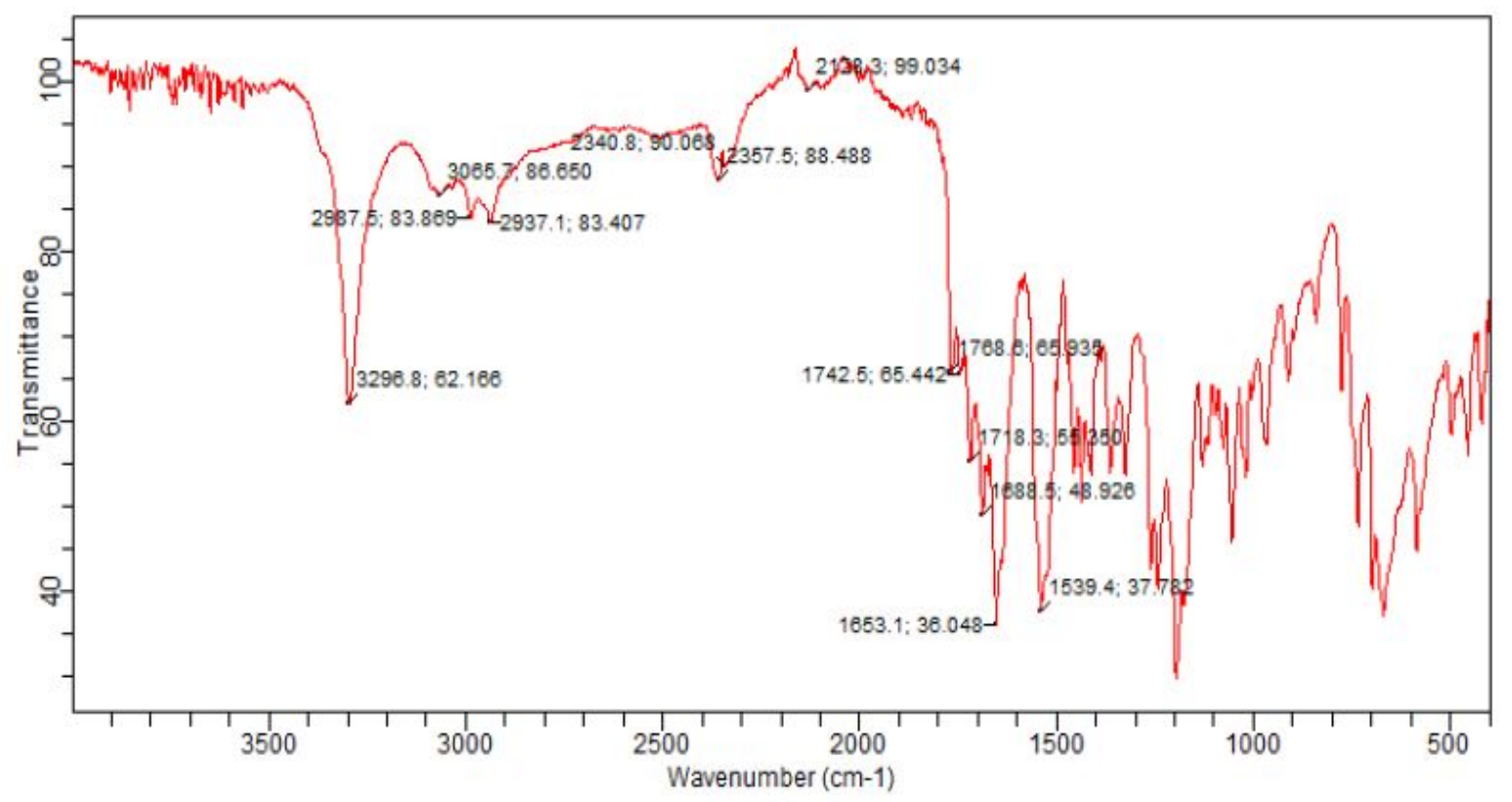

Figure S129. IR spectrum of compound 6.

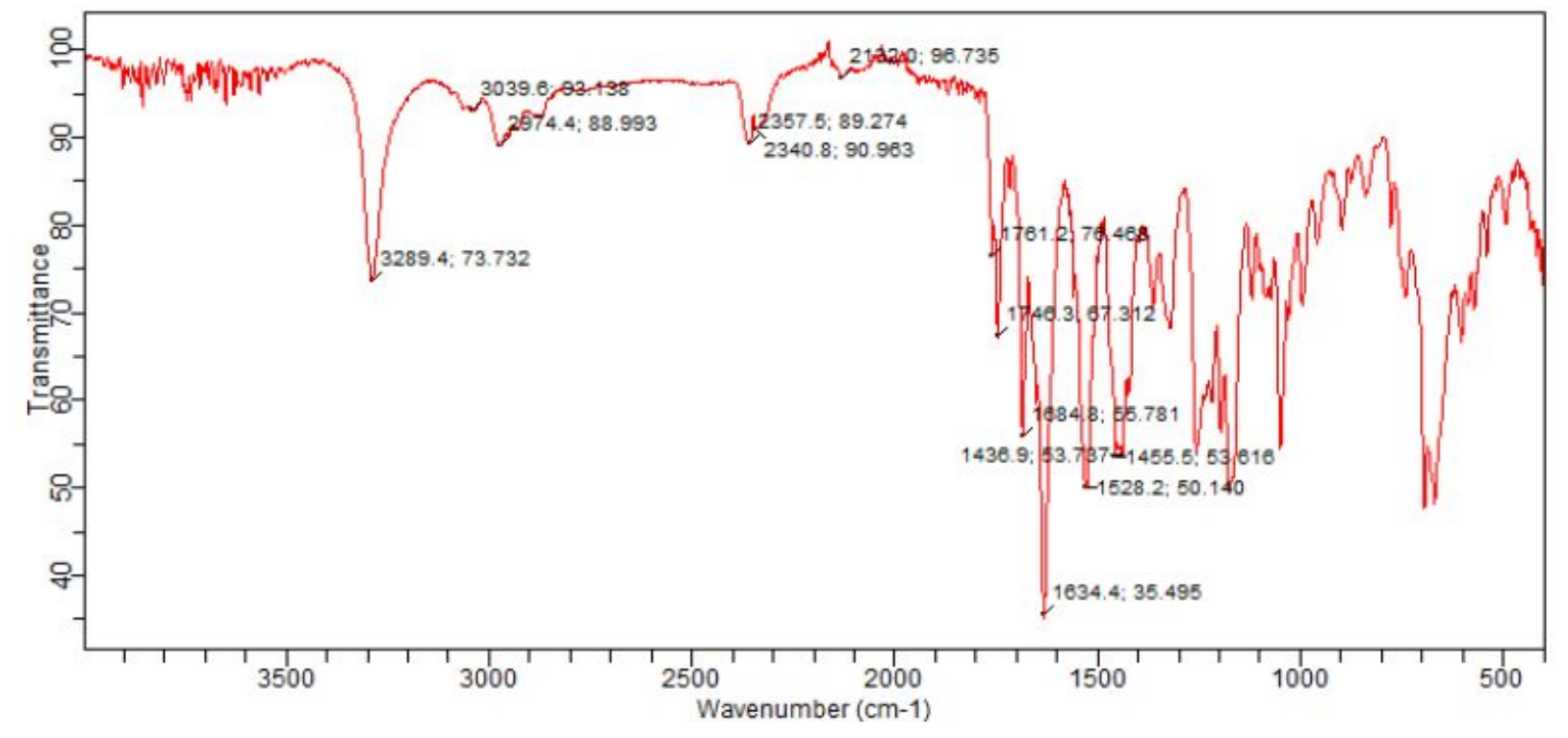

Figure S130. IR spectrum of compound 7. 


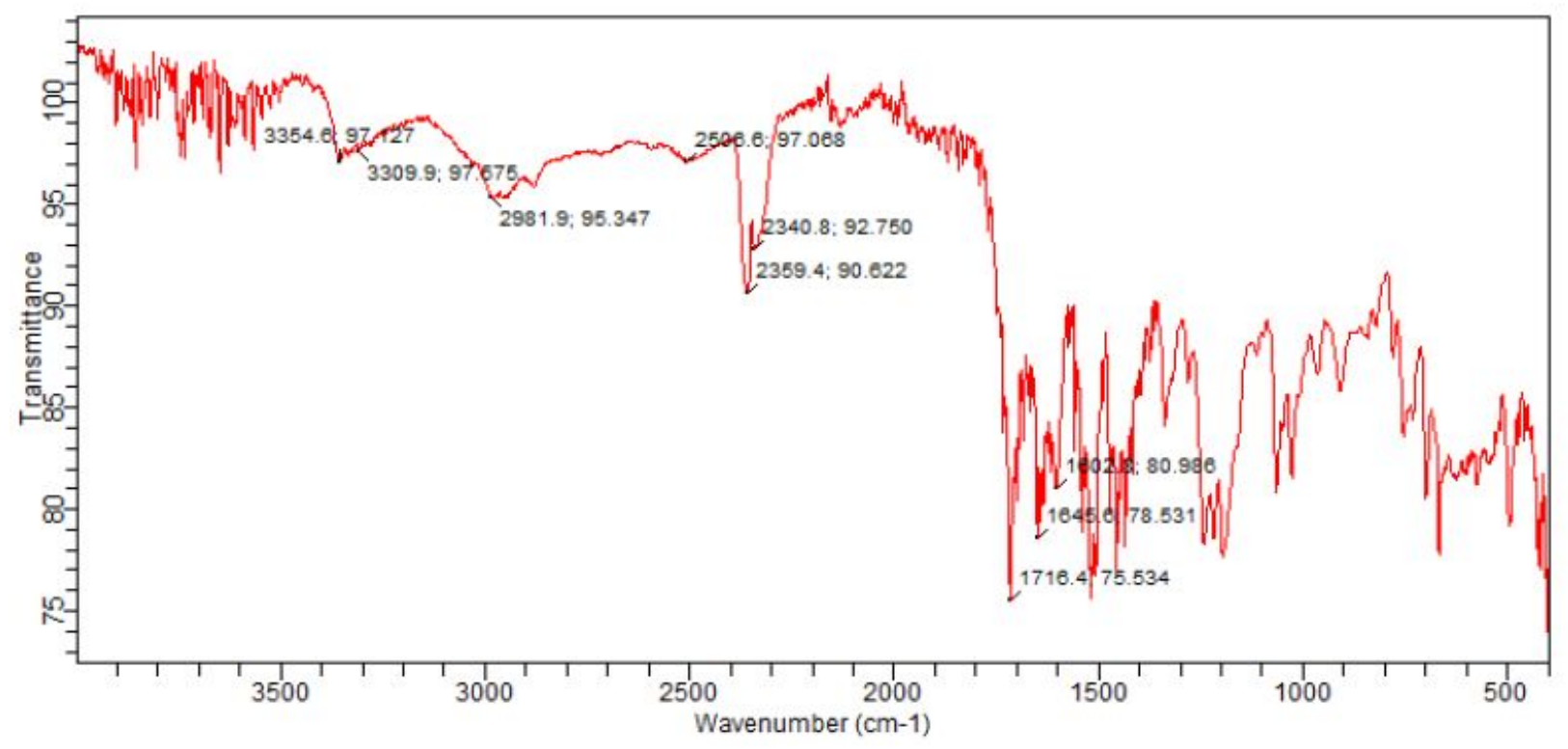

Figure S131. IR spectrum of compound 8.

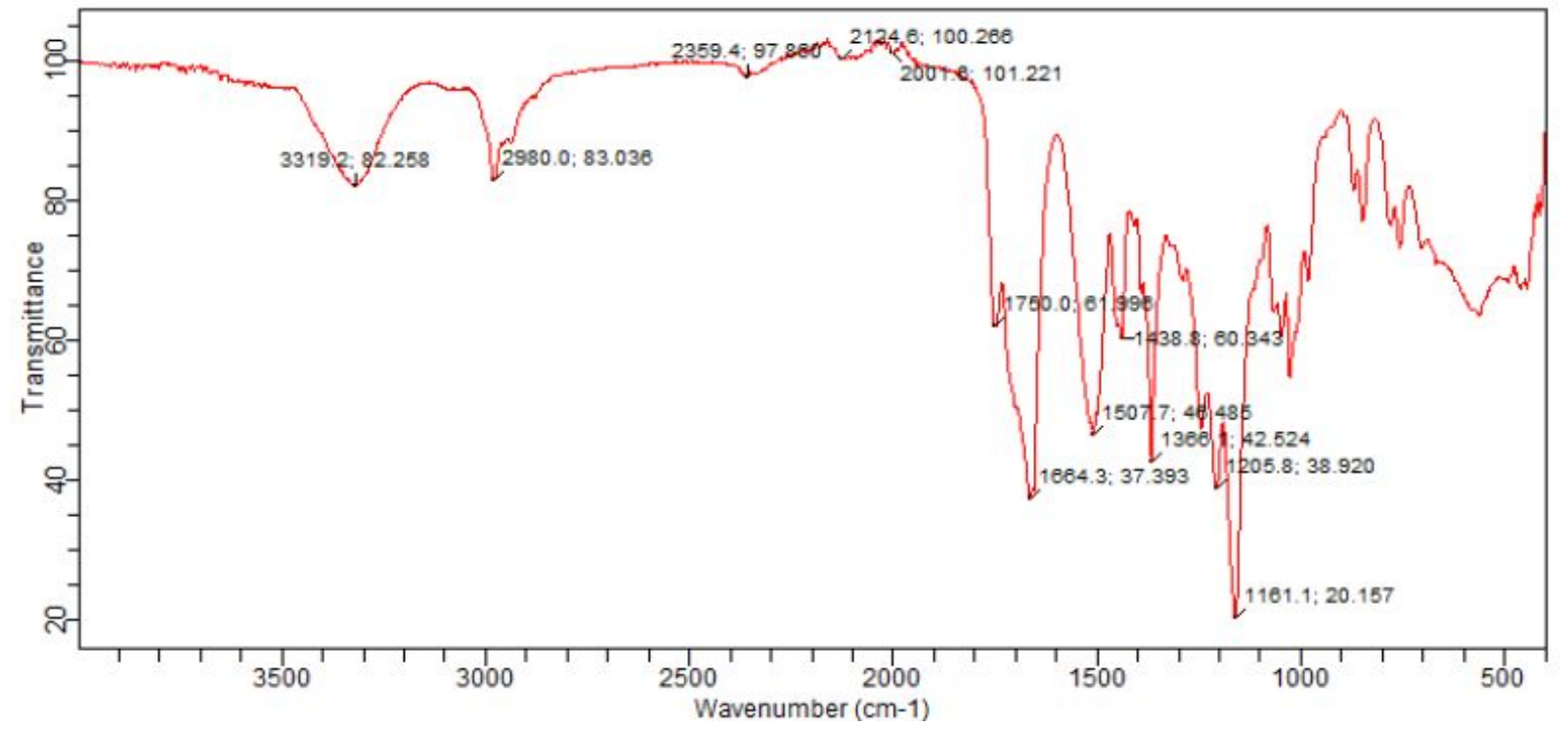

Figure S132. IR spectrum of compound 10. 


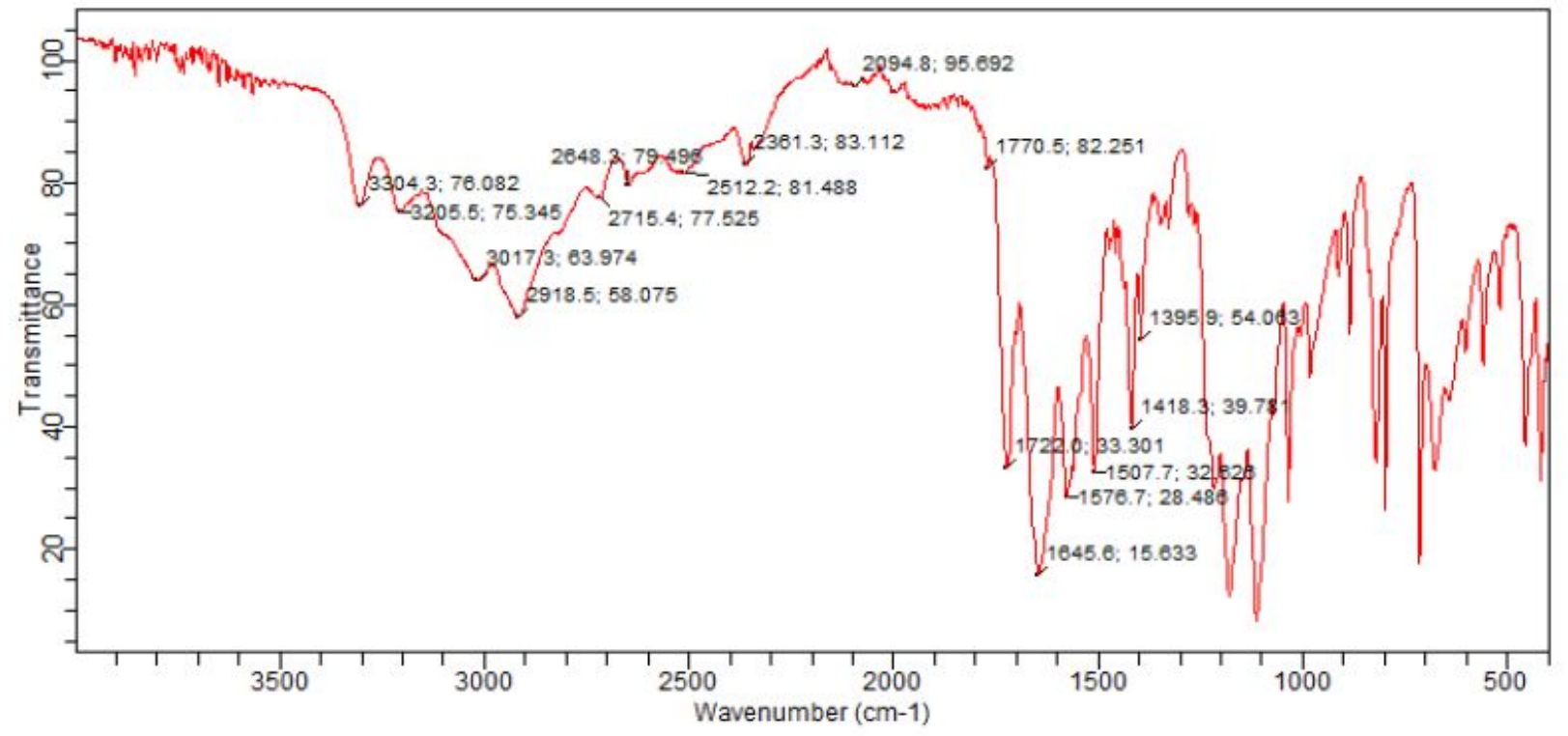

Figure S133. IR spectrum of compound 11.

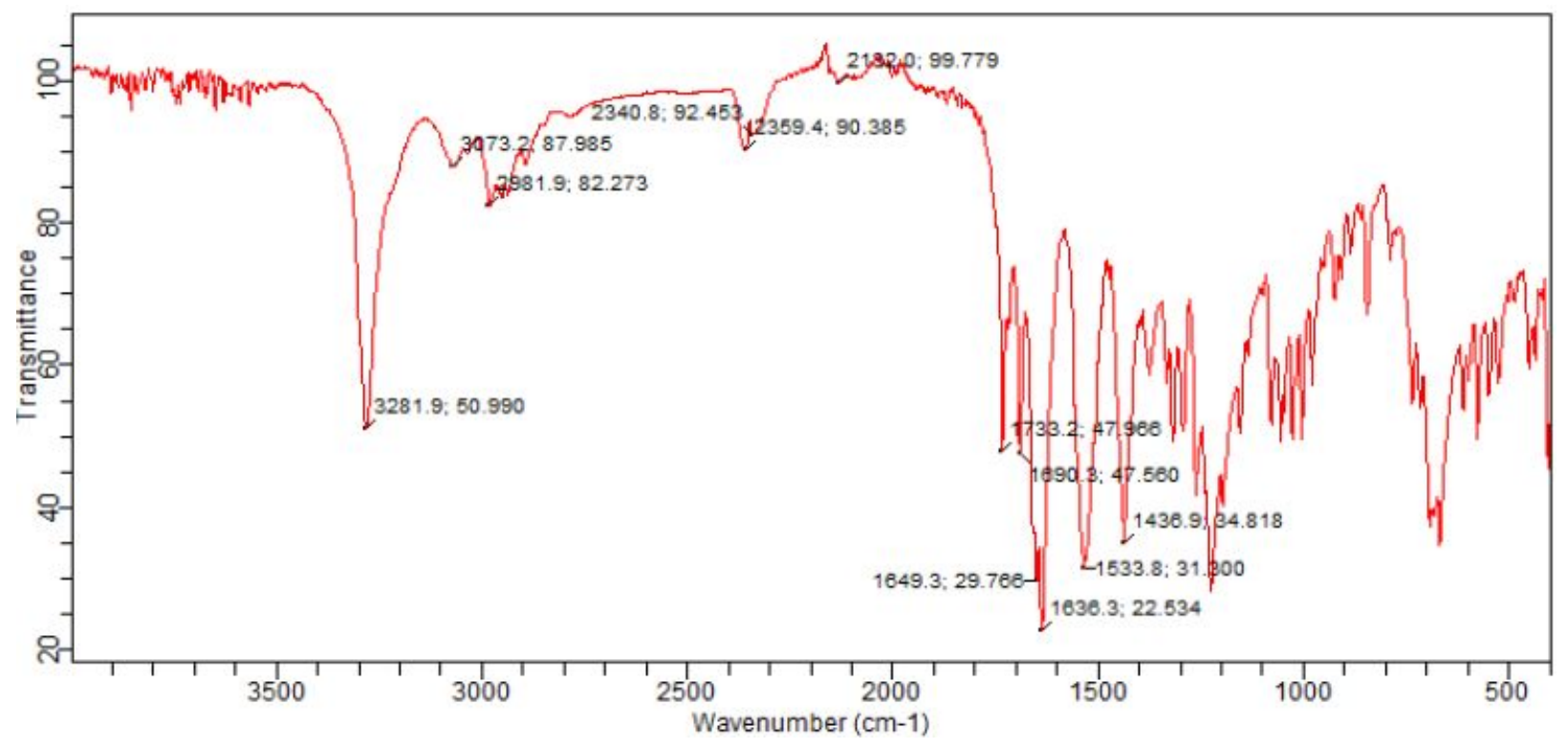

Figure S134. IR spectrum of compound 12. 


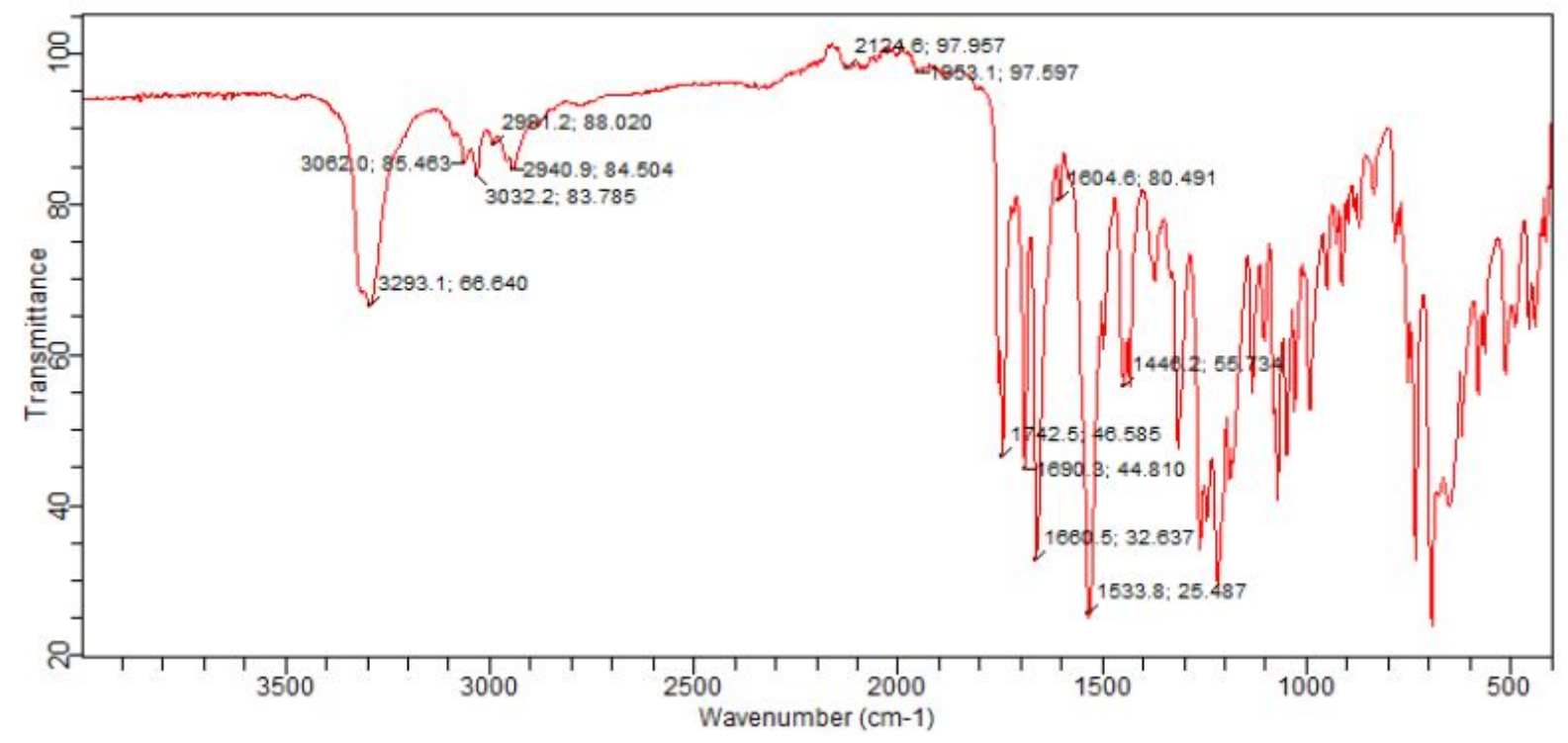

Figure S135. IR spectrum of compound 13.

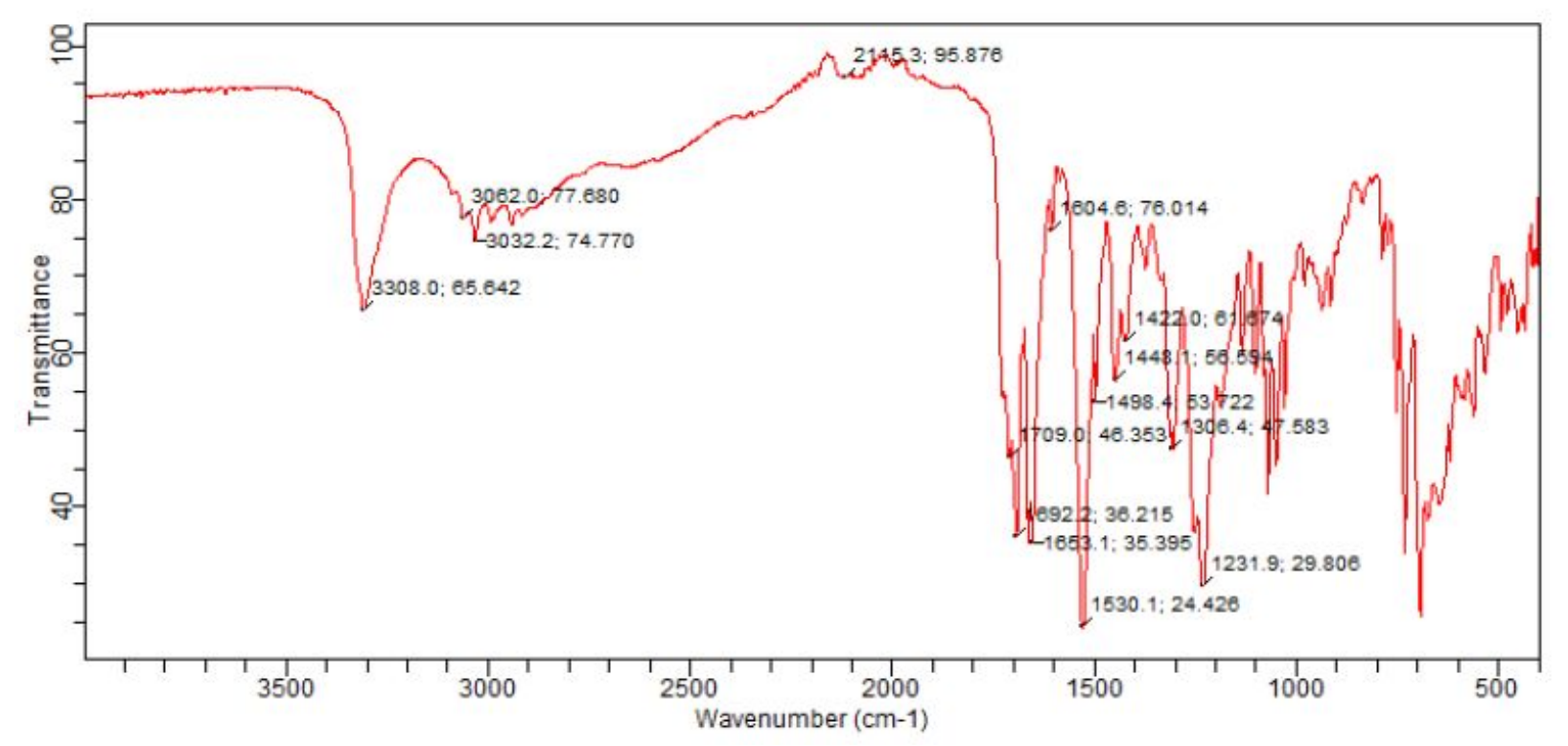

Figure S136. IR spectrum of compound 14. 


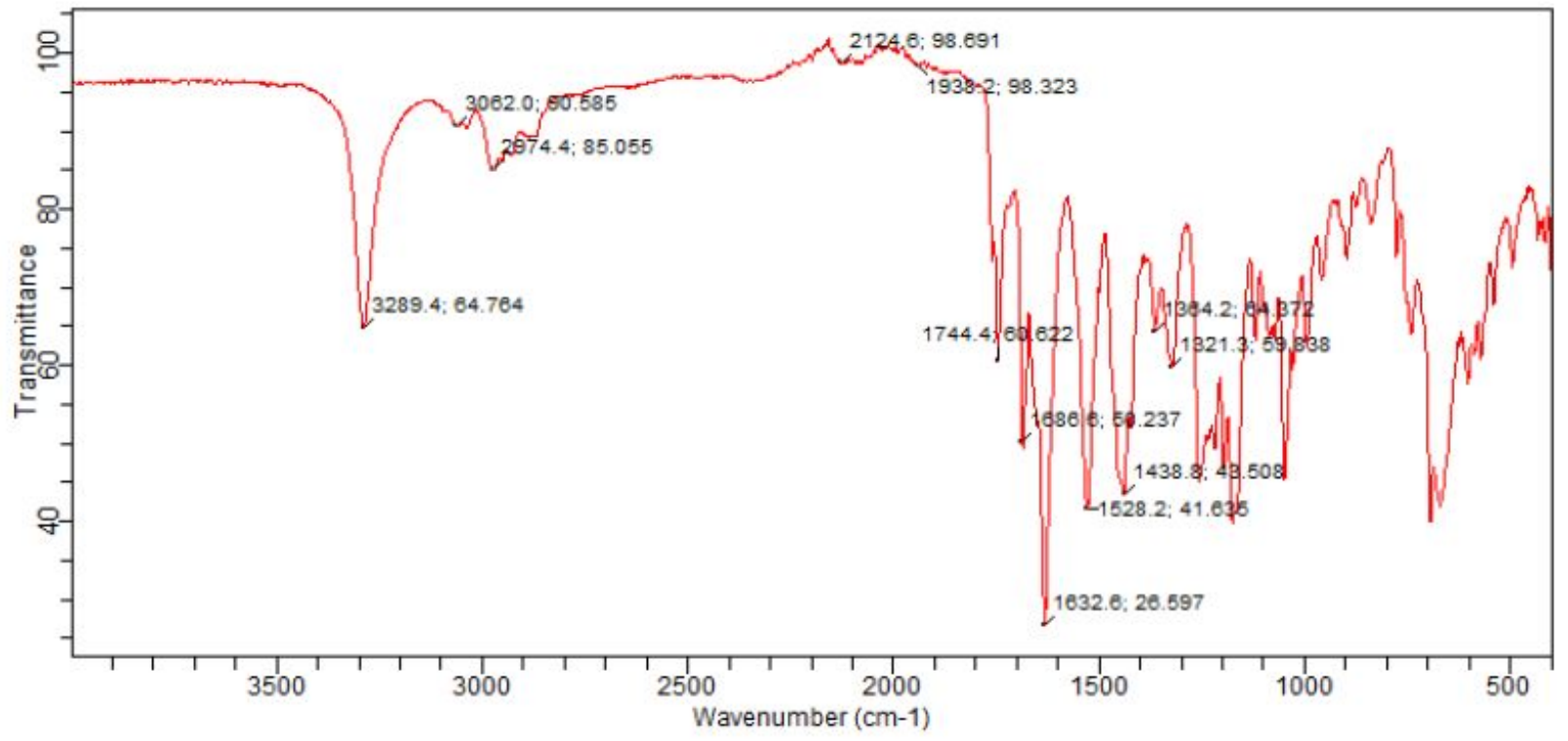

Figure S137. IR spectrum of compound 15.

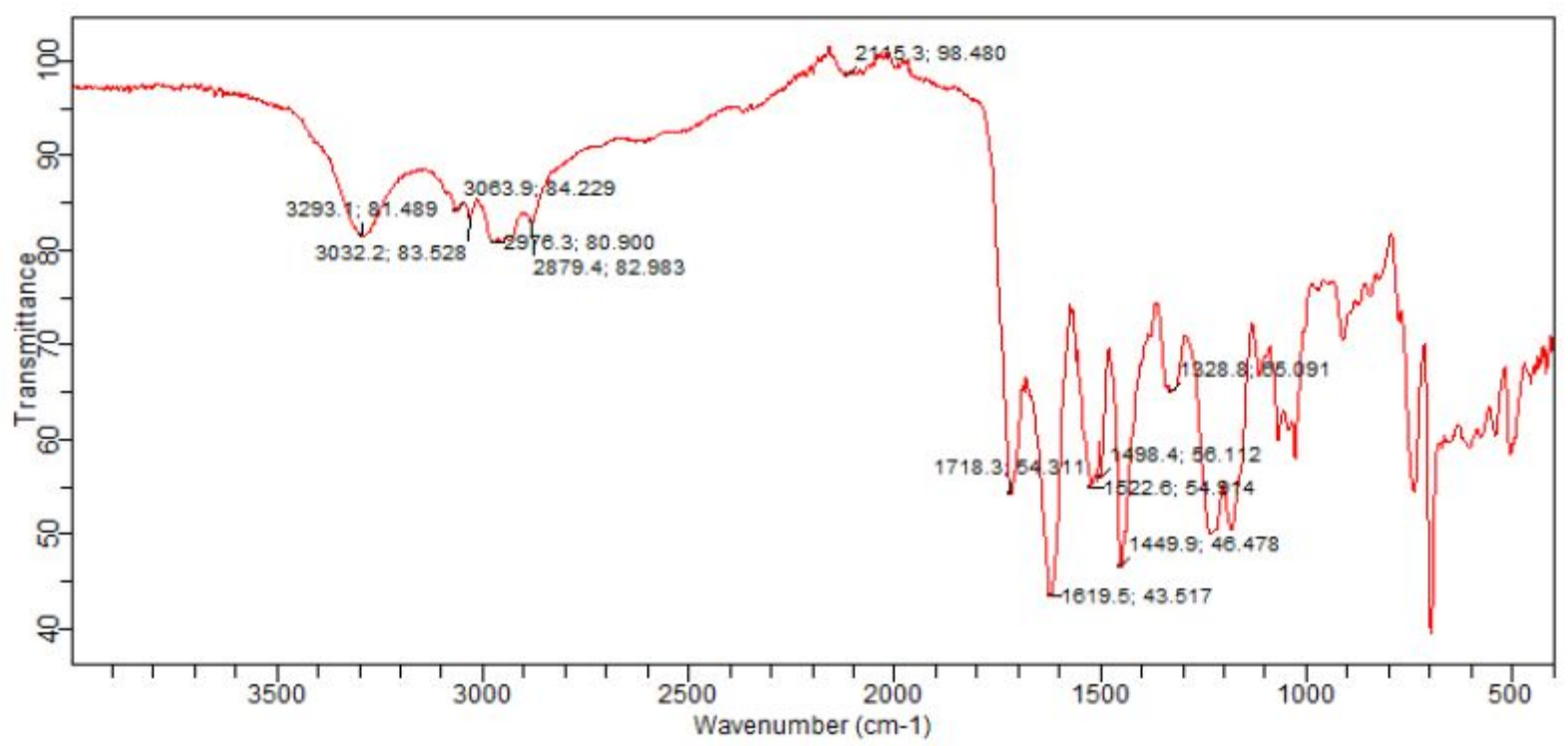

Figure S138. IR spectrum of compound 16. 


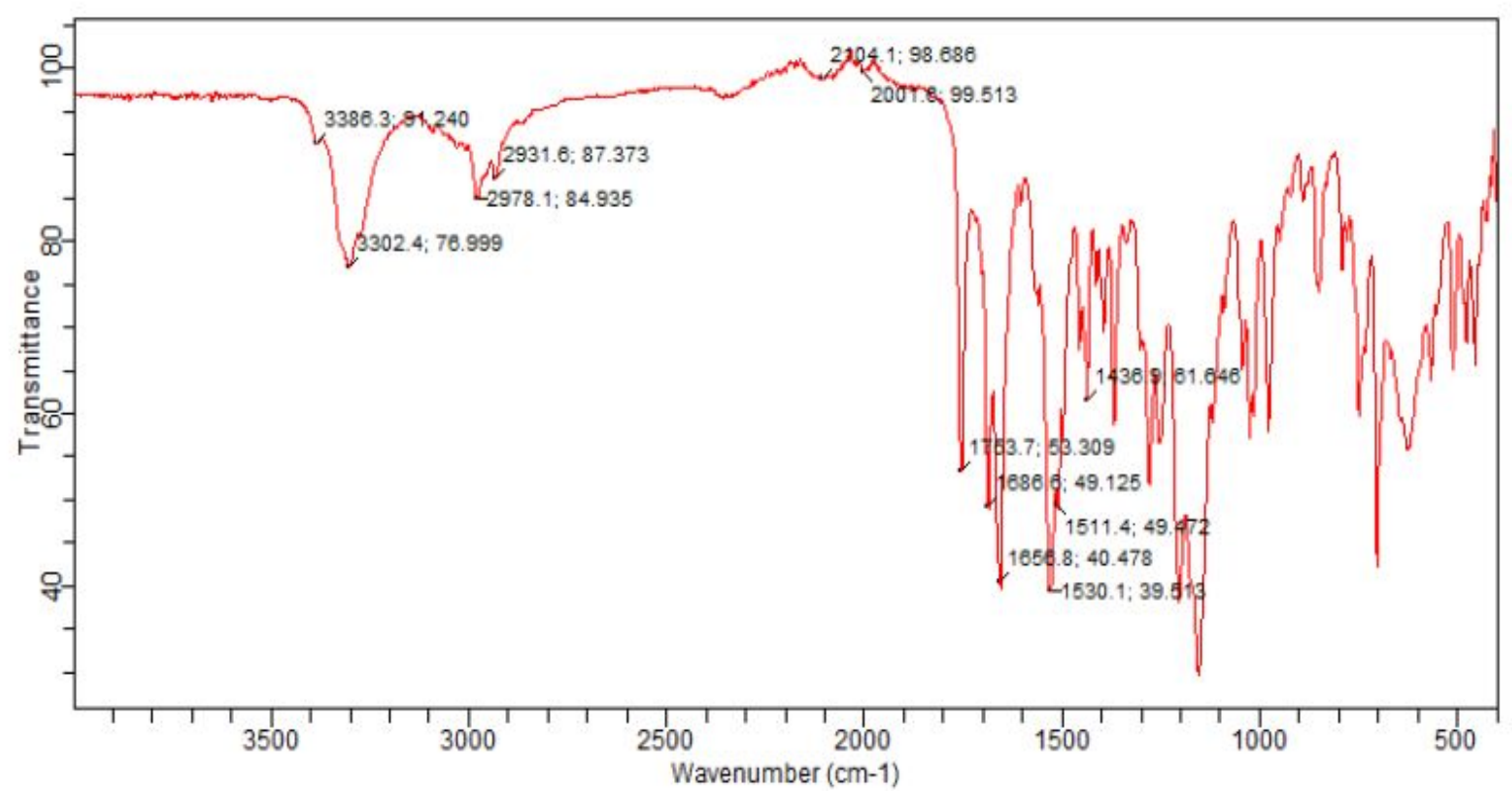

Figure S139. IR spectrum of compound 18.

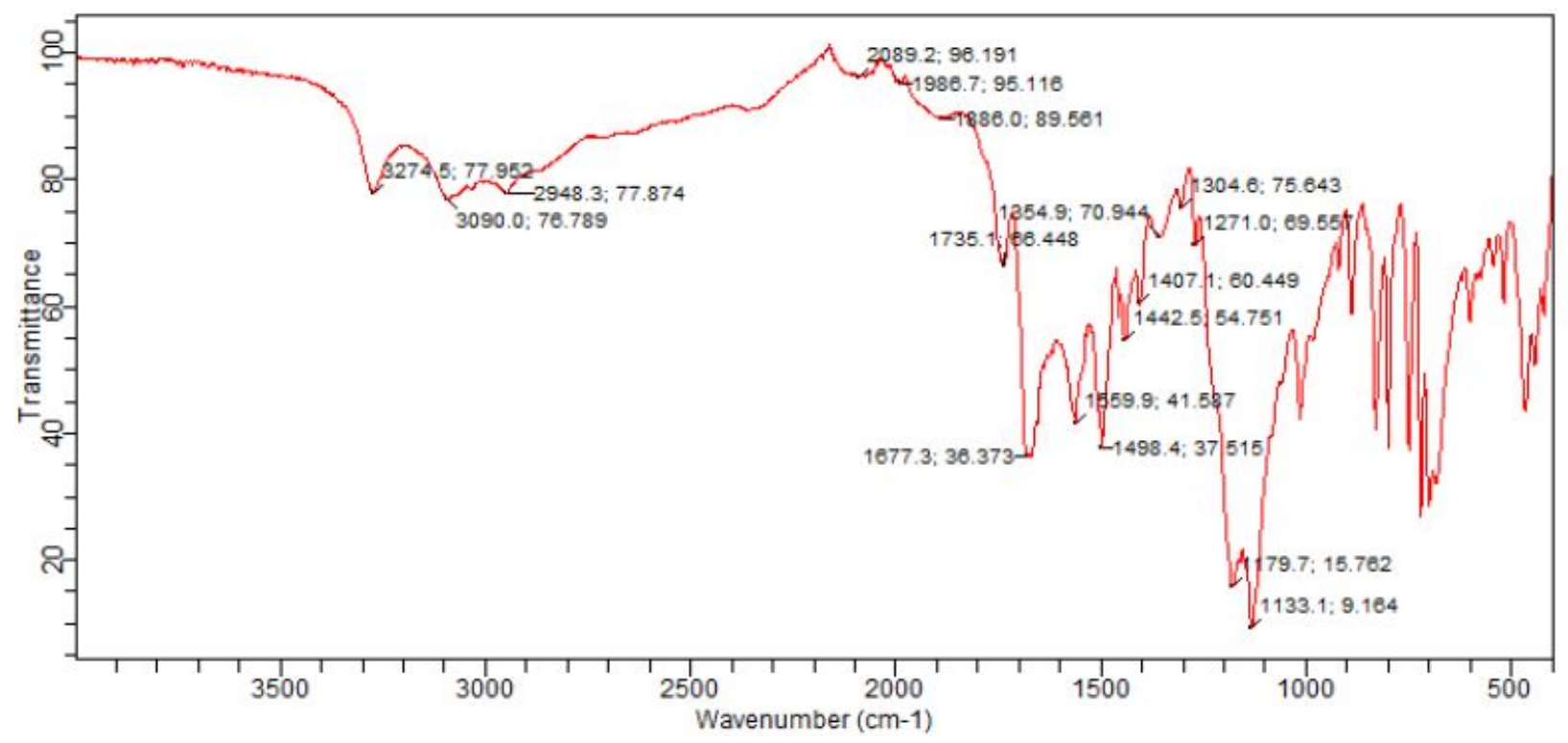

Figure S140. IR spectrum of compound 19. 


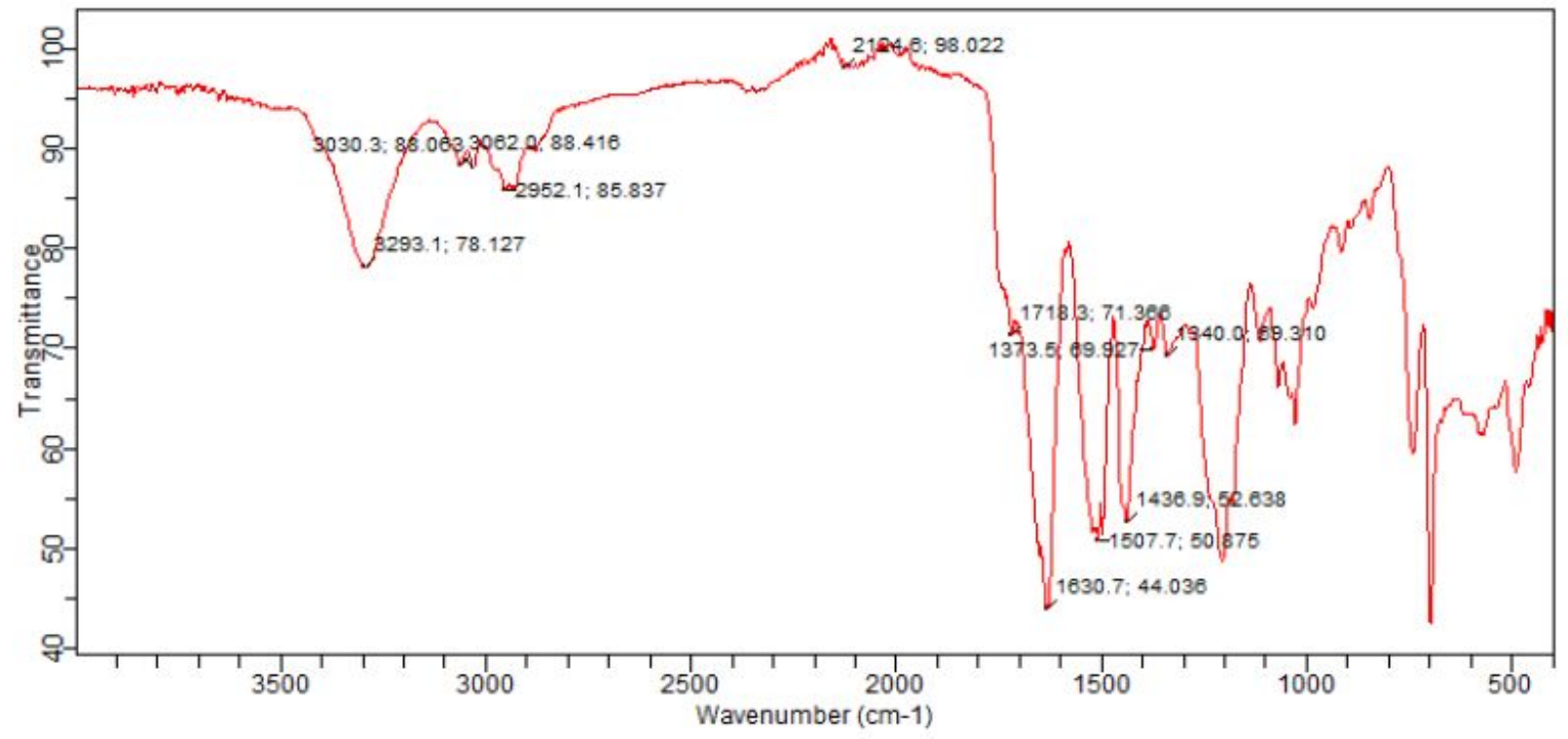

Figure S141. IR spectrum of compound 20.

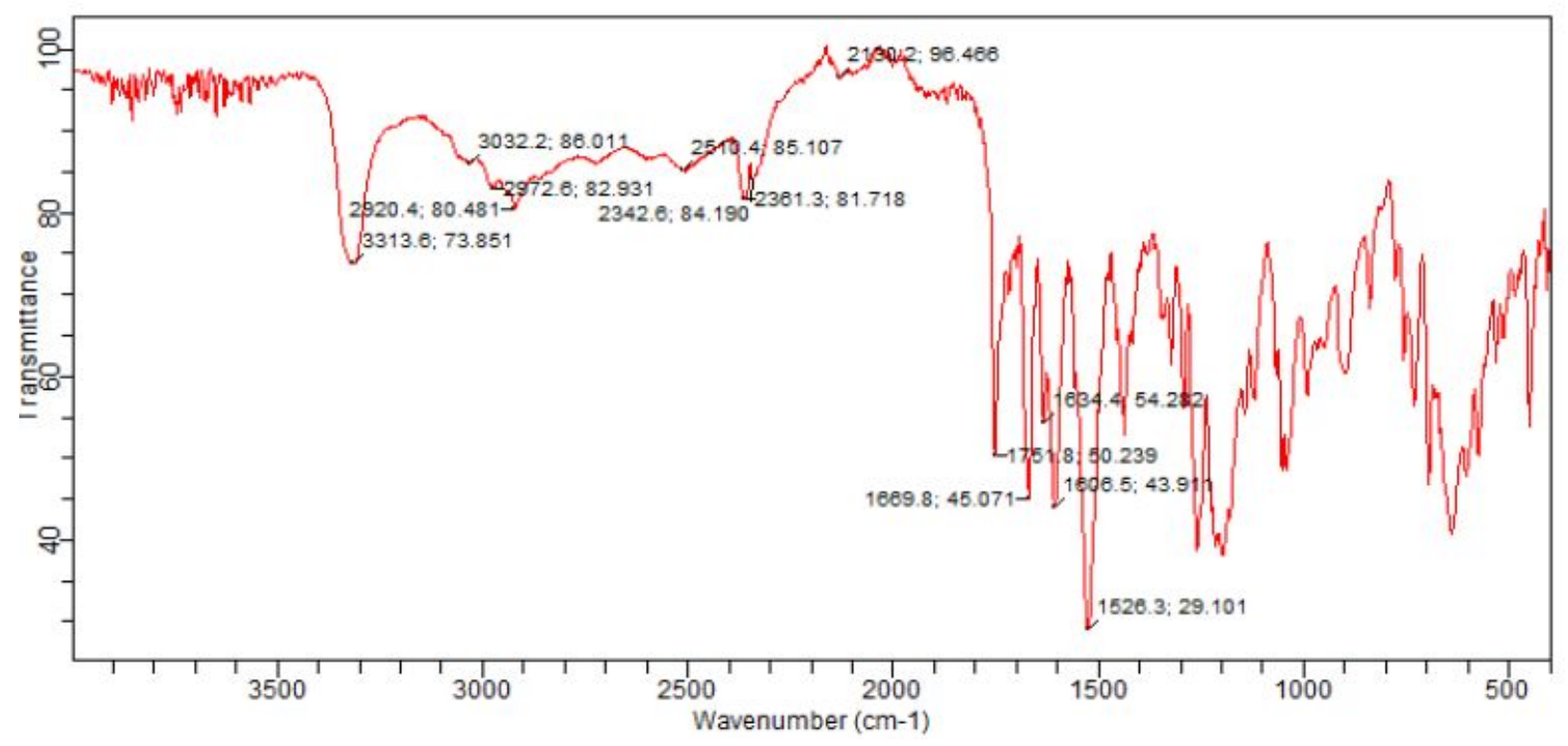

Figure S142. IR spectrum of compound 21. 


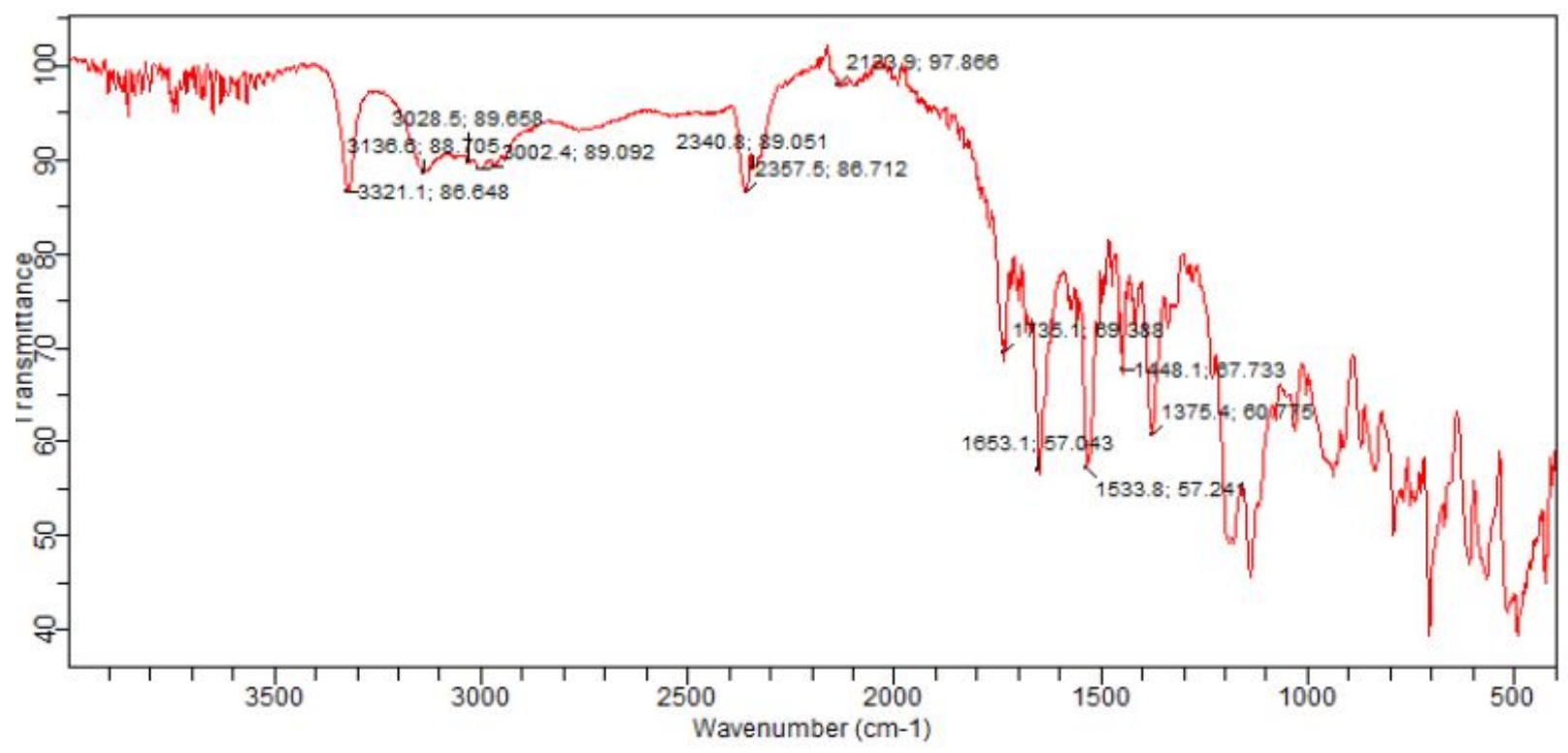

Figure S143. IR spectrum of compound 22.

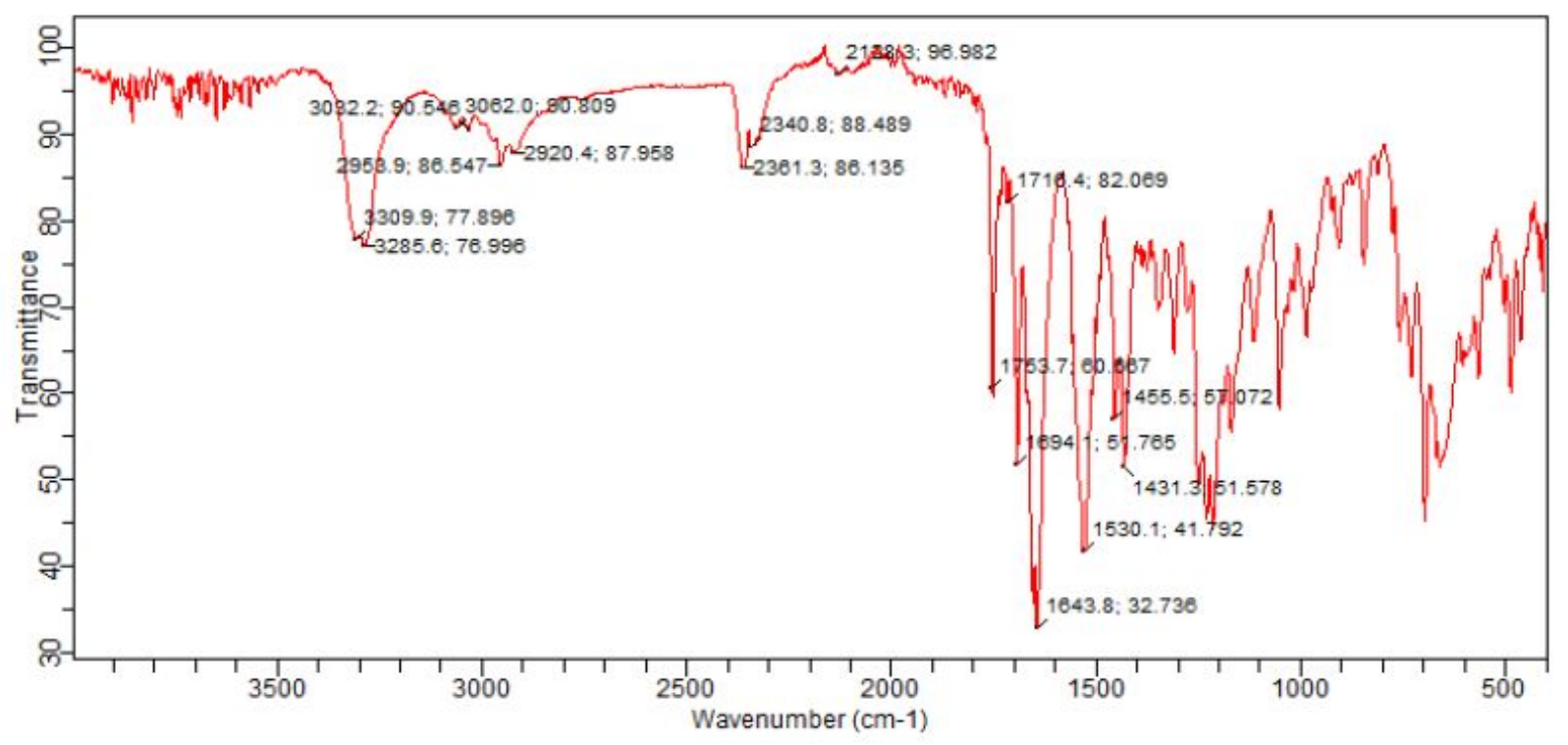

Figure S144. IR spectrum of compound 23. 


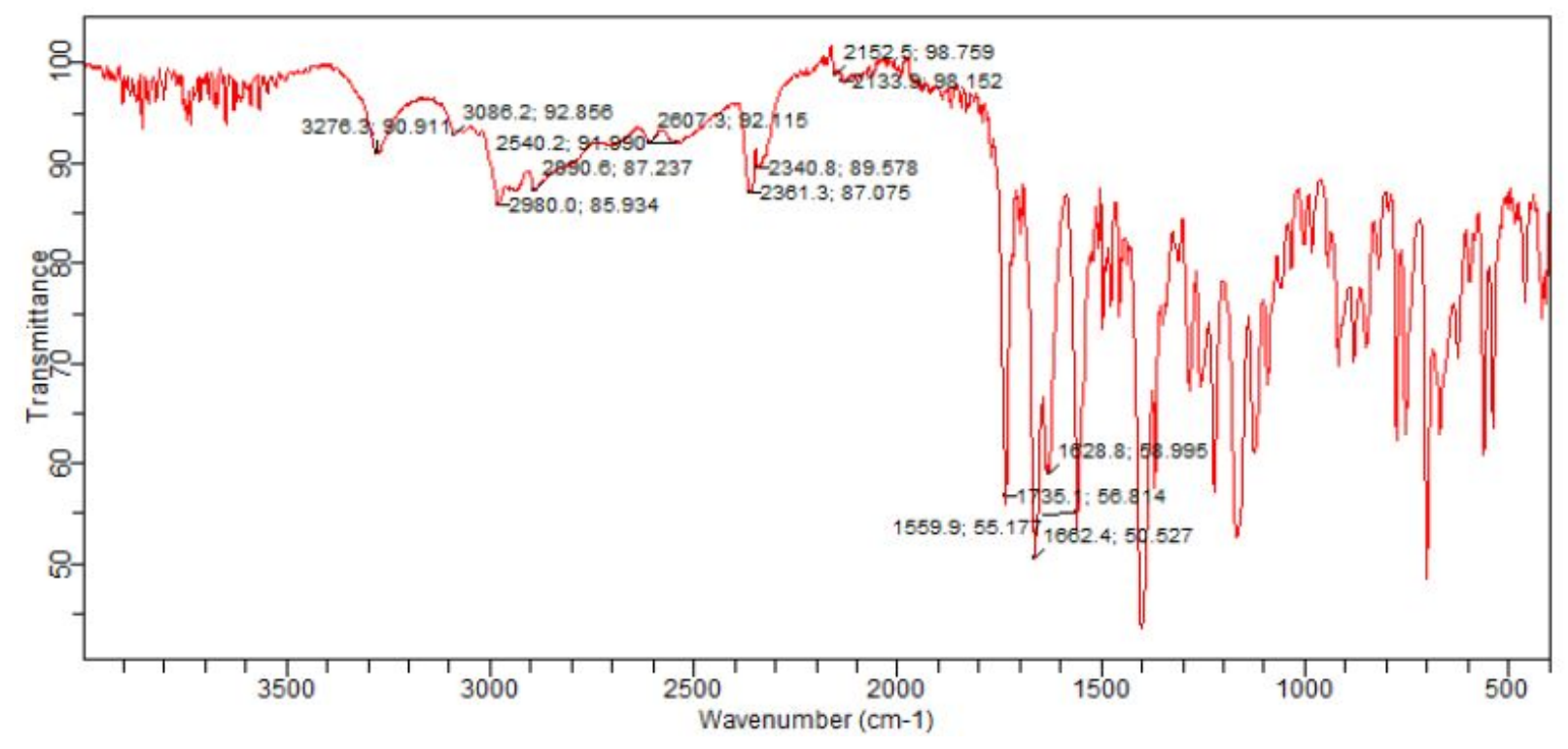

Figure S145. IR spectrum of compound 24.

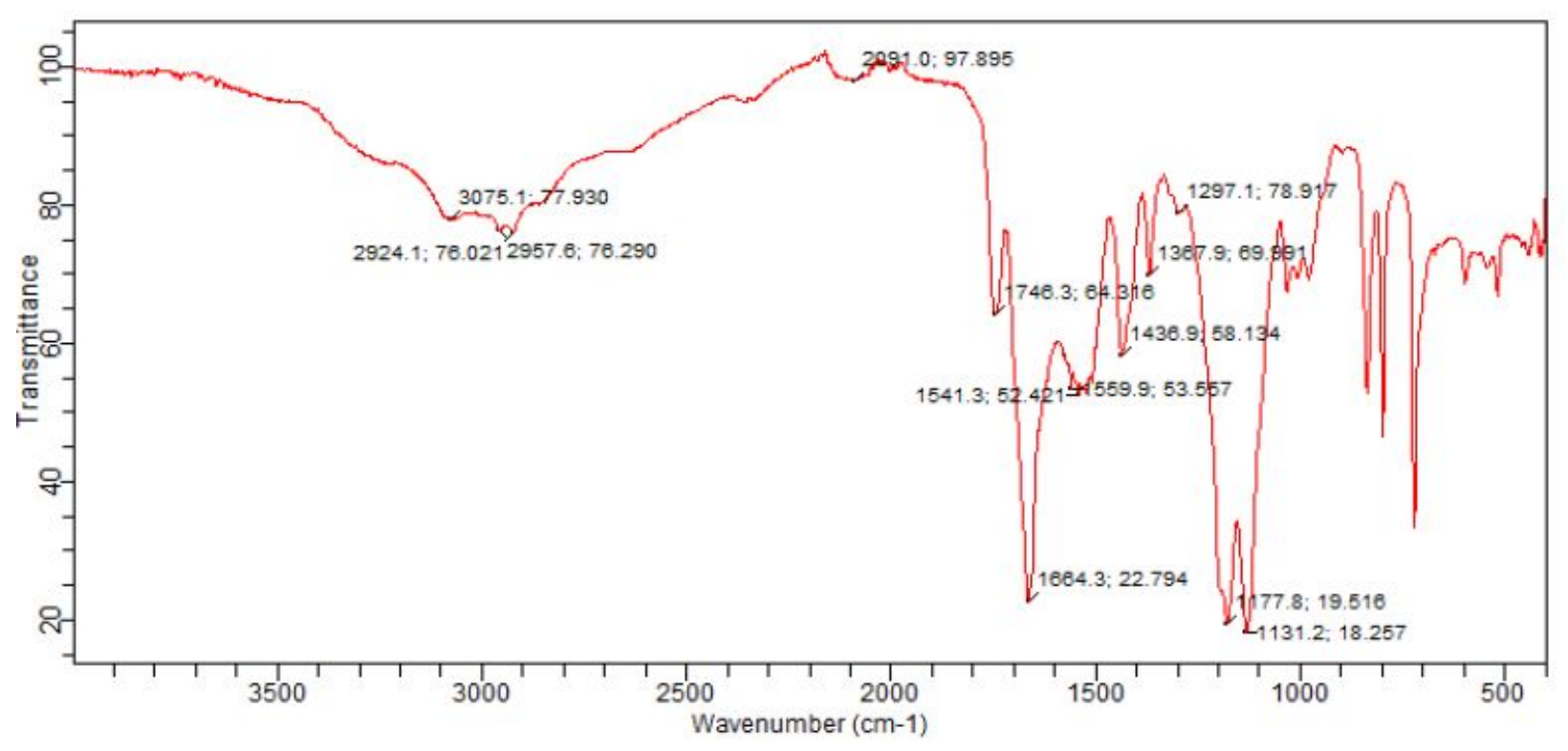

Figure S146. IR spectrum of compound 25. 


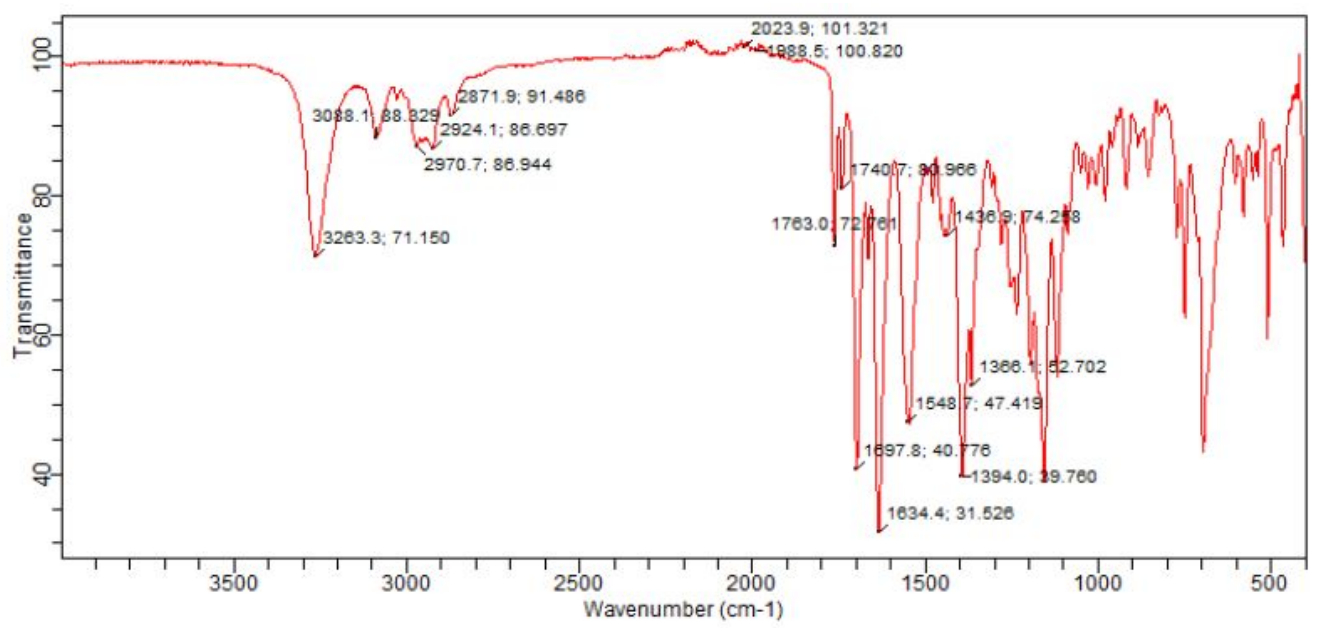

Figure S147. IR spectrum of compound 26.

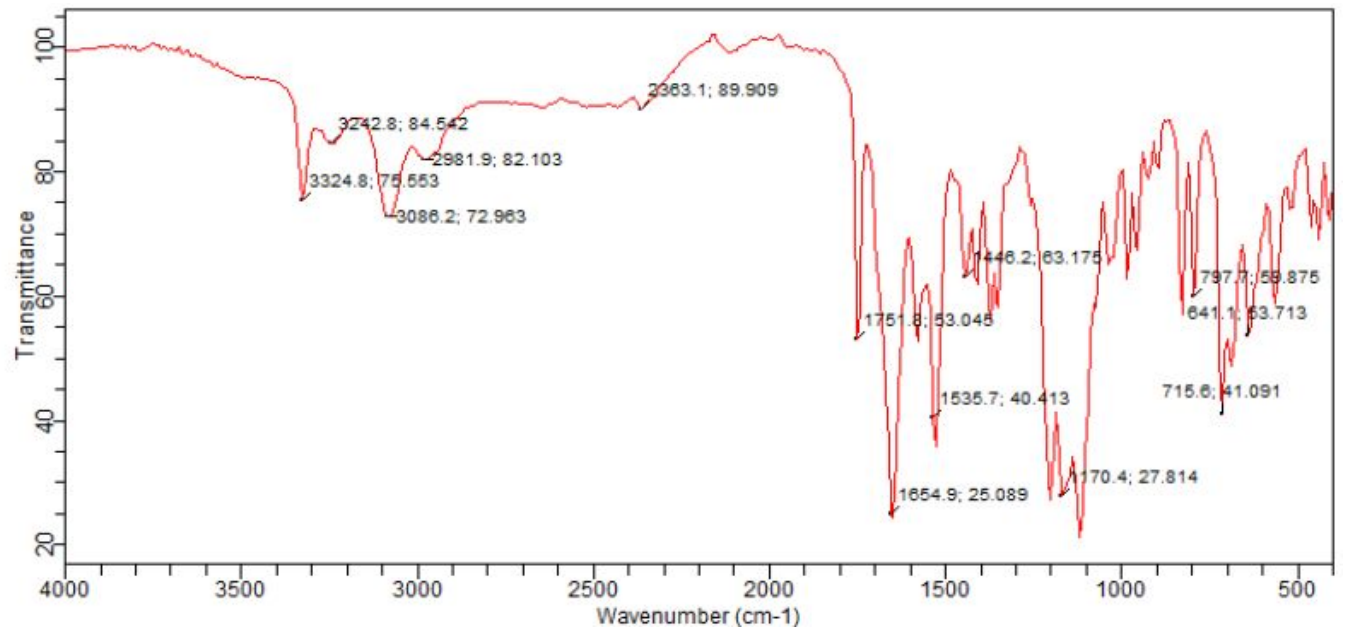

Figure S148. IR spectrum of compound 30.

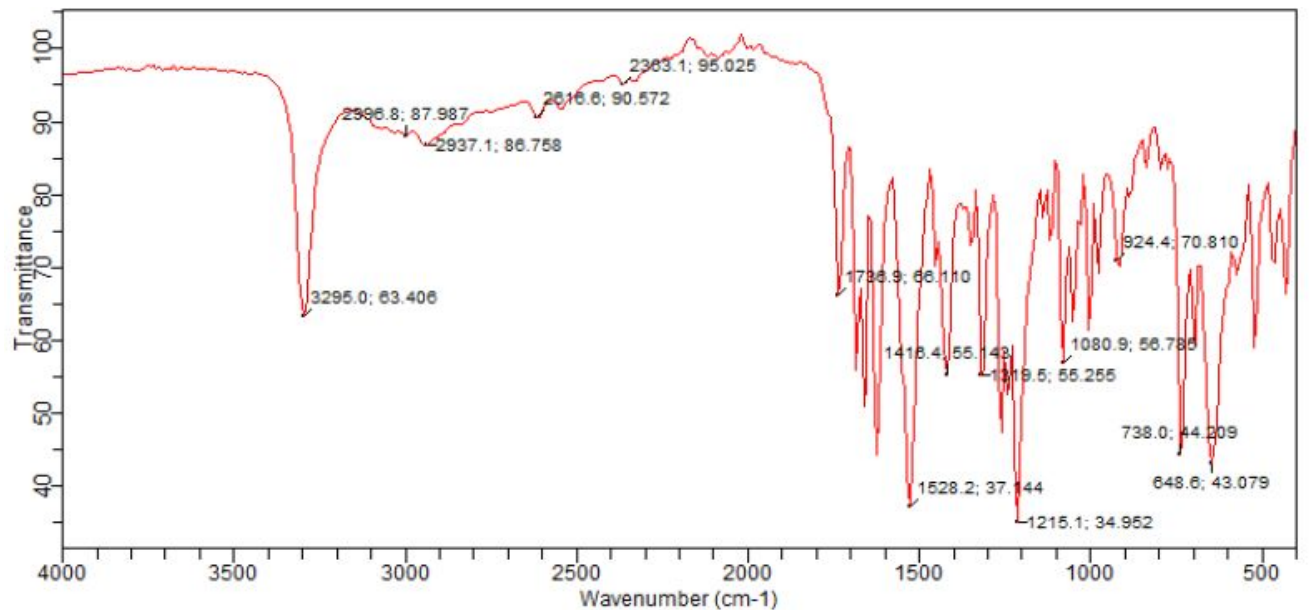

Figure S149. IR spectrum of compound 32. 


\section{Studying the breakdown of peptide 2 with LC-MS}

The animals (male wistar rats, 250-300 g) were administered intraperitonealy a dose of $10 \mathrm{mg}$ $\mathrm{kg}^{-1}$ of $0.1 \% \mathrm{CMC}$ suspension of compound 2 . Before withdrawing the blood samples from jugular vein at intervals of 30,60,120,180, 240 and $300 \mathrm{~min}$, the animals were anesthetized with ketamine (50 mg kg-1 i.p). Blood samples were taken in heparinised tubes. In order to remove the proteinaceous components, the samples were centrifuged at $-4{ }^{\circ} \mathrm{C}$ with $8000 \mathrm{rpm}$ for $10 \mathrm{~min}$ and the clear serum was separated and stored at $-20{ }^{\circ} \mathrm{C} .100 \mu \mathrm{L}$ of the sample was taken in $1.5 \mathrm{~mL}$ tube and vortex for $3 \mathrm{~min}$ followed by the addition of $300 \mu \mathrm{L}$ acetonitrile with internal standard. The tube was vortex for $5 \mathrm{~min}$ and centrifuged at $4{ }^{\circ} \mathrm{C}, 16000 \mathrm{rpm}$ for $40 \mathrm{~min}$. Compound 2 with initial concentration $1 \mathrm{mg} \mathrm{mL}^{-1}$ followed by serial dilution was used for obtaining standard curve. The test samples were appropriately diluted for getting good LC chromatogram. Dionex ultimate 3000 HPLC having $50 \mathrm{~mm}, 5 \mu \mathrm{m}$ PRP C18 column was attached to Bruker MicroTof QII mass spectrometer for LC-MS experiments. HPLC was performed in gradient mobile phase consisting of water and acetonitrile (each containing $0.1 \%$ formic acid). The initial composition was $20 \%$ acetonitrile and linearly increased to $100 \%$ in the total LC run. Sodium formate was used for internal calibration. The peak near time 0 min in each LC is due to sodium formate. Each peak in the LC chromatogram was analyzed with its corresponding $\mathrm{m} / z$. Same LC method was used for in-vitro analysis of peptide breakdown and for calculating kinetic constants as described previously ${ }^{4}$ but taking peptide $\mathbf{2}$ and arachidonic acid as the substrates. In order to confirm the role of acid catalysis in the breakdown of the peptide, LC-MS of solution of peptide 2, COX-2 in HEPES buffer containing $\mathrm{D}_{2} \mathrm{O}$ was also analyzed. Although the breakage of the peptide was slowed down but we were not able to see exactly if all the exchangeable protons of COX-2 are exchanged with deuterium and it becomes the reason for the slow activity of the enzyme. Therefore, this data (reaction in $\mathrm{D}_{2} \mathrm{O}$ ) is not included here. LCMS monitoring of peptide 2 breakdown in the presence of Y385F COX-2 was also performed. Variation in the RT of some the peaks was observed but identified with HRMS.

\section{Reference}

4. H. Singh, B. Kaur, H. Kaur, P. Singh. Org. Biomol. Chem. 2018, 16, 9446-9453. 


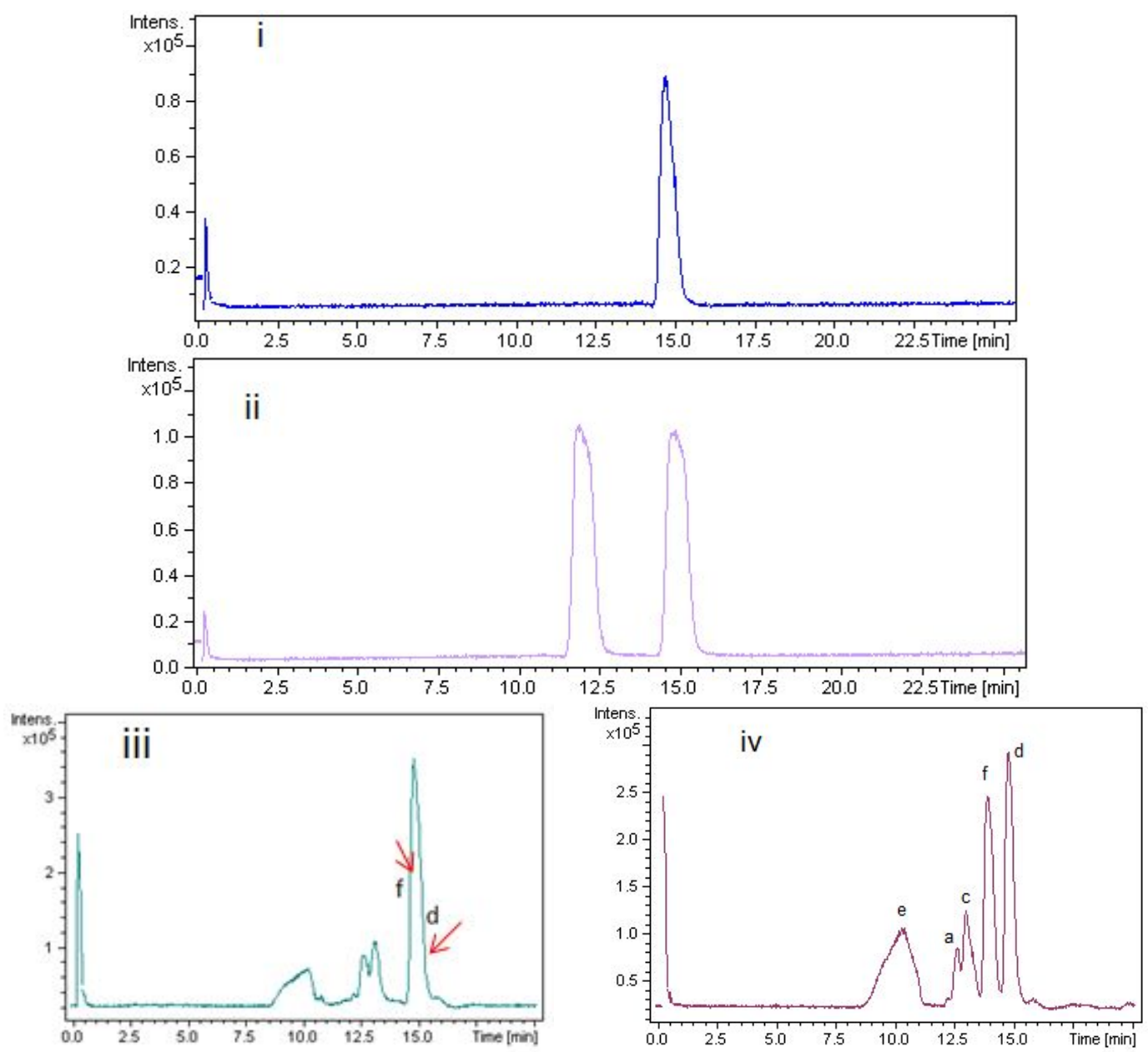

Figure S150. LC chromatograms of the blood serum samples of compound 2 treated rats with prior treatment with Substance P, taken at (i) $30 \mathrm{~min}$, (ii) $60 \mathrm{~min}$, (iii) $90 \mathrm{~min}$, (iv) 120 min; the proteins were removed by centrifugation and the supernatants were subjected to LC-MS. After 6 h, compound 2 was completely broken to small peptides. Marks a, c, d, e, f in figure iv correspond to the fragments shown in Scheme 1 in the main text, identified with their respective $m / z$. 


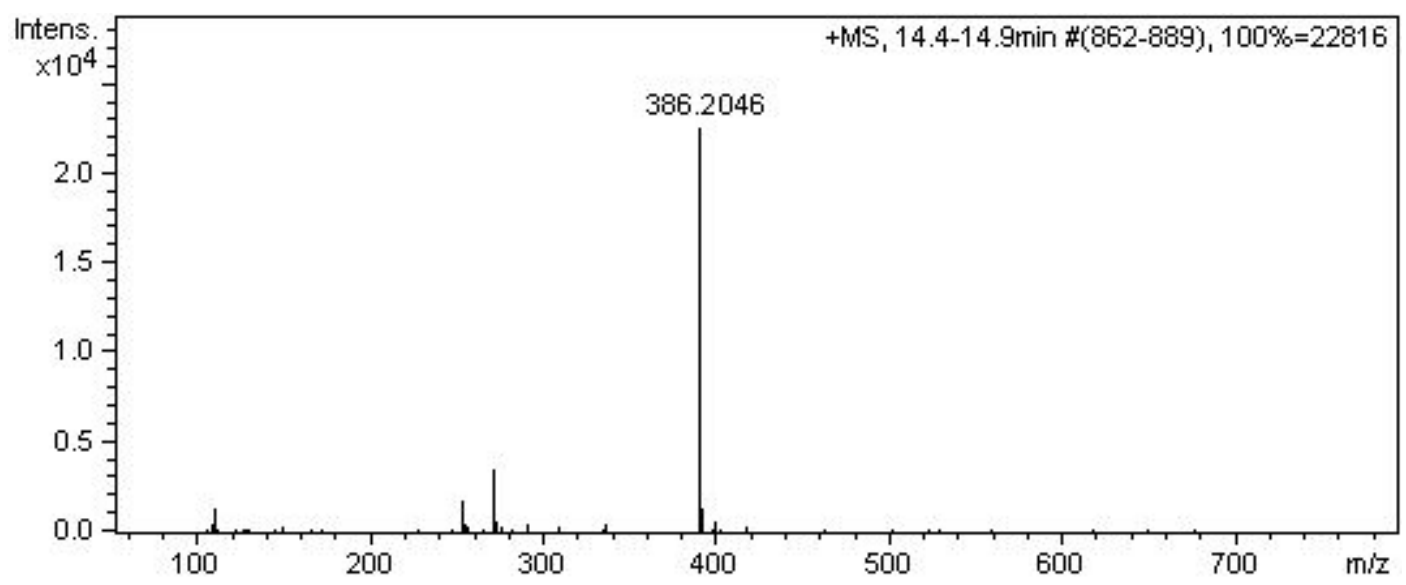

Figure S151. HRMS corresponding to LC chromatogram 'i' in Figure S149.

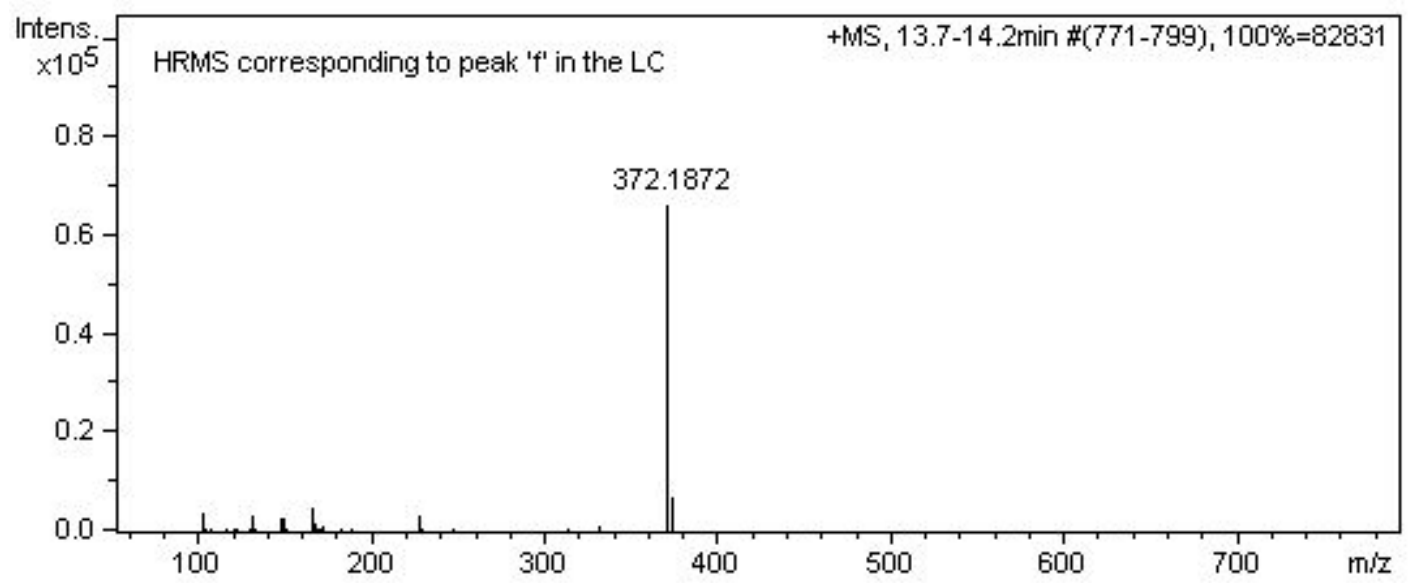

Figure S152. HRMS corresponding to peak ' $\mathrm{f}$ ' in the LC chromatogram in Figure S149.

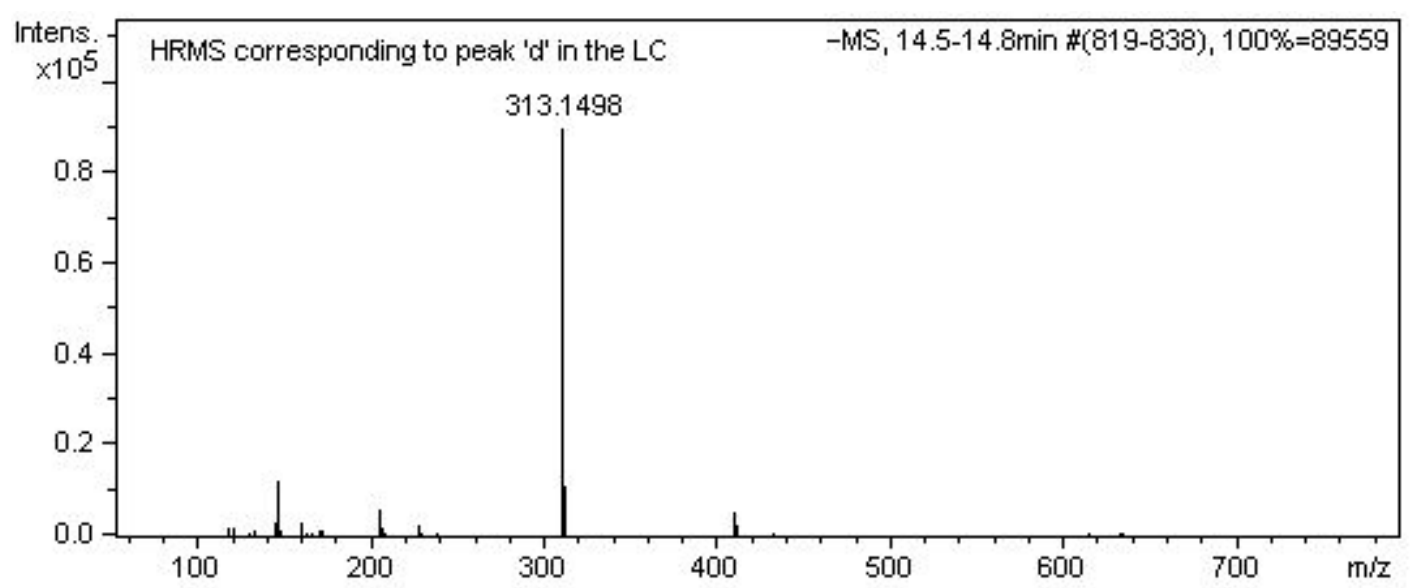

Figure S153. HRMS corresponding to peak ' $d$ ' in the LC chromatogram in Figure S149. 


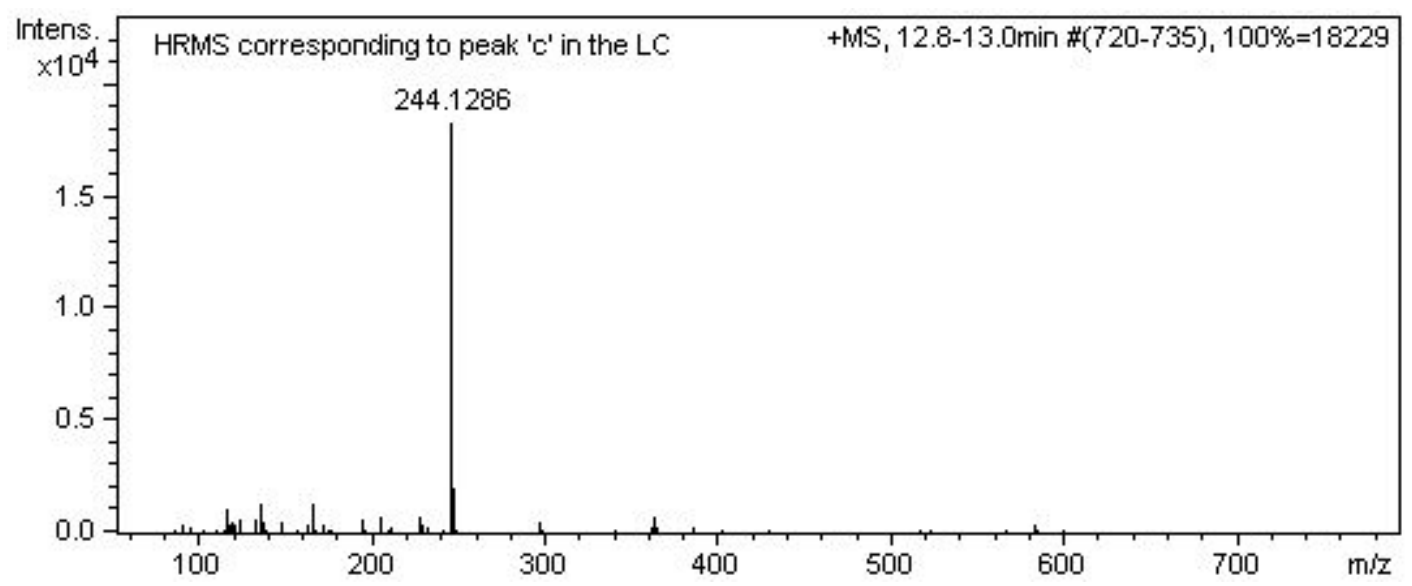

Figure S154. HRMS corresponding to peak 'c' in the LC chromatogram in Figure S149.

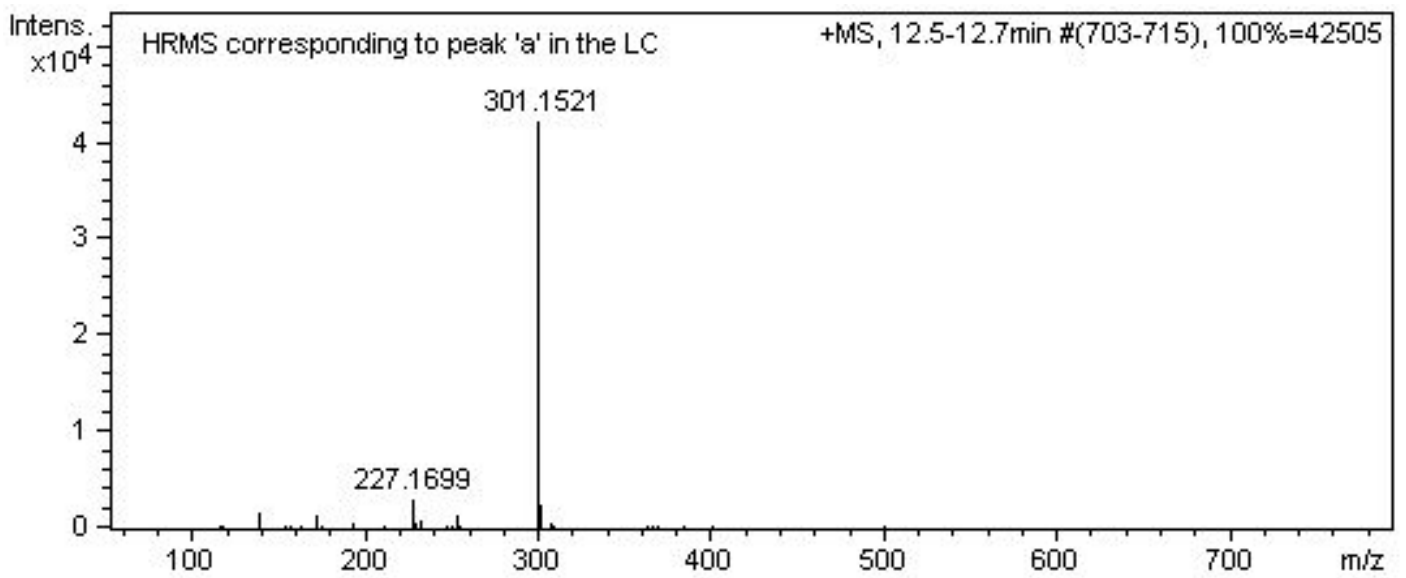

Figure S155. HRMS corresponding to peak ' $a$ ' in the LC chromatogram in Figure S149.

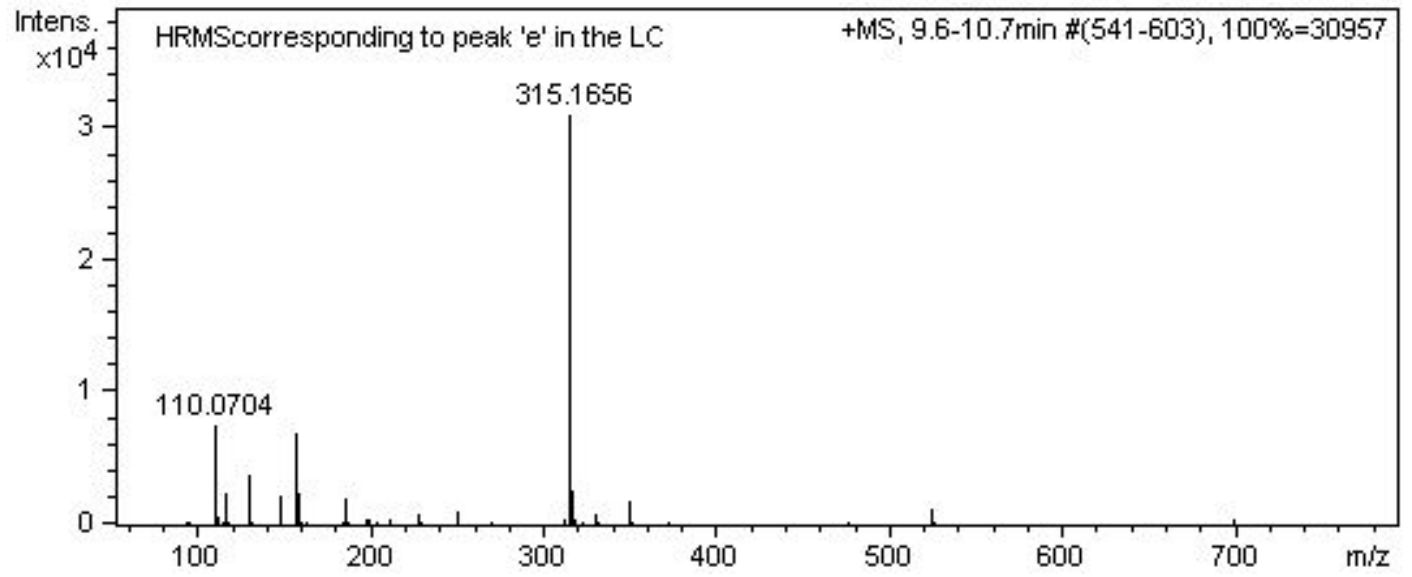

Figure S156. HRMS corresponding to peak 'e' in the LC chromatogram in Figure S149. 

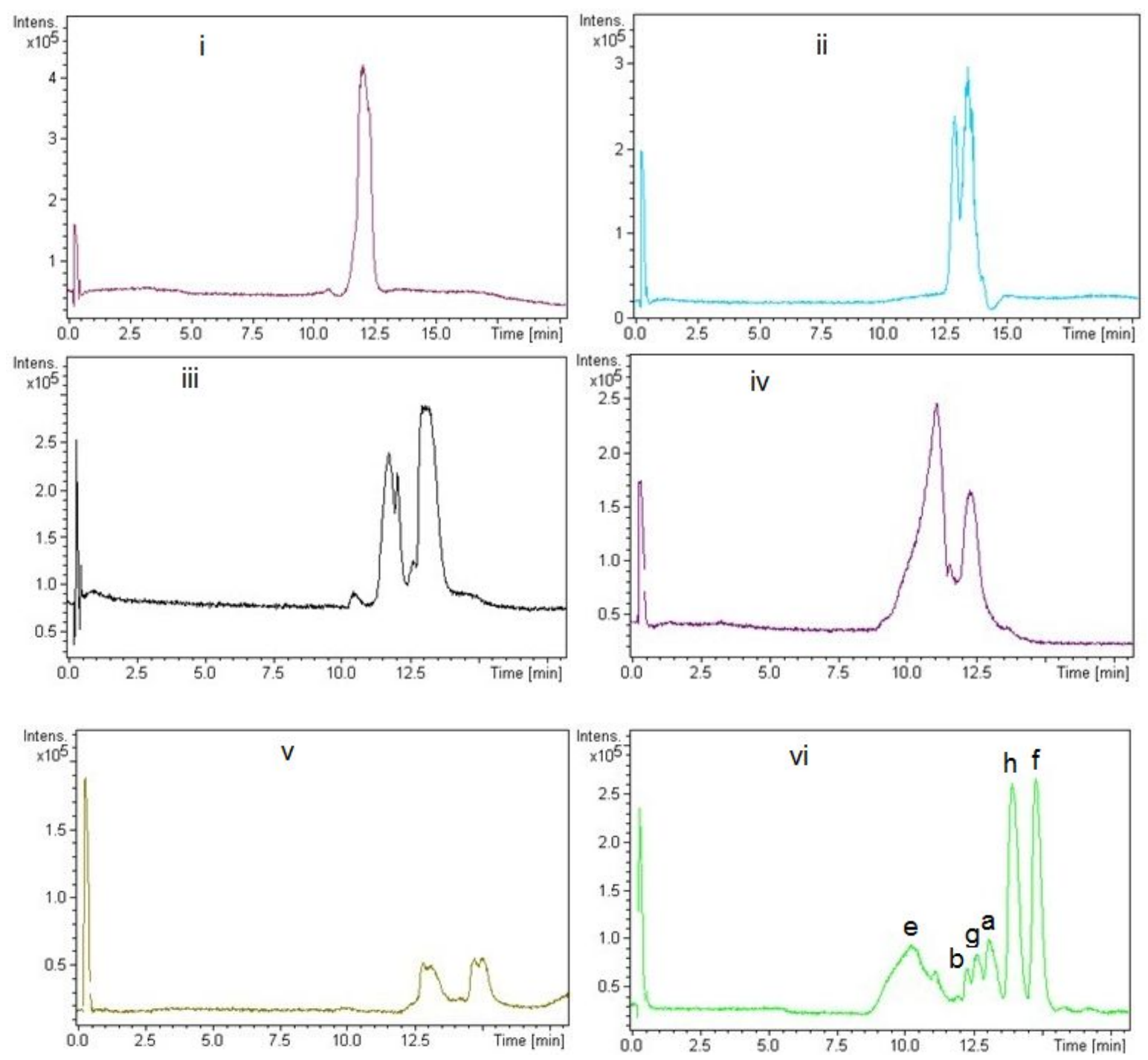

Figure S157. LC chromatograms of the blood serum samples of the rats treated with compound 2 without prior treatment with Substance P. Sample taken at (i) $30 \mathrm{~min}$, (ii) 60 min, (iii) $180 \mathrm{~min}$, (iv) $240 \mathrm{~min}$, (v) $300 \mathrm{~min}$ and (vi) $420 \mathrm{~min}$. After $7 \mathrm{~h}$, compound 2 was completely broken to small peptides. Since Substance P activates expression of COX-2, the animals not treated with Substance $\mathrm{P}$ have taken more time to metabolize peptide 2 in comparison to its breakdown observed in Figure S150. 


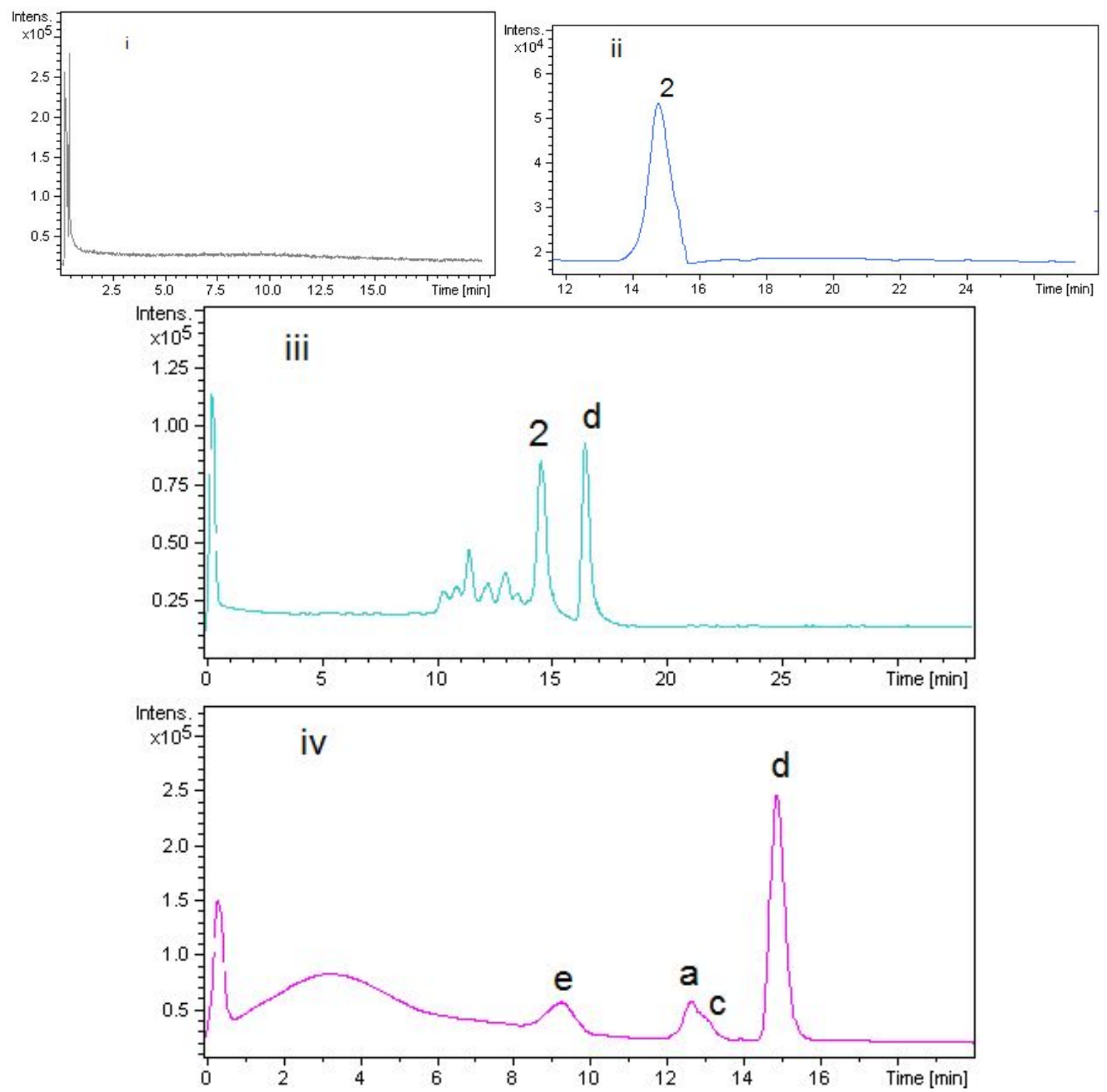

Figure S158. LC chromatograms of solution of peptide 2, COX-2 in HEPES buffer at $\mathrm{pH}$ 7.5. (i) solution of COX-2 in HEPES buffer without peptide 2 showing that all the proteinaceous part is removed as per the general procedure described above, (ii) after 30 min of adding peptide 2 to the solution of COX-2, (iii) after $60 \mathrm{~min}$, (iv) after $120 \mathrm{~min}$. Marks a, c, d, e in figure iv correspond to the fragments in Scheme 1 and Scheme S7, identified with their respective $m / z$. We observed a large similarity between the stage 'iii' of Figure S150 and the stage 'iv' here indicating the similar breakdown of peptide 2 under in-vivo and in-vitro conditions except peak ' $f$ ' under in-vivo conditions that is coming due to esterase hydrolysis of 2. 


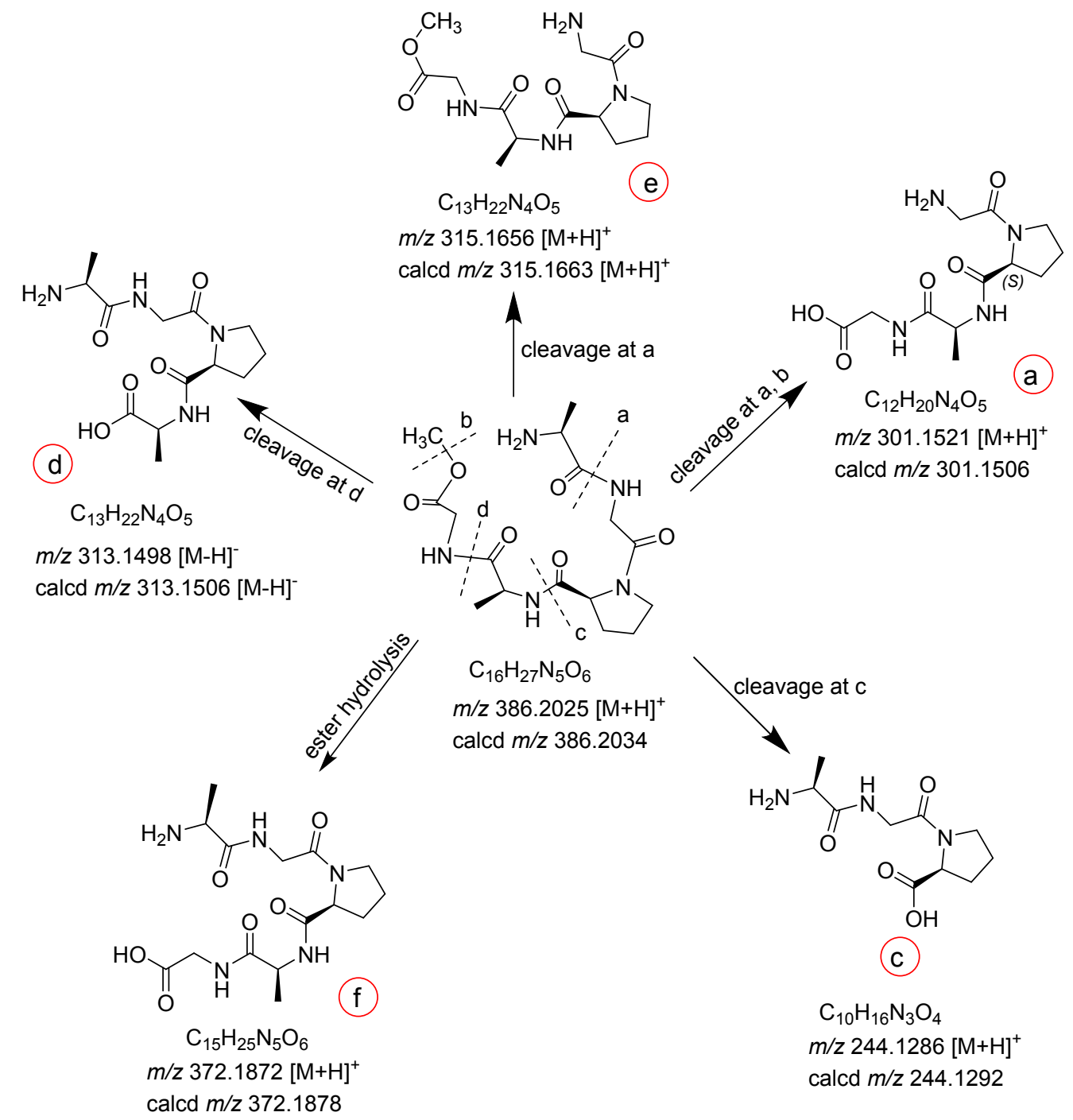

Scheme S2. The fragmentations of peptide 2 as observed from LC-MS. We recorded the spectra in both +ve and -ve modes. The peaks for fragments ' $a$ ', 'c', 'd' and ' $f$ ' were also seen in the -ve ESI mode while peaks due to all the fragments were also observed in the +ve ESI mode. On the basis of its appearance in the -ve ESI mode, the fragment ' $d$ ' was differentiated from fragment 'e'. 

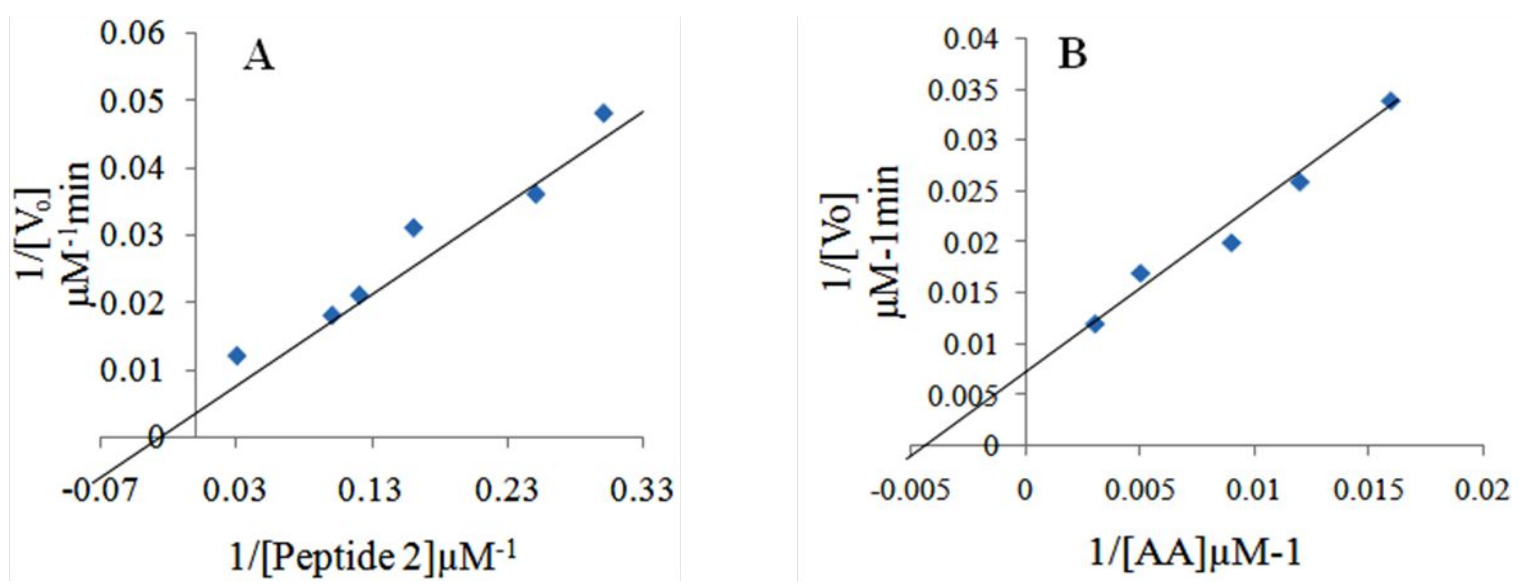

Figure S159. Kinetic parameters of: (A) COX-2 catalyzed breakdown of peptide 2, (B) COX-2 catalyzed breakdown of arachidonic acid.

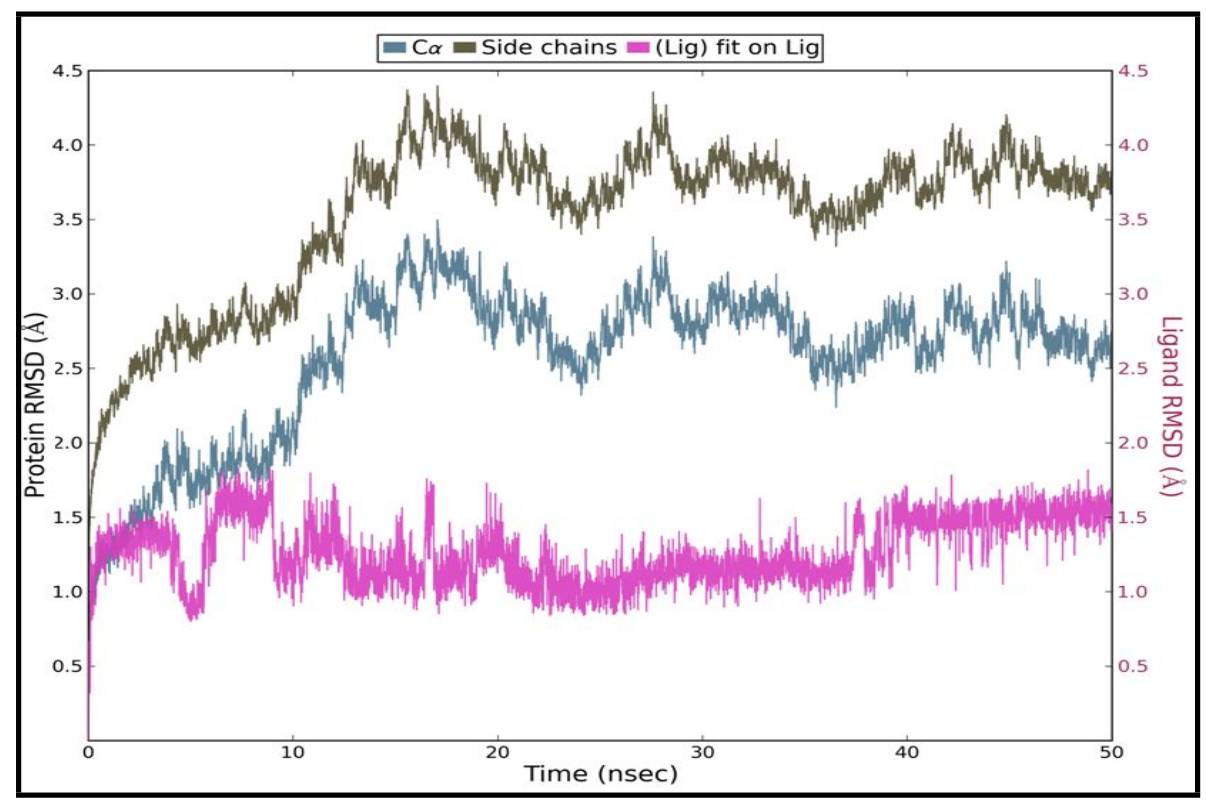

Figure S160. Protein- Ligand RMSD plot formed during evolution of trajectory over a time period of 50 ns showing $\mathrm{C} \alpha$ (blue), side chain of protein (brown), and atoms of ligand 2 (pink). 


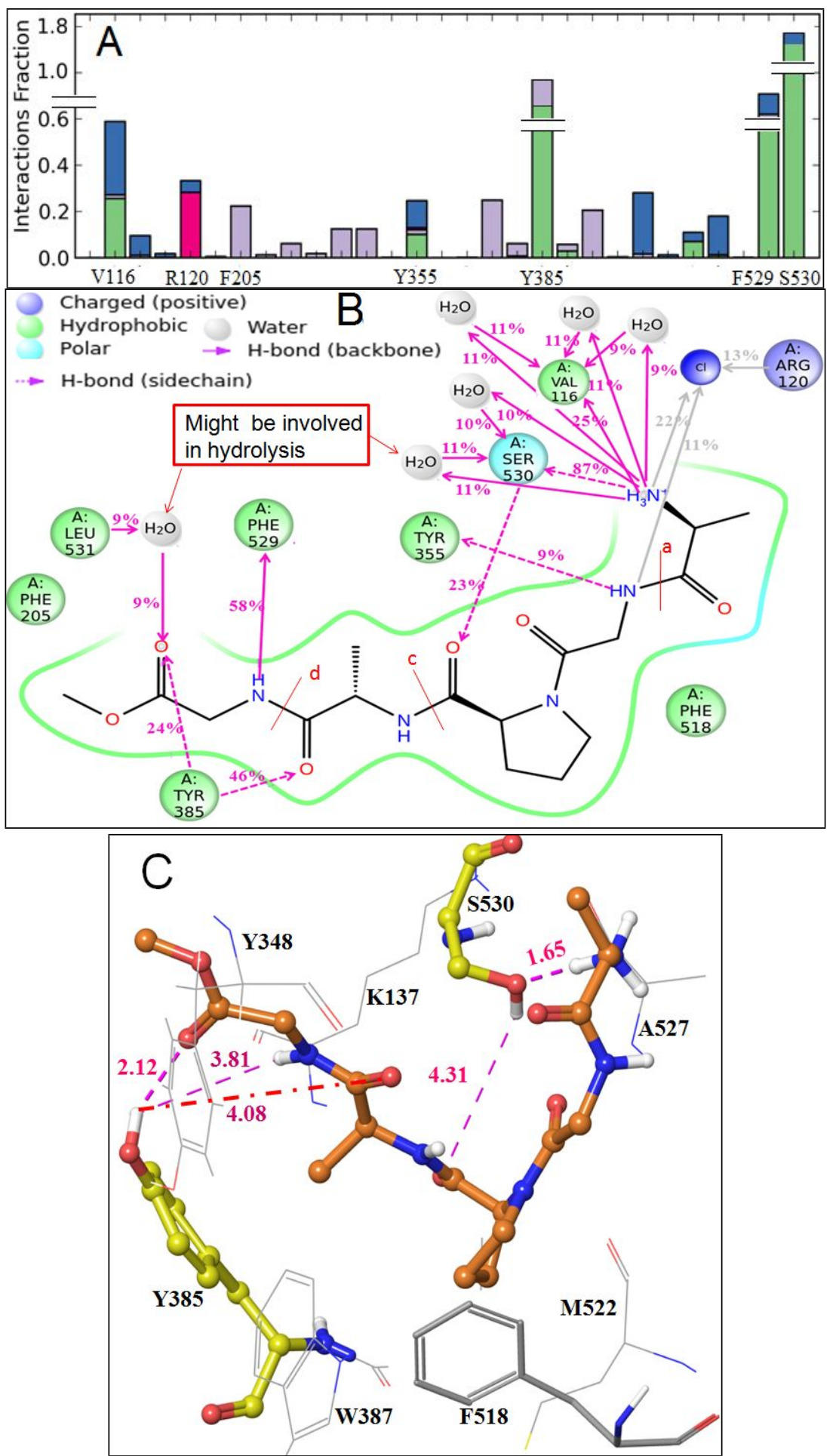

Figure S161. Molecular dynamics of COX-2 - peptide 2 complex (pdb ID 1CVU). (A) Normalized stacked bar chart showing protein interactions with ligand during evolution of trajectory $(0.00-50 \mathrm{~ns})$ that occur more than $11 \%$. (B) Ligand showing contacts with protein through different interaction over a simulation period of $50 \mathrm{~ns}$. (3) 3D view of COX-2 - peptide 2 complex after MD. 

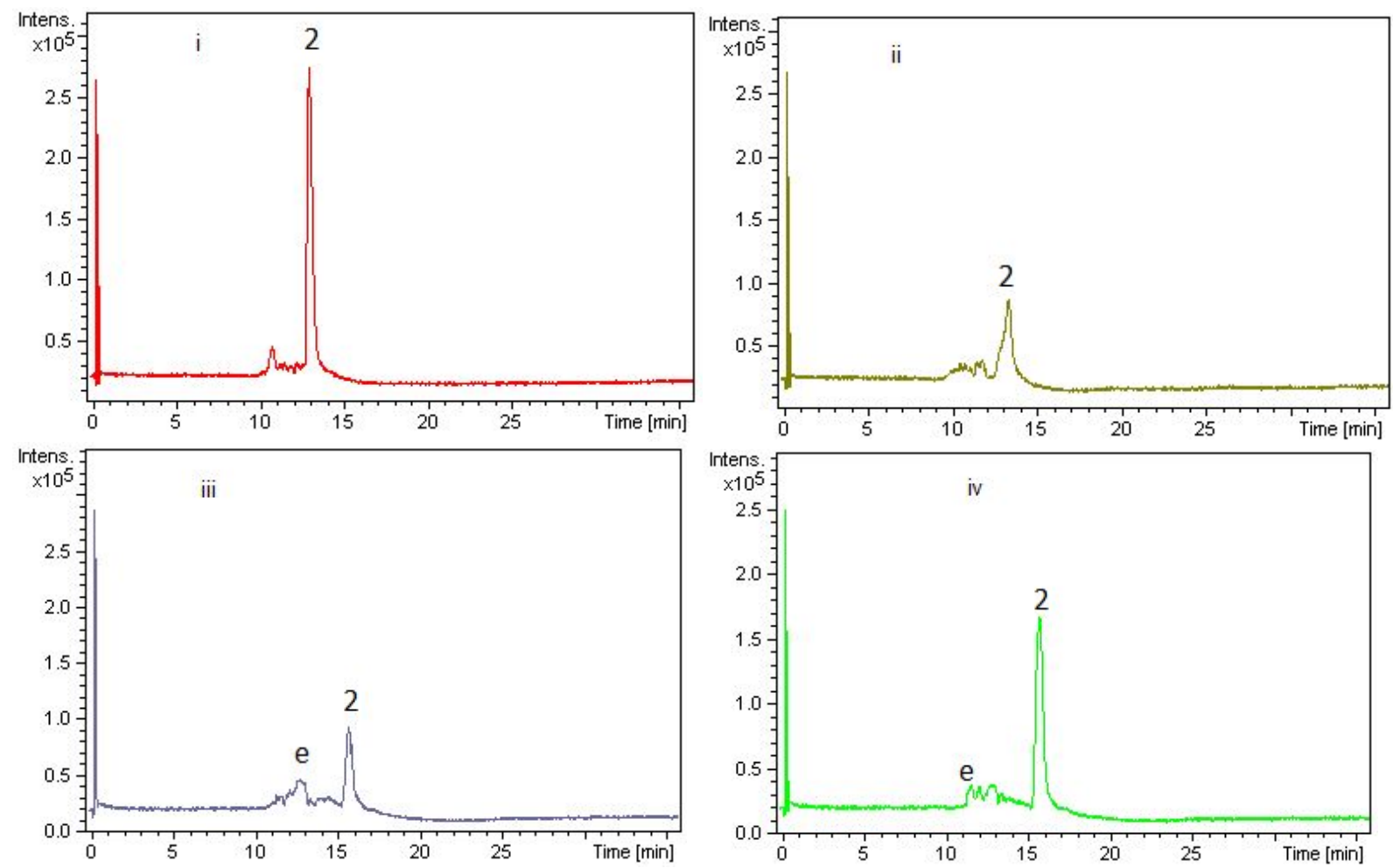

Figure S162. LC chromatograms of the solution of Y385F COX-2 (Cayman Chemicals), peptide 2 in HEPES buffer recorded after (i) $30 \mathrm{~min}$, (ii) $60 \mathrm{~min}$, (iii) $90 \mathrm{~min}$ and (iv) $540 \mathrm{~min}$ of incubation. The peak due to peptide $\mathbf{2}$ was intact, only a small peak corresponding to fragment 'e' (Scheme 7) was observed along with some unidentified small peaks. We observed variation in the RT of 2 but its identification was ensured with HRMS. 

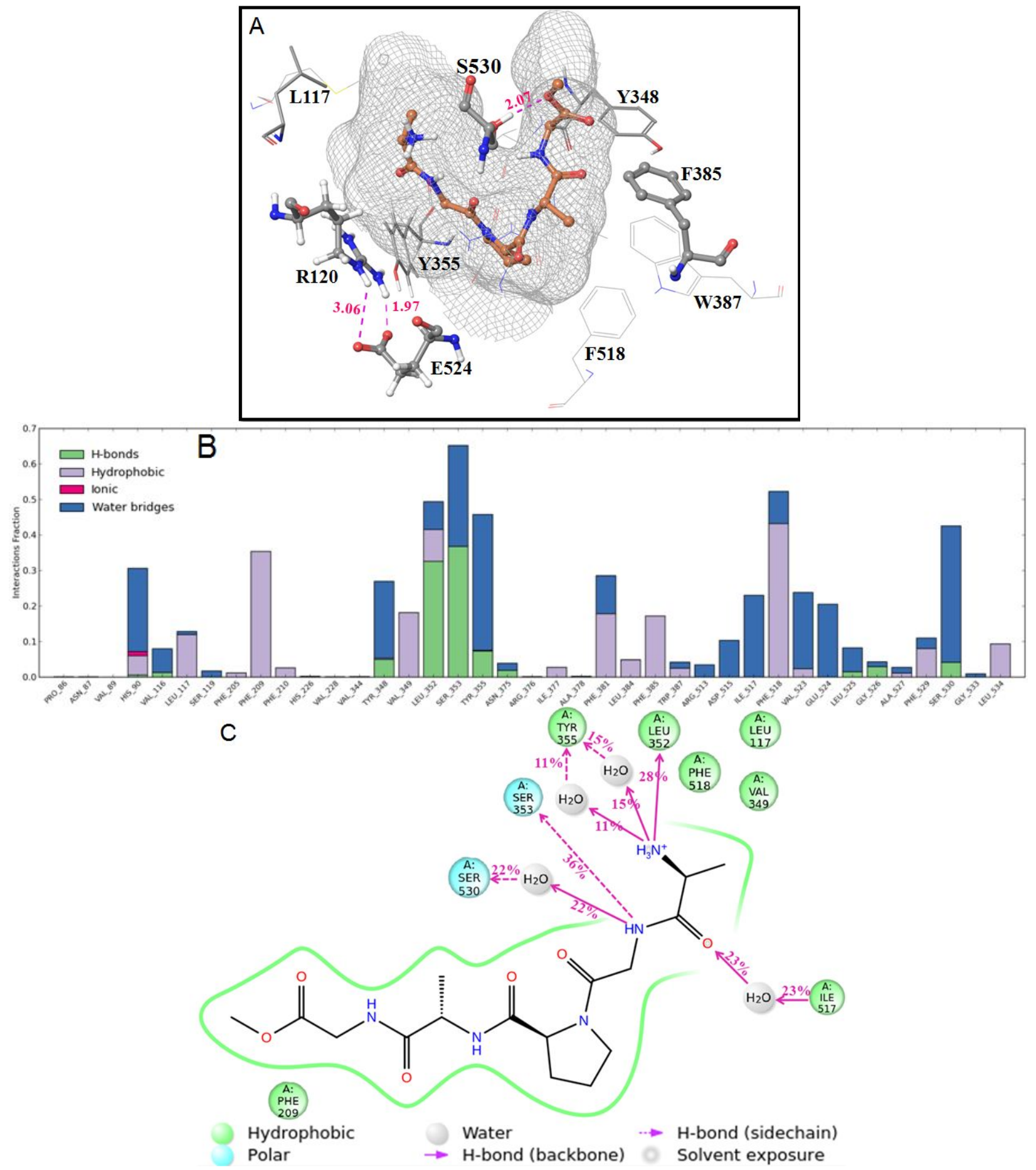

Figure S163. (A) Molecular docking of peptide 2 into the active site of Y385F COX-2 using the crystal coordinates with pdb ID 1CVU. Molecular dynamics of enzyme - substrate complex showing (B) Normalized stacked bar chart for interactions with ligand during evolution of trajectory $(0.00-50 \mathrm{~ns})$ that occur more than $11 \%$ and $(\mathrm{C})$ Ligand contacts with protein over a simulation period of $50 \mathrm{~ns}$. 

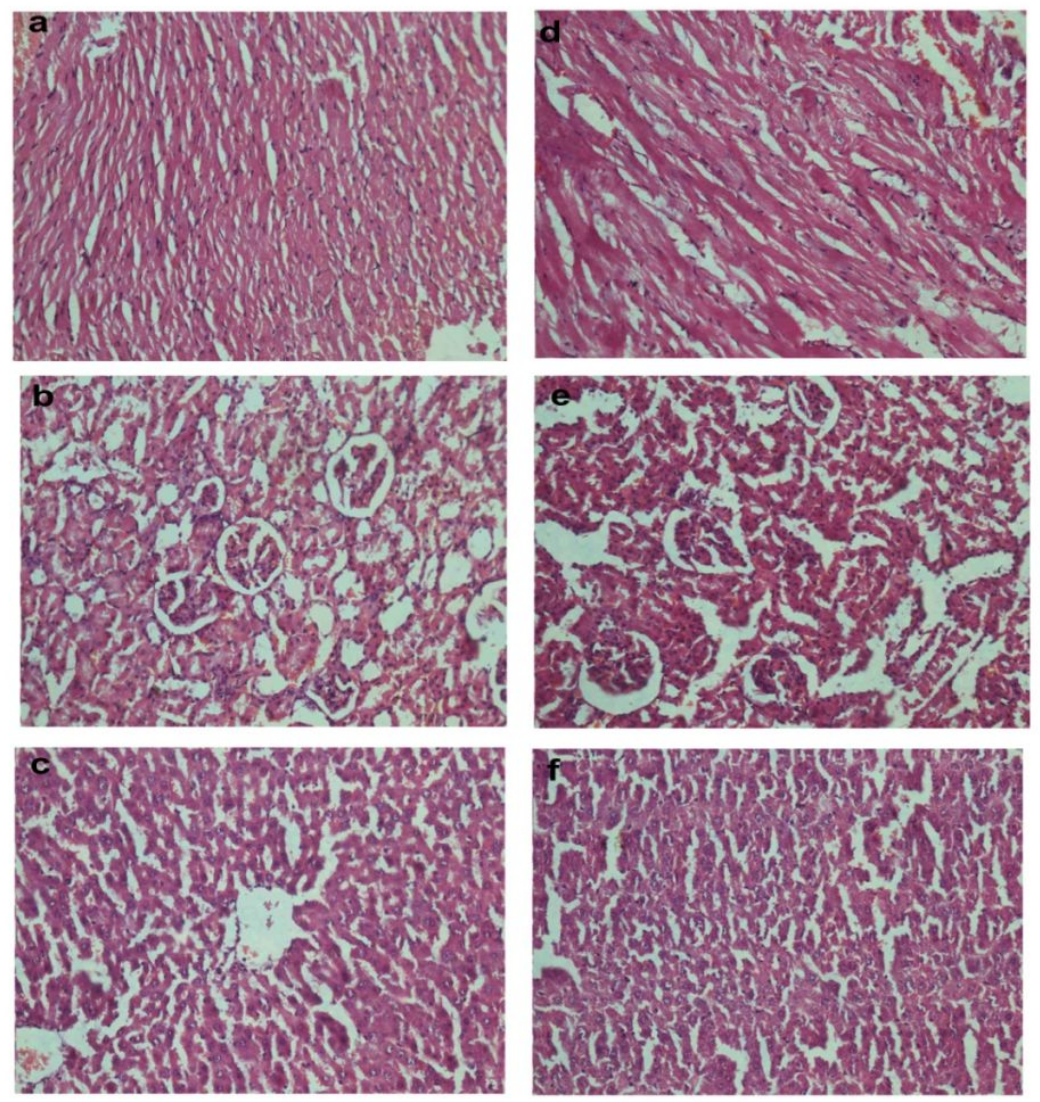

Figure S164. Histology of myocardium: (a) control and (b) compound 2 treated. Histology of kidney: (c) control and (d) compound 2 treated. Histology of liver: (e) control and (f) compound 2 treated. Each image was $20 \times$ magnified. The acute toxicity studies were performed with four groups of animals each having three rats. 